NUREG/CR-1615

ORNL/NUREG/CSD/TM-15

\title{
NUCLEAR
}

DIVISION

UNION

CARBIDE

\section{Solid Angle and Surface Density as Criticality Parameters}

\author{
J. T. Thomas
}

\section{MASTER}

Do

\footnotetext{
Prepared for the U.S. Nuclear Regulatory Commission

Office of Nuclear Regulatory Research

Under Interagency Agreement DOE 40-550-75
}

OPERATED BY

UNION CARBIDE CORPORATION

FOR THE UNITED STATES

DEPARTMENT OF ENERGY 


\section{DISCLAIMER}

This report was prepared as an account of work sponsored by an agency of the United States Government. Neither the United States Government nor any agency Thereof, nor any of their employees, makes any warranty, express or implied, or assumes any legal liability or responsibility for the accuracy, completeness, or usefulness of any information, apparatus, product, or process disclosed, or represents that its use would not infringe privately owned rights. Reference herein to any specific commercial product, process, or service by trade name, trademark, manufacturer, or otherwise does not necessarily constitute or imply its endorsement, recommendation, or favoring by the United States Government or any agency thereof. The views and opinions of authors expressed herein do not necessarily state or reflect those of the United States Government or any agency thereof. 


\section{DISCLAIMER}

Portions of this document may be illegible in electronic image products. Images are produced from the best available original document. 


\section{The following pages are an exact representation of what is in the original document folder.}




\section{Printed in the United States of America. Available from National Technical Information Service \\ U.S. Department of Commerce 5285 Port Royal Road, Springfield, Virginia 22161}

\begin{tabular}{|c|}
\hline Available from \\
GPO Sales Program \\
Division of Technical Information and Document Control \\
U.S. Nuclear Regulatory Commission \\
Washington, D.C. 20555
\end{tabular}

This report was prepared as an account of work sponsored by an agency of the United States Government. Neither the United States Government nor any agency thereof, nor any of their employees, makes any warranty, express or implied, or assumes any legal liability or responsibility for the accuracy, completeness, or usefulness of any information, apparatus, product, or process disclosed, or represents that its use would not infringe privately owned rights. Reference herein to any specific commercial product, process, or service by trade name, trademark, manufacturer, or otherwise, does not necessarily constitute or imply its endorsement, recommendation, or favoring by the United States Government or any agency thereof. The views and opinions of authors expressed herein do not necessarily state or reflect those of the United States Government or any agency thereof.

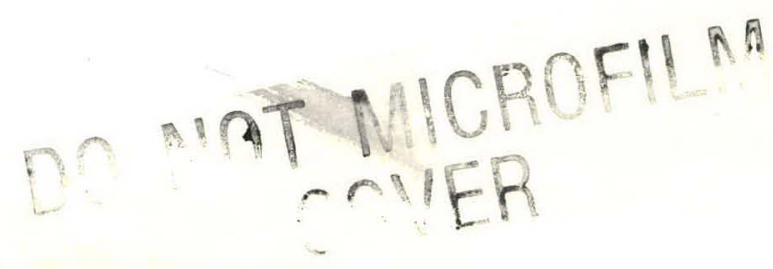




\title{
DISCLAIMER
}

This report was prepared as an account of work sponsored by an agency of the United States Government. Neither the United States Government nor any agency thereof, nor any of their employees, makes any warranty, express or implied, or assumes any legal liability or responsibility for the accuracy, completeness, or usefulness of any information, apparatus, product, or process disclosed, or represents that its use would not infringe privately owned rights. Reference herein to any specific commercial product, process, or service by trade name, trademark, manufacturer, or otherwise does not necessarily constitute or imply its endorsement, recommendation, or favoring by the United States Government or any agency thereof. The views and opinions of authors expressed herein do not necessarily state or reflect those of the United States Government or any agency thereof.

\section{NUREG/Cl:-1615}

ORNL/NUREG/CSD/TM-15

Distribution Category RC

SOLID ANGLE AND SURFACE DENSITY AS CRITICALITY PARAMETERS

\author{
J. T. Thoma s
}

\section{COMPUTER SCIENCES DIVISION}

at

Oak Ridge National Laboratory

Post Office Box $X$

Oak Ridge, Tennessee 37830

\author{
Techmonitor: Donald E. Solberg \\ Manuscript Completed: July 17, 1980 \\ Date Published: October 1980 \\ PREPARED FOR THE U.S. NUCLEAR REGULATORY COMMISSION \\ OFFICE OF NUCLEAR REGULATORY RESEARCH \\ UNDER INTERAGENCY AGREEMENT DOE 40-550-75 \\ NRC FIN No. B0419
}

NOTICE This document contains information of a preliminary nature. It is subject to revision or correction and therefore does not represent a final report.

\section{Union Carbide Corporation, Nuclear Division operating the}

Oak Ridge Gaseous Diffusion Plant. Paducah Gaseous Diftusion Plant

Oak Ridge Y-12 P1 ant - Oak Ridge National Laboratory

under Contract No. W-7405 eng 26

for the

Department of Energy 


\section{THIS PAGE \\ WAS INTENTIONALLY LEFT BLANK}




\section{TABLE OF CONTENTS}

Tit1e

Page

LIST OF FIGURES. . . . . . . . . . . . . . . . . . . . . . . . v

LIST OF TABLES . . . . . . . . . . . . . . . . . . . . . . . ix

ACKNOWLEDGMENTS. . . . . . . . . . . . . . . . . . . . xi

ABSTRACT . . . . . . . . . . . . . . . . . . . 1

INTRODUCTION . . . . . . . . . . . . . . . . . . . . 3

CRITICALITY DATA BASE AND SURFACE DENSITY AS AN ARRAY PARAMETER. • . 7

Limiting surface density . . . . . . . . . . . . . . 7

SOLID ANGLE AS AN ARRAY PARAMETER. . . . . . . . . . . . . . . . . 12

Fundamental concepts . . . . . . . . . . . . . . 12

Solid angle and criticality. . . . . . . . . . . . 16

Omega and array $k$-eff's. . . . . . . . . . . . 21

UNIT SHAPE VARIATION . . . . . . . . . . . . . . . . . . 23

ARRAY SHAPE VARIATIONS . . . . . . . . . . . . . . . . . 37

Cuboidal ..................... . 37

Infinite planar arrays .......... . . . . 47

Linear arrays. . . . . . . . . . . . . . . . 54

REFLECTORS . . . . . . . . . . . . . . . . . . . 60

Reflector thickness. . . . . . . . . . . . . . . 60

Ref1ector density . . . . . . . . . . . . . 70

Reflector location.................. 70

OTHER FISS ILE MATERIALS AND ARRAYS OF MIXED UNITS. . • . • . . . • . 85

LOW ${ }^{235}$ U ENRICHED URANIUM. . . . . . . . . . . . . . . . . . . . . . . . . .

DISCUSSION AND CONCLUSIONS . . . . . . . . . . . . . . . . . . . . . . . .

Models for Subcriticality . . . . . . . . . . . . . 125 
Surface density. . . . . . . . . . . . . . . .125

Solid angle. . . . . . . . . . . . . . . . . . 126

Models for Criticality. . . . . . . . . . . . . . . 126

Surface density - solid angle methods and criticality. . .126

Number of units. . . . . . . . . . . . . . . .128

Unit shape . . . . . . . . . . . . . . . . 128

Array shape. . . . . . . . . . . . . . . 129

Ce11 shape . . . . . . . . . . . . . . . . 129

Reflectors . . . . . . . . . . . . . . . . . 130

Arrays of mixed units. . . . . . . . . . . . . . . 130

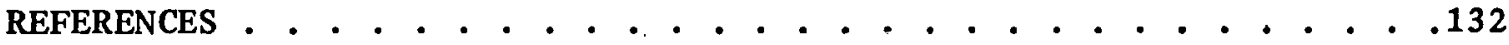




\section{LIST OF FIGURES}

Figure

Page

1. Sum of the inverse of the sum of the squares of the coordinates of units in an array as a function of the number of units in the array and their arrangement . . . . 15

2. Dimensionless ratio of solid angles, as a function of $r / r_{0}$, the fraction of critical radius for the unit in

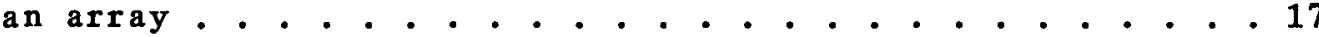

3. Dependence of parameters $\beta(s r)$ and $F(N)$ on the number of units in a cubic array . . . . . . . . . . . . 20

4. Solid angles for water reflected arrays of spherical units illustrating dependence on number of unit in the array and representation by an average $\beta$ for $U(93.2)$ netal

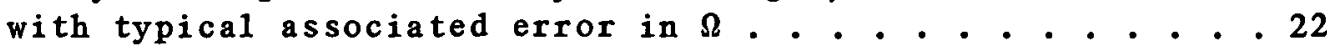

5. Total solid angle for a water reflected cubic array with units of constant mass showing the effects of changing the shape of the units and resulting array k-eff . . . . . 27

6. Surface density representation of critical water reflected arrays of 64 units of various geometries... . 31

7. Solid angle representation of critical water reflected arrays of 64 units of various geometries... . . . . . 32

8. Total solid angle of water reflected cubic arrays illustrating the effects of number of units, cell dimension and unit shape. . . . . . . . . . . . . . . . . 34

9. Effects of unit rearrangements into water reflected cuboidal arrays of 512 spherical units on the 1 imiting surface density. . . . . . . . . . . . . . . . . 40

10. Effects of unit rearrangements in water reflected cuboida1 arrays of 512 spherical units on the total solid angle. . . 42

11. The parameter $F(N)$ of the solid angle representation for finite planar arrays of Table 8 for $n_{x}=n_{y}$ and the dependence on the number of units in the $z$ direction of arrays.. . . . 53

12. Solid angle representation of critical and subcritical water reflected 1 inear arrays of $U(93.2)$ metal spheres showing dependence on number of units and cell dimension . . . . 58 
13. Limiting surface density representation of critical experiments with $U(93.2)$ metal cylinders of various height-todiameter ratios. Data for spherical units are also given. Note that the unreflected data extrapolates to the unreflected critical mass for a cube . . . . . . . . . . 63

14. Variation of the ratio of characteristic slopes, $c_{2}$, as the reflector thickness varies... . . . . . . . . . 65

15. Total reactivity worth of thick concrete and of thick water as reflectors closely fitting cubic arrays of air-spaced U(93.2) metal units....................66

16. Reactivity worth of a water reflector of thickness, $t$, on cuboidal arrays of $U(93.2)$ metal units.......... . 68

17. Solid angle representation of critical experiments with $\mathrm{U}(93.2)$ metal cylinders of various height-to-diameter ratios. The solid 1 ines shown represent spherical units of $U(93.2)$ metal for the array reflector thickness, t. . . 69

18. Criticality of water reflected cubic arrays of $U(93.2)$ metal spheres as a function of reflector location given as multiples of the array dimension, $A$. The 1 ines with positive slope represent array geometries with constant ce11 dimension and number of units... . . . . . . . . 73

19. Criticality of concrete reflected cubic arrays of $U(93.2)$ metal spheres as a function of reflector location given as multiples of the array dimension, A. The lines with positive slope represent array geometries with constant cell dimension and number of units. . . . . . . . . . . . 74

20. Representation of the fractional total worth of a reflector to an array as a function of reflector location expressed in multiples of the array dimension, A . . . . . . . 75

21. Representation of the fraction total worth of three sides of thick concrete reflector as a function of the reflector location expressed in terms of the array dimension, A. . . 77

22. Reactivity equivalence between the location of a thick reflector from the array surfaces and the thickness of a closely fitting water reflector on arrays. . . . . . : 79

23. Total solid angle required for concrete reflected critica1 arrays as the reflector recedes from the array surfaces. The reflector location is expressed in terms of the array dimension, A. Parabolic 1 ines represent array geometries with constant cell dimension and number of units . . . . 80 
24. Representation of array reactivity loss as a thick water reflector recedes from five surfaces of planar arrays. . . 81

25. Calculated neutron multiplication factors of a single cell having a centered $22.5 \mathrm{~kg} \mathrm{U}(93.2)$ metal cylinder with a height-to-diameter ratio of 0.5 as a function of the cell reflector condition and location of the bottom reflector. Data for a $32 \times 16 \times 1$ array are shown for comparison. . . 84

26. Calculated total solid angle at the center of arrays with units of $U(93.2)$ metal having different shapes illustrating the distinction between arrays with even and odd numbers of units along the edges of an array . . . . . . .106

27. Limiting surface density representation of spherical units of $U(5) \mathrm{O}_{2}$ at an $\mathrm{H}: U=3$. The arrays are cubic and are reflected by concrete and water. . . . . . . . . . . .112

28. Limiting surface density representation of infinite planar arrays of $\mathrm{U}(5) \mathrm{O}_{2}$ at an $\mathrm{H}: \mathrm{U}=3$ as spheres. The arrays are reflected by concrete and by water . . . . . . . . . .115

29. Criticality of water and concrete reflected infinite arrays of spherical units of $U(5) \mathrm{O}_{2}$ at an $H: U=3$ normalized to the critical slab surface density for the respective reflector condition. . . . . . . . . . . . . . . .116

30. Total solid angle representation of concrete and water reflected cubic arrays of $U(5) \mathrm{O}_{2}$ at an $H: U=3$. The $\Omega$ contribution of the units is summed at the center of the array. . . . . . . . . . . . . . . . . . . . 117

31. Calculated k-eff of unreflected single units of $U(5) \mathrm{O}_{2}$ at an $H: U=3$ as a function of the fraction of the critical radius of the unit geometry. . . . . . . . . . . . . .119

32. Limfing surface density rcprcsentation of concrete reflected planar arrays of 1024 units of $U(5) \mathrm{O}_{2}$ at an $H: U=3$ arranged in a $32 \times 32$ unit pattern. The units are cylinders of various shapes. . . . . . . . . . . . . .120

33. Limiting surface density representation of concrete reflected 1 inear arrays of 128 units of $U(5) 0_{2}$ at an $\mathrm{H}: \mathrm{U}=3$ for cylinders of various shapes. . . . . . . . .121

34. Total solid angle representation of oritioality for concrete reflected 128 unit 1 inear array and 1024 unit planar arrays of $\mathrm{U}(5)_{2}$ at an $\mathrm{H}: \mathrm{U}=3$ as cylinders of various shape 3 


\section{LIST OF TABLES}

$\underline{\text { Table }}$

$\underline{\text { Page }}$

1. Radius, fraction of critical radius, and k-eff for spherical units of $U(93.2)$ metal in critical water reflected cubic arrays. . . . . . . . . . . . . . 11

2. Total solid angle in steradians for critical water reflected cubic arrays of Table 1............ 19

3. Effect of unit shape on the neutron multiplication factor of unreflected and reflected arrays of U(93.2) metal cylinders . . . . . . . . . . . . . . . . . 26

4. Equivalent masses for units of different shape in critical water reflected cubic arrays of 64 units. . . . . . . . . . 29

5. Confirmation of expected supercriticality by comparison of estimated ratio of radii, $r / r$, for criticality and calculated neutron multiplication factor for 64-unit, water reflected arrays. . . . . . . . . . . . . . 36

6. Criticality parameters for various rearrangements of 512 units in cells of constant size as water reflected arrays. . .38

7. Calculated neutron multiplication factor for unreflected and water reflected arrays with constant cell volume of different cell shapes. The units are metal cylinders with $\mathrm{h} / \mathrm{d}=1$ and a mass of $26.2 \mathrm{~kg} \mathrm{U}(93.2)$. . . . . . . . 46

8. Finite number of units and array shapes exhibiting characteristics of infinite planar arrays . . . . . . . . . 49

9. Monte Carlo calculated neutron multiplication factors for some linfinite planar arrays of metal spheres with $n_{z}=1$, 2 , and 4. . . . . . . .............. . 51

10. Calculated neutron multiplication factors and total solid angles for some water reflected linear arrays of spherical U(93.2) metal units................. 56

11. Cunfirmatory Monte Carlo calculations of estimated equivalent masses for criticality with cylindrical units of various shajpe . . . . . . . . . . . . . . . . 59

12. Experimentally determined spacing for $U(93.2)$ metal cylindorc aoomblod to oriticality iii cubvidal arrangemenls for various reflector conditions. . . . . . . . . . . . . 62 
13. Categories of equivalent masses in water reflected cubic arrays. . . . . . . . . . . . . . . . . 87

14. Value of criticality indicator assigned to a cell in critical water reflected cubic arrays as a function of mass category of fissile materials . . . . . . . . . . . . 95

15. Description of units in 27-unit critica1, water reflected arrays and their arrangement in mixed unit arrays. Ce11s are cubic with a dimension of $30.48 \mathrm{~cm}$. . . . . . . . . .98

16. Monte Carlo calculated reflected critical arrays of U(93.2) metal at a density of $18.76 \mathrm{~g} \mathrm{U} / \mathrm{cm}^{3}$ and of mixed unit arrays with different cell volumes and unit masses. . . . . . . 99

17. Solid angle calculation of mixed unit arrays of Table 15. . 102

18. Comparison of calculated solid angles subtended at the center of arrays with those subtended at the center of the unit nearest the center of the array. The arrays are those of Table 16 . . . . . . . . . . . . . . . . . .104

19. Criticality of $\mathrm{U}(5) \mathrm{O}_{2}$ at an $\mathrm{H}: \mathrm{U}=3$ in water reflected cubic arrays. . . . . . . . . . . . . . . . 109

20. Criticality of $\mathrm{U}(5) \mathrm{O}_{2}$ at an $\mathrm{H}: \mathrm{U}=3$ in concrete reflected cubic arrays. . . . . . . . . . . . . . . . .110

21. Criticality of $U(5) O_{2}$ at an $\mathrm{H}: U=3$ in water reflected infinite planar arrays. . . . . . . . . . . . . . .113

22: Criticality of $\mathrm{U}(5) 0_{2}$ at an $\mathrm{H}: \mathrm{U}=3$ in concrete reflected infinite planar arrays. . . . . . . . . . . . . . . . . .114

23. Calculated critical radius for a sing1e unit of $U(5) 0_{2}$ at an $\mathrm{H}: \mathrm{U}=3$ for various cylinder geometries. . . . . . . . .119

24. Characteristic constants for $U(5) O_{2}$ at an $H: U=3$ for finite 1 inear and planar arrays . . . . . . . . . . . . .123 


\section{ACKNOWLEDGMENTS}

It is a pleasure to recognize the interest and support of the Nuclear Regulatory Commission in this study. In particular, the encouragement from R. E. Stevenson, N. Ketzlach, and D. E. Solberg. I am indebted to H. C. Paxton and D. R. Smith of the Los Alamos Scientific Laboratory for their review and comments on an early draft of the document. Finally, my thanks to Mrs. P. S. Young of the Computer Sciences Division of the Oak Ridge National Laboratory for her patience in typing and preparing the manuscript for publication. 


\title{
SOLID ANGLE AND SURFACE DENSITY
}

AS CRITICALITY PARAMETERS

J. T. Thomas

\begin{abstract}
Two methods often used to estab1ish nuclear criticality safety limits for operations with fissile materials are the surface density and solid angle techniques. The two methods are used as parameters to express experimental and validated calculations of critical configurations. It is demonstrated that each method can represent critical arrangements of subcritical units and that there can be established a one-to-one correspondence between them. The analyses further show that the effect on an array neutron multiplication factor of perturbations to the array can be reliably estimated and that each form of fissile material and unit shape has a specific representation.
\end{abstract}




\section{THIS PAGE \\ WAS INTENTIONALLY \\ LEFT BLANK}


INTRODUCTION

Two methods frequently employed to evaluate nuclear criticality safety when there is the possibility of neutron interaction between subcritical units of fissile materials are the surface density and the solid angle techniques. Criticality control or the avoidance of criticality is effected principally by control of neutron leakage from arrangements of fissile materials. Neutron leakage, in turn, depends on the form of fissile material, the unit size and shape, the distance between units, the number of units in an array, the shape of the array and the neutron reflecting properties of the array environment.

The surface density technique is basically the application of a simple concept. If each unit in an array is subcritical by virtue of a limited dimension, the units are oriented in a common plane with the limited dimension normal to the plane, and that dimension is less than the critical thickness of a continuous infinite slab of the fissile material, then the system of units will be subcritical. Paxton applied the concept to critical experiments with arrays of aqueous solutions of fissile materials and demonstrated that the condition of a 1 imited dimension for the units could be replaced by an equivalent one for the array. If the units in a planar arrangement are sufficiently spaced, the common material thickness, obtained by smearing the total mass over the base area of the array, could be'interpreted as a 1 imited dimension. The dimension is also expressib1e as a projected surface density.

Analyses presented at Karlsruhe ${ }^{1}$ in 1961 showed that criticality was possible in some finite arrays with the equivalent thickness less than that of the iufinite slab thickness of the same material and that there 
was a dependence on the unit size. Similar correlations ${ }^{2-7}$ since that time have continued to reference the critical infinite slab thickness, $t_{c}$, or projected surface density, $\sigma_{c}$, and a property of the unit, usually the mass of the unit expressed as a fraction of the critical mass, f, for the fissile material in the same geometry as the unit.

Applications of the technique assume subcriticality of an array is achieved by restricting the value of $f$ and requiring $\sigma$ to be no more than a suitable fraction of $\sigma_{c}$ when the array is considered to be extended indefinitely in a plane. Evidence supports the applicability of the technique when the parameters are suitably limited for a fissile material. Uncertainties arise, however, concerning the definition of area or cell volume to associate with a unit, the location of units out of the plane, arrays with.mixtures of units of different fissile materials, and the array reflector condition, i.e., type of material, density, thickness, and location.

The original concept is valid, of course, and has general applicability, when reflector conditions are no more effeotive than that corresponding to the value $t_{c}$ being used. The conditions for applicability of the various extensions do not enjoy consensus among those employing the technique.

The solid angle technique is similar in nature to the surfaco density technique in that the comparison of an arrangement of units to be evaluated is made to a uniform arrangement of units believed to result in subcriticality rather than to criticality $\left(t_{c}\right)$ as in the surface density technique. The concept is based on the correlations of Henry, Newlon, and Knight ${ }^{2-10}$ from observations of the relation between the solid angle, $\Omega$, subtended at the most central unit in critical arrays 
by other units and the neutron multiplication factor, $k$, of a unit. The available experimental data were obtained for unreflected arrays with fewer than ten units of aqueous solutions of uranium. A conservative evaluation of a water reflector on arrays was inferred from critical experiments conducted with a pair of 25.4-cm-diam. cylinders. Each cy1inder in the experiments had a closely fitting water reflector covering one-half the cylinder surface area, symmetric to a plane containing the axes, and external to the region between the cylinders.

Observations of the correlations between $\Omega$ and $k$ led to the estab1ishment of an arbitrarily assumed linear relation displaced well below the unreflected experimental data. A further displacement to lower values of $\Omega$ and $k$ was made by applying a factor derived from the reflected experimental data. It was recognized that neutron interaction between units of sma11 $k$ at close spacing was more than a simple geometric concept. According1y, units with a $k$ of 0.3 or 1 ess were 1 imited to an $\Omega$ of six steradians. The possibility of flooded arrays required that a unit be subcritical submerged, limiting the unit $k$ to 0.8 , which corresponded to an allowable $\Omega$ of one steradian in the assumed linear relation. Other experiments with the aqueous solutions of fissile materials showed that neutron interaction through $30 \mathrm{~cm}$ of water was negligible. The distance was adopted as a minimum surface separation of units in application of the method to assure subcriticality of flonded arrays and was a further rcstriotion to the application of an acceptable $\Omega$ value to units at small spacings.

In the mid 1950s, with the onset of increasing industrial activities in applications of nuclear energy, those concerned with criticality safety in operations turned to the solid angle technique because of its 
simplicity and successful use in the complex operations of the Atomic Energy Commission. Diversified applications beyond the basic conditions of the method since that time have often required verification by experiment, other methods of assessment, or experienced judgement. Various independent treatments of mixed units, partial and total shadowing of units, materials interspersed between the units, and the reflector environment of the arrays in operations with fissile materials have contributed to the solid angle technique, but also do not enjoy consensus among users.

Recent studies by Tang $^{11}$ and by $\operatorname{Oden}^{12}$ have raised questions about the general applicability of the method. These have lent impetus to the desire on the part of many, in particular, the Nuclear Regulatory Commission, for an examination of the basis of both methods. The examination of the basis for any method employed in nuclear criticality safety properly begins with the determination of its ability to reproduce critical experiments and validated ${ }^{3}$ calculated criticality data. The interpolation of the data, extensions of the data, and the ability to reproduce the k-response of the fissile material systems to parameter changes in the method should be examined, understood, and documented. Assurance in the reliability of a method to specify subcriticality in operations is increased when the method satisfactorily monitors criticality as the system is changed.

Attention in the following is focused on criticality and the influence of changes in parameters on the critical condition. Experimental and calculated criticality data is used to illustrate both methods. This data base of finite and unlimited numbers of units has been successfully modeled by the 1 imiting surface density method. ${ }^{14}$ The 1 atter is the 
result of semi-empirical relationships developed between the surface density of critical arrays and the mass of the units present. The method estimates changes, confirmed by validated calculation, in the array neutron multiplication factor associated with changes in

- number of units in the array,

- array shape,

- cell shape and/or dimension,

- fissile material in the units,

- reflector material, thickness, location and density, and

- number and types of fissile material units, i.e., possible arrays of mixed units.

Treatment of the surface density and solid angle techniques is deve1oped from simple concepts and becomes progressively more complex as these topics or particular concepts and conditions are introduced and examined. For each of these, the two techniques are applied concurrently, usually establishing a one-to-one correspondence between them. Information in early sections is referred to, or implicitly assumed, in succeeding sections. The majority of criticality data presented has been produced by the KENO-IV Monte Carlo $\operatorname{code}^{15}$ using the Hansen-Roach cross section sets. 16

CRITICALITY DATA BASE AND SURFACE DENSITY AS AN ARRAY PARAMETER

Limiting surface density. A large body of experimental and calculated criticality data has been correlated by a limiting surface density technique which provides an analytic representation of criticality for reflected, regular arrays of units with simple geometries. There is no penalty to this developmeil to consider units of spherical shape. We 
will introduce other shapes 1 ater. The model and relations which follow are described in Ref. 14 .

Units of spherical mass, $m$, in a critical, reflected $N$ unit cubic array with centers separated by a distance, $d_{n}$, are correlated by the expression

$$
\sigma(m)=\frac{\mathrm{nm}}{\mathrm{d}_{\mathrm{n}^{2}}}(1-\mathrm{c} / \sqrt{\mathrm{N}})^{2},(\mathrm{~N}>27)
$$

where $\sigma(m)$, a projected surface density, modified to express the dependence on the number of units, is a constant for arbitrary $N=n^{3}>27$, and $c$ is a constant equal to $0.55 \pm 0.18$. The constant $c$ is valid for fissile materials in critical arrays for which less than $40 \%$ of the fissions are thermal. As the fraction of thermal fissions increases, the constant c tends toward zero. The behavior of $\sigma(m)$ as $m$ is varied is well correlated by the linear fit to critical data as

$$
\sigma(m)=c_{2}\left(m_{0}-m\right)
$$

where $m_{0}$ is the unreflected critical mass having the same shape as the unit of mass $m$. The constant $c_{2}$ is a characteristic of the fissile material for a defined array environment. It depends on the shape of the unit, the type and location of the reflecting material and the arrangement of units in the array. The constants have been defined for the materials described in the American National Standard Guide for Nuclear Criticality Safety in the Storage of Fissile Materials, N16.5 (1975). For these data and a majority of related information, the reflector materials are water and concrete of various thicknesses located at the boundary surfaces by the peripheral cells of an array. 
Water reflected critical arrays of fissile materials characterized by a $c_{2}$ and an mo permit analyses performed for one material to serve for another material through the concept of equivalent mass. We define equivalence between units as that mass of fissile material as a unit which may be substituted for any number of units in a critical array of the same or different fissile material without a significant change in the array k-eff. For a fixed array geometry, i.e., $N$, $d_{n}$, and reflector conditions unchanged, we have from Eq. 1

$$
\sigma(m) / m=n(1-c / \sqrt{N})^{2} / d_{n^{2}}
$$

The right side of the equation is determined by the geometry and for the left side, by the fissile material and the constant, $c_{\ldots}$. Thus for two different fissile units to result in criticality in the same array geometry, a condition that subsists is

$$
\sigma(m) / m=\sigma\left(m^{\prime}\right) / m^{\prime}
$$

which, by Eq. 2, may be explicitly written as

$$
c_{2}\left(m_{0} / m-1\right)=c_{2}^{\prime}\left(m_{0}^{\prime} / m^{\prime}-1\right)
$$

An additional general result concerns cuboidal arrangements of arrays of arbitrary shape. The geometry of an $n_{x}, n_{y}, n_{z}$ arrangement of units reflected by water is related to cubic arrays by a shape factor, $R$, defined as

$$
R=\frac{N^{1 / 3}}{3}\left(\frac{1}{n_{x}}+\frac{1}{n_{y}}+\frac{1}{n_{z}}\right)
$$


and results in the following expression for the limiting surface density relation,

$$
\sigma(m)=c_{2}^{-}\left(m_{0}-m\right)=\frac{n_{z^{m}}}{d^{2}}(1-c / \sqrt{N})^{2}
$$

where $c_{2}^{\prime}$ is evaluated from the following relation, ${ }^{4}$

$$
\frac{n_{2} c_{2}}{n c_{2}^{\prime}}=\left(5 R^{-0.672}-1\right) / 4
$$

Critical arrays in which $\mathrm{N}$ is not the cube of an integer are proper1y specified by Eq. 7. The largest value of $R$ for $N$ units results from a linear arrangement. The values of $R$ are bounded14 by 5.34 to exclude single unit criticality and to provide consistent correlation with validated data. Values of $R$ determined from Eq. 10 which exceed 5.34 should be set equal to this maximum for use in Eq. 8 .

Exploration of the relative effects of perturbations to critical arrays may be made with a single fissile material since by Eq. 4 they may be interpreted for any other material of interest. Much of the following will be illustrated by the validated calculated data for U(93.2) metal as spheres utilized as a bases for the American National Standard N16.5 (1975). The critical radii for units as a function of the number of units and their spacing in water reflected arrays is given in Table 1. Two other quantities useful in later illustrations are also given for each array. These are the unit radius expressed as a fraction of the unreflected critical radius $\left(r_{0}=8.917 \mathrm{~cm}, \rho=18.76 \mathrm{~g} / \mathrm{cm}^{3}\right)$ and the k-eff calculated for the unit without the contribution of nentrons from other units and reflecting materials. We shall interpret these data in terms of the solid angle as a parameter and later provide illustrations with typical fissile materials other than the $0(93.2)$ metal. 
Table 1. Radius, fraction of critical radius, and k-eff for spherical units of $U(93.2)$ metal in critical water reflected cubic arrays

\begin{tabular}{|c|c|c|c|c|c|c|c|}
\hline \multirow[b]{2}{*}{$\mathrm{N}$} & \multicolumn{7}{|c|}{ Cubic cell dimension, $d_{n}(\mathrm{~cm})$} \\
\hline & & 25.4 & 30.48 & 38.10 & 45.76 & 50.80 & 60.96 \\
\hline \multirow{3}{*}{64} & $\mathbf{r}$ & 5.470 & 5.968 & 6.553 & 6.989 & 7.218 & 7.568 \\
\hline & $r / r_{0}$ & 0.627 & 0.684 & 0.752 & 0.802 & 0.828 & 0.868 \\
\hline & $k-e f f$ & 0.656 & 0.713 & 0.778 & 0.824 & 0.848 & 0.884 \\
\hline \multirow{3}{*}{125} & $\mathbf{I}$ & 5.107 & 5.607 & 6.211 & 6.677 & 6.928 & 7.320 \\
\hline & $\mathbf{r} / \mathbf{r}_{0}$ & 0.586 & 0.643 & 0.712 & 0.766 & 0.795 & 0.840 \\
\hline & $k-\mathbf{e f f}$ & 0.615 & 0.672 & 0.740 & 0.790 & 0.817 & 0.858 \\
\hline \multirow{3}{*}{216} & $\mathbf{r}$ & 4.828 & 5.323 & 5.934 & 6.417 & 6.682 & 7.104 \\
\hline & $I / r_{0}$ & 0.544 & 0.611 & 0.681 & 0.736 & 0.766 & 0.815 \\
\hline & $k-e f f$ & 0.582 & 0.641 & 0.707 & 0.762 & 0.791 & 0.836 \\
\hline \multirow{3}{*}{343} & $\mathbf{r}$ & 4.603 & 5.091 & 5.702 & 6.194 & 6.469 & 6.913 \\
\hline & $r / r_{0}$ & 0.528 & 0.584 & 0.654 & 0.710 & 0.742 & 0.793 \\
\hline & $k-e f f$ & 0.577 & 0.612 & 0.683 & 0.738 & 0.768 & 0.816 \\
\hline \multirow{3}{*}{512} & $\mathbf{r}$ & 4.416 & 4.895 & 5.503 & 6.001 & 6.282 & 6.742 \\
\hline & $r / r$ & 0.506 & 0.561 & 0.631 & 0.688 & 0.721 & 0.773 \\
\hline & $k-e f f$ & 0.535 & 0.590 & 0.661 & 0.717 & 0.748 & 0.796 \\
\hline \multirow{3}{*}{729} & $\mathbf{r}$ & 4.256 & 4.727 & 5.331 & 5.830 & 6.115 & 6.588 \\
\hline & $r / r$ & 0.488 & 0.542 & 0.611 & 0.669 & 0.701 & 0.756 \\
\hline & $k-e f f$ & 0.517 & 0.570 & 0.639 & 0.696 & 0.730 & 0.781 \\
\hline \multirow{3}{*}{1000} & $\mathbf{I}$ & 4.118 & 4.581 & 5.178 & 5.678 & 5.965 & 6.447 \\
\hline & $r / r_{0}$ & 0.472 & 0.525 & 0.594 & 0.651 & 0.684 & 0.739 \\
\hline & $k-e f f$ & 0.500 & 0.554 & 0.623 & 0.680 & 0.713 & 0.767 \\
\hline \multirow{3}{*}{1331} & $\mathbf{r}$ & 3.996 & 4.451 & 5.042 & 5.541 & 5.829 & 6.317 \\
\hline & & 0.458 & 0.510 & 0.578 & 0.636 & 0.669 & 0.725 \\
\hline & $k-e f f$ & 0.486 & 0.540 & 0.607 & 0.665 & 0.697 & 0.751 \\
\hline \multirow{3}{*}{1728} & $\mathbf{r}$ & 3.888 & 4.335 & 4.920 & 5.416 & 5.706 & 6.198 \\
\hline & $r / r$ & 0.446 & 0.497 & 0.564 & 0.621 & 0.654 & 0.711 \\
\hline & $k-e$ & 0.472 & 0.525 & 0.594 & 0.652 & 0.683 & 0.737 \\
\hline \multirow{3}{*}{2197} & $\mathbf{r}$ & 3.791 & 4.231 & 4.808 & 5.302 & 5.592 & 6.087 \\
\hline & $\mathbf{r} / \mathbf{r}$ & 0.435 & 0.485 & 0.551 & 0.608 & 0.641 & 0.698 \\
\hline & $k-e \stackrel{f}{f}$ & 0.460 & 0.512 & 0.580 & 0.637 & 0.669 & 0.726 \\
\hline \multirow{3}{*}{2744} & $i$ & 3.703 & 4.136 & 1.707 & 5.198 & 5.486 & 5.984 \\
\hline & $r / r_{0}$ & 0.425 & 0.474 & 0.540 & 0.596 & 0.629 & 0.686 \\
\hline & $k$-eff $f$ & 0.451 & 0.502 & 0.569 & 0.625 & 0.656 & 0.715 \\
\hline
\end{tabular}


SOLID ANGLE AS AN ARRAY PARAMETER

Fundamental concepts. The desire is not necessarily for accuracy in calculating values of the total solid angle subtended at a unit among other units. Rather, the calculation should be one of uniqueness, consistency, and ability to correctly specify adequate separation of units in app1ications. Let us adopt as a simple definition of the solid angle, $\Omega$, that area, A, seen at the center of one in a pair of identical spherical units divided by the square of the distance, d, between their centers, i.e.,

$$
\Omega=\frac{A}{d^{2}}
$$

More information is obtained about the properties of $\Omega$ when extended to larger numbers of units if we confine our consideration to uniform regular arrays. Applying Eq. 9 to a linear array of $N$ units with identical shape and equal center spacing, yie1ds

$$
\Omega=\frac{A}{d^{2}}+\frac{A}{(2 d)^{2}}+\frac{A}{(3 d)^{2}}+\cdots+\frac{A}{[(N-1) d]^{2}}=\frac{A}{d^{2}} \sum_{i=1} \frac{1}{i^{2}},
$$

for the solid angle subtended at the first unit. For a planar array, $N=n_{x} \times n_{y}$, the solid angle at a corner unit is

$$
\Omega=\frac{A}{d^{2}} \sum_{i=1}^{n_{x}-1} \sum_{j=1}^{n_{y}-1} \frac{1}{i^{2}+j^{2}}
$$


and for a cubic array,

$$
\Omega=\frac{A}{d^{2}} \sum_{i=1}^{n-1} \sum_{j=1}^{n-1} \sum_{k=1}^{n-1} \frac{1}{i^{2}+j^{2}+k^{2}}
$$

We observe that there are as many different values of $\Omega$ to associate with an $N$ unit array as there are symmetric locations in the array. If there is to be a general correlation of criticality data, there must be a unique assignment of $\Omega$ for a configuration of units. Let us associate with an array the solid angle determined at the unit nearest the center of the array.* Thus, we may define as a "location" function the quantity,

$$
F(N)=\sum_{i} \sum_{j} \sum_{k} \frac{1}{i^{2}+j^{2}+k^{2}}
$$

where the 1 imit of summation will depend on whether the number of units in a direction of the array is even or odd. If the number is odd, then the 1 imits will be $\pm\left(\frac{n-1}{2}\right)$ and if it is even, the summation is from $-\left(\frac{n}{2}-1\right)$ to $n / 2$. We exclude the term $i=j=k=0$ from the summation and note that $F(N)$ converges for un1imited $N$. For example, a 1 inear array of eight units yie1ds

$$
F(8)=\sum_{i=-3}^{4} \sum_{j=0}^{0} \sum_{k=0}^{0} \frac{1}{i^{2}+j^{2}+k^{2}}=2.785
$$

while a $3 \times 3 \times 1$ planar array would be expressed as

$$
F(9)=\sum_{i=-1}^{1} \sum_{j=-1}^{1} \sum_{k=0}^{1} \frac{1}{i^{2}+j^{2}+k^{2}}=6.0
$$

*The maximum value for $\Omega$ may be at some point in the volume of the array other than the unit designated by this association. 
and a cuboidal array of $6 \times 7 \times 4$ units as

$$
F(168)=\sum_{i=-2}^{3} \sum_{j=-3}^{3} \sum_{k=-1}^{2} \frac{1}{i^{2}+j^{2}+k^{2}}=31.729 .
$$

The typical behavior of $F(N)$ as a function of the $\log _{10} N$ is displayed in Fig. 1 for several array geometries. We can conclude that for an $N$ unit $\operatorname{array} F(N)$ wi11

i) have a minimal value for a 1 inear array,

ii) approach an asymptotic value rapidly if the number of units in two directions of the array is bounded, and

iii) achieve a maximal value if the array is cubic.

The solid angle given by Eq. 10 is now more easily written as

$$
\Omega=\frac{A}{d^{2}} F(N)
$$

The value of $\Omega$ given by Eq. 12, when applied to regular uniform arrays, will be unique, consistent, and permit the correlation of arbitrary arrangements of units in an array. Evident in the equatiou is the inclusion of contributions to $\Omega$ from all units in an array, i.e., units are considered whether or not they are in the shadow of others. To allow shadowing in computing $\Omega$ is to 1 imit $\Omega$ to $4 \pi$ steradians arbitrarily, to ignore units that do effect the array k-eff, and to assign to a 1 arge number of units an $\Omega$ value properly associated with a smaller number of units. It will be shown 1 ater that the point in an array at which contributions to $\Omega$ are summed as defined here is adequate for regular, uniform arrays but is not suitable for arrays of mixed cel1 sizes and mixed units.

We turn our attention next to a method of defining the separation of fissile units in a critical array in order to express $\Omega$ in terms of simple properties of the units in an array. 


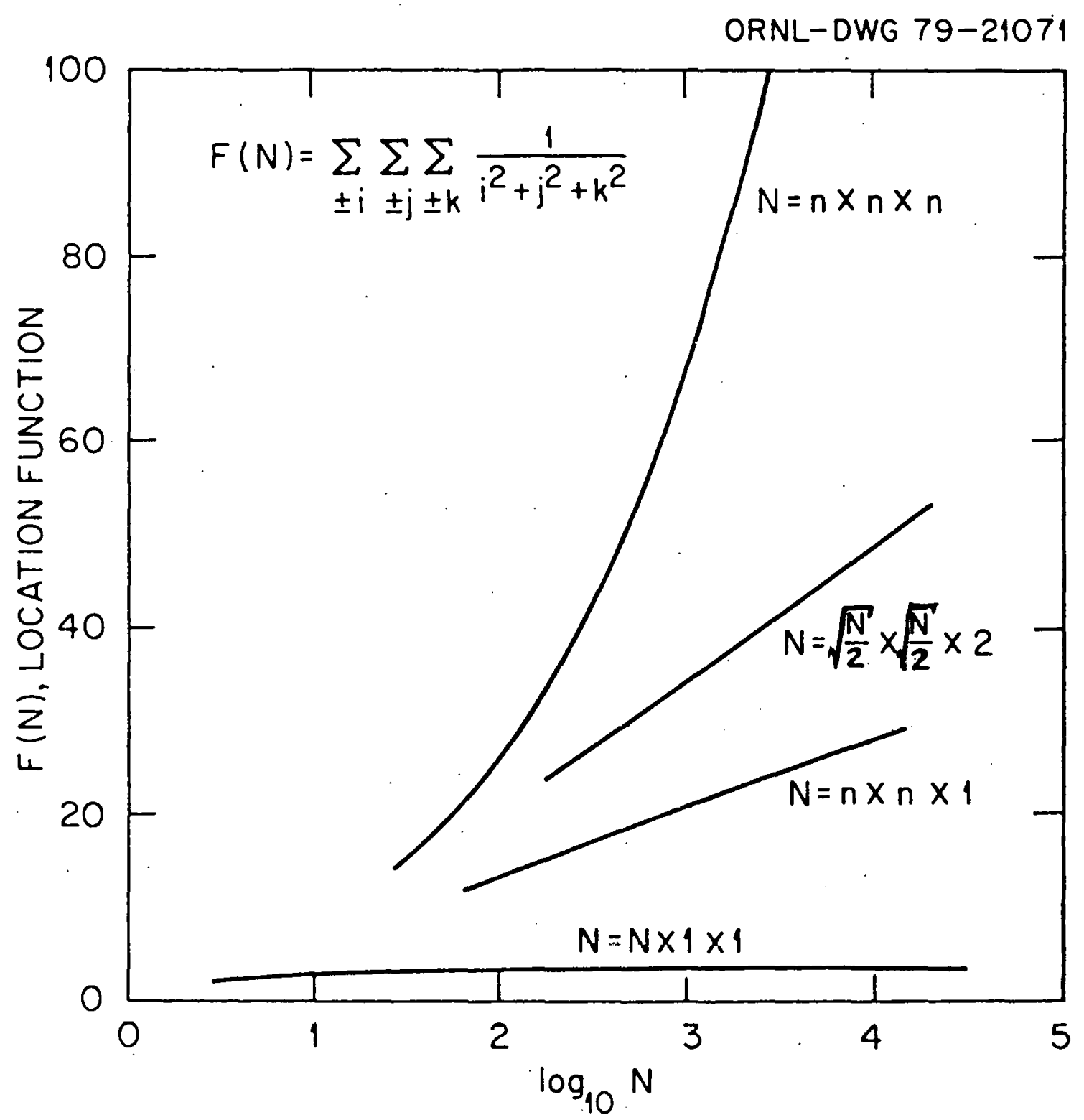

Fig. 1. Sum of the inverse of the sum of the squares of the coordinates of units in an array as a function of the number of units in the array and their arrangement. 
Solid angle and criticality. Equation 5 may be regarded as an expression for the spacing of units given the mass and number of units to be arranged into a critical cubic array reflected by water. Substituting dn from Eq. 1 into Eq. 12 results in the solid angle to be associated with critical cubic arrays,

$$
\Omega=\frac{F(N) A \sigma(m) / m}{n(1-c / \sqrt{N})^{2}}
$$

Let us make the radial dependence explicit through Eq. 2 and the area of the unreflected critical sphere, $\left(\pi r_{0}^{2}\right)$, as

$$
\begin{aligned}
A \frac{\sigma(m)}{m} & =A_{\circ} \frac{A c_{2}}{A_{0}}\left(\left(r_{0} / r\right)^{3}-1\right) \\
& =A_{0} c_{2}\left(r / r_{0}\right)^{2}\left[\left(r_{0} / r\right)^{3}-1\right] \\
& =A_{0} c_{2}\left[r_{0} / r-\left(r / r_{0}\right)^{2}\right]
\end{aligned}
$$

Eq. 13 becomes

$$
\Omega=\frac{F(N) A_{0} c_{2}}{n(1-c / \sqrt{N})^{2}}\left[r_{0} / r-\left(r / r_{0}\right)^{2}\right]
$$

and by appropriate definition of a quantity, $\beta$, express this as

$$
\Omega=\beta\left[r_{0} / x-\left(r / r_{0}\right)^{2}\right]
$$

This relation is presented in Fig. 2 where $\Omega / \beta$ is shown as a function of the dimensionless ratio, $r / r_{0}$. The relation is generic for cubic arrays and for all fissile materials satisfying the equivalence relation, Eq. 5 . The solid angle for a cubic array would be determined by the defined 


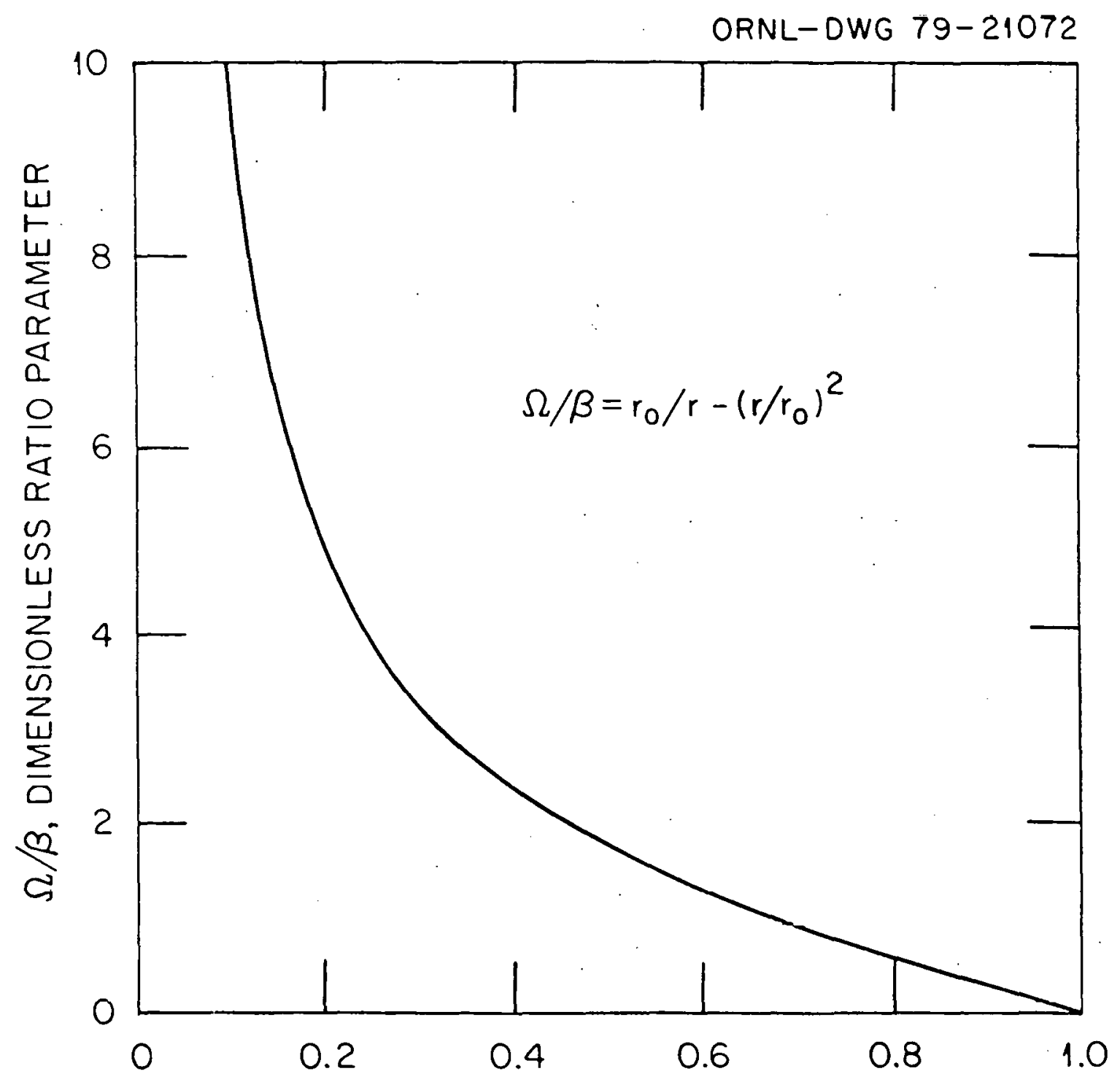

$r / r_{0}$, FRACTION OF CRITICAL RADIUS OF UNIT IN AN ARRAY

Fig. 2. Dimensionless ratio of solid angles, as a function of $\mathrm{r} / \mathrm{r}_{\mathrm{o}}$, the fraction of critical radius for the unit in an array. 
coefficient $\beta$. For example, consider the array from Table 1 for $N=64$, $\mathrm{d}_{4}=25.4 \mathrm{~cm}$ and $\mathrm{r} / \mathrm{r}_{\mathrm{o}}=0.627: \mathrm{F}(64)=20.942, \mathrm{n}(1-\mathrm{c} / \sqrt{\mathrm{N}})^{2}=$ $4(1-0.55 / 8)^{2}=3.469$, giving

$$
\beta=\frac{20.942}{3.469} \pi(8.719)^{2}(0.001762)=2.540 \mathrm{sr}
$$

and

$$
\Omega=2.540(1.202)=3.053 \mathrm{sr} .
$$

Note that the spacing, $d_{4}$, was not used. On the other hand, $F(N), r$ and d, yie1d, by Eq. 12,

$$
\Omega=20.942 \frac{\pi(5.47)^{2}}{(25.4)^{2}}=3.051 \mathrm{sr}
$$

Equation 15 requires definition of array arrangement and unit cizo whilo Eq. 12 requires in addition the unit spacing in the array. Results from the two equations should agree, of course; however, the utility of each is not diminished because a difference of a few parts in a thousand does not alter the calculated array $k$-eff. The solid angles computed for the arrays of Table 1 are given in Table 2. The dependence of $\beta$ on the num ber of units may be illustrated by the data of Tables 1 and 2 . The quantity $F(N) / n(1-c / \sqrt{N})^{2}$ is easily calculated by Eq. 11, given $n$. The result is shown in Fig. 3. The quantity $\beta$ is a constant $\left(A_{\circ} c_{2}\right)$ times $F(N) /$ $n(1-c / \sqrt{\mathrm{N}})^{2}$. The two quantities shown in the figure exhibit a maximum. The solid angle for critical arrays can be expected to exhibit a dependence on the number of units in an array being more pronounced in the lower 
Tab1e 2. Total solid angle in steradians for critical water reflected cubic arrays of Table 1

\begin{tabular}{rlllllll}
\hline \multicolumn{7}{c}{ Cubic ce11 dimension, $d_{n}(\mathrm{~cm})$} \\
$\mathrm{N}$ & $\mathrm{F}(\mathrm{N})$ & 25.40 & 30.48 & 38.1 & 45.72 & 50.8 & 60.96 \\
\hline 64 & 20.942 & 3.052 & 2.523 & 1.946 & 1.537 & 1.328 & 1.104 \\
125 & 29.800 & 3.785 & 3.168 & 2.488 & 1.997 & 1.741 & 1.350 \\
216 & 36.560 & 4.150 & 3.503 & 2.786 & 2.263 & 1.987 & 1.560 \\
343 & 45.052 & 4.648 & 3.949 & 3.170 & 2.598 & 2.295 & 1.820 \\
512 & 52.048 & 4.942 & 4.217 & 3.411 & 2.817 & 2.500 & 2.000 \\
729 & 60.346 & 5.323 & 4.560 & 3.712 & 3.082 & 2.747 & 2.214 \\
1000 & 67.481 & 5.572 & 4.789 & 3.916 & 3.270 & 2.923 & 2.371 \\
1331 & 75.660 & 5.883 & 5.069 & 4.163 & 3.491 & 3.129 & 2.552 \\
1728 & 82.887 & 6.101 & 5.267 & 4.342 & 3.654 & 3.285 & 2.692 \\
2197 & 90.984 & 6.367 & 5.508 & 4.552 & 3.844 & 3.464 & 2.850 \\
2744 & 98.276 & 6.562 & 5.685 & 4.712 & 3.991 & 3.601 & 2.975 \\
\hline
\end{tabular}




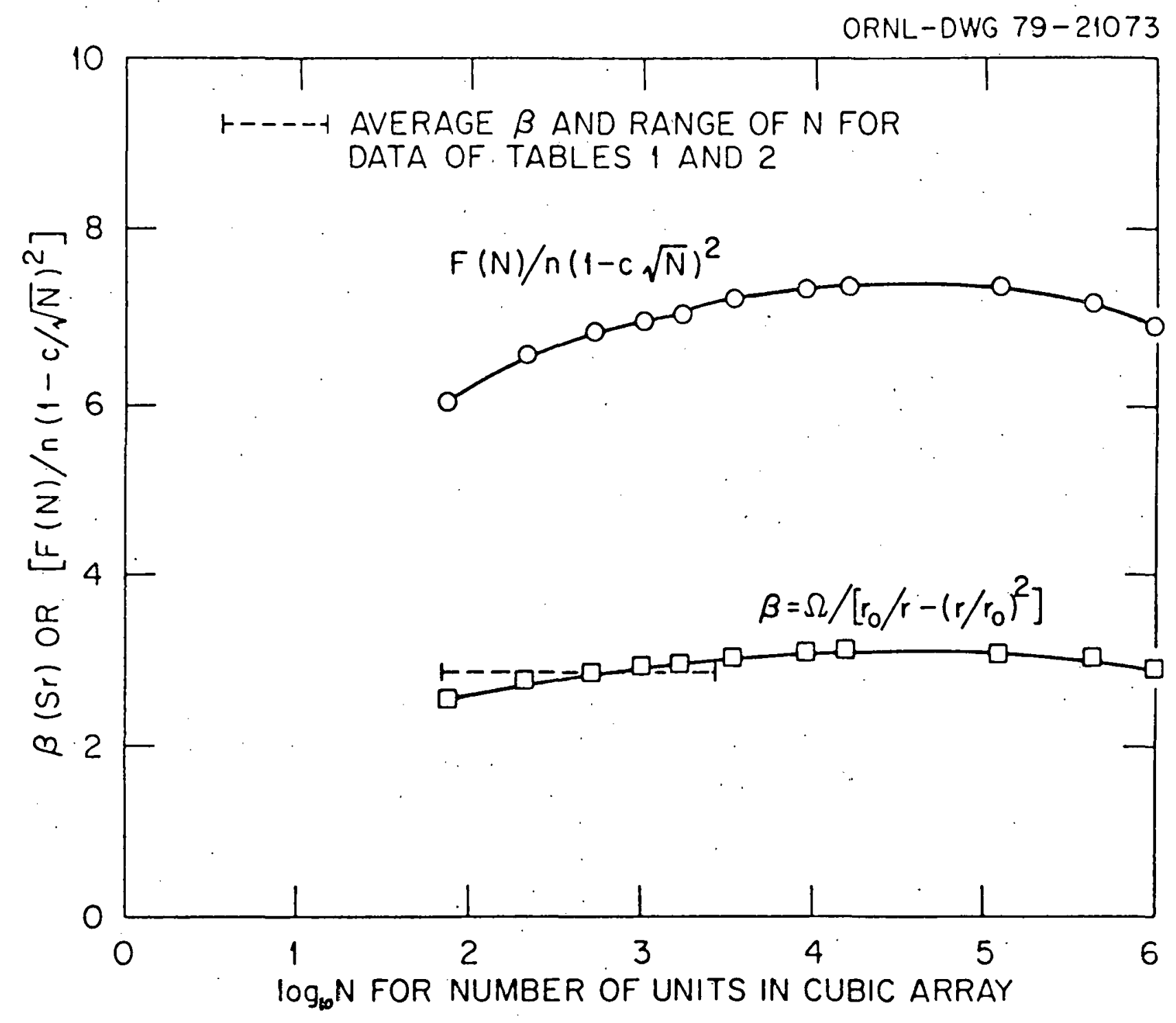

Fig. 3. Dependence of parameters $\beta(s r)$ and $F(N)$ on the number of units in a cubic array. 
range of the $N$ shown. The average value of $\beta$ over the range of $N$ shown (64 to $10^{6}$ ) is $2.945 \pm 0.172$ and may be compared to an average value of $\beta$ for the data of Table 2 obtained by applying Eq. 15 to each array as $\beta=\Omega /\left[r_{0} / r-\left(r / r_{0}\right)^{2}\right]$. This provides an average value for $\beta$ of 2.884 \pm 0.143 . The result is shown by the dashed 1 ine in Fig. 3 over the range $\mathrm{N}=64$ to $\mathrm{N}=2744$.

The value $\beta=2.884$ is the constant appearing in the equation of the dashed 1 ine shown in Fig. 4 and the error of \pm 0.143 defines the error to be associated with each abscissa value. The data shown are for some of the arrays of Tab1e 2, and the figure is a further illustration of the generic relation presented in Fig. 2. The $\Delta \beta$ has been interpreted as an $\Delta \Omega$ and it increases with decreasing $r / r_{\text {。 }}$ values, encompasing all the data points shown except for some of the $N=64$ unit arrays. The use of an average $\beta$ in Eq. 15 will facilitate relative comparisons of $\Omega^{\prime} s$ for different fissile materials by means of Eqs. 4 and 5 .

Omega and arrayk-eff's. Before exploring perturbations to critical cubic arrays of spheres, let us interpret $\Omega$ for subcritical arrays. It has been shown' and confirmed by Monte Carlo calculations that, if each unit in an artay is subjected to a reactivity change $(\rho=1-1 / k$, constant), then the array will exhibit the same reactivity change in sign and magnitude. Let $k$-eff of the array be $k_{a}$ and that of the unit $k_{u}$, then it follows that

$$
\frac{\mathbf{k}_{a}^{-}}{k_{a}}=\frac{k_{\underline{u}}^{-}}{k_{u}} .
$$

If a radius $r$ results in a critical array and the radius is reduced to $r^{-}<x$, then the array will be subcritical and the solid angle diminished. 


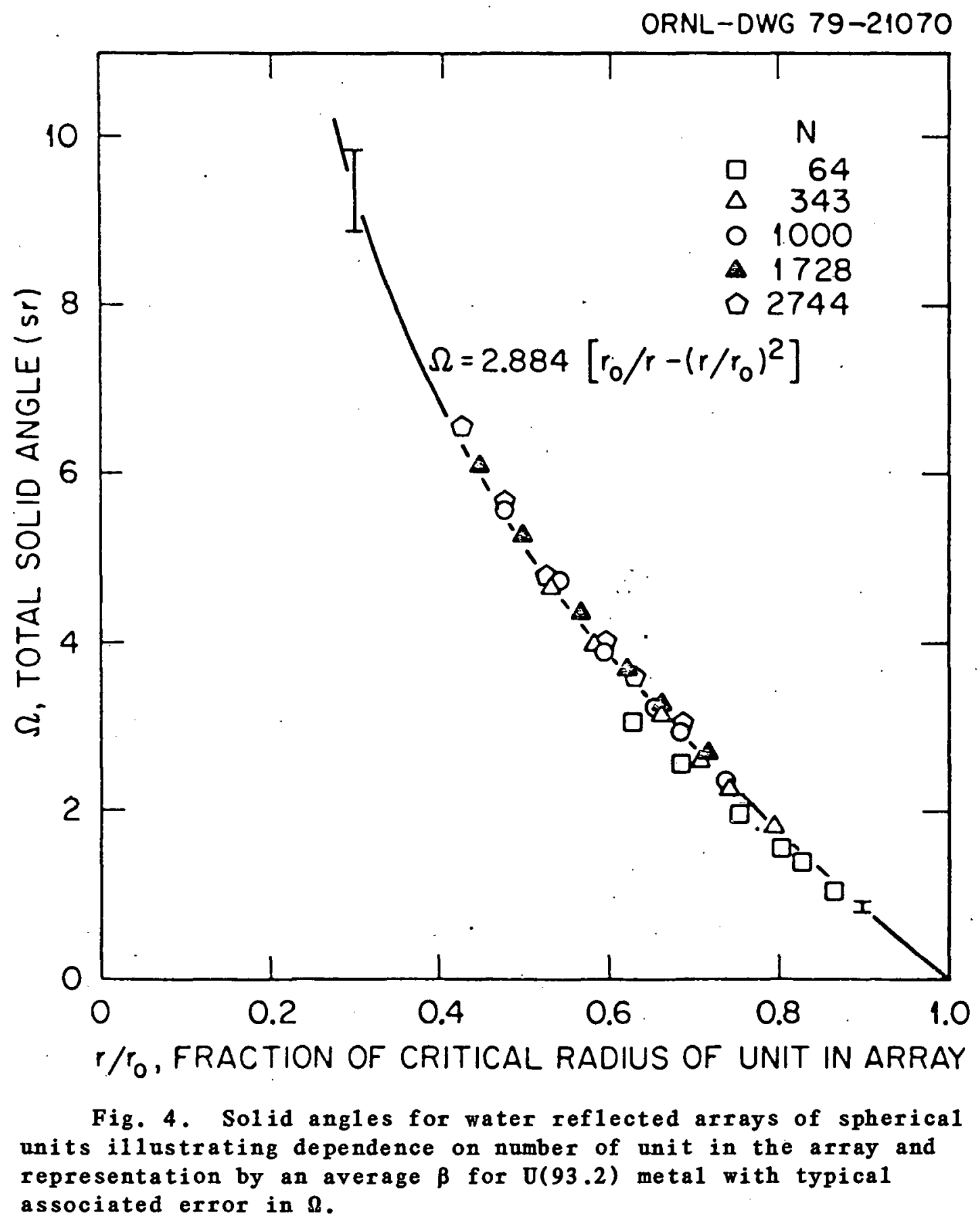


Since $k_{u}$ is proportional to the radius of the unit, a good approximation to $k_{\mathfrak{u}}^{\mathfrak{r}} / k_{\mathfrak{u}}$ is $r / r$, as is evident from the values in Table 1; and we may write

$$
k_{a}^{\prime}=r^{\prime} / r\left(\text { for } k_{a}=1\right)
$$

Applying Eq. 12 to a critical array with units of radius $r$ and to the same array with units of radius $I^{-}<r$, we have for the ratio of $\Omega^{\prime} s$,

$$
\Omega^{-}=\Omega\left(\frac{r_{0}}{r}\right)^{2}\left(\frac{r^{-}}{r_{0}}\right)^{2}
$$

or, setting $a_{\circ}=\Omega\left(\frac{r_{0}}{r}\right)^{2}$,

$$
\Omega^{-}=a_{0}\left(r / r_{0}\right)^{2}
$$

which is the equation of a parabola passing through the origin. If $r^{\prime}$ is greater than $r$, then the array is supercritical and $\Omega^{\prime}$ is given by Eq. 17. Equation 17 is the equivalent of Eq. 4. The equation describes a fixed array geometry and may be used to approximate the $\Omega$ and array k-efi response to changes in the mass of the units. We shail utilize this result 1 ater, but remark here that Eq. 17 is useful in providing an estimate of $\Omega$ for criticality if the k-eff is known for a subcritical configuration.

\section{UNIT SHAPE VARIATION}

Calculations of the solid angle thus far presented have been for spherical units. Applications of Eq. 12 to arrays of spherical units is appropriate since the area of each unit in the array is that of a circle 
and the area, constant for each unit, is always normal to the 1 ine joining the center of a unit and the point about which $\Omega$ is summed. The $\Omega$ computed by Eq. 4 for spherical units is in good agreement with the value obtained by analytic methods such as the SNAKE code, ${ }^{18}$ which consider the contributions from the surface of a sphere rather than an approximating disc. The results from Eq. 12 have been compared to solid angles computed by the SNAKE code, and the ratio of the former to the latter was observed as $0.9958 \pm 0.0027$. The SNAKE code a1 so has the capability of computing the solid angle by the approximate formulae given in Ref. 24 , the Nuclear Safety Guide.

Equation 12 would not be appropriate for unit shapes other than spherical since the area of a unit relative to the point about which $\Omega$ is summed does not remain constant but is dependent on the location of the unit in the array and the value of $d_{n}$. We will denote solid angles computed analytically, such as result from the SNAKE code by the subscript s as $\Omega_{s}$.

Consider a reflected critical array of spherical units. Without changing the array geometry and the mass of units, let us examine the response of the array k-eff and $\Omega$ to changes in unit shape. Changing the shape of the unit from spherical to cylindrical, for example, at a height-to-diameter ( $h / d)$ ratio of unity will result in an array k-eff change that is dependent on the mass of the unit. The solid angle, however, increases independent of the mass. Compensation for the array reactivity change is accomplished by changing the mass of the units under the constraint of constant h/d. The point to be examined is whether or not there is an $\mathrm{h} / \mathrm{d}$ that results in a solid angle less than that of the initial array of spheres when criticality has been restored. 
This behavior is explored by calculations of arrays with cylindrical units. The characteristic constants for cylinders of U(93.2) metal at an $\mathrm{h} / \mathrm{d}=1$ are $c_{2}=1.578 \times 10^{-3} \mathrm{~cm}^{-2}$ and $\mathrm{m}_{0}=57.87 \mathrm{~kg} \mathrm{U}(93.2)$. A 216-unit water reflected array of $26.18 \mathrm{~kg}$ cylinders centered in ce11s with a square base of $54.24 \mathrm{~cm}$ and a height of $56.21 \mathrm{~cm}$ results in a $k$-eff $=0.995 \pm 0.006$ and an $\Omega_{s}=2.076 \mathrm{sr}$. The spherical mass required for criticality in this array is $25.45 \mathrm{~kg} \mathrm{U}(93.2)$, and has, by Eq. 4 an $\Omega_{s}=1.798 \mathrm{sr}$. We can infer that, were the spherical shape of the units converted to cylinders at $h / d=1$, the $k$-eff would be reduced.

The cylinders of the array were subjected to further shape changes and an extensive series of Monte Car1o calculations performed. Arrays with and without the water reflector were calculated. The spacing of units in the unreflected array was reduced to establish criticality for the $h / d=1$ units. A summary of the calculations is presented in Section (a) of Table 3 where the shape of the unit was varied from an $h / d$ of 0.1 to 4.0 for each array reflector condition. There is a decrease in k-eff and an increase in $\Omega$ as the unit shape deviates from the $h / d=1$ value. The data for the reflected arrays is shown in Fig. 5 where each point has been 1 abeled with the unit $h / d$ and the corresponding array k-eff. Units of this mass have the property of requiring larger solid angles than the array of spheres when unit shape is changed and criticality restored, i.e., the point being examined.

The results shown in Sect. (b) of Table 3 are for a cylinder with $h / d=1$, but the mass of the unit has been adjusted to result in a unit k-eff equal to that of the unit in Sect. (a). Even for untls wilh h/d near unity, the result is a decrease in $k$-eff and in $\Omega_{s}$. The arrays shown in Sect. (c) have the same $k$-eff as the arrays of Sect. (a), but 
Table 3. Effect of unit shape on the neutron multiplication factor of unreflected and reflected arrays of $\mathrm{U}(93.2)$ meta 1 cylinders

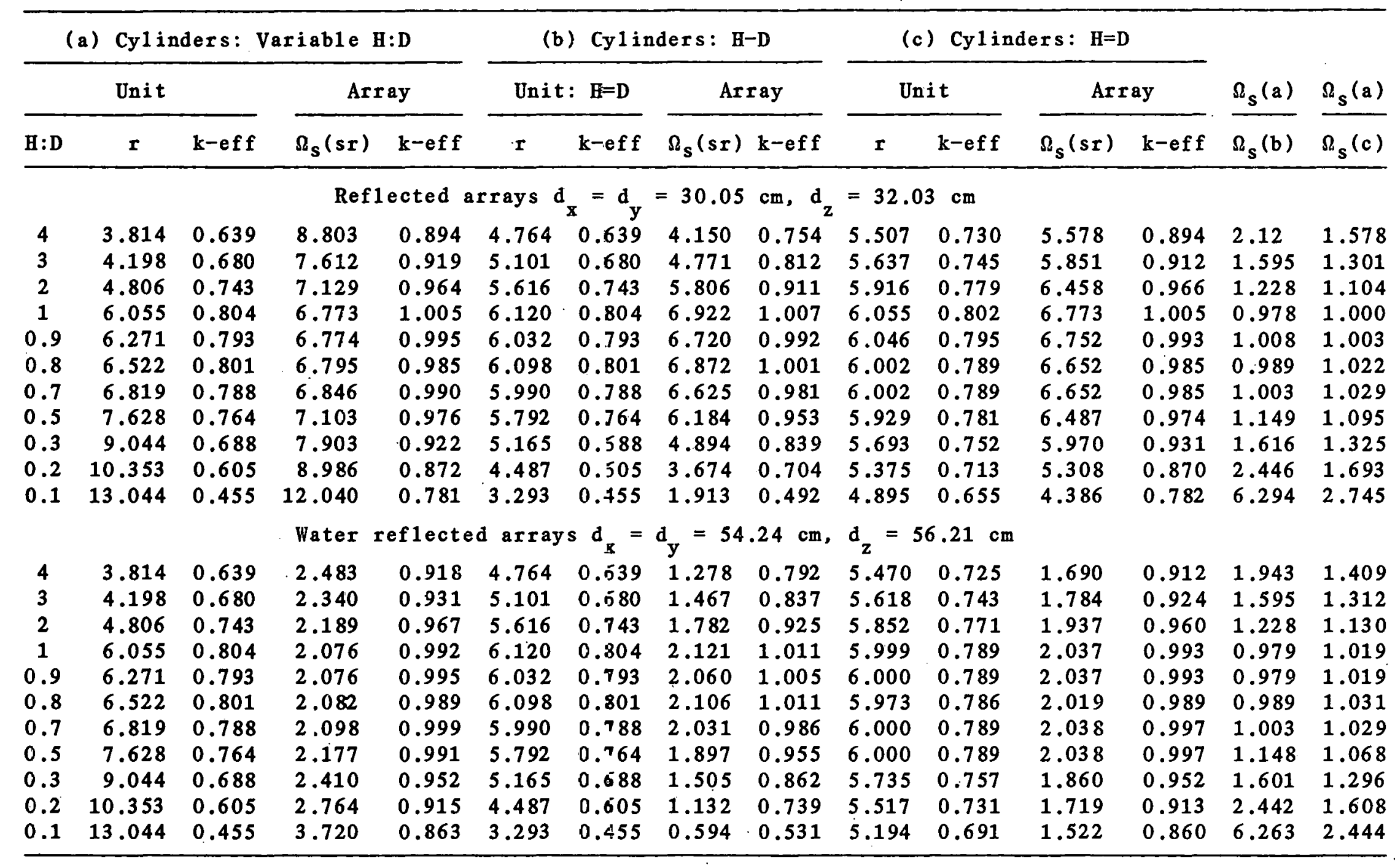




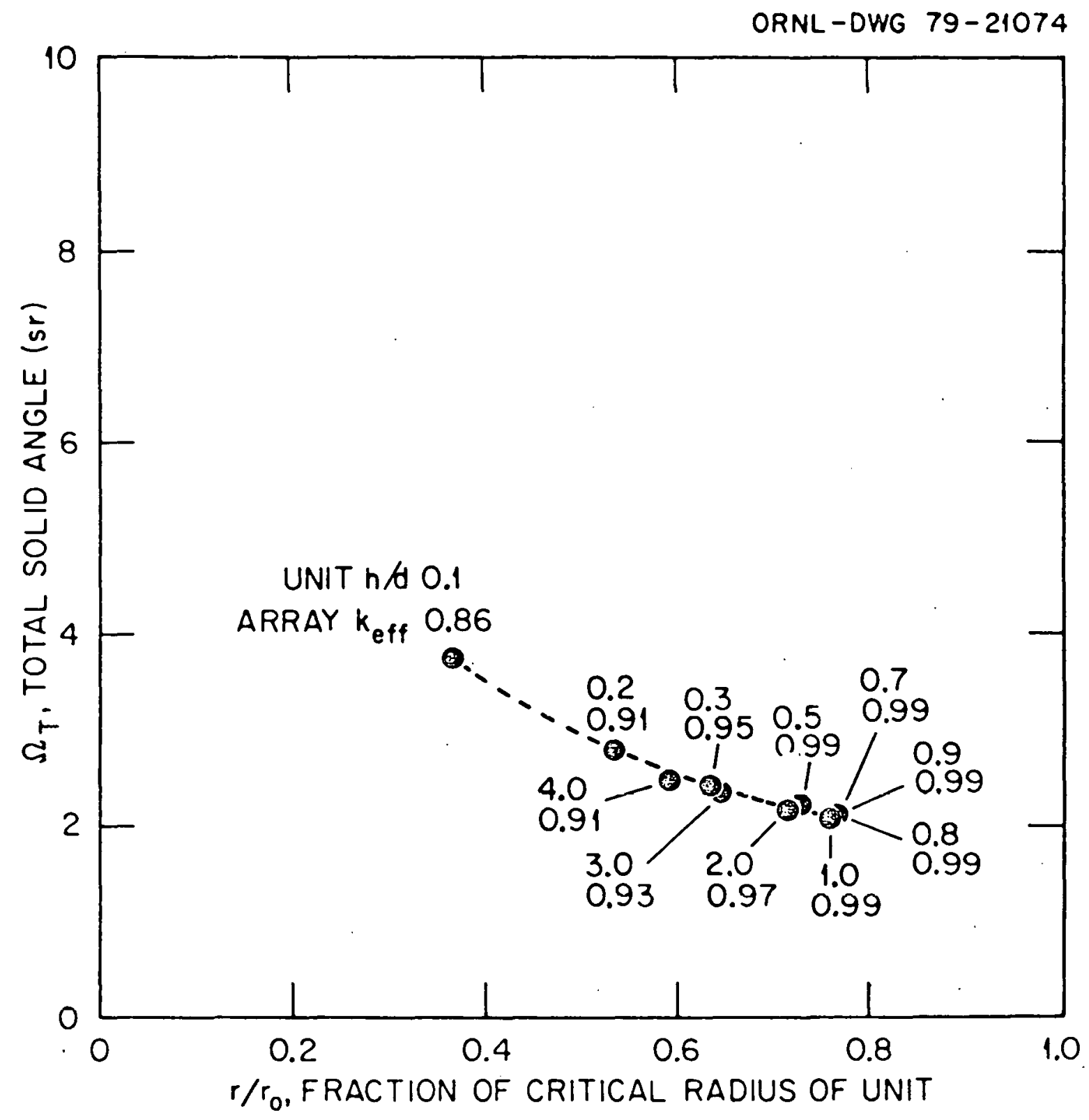

Fig. 5. Total solid angle for a water reflected cubic array with units of constant mass showing the effects of changing the shape of the units and resulting array k-eff. 
the units have an $h / d=1$ and their mass has been adjusted to produce the same array $k$-eff as the corresponding array in Sect. (a). The 1ast two columns of the table present the ratio of solid angles for an array of Section (a) to the corresponding arrays of Sections (b) and (c). The ratios may be considered unity or greater, allowing for the standard deviation of the calculated k-eff's. The ratios would be clearly greater than unity for all the reflected arrays of the table with respect to the $\Omega$ for the spherical array.

The data of Table 3 also show that unit shape deviations from equilateral result in larger solid angles even were the mass for the resultant shape increased to maintain either the unit k-eff or the array k-eff. Further, consistent with an array response to changes in unit reactivity, these data show that the fractional changes in the solid angle for a reactivity. change in the units is independent of the reflector condition of the array.

While the above results confirm the expected response of array k-eff for a mass of $26.18 \mathrm{~kg}$ when the unit shape is changed, they are not sufficient to imply the behavior is true for all masses in the range from 0 to $m_{\circ}$ for $U(93.2)$ metal. The unit k-eff will decrease upon changing unit shape from a sphere to a cylinder, and the $\Omega_{s}$ does increase; however, it is not always the case that the array k-eff will decrease. This effect is illustrated by arrays of spheres from Table 1 and use of the equivalence relation, Eq. 4 or 5, to define cylindrical units resulting in criticality. The mass for various h/d ratios, I, $r / r_{0}$, unit k-eff, and the corresponding $\Omega_{s}$ for each is given in Table 4 . The characteristic constants, $c_{2}$ and $m_{0}$, for the various cylinders are a1 so given in the table. 
Table 4. Equivalent masses for units of different shape in critical water reflected cubic arrays of 64 units

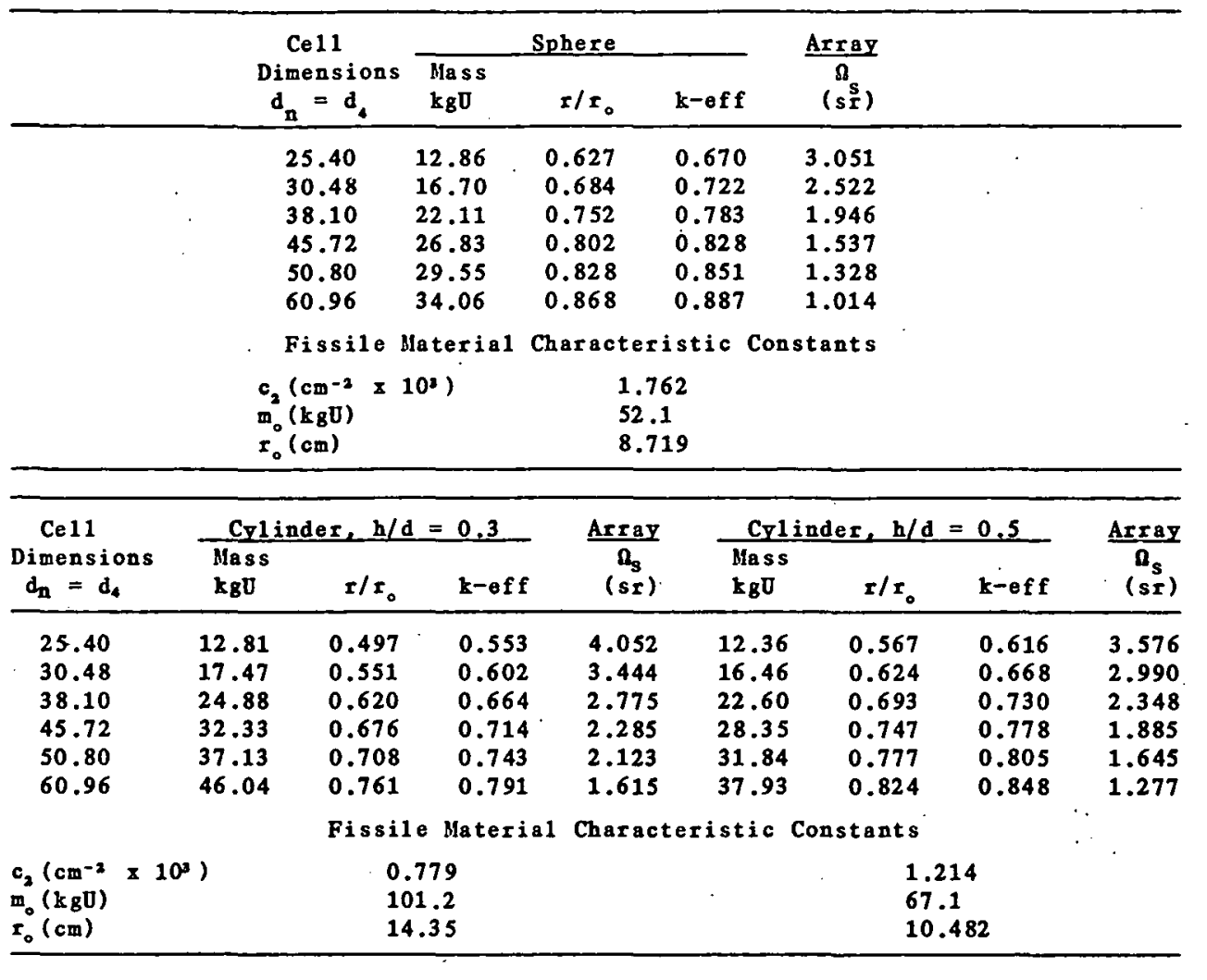

\begin{tabular}{|c|c|c|c|c|c|c|c|c|}
\hline \multirow{2}{*}{$\begin{array}{c}C e 11 \\
\text { Dimensions } \\
d_{n}=d_{4}\end{array}$} & \multicolumn{3}{|c|}{ Cylinder, $h / d=1.0$} & \multirow{2}{*}{$\frac{\frac{\text { Array }}{g_{3}}}{(\mathrm{sr})}$} & \multicolumn{3}{|c|}{ Cylinder, $h / d=2,0$} & \multirow{2}{*}{$\frac{\frac{\text { Array }}{\Omega_{3}}}{(\mathbf{s r})}$} \\
\hline & $\begin{array}{l}\text { Mass } \\
\mathrm{kgU}_{\mathrm{gU}}\end{array}$ & $r / r_{0}$ & $k$-eff & & $\begin{array}{l}\text { Mass } \\
\text { kgU }\end{array}$ & $r / x_{0}$ & $k-e f f$ & \\
\hline $\begin{array}{l}25.40 \\
30.48\end{array}$ & $\begin{array}{l}12.54 \\
16.44\end{array}$ & $\begin{array}{l}0.601 \\
0.657\end{array}$ & $\begin{array}{l}0.647 \\
0.697\end{array}$ & $\begin{array}{l}3.468 \\
2.867\end{array}$ & $\begin{array}{l}13.17 \\
17.58\end{array}$ & $\begin{array}{l}0.558 \\
0.614\end{array}$ & $\begin{array}{l}0.608 \\
0.659\end{array}$ & $\begin{array}{l}3.792 \\
3.179\end{array}$ \\
\hline 38.10 & 22.05 & 0.725 & 0.759 & 2.214 & 24.19 & 0.684 & 0.722 & 2.495 \\
\hline 45.72 & 27.07 & 0.776 & 0.804 & 1.753 & 30.41 & 0.738 & 0.770 & 2.006 \\
\hline 50.80 & 30.03 & 0.804 & 0.830 & 1.516 & 34.20 & 0.767 & 0.796 & 1.752 \\
\hline 60.96 & 35.00 & 0.846 & 0.867 & 1.159 & 40.84 & 0.814 & 0.839 & 1.362 \\
\hline
\end{tabular}

Fissile Material Characteristic Constants

\begin{tabular}{lll}
$\mathrm{c}_{2}\left(\mathrm{~cm}^{-2} \times 10^{2}\right)$ & 1.548 & 1.183 \\
$\mathrm{~m}_{0}(\mathrm{~kg})$ & 57.7 & 73.1 \\
$\mathrm{r}_{0}(\mathrm{~cm})$ & 7.889 & 6.850 \\
\hline
\end{tabular}

\begin{tabular}{|c|c|c|c|c|c|c|c|c|}
\hline \multirow{2}{*}{$\begin{array}{c}\text { Ce11 } \\
\text { Dimensions } \\
d_{n}=d\end{array}$} & \multicolumn{3}{|c|}{ Cylindex, $h / d=3.0$} & \multirow{2}{*}{$\begin{array}{c}\frac{\text { Array }}{\Omega_{3}} \\
(\mathrm{sx})\end{array}$} & \multicolumn{3}{|c|}{ Cylinder, $h / d=4.0$} & \multirow{2}{*}{ 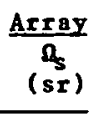 } \\
\hline & $\begin{array}{l}\text { Mass } \\
\text { kgD }\end{array}$ & $r / r_{0}$ & $\mathbf{k}-\mathbf{e f f}$ & & $\begin{array}{l}\text { Mass } \\
\text { kgO }\end{array}$ & $r / r_{0}$ & $k-0 f f$ & \\
\hline 25.40 & 13.30 & 0.510 & 0.565 & 4.084 & 13.81 & 0.478 & 0.536 & 4.466 \\
\hline 30.48 & 18.07 & 0.564 & 0.614 & 3.458 & 18.85 & 0.530 & 0.583 & 3.784 \\
\hline 38.10 & 25.60 & 0.634 & 0.677 & 2.772 & 26.86 & 0.596 & 0.642 & 3.042 \\
\hline 45.72 & 33.09 & 0.690 & 0.727 & 2.272 & 34.92 & 0.651 & 0.692 & 2.501 \\
\hline 50.80 & 37.88 & 0.722 & 0.756 & 2.008 & 40.13 & 0.682 & 0.720 & 2.216 \\
\hline 60.96 & 46.66 & 0.774 & 0.806 & 1.595 & 49.34 & 0.730 & 0.763 & 1.751 \\
\hline
\end{tabular}

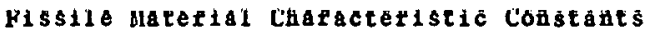

$\begin{array}{lll}c_{2}\left(\mathrm{~cm}^{-2} \times 10^{\prime}\right) & 0.837 & 0.772 \\ m_{0}\left(\mathrm{kgU}^{\prime}\right) & 98.7 & 110.0 * \\ r_{n}(\mathrm{~cm}) & 6.575 & 6.452\end{array}$

-This value of mo satisfied by Eq. 6 over the mass range for 0 to $64 \mathrm{kgJ}$. The critical mass for this unit geometry is $125 \mathrm{kgU}$ and $a c_{2}$ of $6.088 \times 10^{-4} \mathrm{~cm}^{-2}$ in Eq. 2 is appropriate over the mass range from 45 to $125 \mathrm{kgU}$. 
Several of the cylindrical units have masses about that of the spheres or s1ightly less. This is most easily seen in the graphical display of the data presented in Fig. 6 showing the 1 imiting surface density, Eq. 1, as a function of the unit mass independent of the unit geometry. The lines labeled with the cell dimensions are representations of Eq. 5, i.e., constant $\sigma(\mathrm{m}) / \mathrm{m}$, and depict the identical geometry of critical arrays of the different unit shapes. At the lower mass range of the data, it is seen that the $\sigma(m)$ values for the units with $\mathrm{h} / \mathrm{d}=0.3,0.5$, and 1.0 are less than that for the sphere. The slight reduction in mass and, hence, surface density would correspond to a k-eff change of about 1.5 percent for the 1 argest difference $\left(\Delta_{m}=500 \mathrm{~g}\right)$ shown were the cylindrical mass not reduced from that of the sphere. These arrays with masses of units less than the spherical masses exemplify the conditions mentioned earlier, i.e., the unit has lost reactivity, and the solid angle has increased, but the array k-eff is also increased.

Representation of the data in Table 4 in terms of the solid angle is made in Fig. 7 where the abscissa is the fraction of the critical radius for the units. The data may be compared to the results of Eq. 15 with $\beta=2.540$ for $N=64$. One can conclude from these data that $\Omega$ is not strongly dependent on unit shape in the h/d range of 0.3 to 4.0 for the 64-unit arrays, and that a one-to-one correspondence between the $\sigma(\mathrm{cm})$ and $\Omega$ methods is possible for units of shape other than spherical.

Given an $r / r_{0}$ value, units having an $h / d$ ratio less than 0.3 evidence a smaller total solid angle at criticality than do units having near equilateral shapes. Further, these extreme unit shapes cause $\Omega$ to 


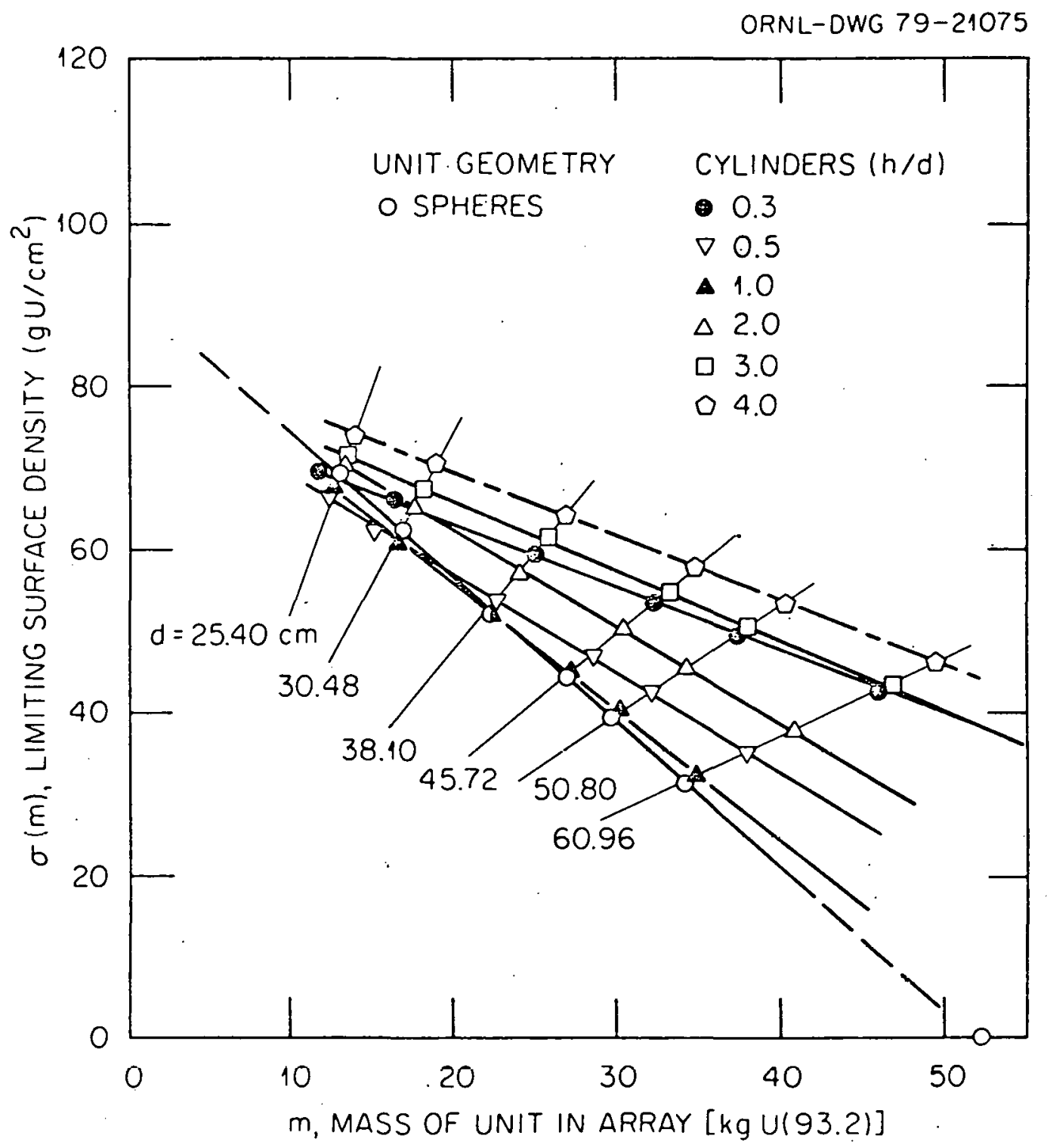

Fig. 6. Surface density representation of critical water reflected arrays of 64 units of various geometries. 


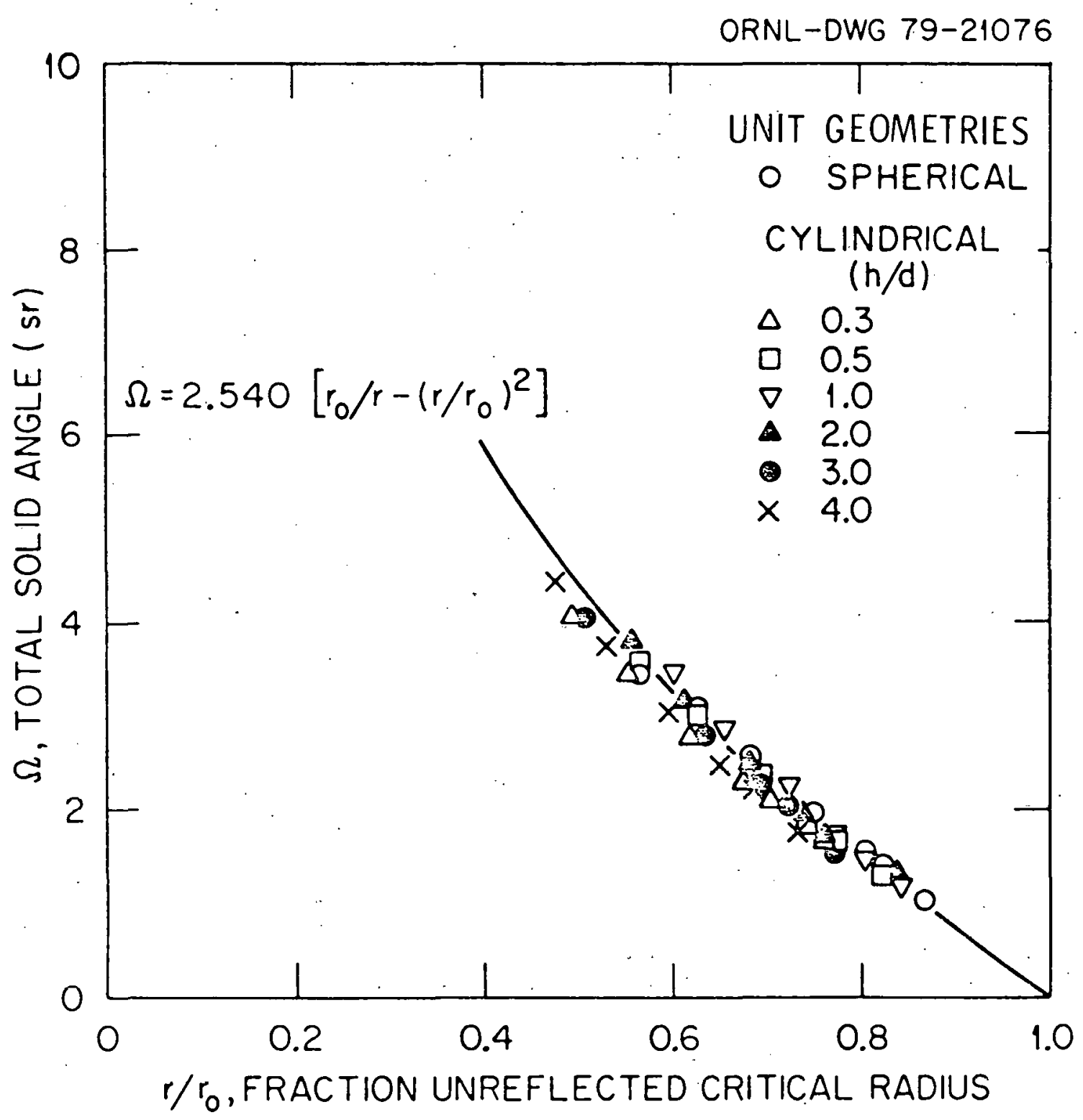

Fig. 7. Solid angle representation of critical water reflected arrays of 64 units of various geometries. 
exhibit a more pronounced dependence on the number of units in an array. These observations are manifest in previously reported datalo for cylinders with $\mathrm{h} / \mathrm{d}=0.1,1.0$, and $4: 0$ in which the number of units were allowed to vary. The data are shown in Fig. 8 and are useful in illustrating application of the analytic expressions to interpretation of the calculated data. Comparison is made in the figure to the spherical unit arrays for $N=64$ of $\mathrm{Fig}$. 7 . In the $\mathrm{h} / \mathrm{d}$ range from 0.3 to 4.0 , an increase in $N$ results in 1 arger $\Omega$ values than is represented by the arrays of spheres. The $h / d=0.1$ units, however, have $\Omega$ values less than those of the spherical units for $N=64$. The difference is significant and their criticality warrents confirmation. One could search for the critical radius with the KENO code eliminating known biases such as may occur with the differential albedo reflector option. ${ }^{20}$ We choose instead to demonstrate the use of Eq. 17 to estimate what the $k$-eff would be if the unit radius were defined by the equation for the 64-unit arrays of spherical units. Consider the array with $\mathrm{N}=64, \mathrm{~d}_{4}=60.96 \mathrm{~cm}$, $r=17.95 \mathrm{~cm}$, and $\Omega_{s}=3.179 \mathrm{sr}$. The constant $a_{\circ}$ of $\mathrm{Eq} .17$ is evalua ted as

$$
a_{0}=\frac{U_{s}}{\left(x / r_{0}\right)^{2}}=\frac{3.179}{(17.95 / 35)^{2}}=12.073 \mathrm{sr}
$$

so that the locus of $\Omega$ as a function of the array k-eff is given by

$$
\Omega=12.073\left(r / r_{0}\right)^{2} .
$$

This curve is described in Fig. 8 . 


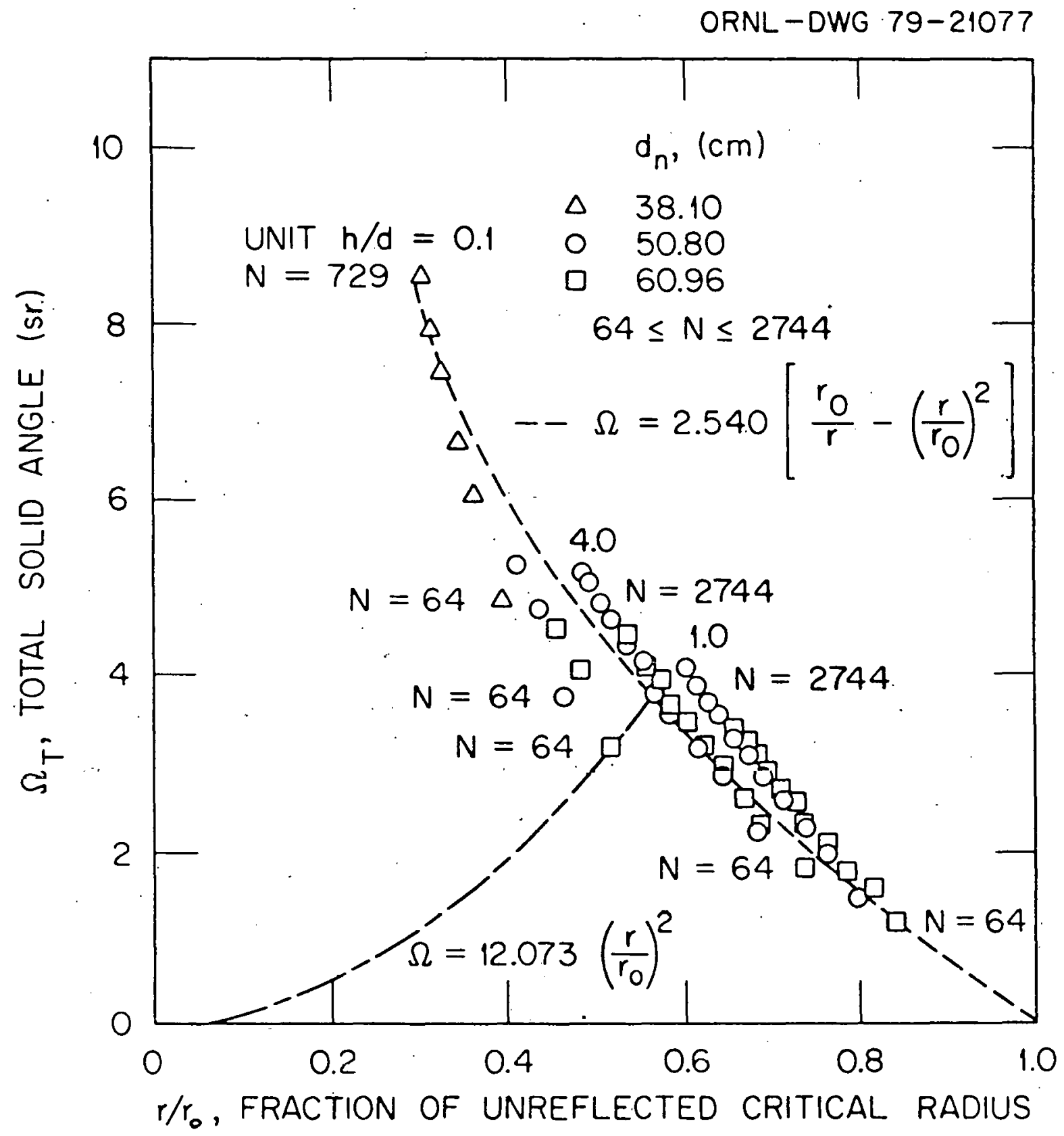

Fig. 8. Total solid angle of water reflected cubic arrays illustrating the effects of number of units, cell dimension and unit shape. 
If criticality for the cylindrical units is to be defined by Eq. 15 for the spherical arrays, then

$$
a_{0}\left(r / r_{0}\right)^{2}=\beta\left[r_{0} / x-\left(r / r_{0}\right)^{2}\right],
$$

giving

$$
a_{0} / \beta=m_{0} / m-1
$$

so that

$$
\frac{\mathrm{m}_{\circ}}{\mathrm{m}}=1+\frac{\mathrm{a}_{0}}{\beta}=5.753=\left(\mathrm{r}_{\mathrm{o}} / \mathrm{r}\right)^{3}
$$

Thus $r=35 /(5.753) 1 / 3=19.53 \mathrm{~cm}$ where $r_{\circ} \sim 35 \mathrm{~cm}$ for an $\mathrm{h} / \mathrm{d}=0.1$. It follows that, if the data in the figure is correct, i.e., if $r=17.95 \mathrm{~cm}$ produces a $k=1$; a calculation of the array with a radius of $19.53 \mathrm{~cm}$ should result in a k-eff of $19.35 / 17.95$ or 1.078 by Eq. 16. This array and two others with $h / d=0.1$ were calculated by the KENO Monte Carlo code. The calculations were performed with complete neutron tracking in a 30-cm-thick water reflector. The results are presented in Tab1e 5 and confirm the expected supercriticality of the arrays.

With respect to the points raised and examined as to the effect of unit shape on $\Omega$ and the array k-eff, we can conclude that in every case examined, the total solid angle increases when the unit geometry is changed from spherical to cylindrical. The magnitude of the change is dependent on the unil máśs and its h/d ratios. There are unit shapcs in the region near equilateral cylinders where masses less than about 0.1 mo may cause an array to experience a slight increase in reactivity. The magnitude of this reactivity change is no more than a few standard deviations of the calculated k-eff. Onit masses larger than $\sim 0.1 \mathrm{~m}$ 。 
Tab1e 5. Confirmation of expected supercriticality by comparison of estimated ratio of radii, $r / r$, for criticality and calculated neutron multiplication factor for 64-unit, water reflected arrays

\begin{tabular}{|c|c|c|c|c|c|c|c|}
\hline \multirow{2}{*}{$\begin{array}{c}C e 11 \\
\text { Dimension } \\
\mathrm{d}_{4}\end{array}$} & \multirow{2}{*}{$\begin{array}{c}\text { Eqs. } 5,9 \\
r(\mathrm{~cm})\end{array}$} & \multirow{2}{*}{$\begin{array}{c}\text { Eq. } 17 \\
-a_{0} \cdot\end{array}$} & \multicolumn{2}{|c|}{$\mathrm{Eq} \cdot 18$} & \multicolumn{3}{|c|}{$k-e f f$} \\
\hline & & & $1+a_{0} / \beta$ & $\mathbf{r}^{-}$ & $r / x$ & KENO & $\pm \sigma$ \\
\hline 60.96 & 17.95 & 12.073 & 5.735 & 19.53 & 1.078 & 1.085 & 0.005 \\
\hline 50.80 & 16.291 & 17.632 & 7.942 & 17.54 & 1.077 & 1.067 & 0.007 \\
\hline 38.10 & 13.803 & 31.107 & 13.247 & 14.79 & 1.072 & 1.048 & 0.007 \\
\hline
\end{tabular}


produce a loss in array reactivity when the unit geometry is changed. The restoration of criticality in these cases requires positive fractional change in the total solid angle that is independent of the reflector condition of the array.

There is a one-to-one correspondence between the 1 imiting surface density and solid angle expressions of criticality. The analytic expression derived appears to monitor the calculated array k-eff's very we11. The characterization of criticality for some extreme unit shapes may require several sets of constants $c_{2}$ and $m_{0}$, which will be valid over intervals of the full range of the parameters $m$ and $r / r_{0}$. These 1 imits of applicability would have to be determined by validated calculations.

\section{ARRAY SHAPE VARIATIONS}

Cuboida1. Deviations of array shape from cubic to cuboidal will, in genera1, result in a decrease in the array $k$-eff because of increased neutron leakage from the array. This negative reactivity may be compensated by an increase in the unit mass or a reduction in the spacing of the units to restore array criticality. The limiting surface density, $\sigma(m)$, required for criticality of arrays with noncubic arrangements of units is specified by Eqs. 7 and 8 . We illustrate the change in $\sigma(m)$ due to array shape by beginning with a cubic array, removing units from the top of the array and placing them at the array sides. The array of 512 units having cubic cell sith $d_{8}=32.908 \mathrm{~cm}$ results in criticality with a spherical mass of $10.42 \mathrm{~kg} \mathrm{U}(93.2)$. Rearranging the units into an array having $n_{x}=32, n_{y}=4$, and $n_{z}=4$ gives $k=1.41 \%, \dot{c}_{2} \equiv 1.192 x$ $10^{-3} \mathrm{~cm}^{-2}, \mathrm{~m}=13.38 \mathrm{kgU}$ and $\sigma(\mathrm{m})=47.048 \mathrm{~g} / \mathrm{cm}^{2}$. The other possible rearrangements are summarized in Table 6 along with parameters from Eqs. 7 and 8 . 
Tab1e 6. Criticality parameters for various rearrangements of 512 units in cells of constant size as water reflected arrays

\begin{tabular}{|c|c|c|c|c|c|c|c|c|c|c|c|c|c|}
\hline \multirow{2}{*}{$\mathbf{n}_{\mathbf{X}}$} & \multirow[b]{2}{*}{$\mathbf{n}_{\mathbf{y}}$, } & \multirow[b]{2}{*}{$\mathbf{n}_{\mathbf{z}}$, } & \multirow{2}{*}{$\begin{array}{l}\text { Array } \\
k-e f f\end{array}$} & \multirow{2}{*}{$I(\mathrm{~cm})$} & \multirow{2}{*}{$\begin{array}{l}\text { Shape } \\
\text { factor } R\end{array}$} & \multirow{2}{*}{$\begin{array}{c}c_{2}\left(\times 10^{+3}\right) \\
\left(\mathrm{cm}^{-2}\right)\end{array}$} & \multirow{2}{*}{$\begin{array}{c}M \\
\mathrm{kgU}(93.2)\end{array}$} & \multirow{2}{*}{$\begin{array}{l}\sigma(\mathrm{m}) \\
\mathrm{gU} / \mathrm{cm}^{2}\end{array}$} & \multirow{2}{*}{$F(N)$} & \multicolumn{4}{|c|}{$\Omega(s r)$} \\
\hline & & & & & & & & & & $\Omega_{S}$ & $\mathrm{Eq} \cdot 12$ & TID-7016R.2 & $\mathrm{Eq} \cdot 15$ \\
\hline$\dot{\mathbf{8}}$ & 8 & 8 & 1.005 & 5.099 & 1.000 & 1.762 & 10.42 & 73.26 & 52.048 & 3.932 & 3.925 & 4.356 & 3.934 \\
\hline 16 & 16 & 2 & 0.996 & 5.635 & 1.667 & 0.692 & 14.06 & 24.72 & 30.137 & 2.782 & 2.776 & 3.274 & 2.954 \\
\hline 32 & 4 & 4 & 1.003 & 5.542 & 1.417 & 1.192 & 13.38 & 47.03 & 32.670 & 2.918 & 2.911 & 3.499 & 2.855 \\
\hline 32 & 8 & 2 & 1.002 & 5.740 & 1.750 & 0.724 & 14.86 & 26.13 & 26.788 & 2.567 & 2.560 & 3.065 & 2.641 \\
\hline 32 & 16 & 1 & 1.006 & 6.450 & 2.917 & 0.614 & 21.09 & 18.54 & 18.048 & 2.185 & $2: 178$ & 2.643 & 2.236 \\
\hline 64 & 4 & 2 & 1.000 & 6.040 & 2.042 & 0.814 & 17.32 & 30.44 & 19.670 & 2.089 & 2.082 & 2.593 & 1.935 \\
\hline 64 & 8 & 1 & 1.002 & 6.488 & 3.042 & 0.644 & 21.46 & 18.86 & 15.119 & 1.853 & 1.846 & 2.297 & 1.930 \\
\hline 128 & 2 & 2 & 1.002 & 6.403 & 2.688 & 1.120 & 20.63 & 36.27 & 11.694 & 1.397 & 1.391 & 1.797 & 1.351 \\
\hline 128 & 4 & 1 & 1.003 & 6.729 & .3 .354 & 0.724 & 23.94 & 21.05 & 11.042 & 1.458 & 1.451 & 1.895 & 1.404 \\
\hline 256 & 2 & 1 & 1.001 & 7.062 & 4.010 & 0.912 & 27.68 & 24.33 & 6.412 & 0.934 & 0.928 & 1.260 & 0.848 \\
\hline 512 & 1 & 1 & 1.002 & 7.514 & 5.339 & 1.416 & 33.34 & 29.31 & 3.282 & 0.542 & 0.536 & 0.760 & 0.487 \\
\hline
\end{tabular}


Arbitrary arrangements of units into cuboidal arrays obviously gives rise to three different values of a projected surface density $\sigma$, i.e.,

$$
\sigma_{i}=\sigma_{j k} \quad \text { where } i, j, k=1,2,3
$$

We have chosen the array orientation such that the z-direction corresponds to the minimum number in the triplet $\left(n_{x}, n_{y}, n_{z}\right)$. Each of the arrays in Table 6 could be expressed in terms of the two other values of $\sigma(m)$ and each would properly represent criticality having the same shape factor $R$ but different values of the characteristic constant $c_{2}$ and associated $\sigma(\mathrm{m})$.

The data of Table 6 are shown in Fig. 9 where the 1 imiting surface density is given as a function of the spherical mass of the units in the water reflected arrays. The equivalence relation for two arrays of different shapes becomes, by. Eq. 7 ,

$$
\frac{n_{z}^{\prime}}{n} \frac{\sigma(m)}{m}=\frac{n_{z}}{n} \frac{\sigma\left(m^{\prime}\right)}{m^{\prime}}
$$

where $\mathrm{n}^{3}=\mathrm{N}$.

If, initialiy $n_{z}=\ddot{n}$, a cublc array, then Eq. 9 becumes for the cuboidal array, denoted by primes,

$$
\frac{m_{0}^{\prime}}{m^{\prime}}=1+\frac{n_{z} c_{2}}{n c_{2}}\left(\frac{m_{0}}{m}-1\right)
$$

or

$$
\underline{m_{0}^{\prime}}=1+\frac{5 R^{-x}-1}{4}\left(\frac{\underline{m}_{0}}{m}-1\right)
$$

by Eq. 8 where $x=0.672$. 


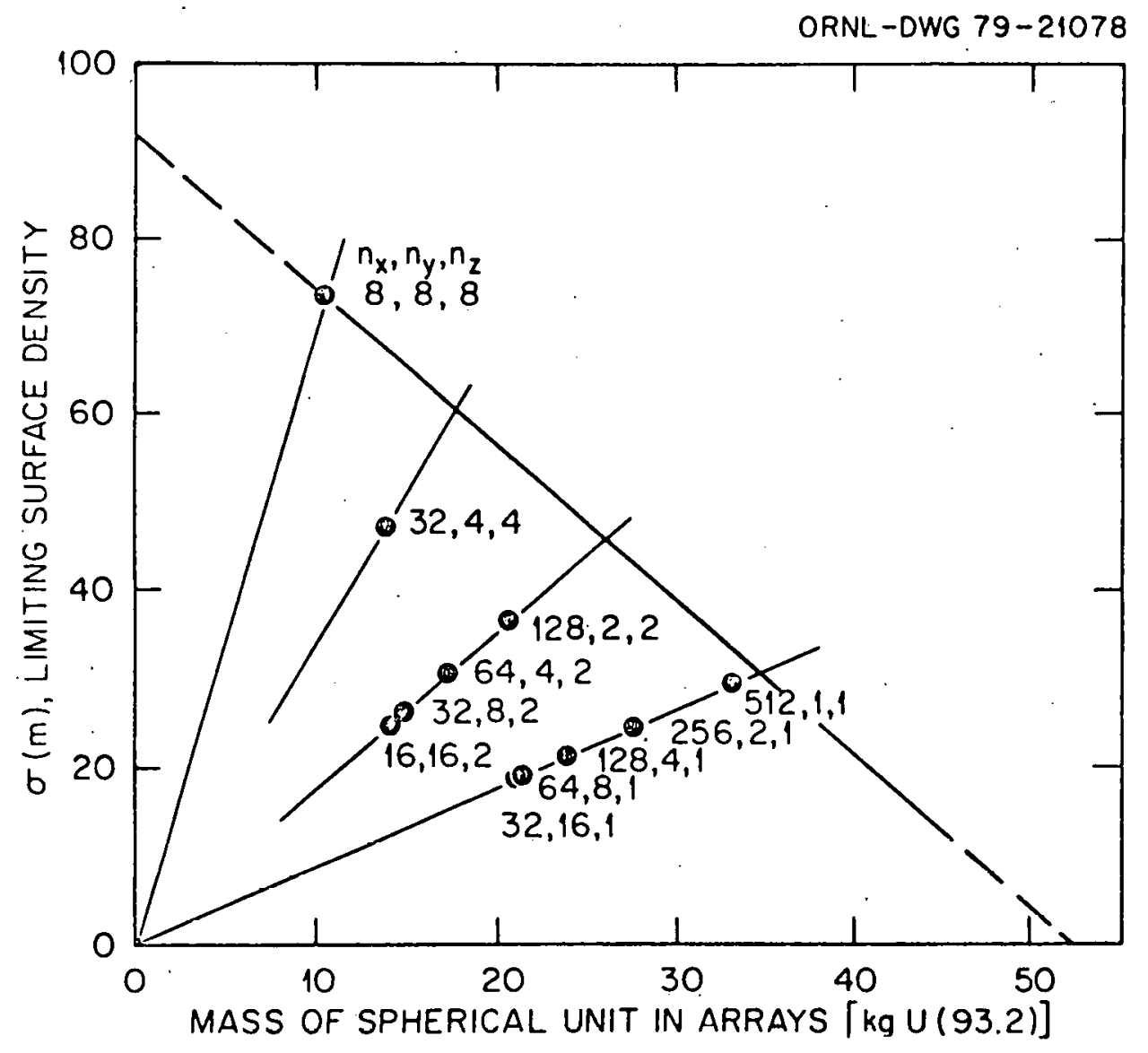

Fig. 9. Effects of unit rearrangements into water reflected cuboidal arrays of 512 spherical units on the limiting surface density. 
The $\Omega_{s}$ and the $\Omega$ from Eq. 12 agree quite well. The result of Eq. 20 in Eq. 12 or the use of Eqs. 7,8 , and 15 gives the values presented in the 1 ast column of the table. The comparison of $\Omega$ from Eq. 15 to $\Omega_{s}$ is within a few percent. Since

$$
\frac{\Omega s}{\Omega}=\left(\frac{r}{r^{\prime}}\right)^{2} \simeq k^{2},
$$

one can characterize the k-eff for the arrays in Table 6 as estimated by Eq. 15 to have an average of $1.010 \pm 0.029$, i.e., a bias of about $1 \%$ with an uncertainty of \pm 0.03 .

The arrangement of units that will minimize neutron leakage for a given number of units in the $z=$ direction, $n_{z}$, occurs when $n_{x}=n_{y}$. Since the smallest mass producing criticality for a given array shape, $R$, occurs when $n_{x}=n_{y}$, it is the smallest mass on the 1 ine defined by ${ }_{n}^{n} \frac{\sigma(m)}{m}$ and, therefore, these masses form an envelope of the possible critical arrangements for a given number of units. Criticality cannot be sustained with smaller masses and super criticality occurs for larger masses unless controlled by adjusting the neutron leakage through changes in the array shape. Criticality is a continuous function of $N$ and $m$ as defined by Eqs. 1 and 2. It follows, therefore, that there is a region in the $m, \sigma(m)$-plane that is dense with critical systems. The locus of critical systems for a given fissile material separating the $m, \sigma(m)-$ plane into critical and noncritical systems is the locus defined by infinite planar arrays, i.e., given $n_{z}$, the values of $n_{x}$ and $n_{y}$ arc un1 imi ted.

Representation of the data in Table 6 in the $r / x_{0}, \Omega-p 1$ ane is given in Fig. 10. All the arrays have $N=512$ units, each has a different array shape and each would 1 ie on a separate line defining criticality 


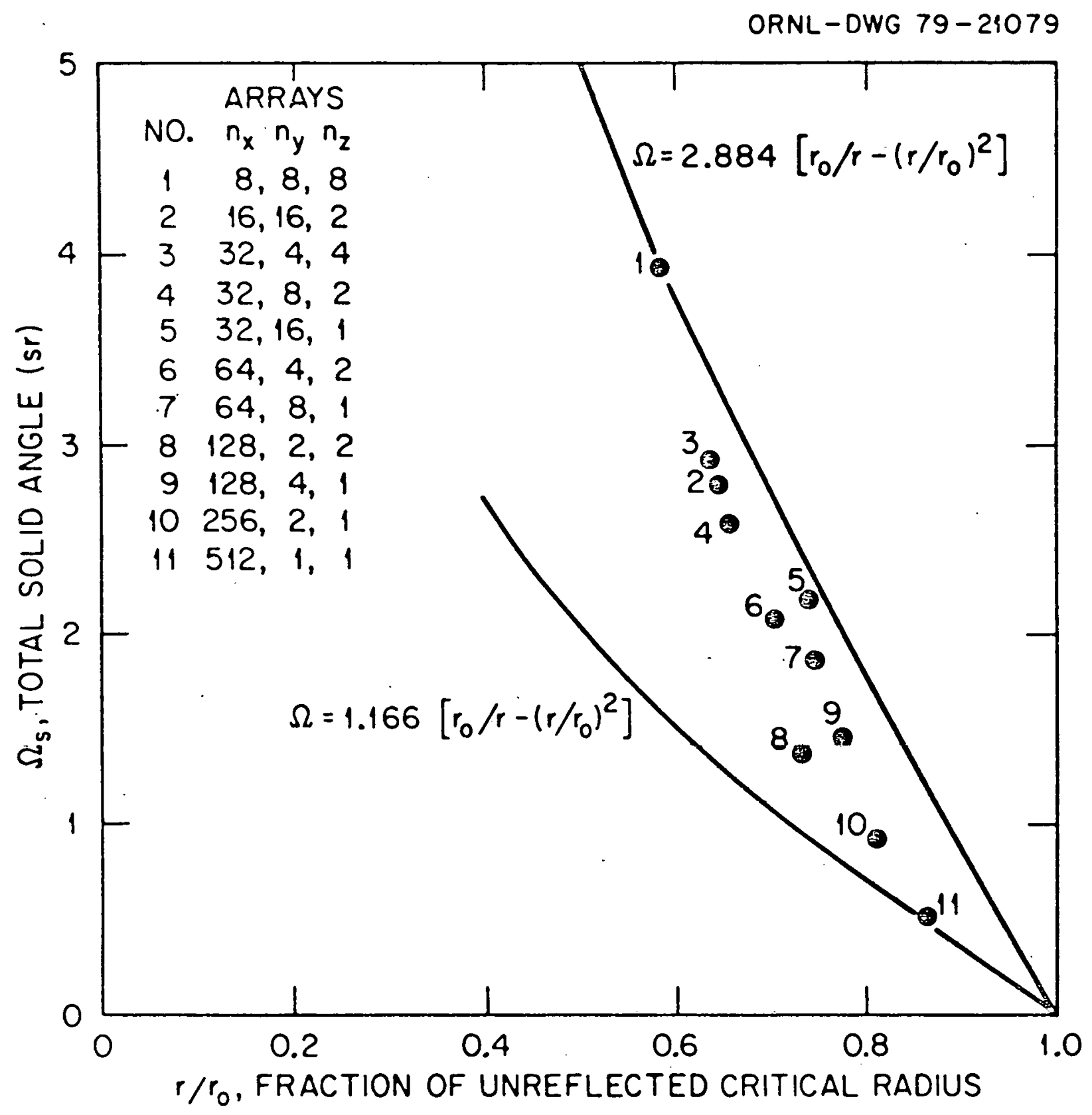

Fig. 10. Effects of unit rearrangements in water reflected cuboidal arrays of 512 spherical units on the total solid angle. 
for the array shape. A data point satisfies Eq. 15 and may be used to define the coefficient $\beta$ in the equation. This is illustrated in the figure for the arrays with $R=2.688$ and 1.0 . All points on a curve represent an array of 512 units with constant array shape. The mass and cel1 dimension are varied to maintain criticality.

The $\sigma(m)$ for arrays of any $N$ and with the same shape factor $R$ satisfy $\mathrm{Eq} .7$ and $1 \mathrm{ie}$ on the 1 ine defined by slope $c_{2}$ from Eq. 8. One would expect that representations of this behavior in terms of the solid angle would also result in a single equation applicable to any $\mathrm{N}$ unit arrays having the same shape factor. However, this is not the case for there is an $\mathrm{N}$ dependence as illustrated by the following example.

Consider the $n^{3}=16^{3}=4096$ unit array of spheres with mass $15.32 \mathrm{kgU}$ centered in $\mathrm{d}_{16}=60.96 \mathrm{~cm}$ cubic ce11s. The array is critical by Eq. 5 when reflected by water. By Eq. 11, $F(N)=F(4096)=113.655$ and since $r=5.797 \mathrm{~cm}, \Omega=3.229 \mathrm{sr}$ by Eq. 12. Suppose the units are rearranged into the array $n_{x}=64, n_{y}=32$, and $n_{z}=2$; we find $R=2.917$ by Eq. 6 and from Eqs. 7 and 8 that $c_{2}=6.14 \times 10^{-4} \mathrm{~cm}^{-2}$ and $m=27.99 \mathrm{kgU}$, or $r=7.088 \mathrm{~cm}$. Equation 11 gives $F(4096)=42.266$ for the rearrangement giving, by Eq. $12, \Omega=1.795 \mathrm{sr}$. The value $\mathrm{R}=2.917$ corresponds to that of the fifth entry in Table 6, i.e., the $32 \times 16 \times 1$ array. For this array, the coefficient. $\beta$ of Eq. 15 is given by

$$
\beta-\Omega_{s} /\left[r_{0} r-\left(r / r_{0}\right)^{2}\right]=2.716 \mathrm{sr} \text {. }
$$

Were the array with units of $r=7.088 \mathrm{~cm}$ and $R=2.914$ to satisfy the equation $\Omega=2.716\left[r_{0} / r-\left(r / r_{0}\right)^{2}\right]$, it would have to have $\Omega=1.546 \mathrm{sr}$. We conclude arrays of the same shape but different $N$ have different coefficients $\beta$ and, hence, cannot be described by a single equation. The 
dependence of $\Omega$ on $N$ is greater than would be expected from the results presented in Fig. 3. We can further conclude that critical arrays of different shape can be related and compared in both methods of representation.

Ce11 shape effect. We consider the units in an array as being centered in the ce11s. A change in cell shape can be described relative to the cubic ce11 of the same volume in terms of ratios of their dimensions. Given an $N$ unit array with units centered in cubic cells of dimension, $d_{n}$, let the cell dimensions be changed to $d_{x}=d_{y} \neq d_{z}$ such that the volume is equal to $d_{n}^{3}$. The shape of the cell may be described as the ratio of $\frac{d_{z}}{d_{x}}=a_{c}$. The solid angle of the array of cubic cells is given by Eq. 12 as

$$
\Omega=F(N) \frac{\bar{A}}{d_{n}^{2}}
$$

where $\bar{A}$ is an averaged area, and for the array of cells with shape $\alpha_{c}$ as $U=F\left(N, \alpha_{c} \frac{\bar{A}}{\alpha^{2} / 3(d x)^{2}}\right.$ where

$$
F\left(N, a_{c}\right)=\sum_{i} \sum_{j} \sum_{k} \frac{1}{i^{2}+j^{2}+\left(a_{c} k\right)^{2}} .
$$

Note that the unit shape has not changed, but because of the change in its distance from the point about which $\Omega$ is summed, it may present a different effective area. Spherical units result in $\bar{A}^{\cdot}=\bar{A}$, but not necessarily for other unit shapes. It is easy to demonstrate that if $a_{c}>1$, then $F\left(N, a_{c}\right)<F(N)$ and if $a_{c}<1, F\left(N, a_{c}\right)>F(N)$. For any variation of $a_{c}$ from $a_{c}=1$, however, there will be an increase in the array neutron leakage fraction and thus $k_{a}^{\prime} \leq k_{a}$. 
The behavior is illustrated in Table 7 by an $N=216$ unit array of cylinders with $\mathrm{h} / \mathrm{d}=1$ and a mass of $26.16 \mathrm{kgU}$. The cell shape, is allowed to vary from 0.15 to 8 for the reflected array and from 0.3 to 8 for the unreflected array. The $\Omega_{s}$ for the unreflected and reflected arrays is seen to pass through a minimum near an $a_{c}$ of 1.6 , but the array $k$-eff experiences no significant change throughout the range of $a_{c}$ until the surface separation of units becomes a few centimeters at the extreme values of $a_{c}$. The values of $F\left(N, a_{c}\right)$ are given in the 1 ast column of the table. We may use these to demonstrate the slight change in the average area of a unit, $\bar{A}$, that occurs in Eq. 12. Now $d_{n}{ }^{3}=a_{c} d_{x}{ }^{3}$ permits $\Omega^{\prime}$ to be written as

$$
\Omega^{\prime}=a_{c}^{2 / 3} F\left(N, a_{c}\right) \frac{\bar{A}^{\prime}}{d_{n^{2}}^{2}}
$$

thus

$$
\frac{\Omega^{\prime}}{\Omega}=a_{c}{ }^{2 / 3} \frac{F\left(N, a_{c}\right)}{F(N)} \frac{\bar{A}^{\prime}}{A}
$$

Taking, for example, $a_{c}=0.2$, we have $\frac{2.556}{2.077}=(0.2)^{2 / 3} \frac{122.115}{36.560} \cdot \frac{\bar{A}^{-}}{A}$ so that $\bar{A} \cdot / \bar{A}=1.077$. For the reflected arrays, as $0.15<a_{c}<8$ the corresponding ratio is $0.93<\overline{\mathrm{A}}^{\cdot} / \overline{\mathrm{A}}<1.17$ while that for the coefficient $\mathrm{F}(\mathrm{N})$ is $0.32<F\left(N, a_{c}\right) / F(N)<5$. The ratio $\Omega^{\prime} / \Omega$ is effectively greater than unity while the array k-eff changes only slightly as long as the surface separation of the units is greater than a few centimeters.

If the unit shape, h/d, were to be changed proportional to the cell shape, $a_{c}$, the $\Omega^{\prime}$ would be larger than the values of Table 7 and the array k-eff further decreased.21. A description of the behavior would be similar to the above. 
Table 7. Calculated neutron nultiplication factor for unreflected and water reflected arrays with constant cell volume of different cell shapes. The units are metal cylinders with $h / d=1$ and a mass of $26.2 \mathrm{~kg} \mathrm{U}(93.2)$

\begin{tabular}{|c|c|c|c|c|c|c|c|c|}
\hline \multicolumn{4}{|c|}{ Unreflected Arrays } & \multicolumn{5}{|c|}{ Water Reflected Arrays } \\
\hline \multicolumn{2}{|c|}{ Ce11 Description } & \multirow[b]{2}{*}{$\begin{array}{l}\text { Array }^{a} \\
\text { k-eff }\end{array}$} & \multirow[b]{2}{*}{$\begin{array}{c}\Omega_{s} \\
(s \mathbf{r})\end{array}$} & \multicolumn{2}{|c|}{ Ce11 Description } & \multirow[b]{2}{*}{$\begin{array}{l}\text { Array } \\
k-e f f\end{array}$} & \multirow[b]{2}{*}{$\begin{array}{c}\Omega_{s} \\
(\mathbf{s} \mathbf{r})\end{array}$} & \multirow[b]{2}{*}{$F\left(N, a_{c}\right)$} \\
\hline $\begin{array}{l}\text { Shape, } \\
\mathrm{d}_{\mathrm{z}} / \mathrm{d}_{\mathrm{x}}\end{array}$ & $\begin{array}{c}\text { dimension } \\
d_{x}, \mathrm{~cm}\end{array}$ & & & $\begin{array}{l}\text { Shape, } \\
\mathrm{d}_{\mathrm{z}} / \mathrm{d}_{\mathrm{x}}\end{array}$ & $\begin{array}{c}\text { dimension } \\
d_{x}, \mathrm{~cm}\end{array}$ & & & \\
\hline 8 & 15.348 & 1.067 & 8.619 & 8 & 27.444 & 0.973 & 2.489 & 11.445 \\
\hline 6 & 16.894 & 1.019 & 7.549 & 6 & 30.204 & 0.972 & 2.204 & 12.391 \\
\hline 4 & 19.338 & 1.004 & 6.717 & 4 & 34.576 & 0.986 & 1.991 & 14.690 \\
\hline 3 & 21.284 & 0.992 & 6.509 & 3 & 38.056 & 0.984 & 1.952 & 17.275 \\
\hline 2 & 24.364 & 1.002 & 6.548 & 2 & 43.564 & 0.993 & 1.990 & 22.600 \\
\hline 1.8 & 25.236 & 0.998 & 6.589 & 1.8 & 45.120 & 0.985 & 2.007 & 24.331 \\
\hline 1.6 & 27.246 & 0.989 & 6.640 & 1.6 & 46.926 & 0.990 & 2.027 & 26.436 \\
\hline 1.4 & 27.440 & 0.991 & 6.649 & 1.4 & 49.062 & 0.995 & 2.048 & 29.037 \\
\hline 1.0 & 30.696 & 0.998 & 6.780 & 1.0 & 54.886 & 1.001 & 2.077 & 36.560 \\
\hline 0.9 & 31.794 & 0.993 & 6.787 & 0.9 & 56.848 & 1.002 & 2.077 & 39.195 \\
\hline 0.8 & 33.068 & 0.998 & 6.785 & 0.8 & 59.124 & 1.003 & 2.072 & 42.307 \\
\hline 0.7 & 34.572 & 1.010 & 6.777 & 0.7 & 61.816 & 0.999 & 2.061 & 46.069 \\
\hline 0.6 & 36.396 & 0.999 & 6.773 & 0.6 & 65.124 & 0.986 & 2.046 & 50.786 \\
\hline 0.5 & 38.676 & 0.999 & 6.807 & 0.5 & 69.074 & 0.998 & 2.030 & 57.060 \\
\hline 0.4 & 41.662 & 1.003 & 6.972 & 0.4 & 74.492 & 0.991 & 2.031 & 66.281 \\
\hline \multirow[t]{3}{*}{0.3} & 45.856 & 1.035 & 7.568 & 0.3 & 81.990 & 0.991 & 2.113 & 82.477 \\
\hline & & & & 0.2 & 93.854 & 0.982 & 2.556 & 122.115 \\
\hline & & & & 0.15 & 103.280 & 1.006 & 3.298 & 174.350 \\
\hline
\end{tabular}

${ }^{a}$ Standard deviation less than \pm 0.006 for all arrays. 
These data show that noncubic cells may be treated as cubic cells of equal volume in both the surface density and solid angle representations of criticality yielding reasonable estimates of array k-eff's, i.e., without great loss of accuracy. They also pointedly illustrate the minor effect on the array $k$-eff caused by variations of cell shape.

Infinite planar arrays. Water reflected critical arrays of $0(93.2)$ metal spheres in infinite planar geometry are characterized22 by Eqs. 1 and 2 with $c_{2}=4.58 \times 10^{-4} \mathrm{~cm}^{-2}\left( \pm 1.8 \times 10^{-4}\right)$ and the unreflected critical mass of $52.1 \mathrm{kgJ}$. For $n_{z}$ cells in the z-direction of the array and an unlimited number of $n_{x}$ and $n_{y}$ cells, Ea. 1 can be written as

$$
\sigma(m)=\frac{n_{z m} m}{d_{n}^{2}}
$$

and is a constant for $n_{z} \geq 4$. We will remark on this $n_{z}$ restriction 1ater. The expression for $\sigma(m)$ is the usual definition of surface density, the mass in the array projected onto one of the array surfaces.

Critical experiments with simple units illustrate the concept to follow. Consider a single unit critical system in cylindrical geometry. The reactivity associated with a change in height of the unit will be greater for an $h / d$ in the region near equilateral shape than for 1 arger values of $h / d$. Near the critical infinite cylinder diameter, targe changes in height can be made without a significant change in the k-eff. The same behavior is true for arrays of extreme shape and suggests that large but finite $N$ unit arrays can have specifications similar to, in this case, infinite planar arrays.

If we suppose an $m$ and a $d_{n}$ satisfying Eq. 21 , there is a finite $N$ unit array by Eqs. 7 and 8 which will also result in criticality for the 
mass and spacing. This is equivalent to asking what values of $n_{z} / n$ and $R$ will result in a $c_{2}$ equal to that for the infinite planar array, $c_{2}=4.58 \times 10^{-4} \mathrm{~cm}^{-2}$. This is expressed by Eq. 8 as

$$
\frac{\mathrm{n}_{\mathrm{z}}}{\mathrm{n}} \frac{4}{\left(5 \mathrm{R}^{-0.672-1)}\right.}=\frac{\mathrm{c}_{2}}{\mathrm{c}_{2}}=\frac{0.458}{1.762}=0.2599
$$

Given a value of the array shape factor $R$, the ratio $n_{z} / n$ is defined. Tab1e 8 illustrates values of $N$ resulting from given values of $R$ when $\mathbf{n}_{\mathbf{z}}=4$

The values of $N$ in Table 8 are large but finite. The implication of these finite arrays having critical conditions of infinite planar arrays for the same $m$ and $d_{n}$ is that extending the finite arrays to unlimited numbers in the $n_{x}$ and $n_{y}$ direction causes no significant change in the k-eff of the arrays. This behavior is similar to that of single unit criticality of extreme geometries and is illustrated by the following example for an array. Consider the $10^{6}$ unit array of $12.26 \mathrm{~kg} \mathrm{U}(93.2)$ metal spheres with cubic cells of dimension $d_{n}=132 \mathrm{~cm}$. This array is calculated as critical when reflected by water. Let us rearrange the units into a $500 \times 500 \times 4$ reflected array, then $R=8.46$, which is set equal to 5.34 , and by Eq. $8, c_{2}=4.53 \times 10^{-4} \mathrm{~cm}^{-2}$. Fquations 1 and 2 give the mass necessary to restore criticality as

$$
m=\frac{m_{0}}{1+\frac{n_{2}(1-c / \sqrt{N})^{2}}{c_{2} d_{n}^{2}}}=\frac{52.1}{1+\frac{4(1-0.55 / 1000)^{2}}{(132)^{2} 4.5310^{-4}}}=34.98 \mathrm{kgU}
$$

This value is used to estimate the $k$-eff of the rearranged array of $12.26 \mathrm{kgD}$ units as $(12.26 / 34.59)^{1 / 3}$ or 0.708 . A Monte Car1o calculation of this array resulted in a $k$-eff $=0.710 \pm 0.006$ 
Tab1e 8. Finite number of units and array shapes exhibiting characteristics of infinite planar arrays

\begin{tabular}{|c|c|c|c|c|c|}
\hline \multirow{2}{*}{$\begin{array}{l}\text { Array } \\
\text { Shape } \\
\text { Factor } \\
\quad \text { R }\end{array}$} & \multirow[b]{2}{*}{$\mathrm{n}_{\mathbf{z}} / \mathbf{n}$} & \multirow[b]{2}{*}{$\mathbf{n}$} & \multirow{2}{*}{$\begin{array}{c}\mathbf{n}^{3}=\mathrm{N} \\
\mathrm{N}\end{array}$} & \multicolumn{2}{|c|}{$\left(n_{z}=4\right)$} \\
\hline & & & & $\mathrm{n}_{\mathrm{x}}=\mathrm{n}_{\mathrm{y}}$ & $F(N)$ \\
\hline 1.5 & 0.182 & 21.92 & 10540 & 51 & 82.4 \\
\hline 2.0 & 0.139 & 28.79 & 23855 & 77 & 92.6 \\
\hline 2.5 & 0.111 & 36.18 & 47371 & 109 & 101.3 \\
\hline 3.0 & 0.090 & 44.29 & 86879 & 147 & 108.6 \\
\hline 3.5 & 0.075 & 53.31 & 151522 & 195 & 115.6 \\
\hline 4.0 & 0.063 & 63.48 & 255830 & 253 & 121.5 \\
\hline 4.5 & 0.0533 & 75.09 & 423378 & 325 & 127.0 \\
\hline 5.0 & 0.0452 & 88.52 & 693507 & 416 & 132.0 \\
\hline $5.34(\max )$ & 0.0404 & 98.96 & 969123 & 492 & 135.0 \\
\hline
\end{tabular}

NOTE: A11 values are rounded. 
On the other hand, if we consider the infinite planar arrays with, $n_{z}=4$ and $d_{n}=132 \mathrm{~cm}$, Eqs. 19 and 2 with $c_{2}=4.58 \times 10^{-4} \mathrm{~cm}^{-2}$, then

$$
m=m_{0} \div\left(i+\frac{n_{z}}{c_{2} d_{n}^{2}}\right)
$$

or

$$
\mathrm{m}=52.1 \div\left(1+\frac{4}{(132)^{2}\left(4.58 \times 10^{-4}\right)}\right)=34.70 \mathrm{kgU}
$$

The difference in mass of the units for these two arrays, 34.70 and $34.59 \mathrm{kgd}$, is about $300 \mathrm{gJ}$ and would amount to a fraction of the standard deviation in a Monte Carlo calculated k-eff.

Let us return to the $n_{z}$ restriction to the application of Eq. 21 . A number of calculations were performed to evaluate water reflected infinite planar arrays specified by Eq. 21 with $n_{z}=1$ and 2 . These are summarized in Table 9 and show that the results produce k-eff's less than unity if the restriction is ignored. Equation 21 is thus conservative in application to spherical units when $n_{z}$ is less than four in that the resulting array may be subcritical by a significant amount. Gaidance in the application of these results to other unit shapes is had through Eq. 4 .

The solid angle for an infinite planar array is determined by $d_{n}$. the area presented by the units, $A$, and the quantity $F(N)$, Eq. 11. The quantity $F(N)$ converges to a 1 imit as $N$ increases indefinitely; therefore, the solid angle has a defined value $\Omega$. The critical arrays of Table 8 suggest that we may express $\Omega$ as the sum of that for a large but finite $N$ and a remainder, i.e.,

$$
\boldsymbol{\Omega}_{\infty}=\boldsymbol{\Omega}_{\mathrm{N}}+\Delta \boldsymbol{\Omega}
$$


Tab1e 9. Monte Car1o calculated neutron multiplication factors for some infinite planar arrays of metal spheres with $n_{z}=1,2$, and 4

\begin{tabular}{|c|c|c|c|c|}
\hline \multirow[b]{2}{*}{$\underline{n_{2}}$} & \multirow{2}{*}{$\begin{array}{l}\text { Unit } \\
\text { Mass } \\
\text { kgU }\end{array}$} & \multirow{2}{*}{$\begin{array}{c}\text { Ce11 } \\
\text { Dimension } \\
d_{n}(\mathrm{~cm})\end{array}$} & \multicolumn{2}{|c|}{ Ca1culated } \\
\hline & & & $k-e f f$ & $\pm \sigma$ \\
\hline 4 & 1.56 & 15.794 & 0.999 & 0.006 \\
\hline 1 & & 7.968 & 0.959 & 0.006 \\
\hline 4 & 3.23 & 23.528 & 0.996 & 0.006 \\
\hline 1 & & 11.764 & 0.952 & 0.004 \\
\hline 4 & 5.12 & 30.728 & 0.992 & 0.006 \\
\hline 2 & & 21.728 & 0.963 & 0.005 \\
\hline 1 & & 15.364 & 0.944 & 0.005 \\
\hline 4 & 13.47 & 55.746 & 1.001 & 0.006 \\
\hline 2 & & 39.416 & 0.983 & 0.004 \\
\hline 1 & & 27.872 & 0.959 & 0.005 \\
\hline 4 & 29.53 & 108.466 & 1.004 & 0.006 \\
\hline 2 & & 76.698 & 0.987 & 0.005 \\
\hline 1 & & 54.234 & 0.977 & 0.004 \\
\hline
\end{tabular}


Now, a fractional change in $\Omega$ caused by a fractional change in the radius of the units is given by Eq. 12 as

$$
\frac{\Delta \Omega}{\Omega}=2 \frac{\Delta \mathbf{r}}{\mathbf{r}}
$$

and

$$
\Delta r / r=\left(1-r^{\prime} / r\right)=1-k_{u}^{\prime} / k_{u}=1-k_{a}^{\prime} / k_{a}
$$

by Eq. 16. It follows that, if $\Delta r / r$ is assumed to be of the order of a standard deviation for a k-eff calculation, typically \pm 0.005 , then

$$
\frac{\Delta \Omega}{\Omega} \sim 0.01
$$

and we can conservatively write

$$
\Omega_{\infty}=1.01 \Omega_{\mathrm{N}}
$$

within the ability to define criticality. This result suggests that it would be acceptable to neglect solid angle contributions to a large array equal to about $1 \%$ of the $\Omega$ for the array.

These analyses demonstrate the applicability of Eq. 15 to infinite planar arrays. The coefficient $\beta$ becomes

$$
\beta=\frac{F(N)}{n_{z}} A_{0} c_{2}
$$

and for water reflected metal spheres is

$$
\beta=0.11 \frac{F(N)}{n_{z}}
$$

The values of $F(N)$ may be those for the arrays of Table 8 and these are shown in Fig. 11 for $n_{z}=4$. Values for $n_{z}=1$ are al so given. The $F(N)$ values would be smaller if $n_{x} \neq n_{y}$ for a given $N$. 


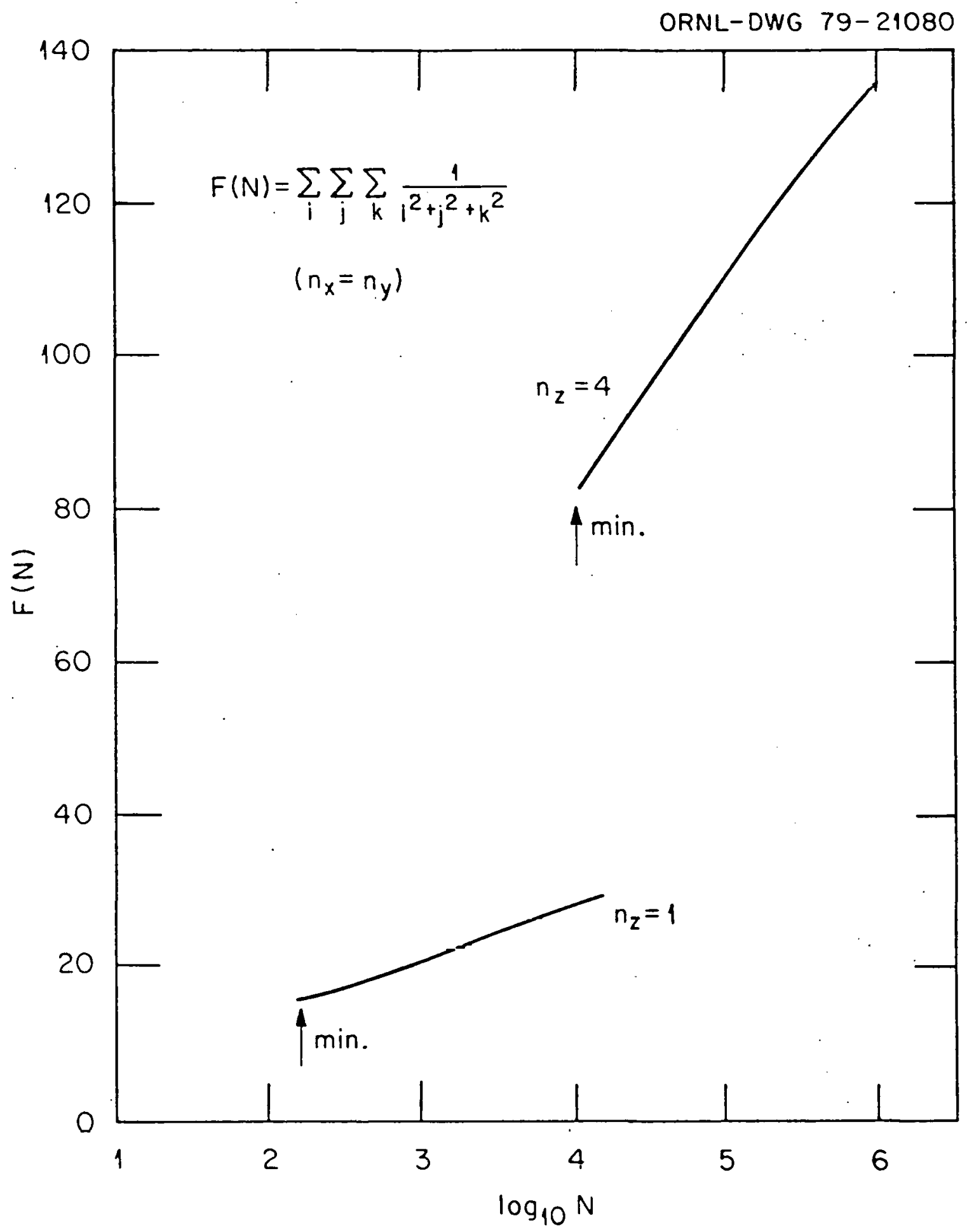

Fig. 11. The parameter $F(N)$ of the solid angle representation for finite planar arrays of Table 8 for $n_{x}=n_{y}$ and the dependence on the number of units in the $z$ direction of arrays. 
Linear arrays. A linear array is one in which two numbers of the, triplet $n_{x}, n_{y}, n_{z}$ are unity. Any other combination is a planar or cuboidal arrangement of units and differs from the above discussions only in the array orientation. For finite values of $\mathrm{N}$ in linear arrays, the surface density representation of criticality is adequately approximated by Eqs. 7 and 8 . Equation 7 , as $N$ becomes indefinitely 1 arge, takes the form

$$
\sigma(m)=\frac{m}{d_{n^{2}}}
$$

Equation 8 , with the maximum value of $R$, is

$$
\frac{\mathrm{c}_{2}}{\mathrm{nc} \mathrm{c}_{2}}=0.1555
$$

For example, $n=8$ gives the $c_{2}$ for the 1 inear array of Table 6 , as $1.416 \times 10^{-3} \mathrm{~cm}^{-2}$. As $\mathrm{n}^{3}=\mathrm{N}$ becomes 1 arge, the product $\mathrm{nc}_{2}^{\prime}$ remains finite and tends toward a limit. We determine a limiting value for the slope $c_{2}$ by considering the solid angle expressions for criticality. The quantity $F(N)$ given in Eq. 11 rapidly approaches a 1 imit as $N$ increases and, by Eq. 12, we can write

$$
\frac{\Delta \Omega}{\Omega}=\frac{\Delta F(N)}{F(N)}=2 \sum_{j=N+1}^{\infty} \frac{1}{j^{2}} / 2 \sum_{j=1}^{\infty} \frac{1}{j^{2}}
$$

and solve for $N$ such that $\frac{\Delta F(N)}{F(N)}<\varepsilon$ where again $\varepsilon$ is chosen subject to our ability to economically define criticality by calculation. We conservatively take $\varepsilon=0.001$ and find that $\Omega=1.001 \Omega_{\mathrm{N}}$. In particular, the 512-unit 1 inear array of Table 6 has $\Omega_{s}=0.542$ sr giving $F(N)=$ 3.285. Applying Eq. 14 to this array as 


$$
\Omega=F(N) A_{0} c_{2}\left[r_{0} / r-\left(r / r_{0}\right)^{2}\right],
$$

we obtain, setting $F(N)=3.285$,

$$
\begin{aligned}
& c_{2}=\frac{0.542}{(3.285)(238.83)(0.418)} \\
& c_{2}=1.654 \times 10^{-3} \mathrm{~cm}^{-2}
\end{aligned}
$$

as the characteristic slope for unlimited linear arrays. Using this value in Eq. 24, we find $N=n^{3} \sim 7^{3}$ or 343 units. Any arbitrary $N$ larger than this will satisfy the condition $\frac{\Delta F(N)}{F(N)}<\varepsilon$. We may thus define criticality for 1 inear arrays of spheres as $\Omega_{\infty}=1.297$ $\left[r_{0} / r-\left(r / r_{0}\right)^{2}\right]$.

The above discussion is illustrated by consideration of the calculated critical and subcritical arrays of Table 10. The first section of the table represents subcritical arrays having units of constant radius $(6.337 \mathrm{~cm})$ and constant ce11 dimension $(20.468 \mathrm{~cm})$. The three largest arrays may be considered as having the same k-eff within one standard deviation. This illustrates the conservative nature of taking $\varepsilon=0.001$, since 1 ittle change in $\dot{k}$-eff occurs for $N$ somewhat less than 243 units rather than the above derived value of 343.

The second section of the table, $d_{n}=32.908 \mathrm{~cm}$ cells, indicates there is very 1 ittle change in $\Omega$ and $k$-eff for a unit of $r=7.514 \mathrm{~cm}$ with increasing $N$. Also, displayed is the decreasing k-eff as $r$ decreases for fixed $N$. The last section for $d_{n}=17.692 \mathrm{~cm}$ shows similar behavior. The data of this table allow one to conclude that, if $\Omega$ for given $r, d_{n}$ and $N$ is less than $\Omega_{\infty}(\beta=1.297)$, the 1 inear array is

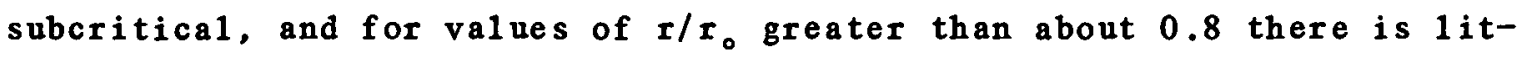
t1e dependence of k-eff on $N$. Below $r / r_{0} \sim 0.8$, the ratio $\Omega / \Omega_{\omega}$ increases as $r / r_{0}$ decreases for criticality to occur. 
Tab1e 10. Calculated neutron multiplication factors and total solid angles for some water reflected 1 inear arrays of spherical $\mathrm{U}(93.2)$ metal units

\begin{tabular}{|c|c|c|c|c|c|}
\hline \multirow[b]{2}{*}{$n_{x}, n_{y}, n_{z}$} & \multirow[b]{2}{*}{$\mathrm{r},(\mathrm{cm})$} & \multirow{2}{*}{$\begin{array}{c}\mathrm{Eq} \cdot 11 \\
\mathrm{~F}(\mathrm{~N})\end{array}$} & \multirow{2}{*}{$\begin{array}{r}\text { Eq. } 12 \\
\Omega(s \mathbf{r})\end{array}$} & \multicolumn{2}{|c|}{ Calculated } \\
\hline & & & & $k-e f f$ & $\pm \sigma$ \\
\hline$\therefore$ & & \multicolumn{2}{|c|}{$\mathrm{d}_{\mathrm{n}}=20.468 \mathrm{~cm}$} & & \\
\hline $1,1,1$ & 6.337 & 0 & 0 & 0.852 & 0.006 \\
\hline $1,3,1$ & 6.337 & 2.0 & 0.602 & 0.911 & 0.007 \\
\hline $1,9,1$ & 6.337 & 2.847 & 0.857 & 0.944 & 0.007 \\
\hline $1,27,1$ & 6.337 & 3.142 & 0.946 & 0.945 & 0.007 \\
\hline $1,81,1$ & 6.337 & 3.240 & 0.976 & 0.950 & 0.006 \\
\hline $1,243,1$ & 6.337 & 3.273 & 0.986 & 0.966 & 0.007 \\
\hline $1,512,1$ & 6.337 & 3.282 & 0.988 & 0.963 & 0.006 \\
\hline $1,729,1$ & 6.337 & 3.284 & 0.989 & 0.958 & 0.006 \\
\hline \multirow[t]{2}{*}{$1,9,1$} & 6.654 & $2: 847$ & 0.945 & 0.990 & 0.007 \\
\hline & & \multicolumn{2}{|c|}{$d_{n}=32.908 \mathrm{~cm}$} & & \\
\hline $1,9,1$ & 7.514 & 2.847 & 0.466 & 0.985 & 0.007 \\
\hline $1,64,1$ & 5.030 & 3.227 & 0.237 & 0.685 & 0.006 \\
\hline $1,64,1$ & 7.284 & 3.227 & 0.497 & 0.969 & 0.007 \\
\hline $1,64,1$ & 7.514 & 3.227 & 0.529 & 0.994 & 0.007 \\
\hline $1,81,1$ & 7.514 & 3.240 & 0.531 & 0.989 & 0.006 \\
\hline $1,100,1$ & 7.514 & 3.250 & 0.532 & 0.989 & 0.006 \\
\hline \multirow[t]{2}{*}{$1,512,1$} & 7.514 & 3.282 & 0.538 & 0.996 & 0.007 \\
\hline & & \multicolumn{2}{|c|}{$\mathbf{d}_{\mathbf{n}}=17.692 \mathrm{~cm}$} & & \\
\hline $1,64,1$ & 5.758 & 3.227 & 1.074 & 0.916 & 0.008 \\
\hline $1,64,1$ & 6.115 & 3.227 & 1.211 & 0.967 & 0.007 \\
\hline $1,64,1$ & 6.333 & 3.227 & 1.299 & 1.001 & 0.007 \\
\hline
\end{tabular}


The behavior is, perhaps, more easily visualized by a discussion of a graphic display of the data as given in Fig. 12. The heavy dark 1ine effectively represents 1 inear arrays with $N$ un 1 imited. Al1 the data represented by points below this line are subcritical. None of the arrays have a k-eff greater than $1.0 \pm \sigma$. The 64-unit arrays with $d_{n}=17.692 \mathrm{~cm} 1 \mathrm{ie}$ on the parabola described by Eq. 17 which calls for $\Omega / \Omega_{\infty}>1$ as it is for k-eff $=1$. Similar1y, the $N=9, \mathrm{~d}=20.468 \mathrm{~cm}$ linear arrays but with less difference between $\Omega$ and $\Omega_{\infty}$. The $N=512^{-}$ unit array, $d_{n}=32.908 \mathrm{~cm}$, having the parabolic representation with $a_{\circ}$ $=0.730$ has $\Omega$ values above those of the $N=64$ arrays for the subcritical and critical arrays. We al so note that there is very little difference between $\Omega$ and $\Omega_{\infty}$ for these arrays, i.e., only a slight dependence on $\mathrm{N}$.

Obviously, 1 inear arrays are an extreme geometry. It is appropriate to illustrate the effect of unit shape changes on $\Omega$ and again exemp1 ify results of the application of the equivalent mass relation, Eq. 4 . Summarized in Table 11 are two arrays of Table 10 to which Eq. 4 has been applied to define dimensions of units of several h/d values. The results of Monte Carlo calculations of the specified arrays are seen to confirm the criticality as described by Eq. 4. The masses for criticality in the arrays is greater than the spherical masses. An estimate of the solid ang1e by Eq. 12 is provided.

One may conclude that infinite planar and infinite 1 inear arrays are tractable by the 1 imiting surface density representation. These arrays are al so expressible in terms of the solid angle method through equivalent, finite but large, arrays with 11ttle loss in accuracy. 


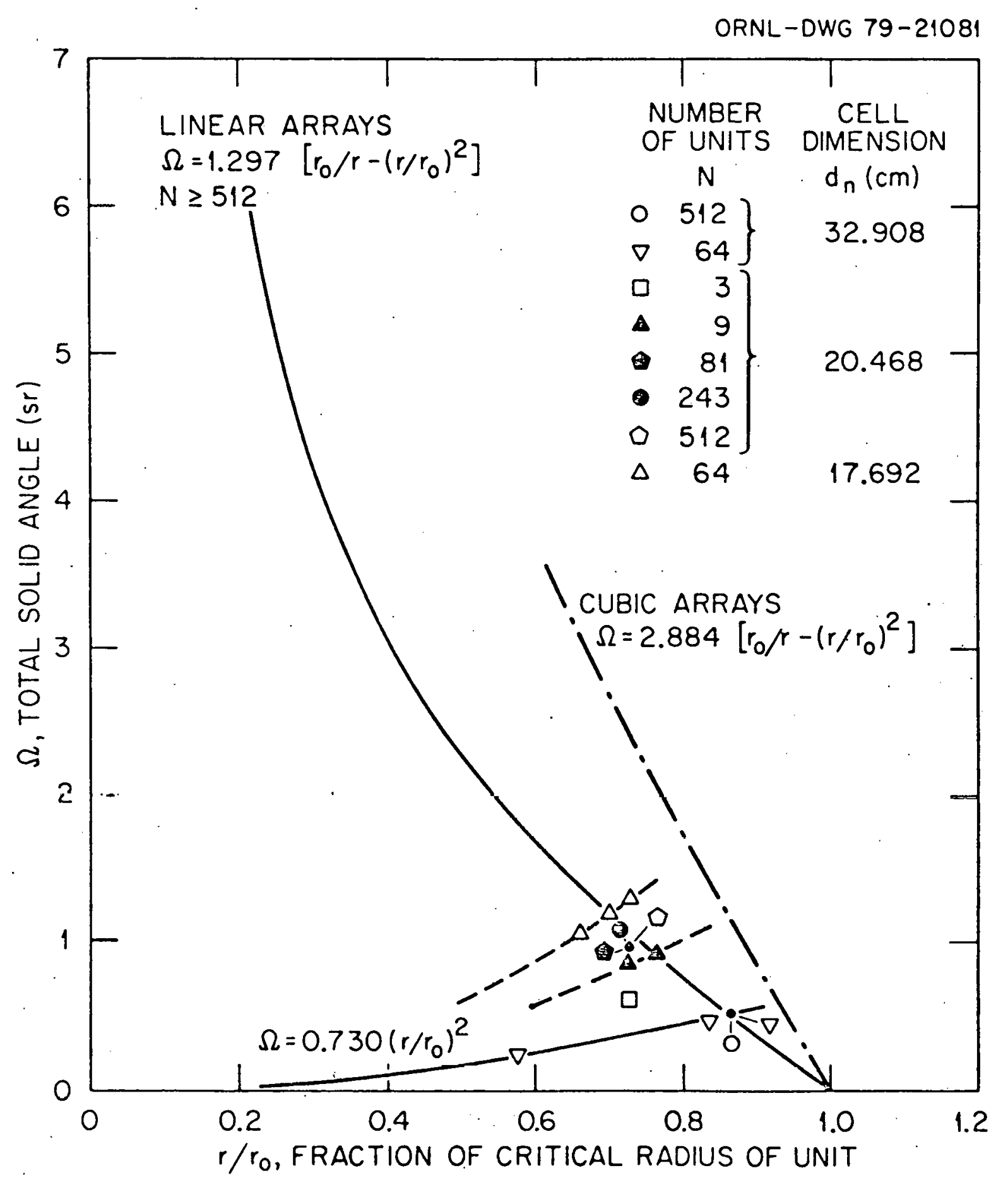

Fig. 12. Solid angle representation of critical and subcritical water reflected linear arrays of $U(93.2)$ metal spheres showing dependence on number of units and cell dimension. 
Table 11. Confirmatory Monte Carlo calculations of estimated equivalent masses for criticality with cylindrical units of various shape

\begin{tabular}{|c|c|c|c|c|c|c|c|c|}
\hline $\mathbf{n}_{x}, n_{Y}, n_{z}$ & $h / d$ & $c_{2}\left(\times 10^{+3}\right) \mathrm{cm}^{-2}$ & $r_{0}(\mathrm{~cm})$ & $r(\mathrm{~cm})$ & $\begin{array}{c}\text { Mass } \\
\operatorname{kgU}(93.2)\end{array}$ & $\begin{array}{c}\mathrm{Ce11} \\
\mathrm{d}_{\mathrm{n}}(\mathrm{cm}) \\
\end{array}$ & $\begin{array}{l}\text { Array } \\
k-e f f\end{array}$ & $\begin{array}{c}(\mathrm{Eq}, 12)^{\mathrm{b}} \\
(\mathrm{sr})\end{array}$ \\
\hline $1,64,1$ & 0.3 & 0.779 & 14.350 & 10.916 & 46.0 & 32.908 & 0.988 & 0.426 \\
\hline $1,6 d, 1$ & 0.5 & 1.214 & 10.482 & 8.591 & 37.4 & 32.908 & 0.991 & 0.440 \\
\hline $1,64,1$ & 1.0 & 1.548 & 7.889 & 6.690 & 35.3 & 32.908 & 1.000 & 0.533 \\
\hline $1,64,1$ & 2.0 & 1.183 & 6.850 & 5.592 & 41.2 & 32.908 & 1.004 & 0.745 \\
\hline $1,64,1$ & 3.0 & 0.837 & 6.575 & 5.068 & 46.0 & 32.908 & 1.000 & 0.913 \\
\hline $1,9.1$ & 2.0 & 1.183 & 6.850 & 4.825 & 26.5 & 20.468 & 1.003 & 1.265 \\
\hline
\end{tabular}

${ }^{a}$ Standard deviation less than \pm 0.007 . Neutrons tracked in water reflector.

${ }^{b}$ For 1 inear array, a good approximation to an average area for the units is the product hxd for $0.3<\mathrm{h} / \mathrm{d}<4$. 


\section{REFLECTORS}

The type of reflector material, its density, water content, thickness, and location affects the k-eff of an array of units and the magnitude of the effect is dependent on the mass and type of fissile material comprising the units in the array. Under the constraint of criticality, units of sma11 mass in an array may be characterized as being strongly neutron coupled, and as the mass per unit in the array increases, the neutron coupling becomes weaker and approaches zero or a very weakly coupled condition for masses near the unreflected critical mass for a single unit. Similar1y, arrays of units with small mass may be regarded as being strong1y coupled with the reflector and this too diminishes as the mass per unit increases, ultimately becoming zero if sing1e unit criticality is to be represented. This behavior is evidenced in both experimental and Monte Carlo calculated criticality data for fissile materials. We shall examine the above reflector parameters and their representation in the surface density and solid angle characterizations of criticality.

Reflector thickness. A series of critical experiments ${ }^{3}$ with $U(93.2)$ metal cylinders having h/d ratios in the range from 0.4 to 2 and masses between 10 and $26 \mathrm{kgU}$ were performed early in 1962 at the Oak Ridge Critical Experiments Facility. Cylindrical units of nearly equal mass were assembled into cuboidal arrays and the spacing and number of units adjusted to criticality for a variety of reflector conditions. The spacing was such that the surface separation of the units was equal in the three principal directions of the array. The cell associated with each unit was a cuboid, i.e., the $x$ - and $y$-dimensions were equal and the z-direction proportional to the $x$-dimension corresponding approximately 
'to the $h / d$ ratio of the cylindrical unit. The reflector was paraffin and varied in thickness from 1.3 to $15.2 \mathrm{~cm}$ and was a1ways located at the boundaries of the peripheral cel1s. A summary of the critical arrays appears in Table 12 .

The data for the 27 unit arrays as a function of reflector thickness is presented in Fig. 13 as given by Eq. 5 where the spacing, $d_{n}$, was taken as that dimension preserving the experimental cell volume, i.e., $d_{\mathrm{n}}^{3}=\mathrm{V}$. The curves labeled unreflected and water reflected arrays of spheres are the result of Monte Carlo calculations. The water reflected arrays of spheres satisfy Eqs. 5 and 6 with $c_{2}=1.762 \times 10^{-3} \mathrm{~cm}^{-2}$ and $m_{0}=52.1 \mathrm{kgU}$. The 1 inear portion of the unreflected data satisfies Eqs. 5 and 6 with $c_{2}=3.959 \times 10^{-3} \mathrm{~cm}^{-2}$ and the unreflected critical mass of a cube, $m_{0}=\sim 63 \mathrm{kgU}$. Spherical masses 1 arger than about $35 \mathrm{~kg}$ deviate from the 1 ine and terminate at the spherical critical mass of $52.1 \mathrm{kgI}$. These two curves bracket the range of experimental data very we11. Unit shape appears not to be a sensitive parameter for the h/d range shown at the top of the figure, consistent with shape effect observed with single unit criticality ${ }^{4}$ for these h/d ratios.

The experimental data of Fig. 13 is utilized to define a characteristic slope, $c_{2}$, to associate with a reflector thickness, $t$. We assume that the effectiveness of paraffin and water as reflectors of equal thickness are comparable and define $c_{2}(t)$ as satisfying Eq. 6 , i.e..

$$
\frac{c_{2}(t)}{o_{2}(15.2)}=\frac{\sigma(m, t)}{\pi(m, 15,2)}=\left(\frac{d_{n}(15.2)}{d_{n}(t)}\right)^{2}, \text { (m constant) }
$$

where $t$ is the reflector thickness. Applying this relation to the data of Fig. 13, one obtains the representation of the ratio presented in 


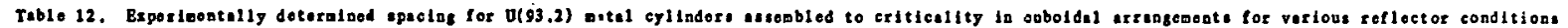

\begin{tabular}{|c|c|c|c|c|c|c|c|c|c|c|c|c|c|c|}
\hline \multicolumn{5}{|c|}{ Refloctor indax, I } & \multicolumn{2}{|l|}{1} & \multicolumn{2}{|c|}{2} & \multicolumn{2}{|c|}{3} & \multicolumn{2}{|c|}{4} & \multicolumn{2}{|c|}{3} \\
\hline & \multirow{2}{*}{\multicolumn{4}{|c|}{ Porstefin rofloctoe thicknosed $(\mathrm{cm})$}} & \multirow{2}{*}{\multicolumn{2}{|c|}{$\frac{0.0}{\text { Costes optotas }}$}} & \multirow{2}{*}{\multicolumn{2}{|c|}{$\frac{1.3^{\mathrm{a}}}{\text { Conter ipacing }}$}} & \multirow{2}{*}{\multicolumn{2}{|c|}{$\frac{3.8}{\text { Centor specing }}$}} & \multirow{2}{*}{\multicolumn{2}{|c|}{$\frac{7.6}{\text { Centor specing }}$}} & \multirow{2}{*}{\multicolumn{2}{|c|}{$\frac{13.2}{\text { Centor ipacing }}$}} \\
\hline \multicolumn{2}{|c|}{ Expr. (1,j) } & \multicolumn{2}{|c|}{ Unte doscriptlon } & & & & & & & & & & & \\
\hline $\begin{array}{l}\text { Gilindox } \\
\text { ladex. } 1\end{array}$ & $\begin{array}{l}\text { Azxey } \\
n_{x}, B_{y}, x\end{array}$ & \begin{tabular}{|c|} 
Bend1uer \\
$(\mathrm{cos})$
\end{tabular} & $\begin{array}{c}\text { Beldght } \\
\text { (ca) }\end{array}$ & 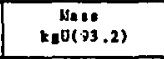 & $\begin{array}{l}\text { Bor 1xosta } \\
(00)\end{array}$ & $\begin{array}{c}\text { Verticel } \\
(\operatorname{exs})\end{array}$ & $\begin{array}{c}\text { Borizonte1 } \\
\text { (om) }\end{array}$ & $\begin{array}{c}\text { Verti cal } \\
\text { (ex) }\end{array}$ & $\begin{array}{l}\text { Bor1200tel } \\
(\text { cm })\end{array}$ & $\begin{array}{c}\text { Vortices } \\
\text { (cos) }\end{array}$ & $\begin{array}{l}\text { Horizonte1 } \\
(00)\end{array}$ & $\begin{array}{c}\text { Vertical } \\
(\text { (co) }\end{array}$ & $\begin{array}{c}\text { Bor izonta1 } \\
(\mathrm{cm})\end{array}$ & $\begin{array}{c}\text { Vertical } \\
(\mathrm{cm})\end{array}$ \\
\hline 1 & 222 & 5.748 & 3.382 & $10.480 \pm 0.009$ & $11.30^{6}$ & $9.38^{5}$ & 11.73 & 5.61 & 13.48 & 7.36 & 14.91 & 8.80 & 15.19 & 9.08 \\
\hline 2 & 22 & 5.748 & 3.382 & $10.480 \pm 0.018$ & 12.83 & 6.73 & -- & - & - & - & - & - & 一 & - \\
\hline 3 & 335 & 3.742 & 3.382 & $10.457 \pm 0.044$ & 14.93 & 8.82 & - & - & - & - & $\dot{-}$ & - & -- & - \\
\hline 4 & 44 & 5.740 & 3.382 & $10.431 \pm 0.048$ & 15.43 & 9.33 & - & - & 一 & - & - & 一 & 23.84 & 17.74 \\
\hline 3 & 33 & 5.748 & 9.382 & $10.481 \div 0.026$ & 13.50 & 7.39 & 14.49 & 8.37 & 17.37 & 11.23 & 19.75 & 13.64 & 20.19 & 14.07 \\
\hline 6 & 222 & 4.542 & 8.641 & $10.507 \geq 0.001$ & $5.00^{\circ}$ & $8.64^{\mathrm{b}}$ & 9.69 & 9.24 & 11.45 & 11.00 & 23.05 & 12.61 & 13.39 & 12.95 \\
\hline 7 & $\begin{array}{lll}3 & 3 & 3\end{array}$ & 4.540 & 8.641 & $10.495 \pm 0.025$ & 11.53 & 11.08 & 12.51 & 12.07 & 25.66 & 15.22 & 18.10 & 27.66 & 18.31 & 18.08 \\
\hline 8 & $22=$ & 5.742 & 8.077 & $15.694 \pm 0.003$ & 12.33 & 8.98 & 13.39 & 9.98 & 16.45 & 33.04 & 18.88 & 15.47 & 19.31 & 15.90 \\
\hline 9 & $33:$ & 9.741 & 8.077 & $19.696 \pm 0.020$ & 13.69 & 12.28 & 17.16 & 13.75 & 21.67 & 18.27 & 25.18 & 21.17 & 25.68 & 22.27 \\
\hline 10 & 222 & 3.126 & 10.765 & $20.803 \pm 0.004$ & 13.67 & 12.98 & - & - & - & - & - & - & - & - \\
\hline 11 & 222 & 3.748 & 10.765 & $20.962 \pm 0.004$ & 13.14 & 13.01 & 15.17 & 14.44 & 19.70 & 18.97 & 23.01 & 22.27 & 23.48 & 22.75 \\
\hline 12 & 333 & 3.736 & 10.763 & $20.877 \pm 0.026$ & 37.84 & 17.19 & 20.05 & 19.34 & 26.24 & 25.53 & 30.19 & 29.49 & 30.62 & 29.91 \\
\hline 13 & 222 & 5.149 & 13.459 & $26.218 \pm 0.003$ & 15.04 & 17.00 & 16.92 & 18.88 & 23.03 & 24.99 & 27.20 & 29.16 & 27.88 & 29.84 \\
\hline 14 & 33 & 3.138 & 13.459 & $26.113 \pm 0.022$ & 19.97 & 21.93 & 22.80 & 24.78 & 31.08 & 33.07 & 35.97 & 37.96 & 36.47 & 38.45 \\
\hline 15 & 222 & 4.542 & 17.282 & $21.008 \pm 0.001$ & 10.55 & 18.73 & - & - & -- & -- & - & - & 19.41 & 27.61 \\
\hline
\end{tabular}

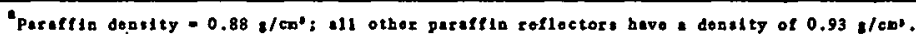

Aluevbly it saberittcal.

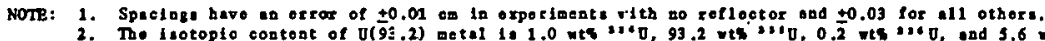

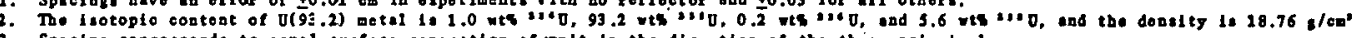

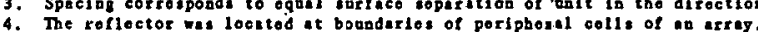




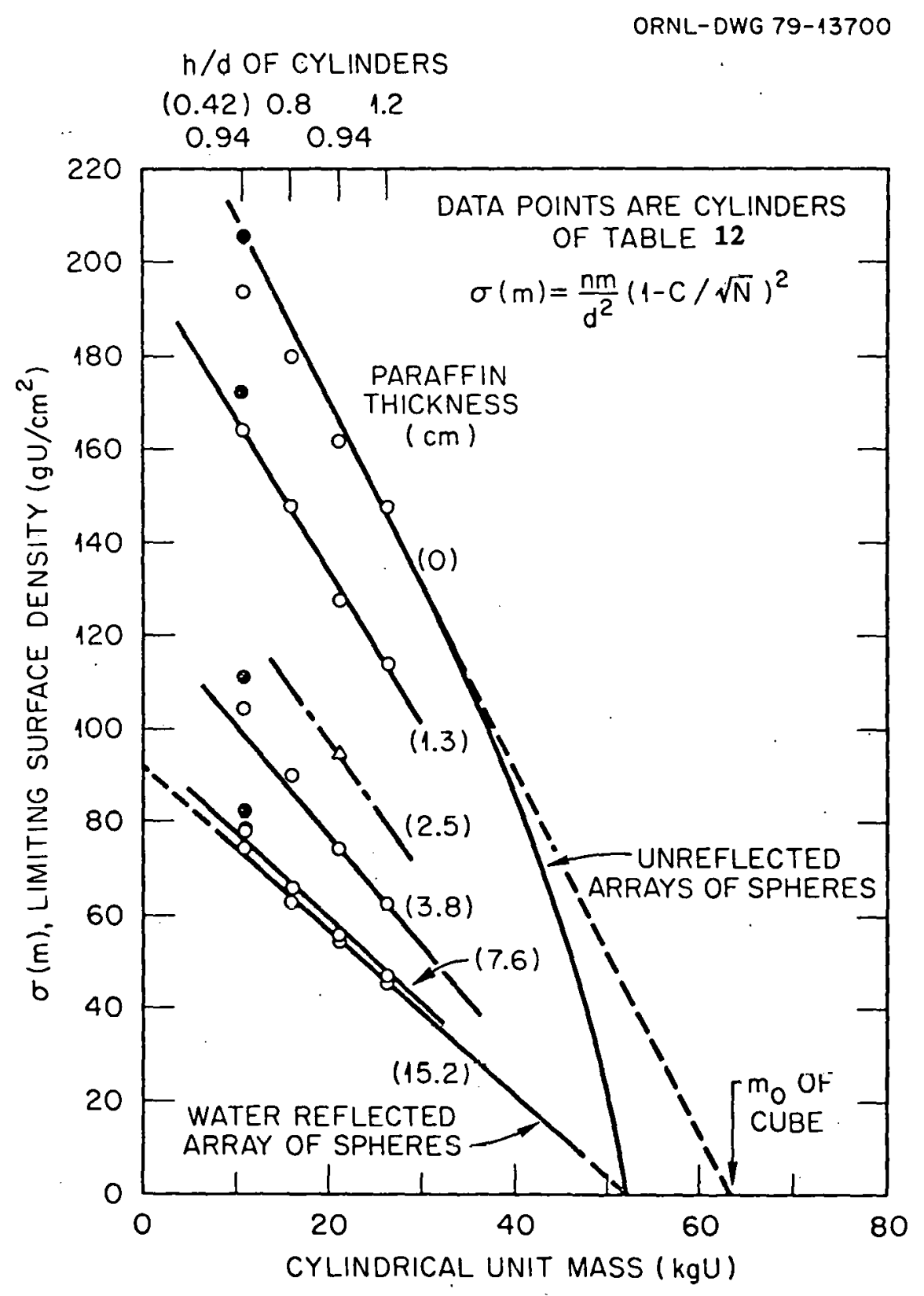

Fig. 13. Limiting surface density representation of critical experiments with U(93.2) metal cylinders of various height-to-diameter ratios. Data for spherical units are also given. Note that the unreflected data extrapolates to the unreflected critical mass for a cube. 
Fig. 14. The 1 ine shown is the result of calculations on arrays of spheres as a function of reflector thickness. The average ratio of the experimental data for each reflector thickness is given. The experimental data points for $t=1.3 \mathrm{~cm}$ and $0 \mathrm{~cm}$ should be displaced above the line as shown because of the lower density of the paraffin at $t=1.3 \mathrm{~cm}$ $\left(\rho=0.83\right.$ vs $\left.0.93 \mathrm{~g} / \mathrm{cm}^{3}\right)$ and partly because the unit self-multiplication is varying in these assemb1ies.

It is possible, since $k-e f f=1$ for these systems, to associate with a reflector of given thickness a reactivity worth by application of Eq. 4. Given two different reflector thicknesses $t_{1}$ and $t_{2}$, in the same array geometry, each is critical with corresponding masses $m_{1}$ and $m_{2}$, and we have by Eq. 5

$$
\frac{m_{2}}{m_{1}}=f_{1}+\frac{c_{2}\left(t_{1}\right)}{c_{2}\left(t_{2}\right)}\left(1-f_{1}\right)
$$

where $f_{1}=m_{1} / m_{0}$ and by Eq. 16 ,

$$
\rho=1-\left(\mathrm{m}_{2} / \mathrm{m}_{1}\right)^{1 / 3}=1-\mathrm{r}_{2} / \mathrm{r}_{1}=1-\mathrm{k}_{\mathrm{u,2}} / \mathrm{k}_{\mathrm{u,1}}=1-\mathrm{k}_{\mathrm{a}, 2} / \mathrm{k}_{\mathrm{a}, 1} .
$$

The reactivityi7, $2 s$ is that associated with changing the reflector from $t_{1}$ to $t_{2}$. Application of Eqs. 25 and 26 to the data of Fig. 13 for the unreflected and thick-water reflected array curves yields the total reactivity worth of the reflector for spherical units. The results are presented in Fig. 15 along with a similar evaluation of 41-cm-thick concrete reflector.

Using Fig. 14 to define $c_{2}(t)$ for a reflector of thickness, $t$, the fractional reactivity worth of a reflector of thickness t may be evaluated over the entire mass range for the spherical units. The result is 


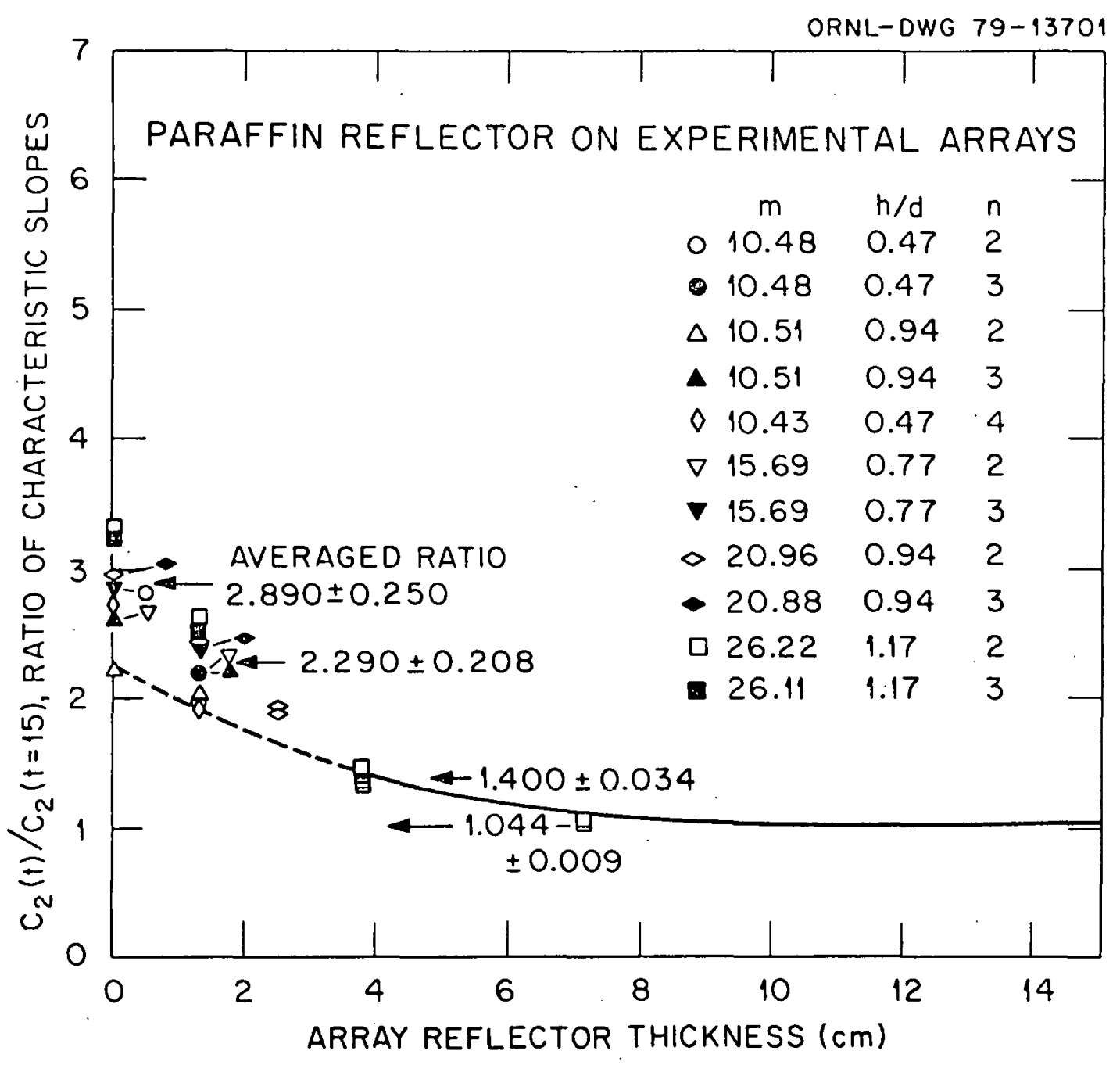

Fig. 14. Variation of the ratio of characteristic slopes, $c_{2}$, as the reflector thi,ckness varies. 


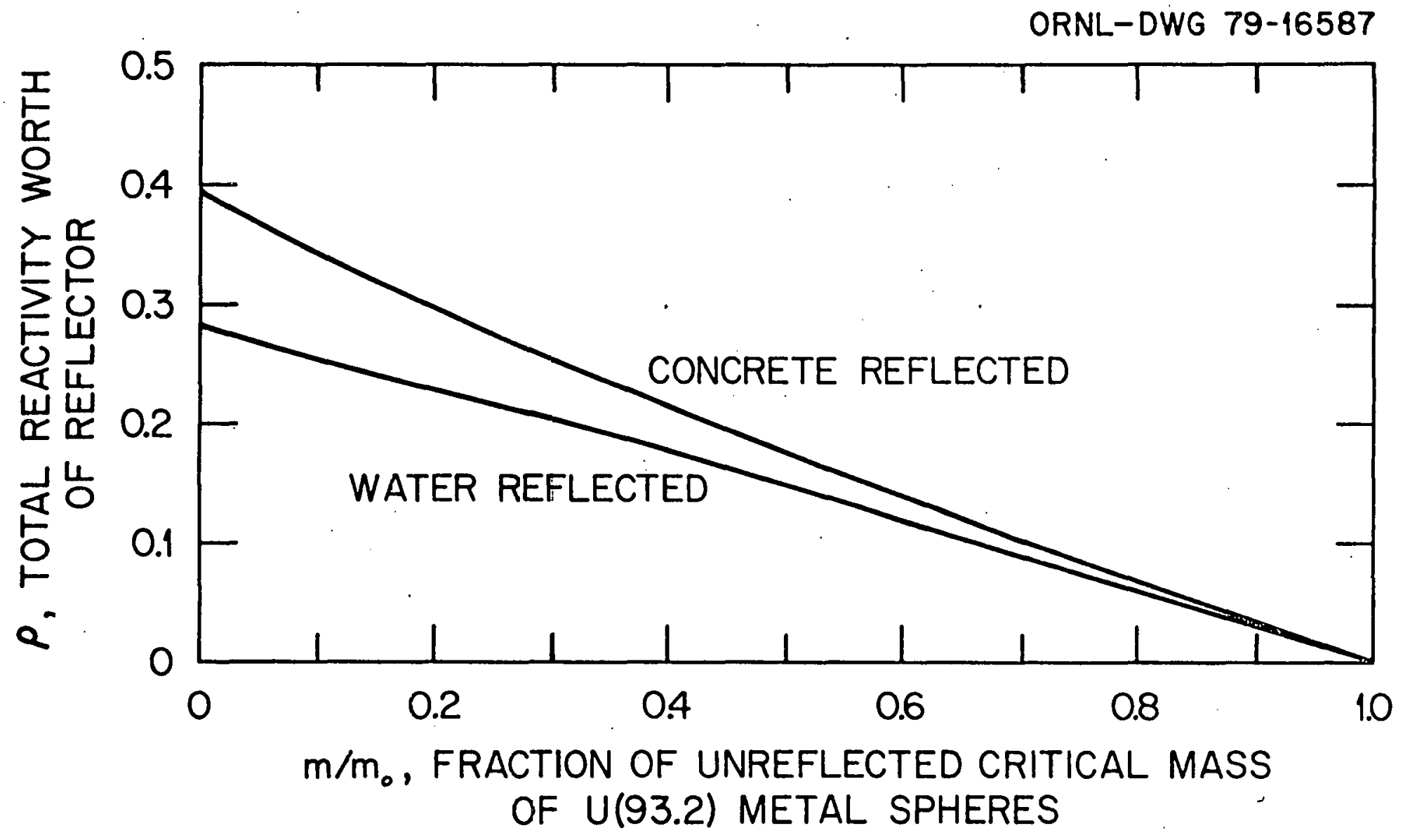

ล

Fig. 15. Total reactivity worth of thick concrete and of thick water as reflectors closely fitting cubic arrays of air-spaced $U(93.2)$ metal units. 
shown in Fig. 16. Also given in the figure is a similar analysis of two single unit critical systems as a function of reflector thickness. Evidently, the above definition of the reactivity worth of a reflector is insensitive to the neutron spectrum and being equally applicable to single units and arrays of units suggests that it is generic to the criticality of systems of fissile materials.

The effect of changing the reflector thickness on critical cubic arrays of spherical units is also expressible in terms of the solid angle. Application of Eq. 15 to the data of Fig. 13 results in the total solid ang1e representation shown in Fig. 17. A1 so presented in the figure are the data points for the 27-unit arrays of Table 12, where the solid angle, $\Omega_{S}$, has been computed by the SNAKE code. The effects of reflector thickness on $\Omega$ for critical arrays is exaggerated relative to the surface density representation and appears to be more dependent upon the unit shape, largely due to the increase in the average area presented by the cylindrical units. The concept of the fraction of the total reactivity worth of a reflector, however, remains valid.

There are two ways to compensate for the loss in array reactivity caused by reduced reflector thickness. One can maintain the unit mass $\left(r / r_{0}\right)$ and decrease the cell spacing which is a vertical displacement in the $\sigma(m)$ and $\Omega$ representations, Fig. 13 and Fig. 17, respectively, or one may maintain the cell dimension and increase the mass of the unit maintaining its shape. In this 1 atter case, one is increasing the mass of the unit and $\sigma(m)$ increases corresponding1y along a line defined by the slope $\sigma(m) / m$, i.e., fixed array geometry. The equivalent behavior in the $\Omega$ representation is described by Eq. 17 and two examples of 


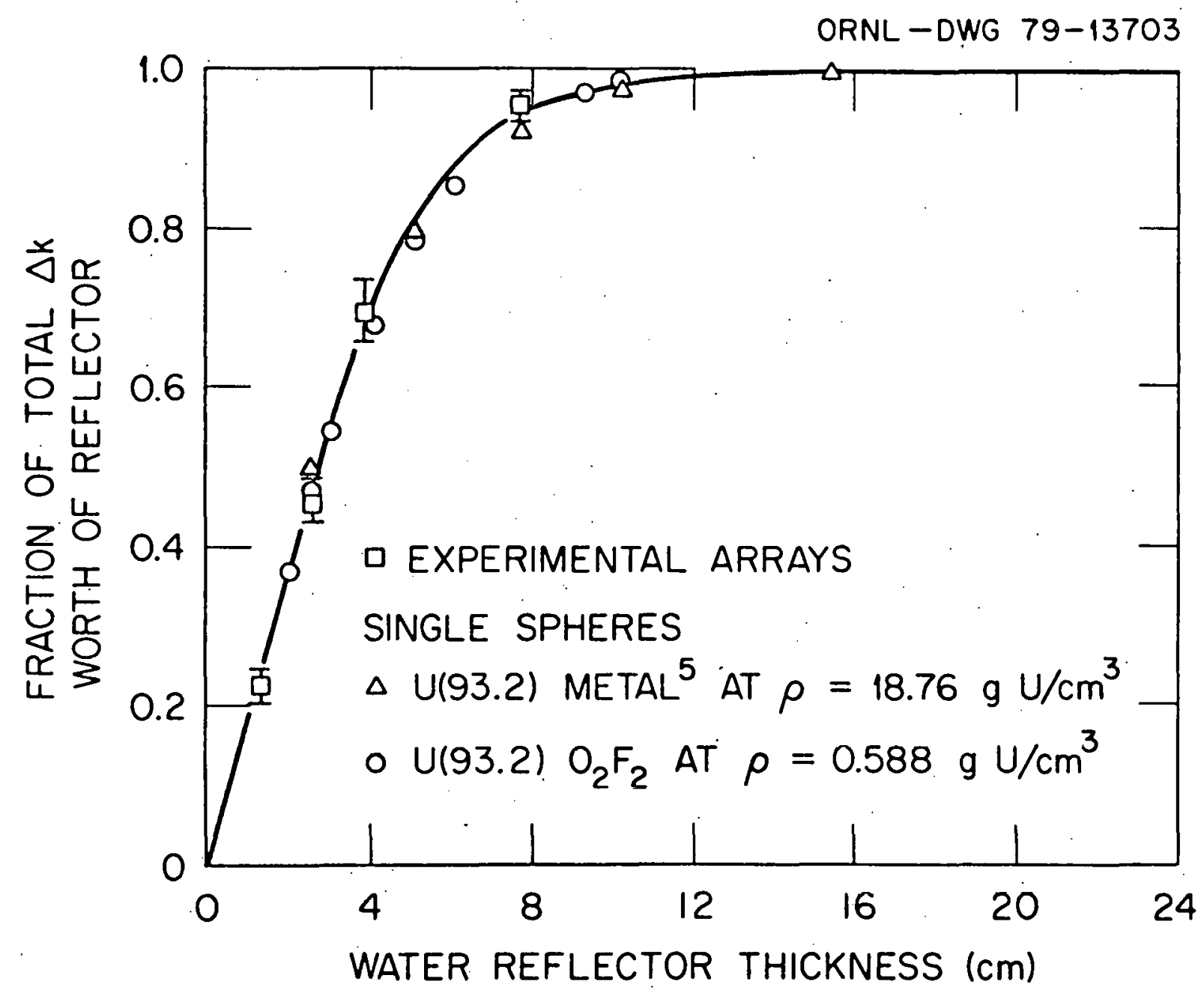

Fig. 16. Reactivity worth of a water reflector of thickness, $t$, on cuboidal arrays of $\mathrm{U}(93.2)$ metal units. 


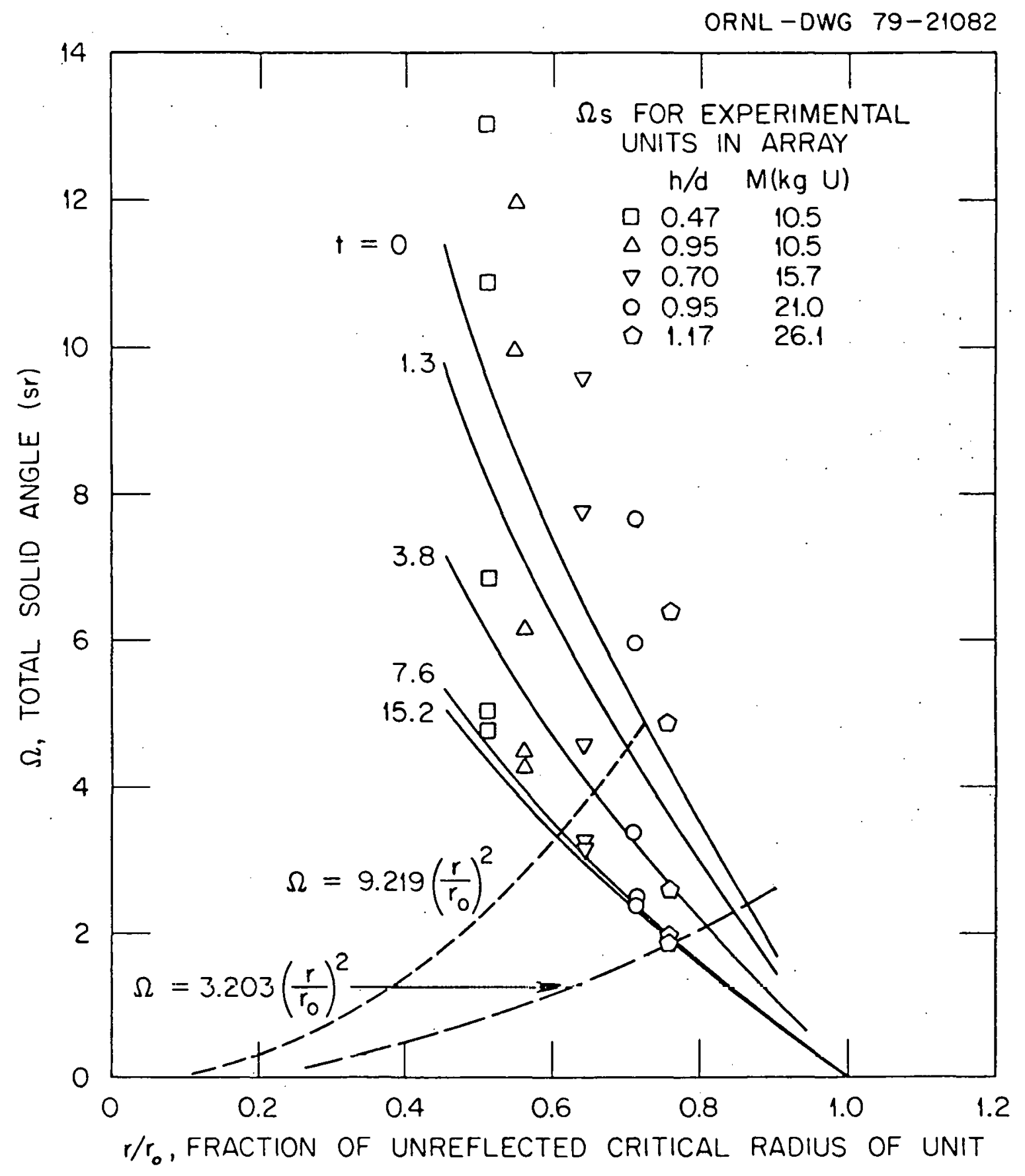

Fig. 17. Solid angle representation of critical experiments with $U(93.2)$ metal cylinders of various height-to-diameter ratios. The solid lines shown represent spherical units of U(93.2) metal for the array reflector thickness, $t$. 
this are given in Fig. 17. The array of cylinders with $h / d=1.17$ is characterized by the equation $\Omega=3.203\left(r / r_{0}\right)^{2}$ and a second array of spheres by $\Omega=9.219\left(r / r_{0}\right)^{2}$. It is important to point out here that in Fig. 17, there is a strong dependence of $\Omega$ on the number of cylinders in the array, e.g. the eight-unit arrays of the experimental data of Table 12 would have data points among and below the representation of spherical arrays shown.

Reflector density. These data of critical arrays with reduced reflector thicknesses may be interpreted as reflectors with constant thickness (say $15.2 \mathrm{~cm}$, or that thickness resulting in a saturated reflector effect, i.e., no observable change in k-eff occurs at a larger thickness) but of reduced density. For example, the reflector surface density of $\sigma(t)=(0.93)(3.6)=3.35 \mathrm{~g} / \mathrm{cm}^{2}$ and would be equivalent to a 15.2-cm-thick paraffin reflector of density $\rho=3.35 / 15.2=0.22 \mathrm{~g} / \mathrm{cm}^{3}$. The equivalence subsists since the point of entry of a neutron into the reflector, the number and effect of events along the neutron's path in the reflector, and the point of reentry of the neutron are identical in the reflectors of constant surface density. This concept is appropriate for reflectors of large planar geometry about arrays. It is not suitable for single unit criticality al though it would probably overestimate the $k$-eff of a lower density reflector.

Reflector location. Experience with criticality has shown that the more distant a reflector is from a system of fissile material, the less will be the reactivity contribution to the neutron multiplication factor of the system. The magnitude of the reactivity contribution of a reflector at a given location to a system of fissile material will depend 
upon the reflector material composition, its density, its thickness, and the effective area the fissile material presents to the reflected neutrons. Thus far, we have considered the criticality of arrays when the reflector has been located adjacent to the array outer surfaces defined by the peripheral cells. The reflector at this location is termed "closely fitting" the array. If the reflector were some distance from the surfaces of the array, there would result an array reactivity loss relative to the closely fitting reflector condition. The behavior in the 1 imiting surface density representation would be similar to that of reduced reflector thickness. The reactivity could be restored by reducing the cell dimension or by increasing the mass of the unit and criticality occurs with a mass value between that required for the reflected array and its unceflected condition.

Changing the cell dimension will change the dimension of the array and, hence, also effectively alter the relative location of the reflector. Changing the mass to restore criticality will not alter the reflector location which is the parameter being examined. Further, it is desirable to express the location of the reflector in a manner that is independent of the dimensions of the array. This is accomplished by expressing the reflector location in terms of the array dimension. A cubic array has a dimension equal to the product of the number of cells along an edge and the cell dimension, $n d_{n}=A$. The inside dimension of a reflector that is closely fitting the array is also nd . The array may be thought of as filling a cavity formed by the reflector material of constant thickness. If the reflector is moved an equal distance from the six faces of the array, the array is centered in a cubic cavity of some dimension, $R_{r}$, proportional to the distance from the array surfaces. 
The ratio of the array dimension to that of the reflector, $A / R_{r}$, adequately specifies the reflector location and ranges from a value of unity for the closely fitting reflector condition to the value zero for a reflector cavity with unlimited inside dimension.

A Monte Car1o calculational study' of the criticality of arrays as a water reflector recedes from the surfaces of cubic arrays was conducted and the results are summarized in Fig. 18. The number of units in the arrays ranged from 64 to 1000 , and the ce11 dimensions from 25 to $61 \mathrm{~cm}$. Similar calculations using "Oak Ridge" concrete as the reflector with a $41 \mathrm{~cm}$ thickness were performed and these data are presented in Fig. 19. Each concrete thickness considered would result in a characteristic slope $c_{2}$ for the reflector condition.

These data display a structure similar to that of variable reflector thickness data. A given value of the ratio. $A / R_{r}$ defines a slope, $c_{2}$, which adequately describes the criticality of arrays as a function of the mass of the spherical units in the array over the linear approximation to $\sigma(m)$ for the unreflected arrays. We extend the characterization of a given reflector location over the entire mass range of the unit by again expressing the effect in terms of the fraction of the total reactivity worth of the reflector. The result is represented in Fig. 20 and applies generally to cubic arrays independent of the reflector material. The loss of reactivity to an array as the distance between the array and reflector surfaces increases is given as a fraction of the total reactivity worth, $F(\rho)$, of the reflector when closely fitting the array, i.e., at $A / R_{I}=1$. The 41-cm-thick concrete and the 30-cm-thick water reflector data of Fig. 18 and 19 are both represented by the relationship given in Fig. 20. The concept is applicable to the reactivity 


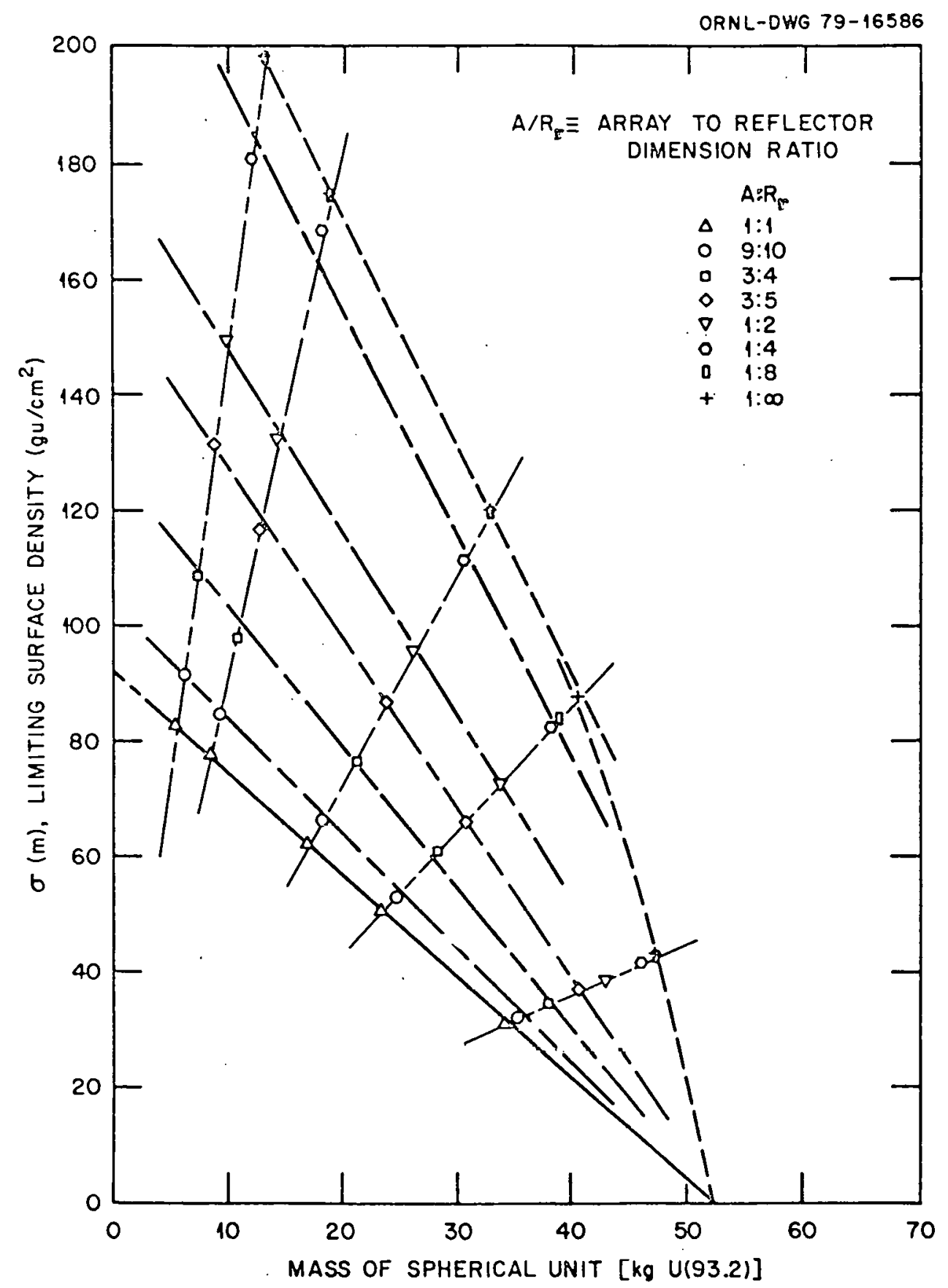

Fig. 18. Criticality of water reflected cubic arrays of U(93.2) metal spheres as a function of reflector location given as multiples of the array dimension, A. The lines with positive slope represent array geometries with constant cell dimension and number of unt $t$. 


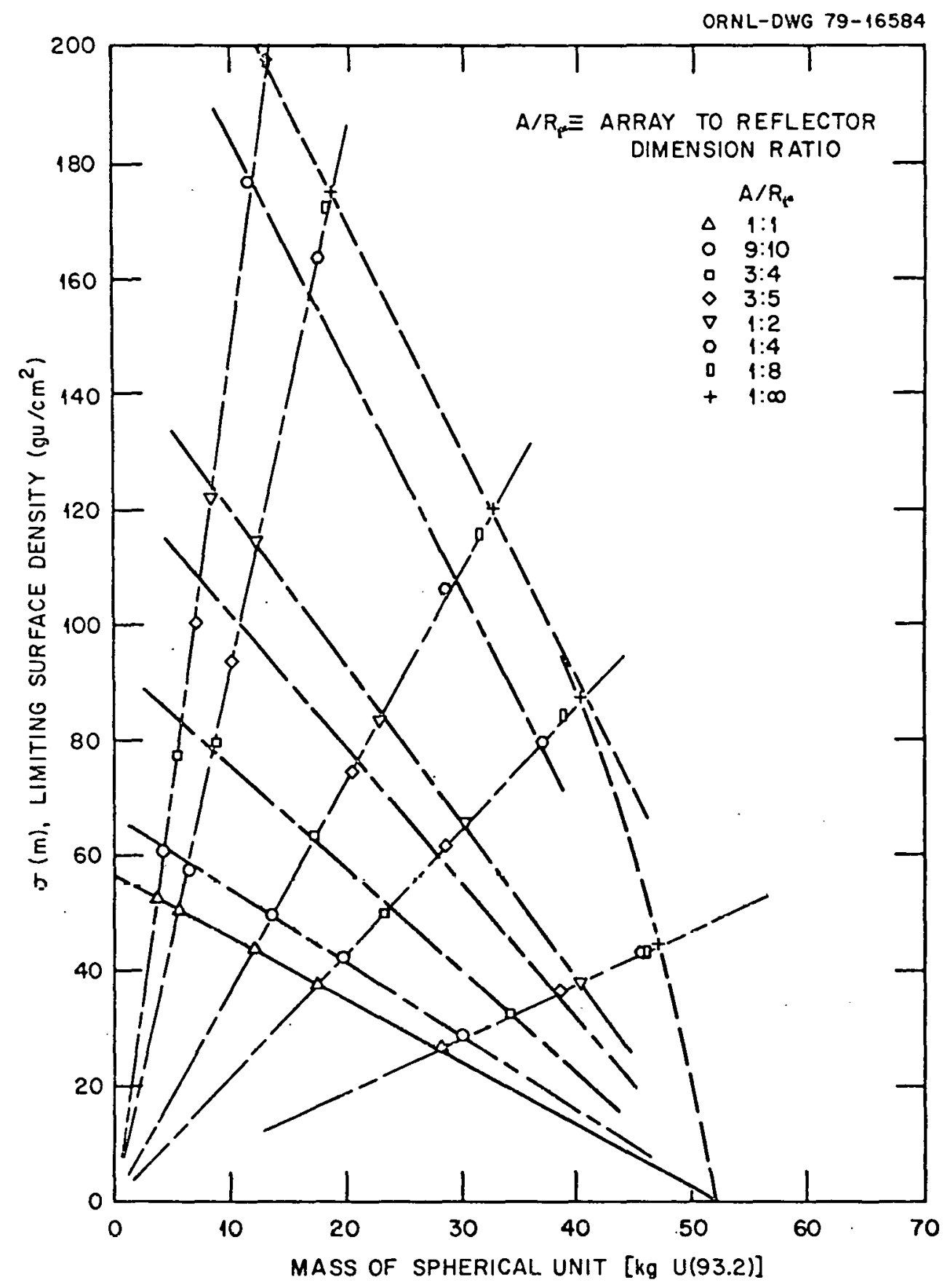

Fig. 19. Criticality of concrete reflected cubic arrays of U(93.2) metal spheres as a function of reflector location given as multiples of the array dimension, A. The lines with positive slope represent array geometries with constant cell dimension and number of units. 
ORNL-DWG 79-16583

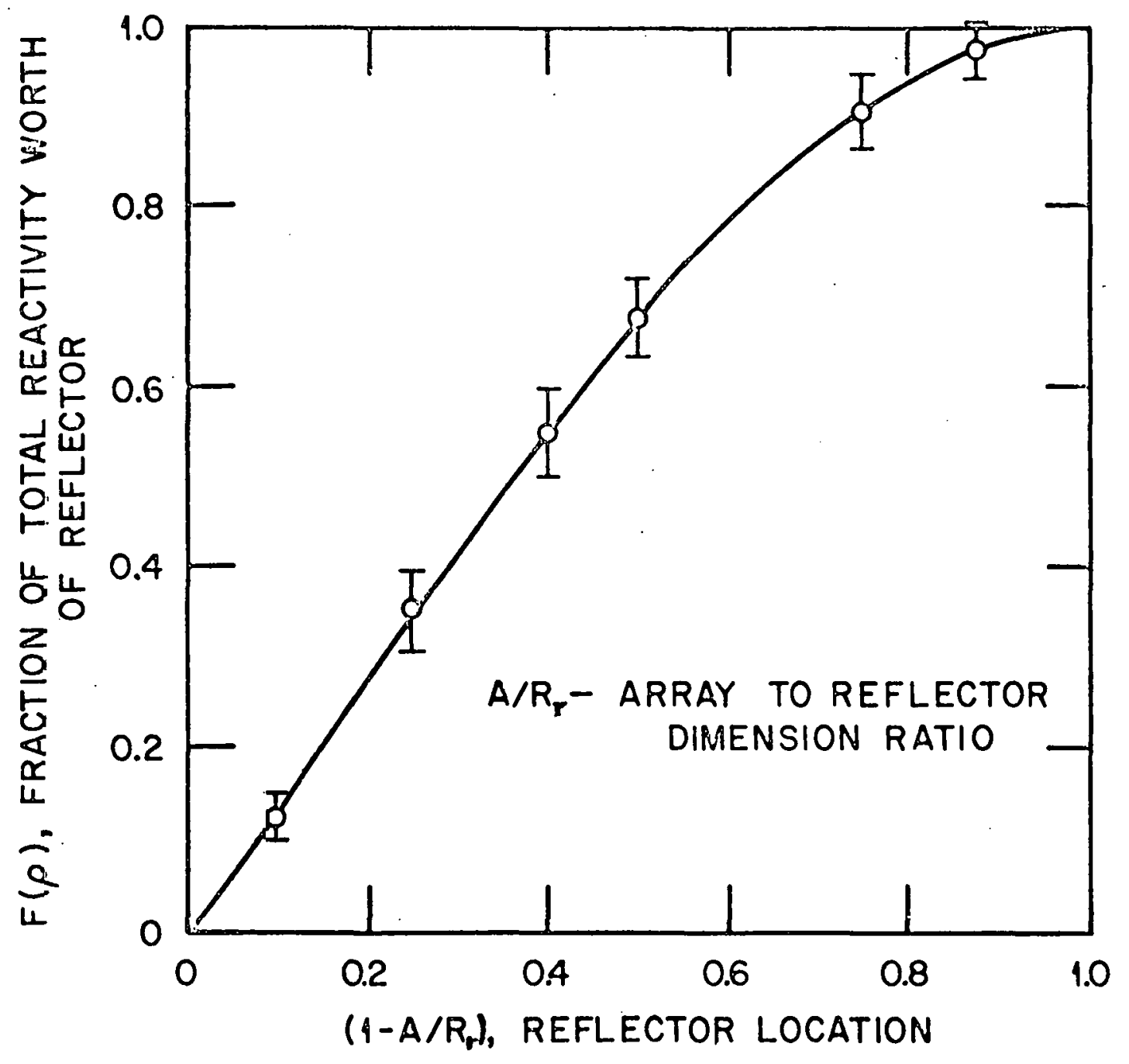

Fig. 20. Representation of the fractional total worth of a reflector to an array as $a$ function of reflector location expressed in multiples of the array dimension, A. 
worth of two or more reflector surfaces to a cubic array. It is necessary to determine the reactivity difference of the two reflector conditions either by experiment or by a validated calculational method. An exception is a single reflecting surface. The location of a single reflecting surface that remains coterminous with four sides of the closely fitting reflector about an array controls 1 ittle reactivity. An example of the evaluation of three sides of a 41-cm-thick concrete reflector is presented in Fig. 21. Three-sided reflection of an array by thick concrete is characterized by a $c_{2}$ value of $2.54 \times 10^{-3} \mathrm{~cm}^{-2}$ and an "m。" of $55.4 \mathrm{~kg}: \mathrm{U}(93.2)$ for spherical units and is shown in Fig. 21 by the 1 ine identified in the legend as "3 Faces". The data points shown on the line through the origin are from Monte Carlo calculations of criticality. For example, an array with $A=2 m$ and $A: R_{I}=1: 2$ represents an array with three reflector surfaces located $2 \mathrm{~m}$ from the array boundary surfaces and three sides closely fitting the array. Two critical experiment ${ }^{2}$ points are al so shown for comparison. The points have 1 arger $\sigma(m)$ values than the curve representing "concrete on three surfaces" because the reflector is paraffin and did not extend beyond the array boundaries.

The relationship given in Fig. 20 is applicable to cubic arrays with units of shape17,23 other than spherical. The reactivity difference between the reflected and unreflected array would have to be determined. Cylindrical units in the range $0.1<\mathrm{h} / \mathrm{d}<4.0$ for which $c_{2}$ and "m。" have been determined for the close fitting refiector condition may be evaluated by the mass equivalence relation, Eq. 5 .

The data of Figs. 16 and 20 may be combined to produce an equivalence relationship between the location of a thick reflector and the 


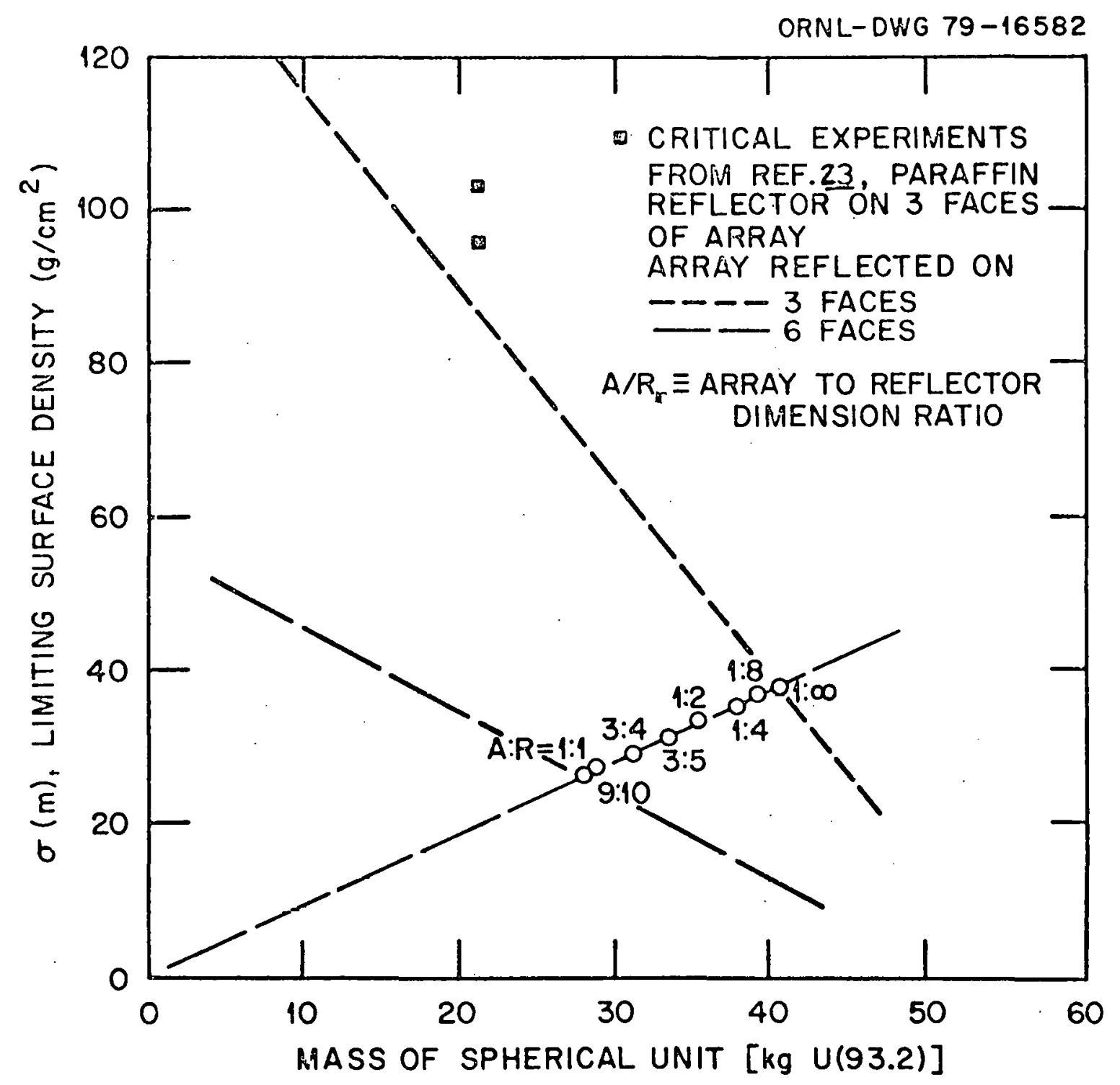

Fig. 21. Representation of the fraction total worth of three sides of thick concrete reflector as a function of the reflector location expressed in terms of the array dimension, $A$. 
water reflector thickness surrounding an array. A relation showing the equivalence is given in Fig. 22. The result has general applicability provided the reactivity controlled by the reflector material has been determined.

The solid ang1e representation of the data for the thick concrete reflector of Fig. 19 is presented in Fig. 23. It is seen that criticality of cubic arrays with spherical units of $U(93.2)$ metal are adequate1y described by Eqs. 7 and 17 with appropriate coefficients $\beta$ and $a_{0}$ and the relationship of Fig. 20. The general application of Fig. 20 to cuboidal arrays, however, is not possible because the reactivity controlled by reflector location to a fissile material is strongly dependent on the shape of the system. For example, consider the extreme geometry of a critical, reflected slab of unlimited size in two dimensions. The k-eff of the system is insensitive to the distance of the reflector from the surface of the fissile material. The mere appearance of the reflector in space contributes reactivity as a "delta" function which has little variation as the distance from the material is varied. Large but finite planar arrays will exhibit a behavior similar to that of the infinite slab. Smaller finite $N$-unit planar arrays can be expected to display a behavior somewhere between that of the cubic arrays represented in Fig. 20 and the $\delta$-function behavior of a reflector to an infinite s1ab. The calculational results of 512-unit arrays when the units have the planar arrangement described by $32 \times 16 \times 1$ are given in Fig. 24 for three different unit shapes. It is observed that the relationship of Fig. 20 may be considered as being displaced downward and would ultimately be represented by the $\delta$-function reactivity response at the 


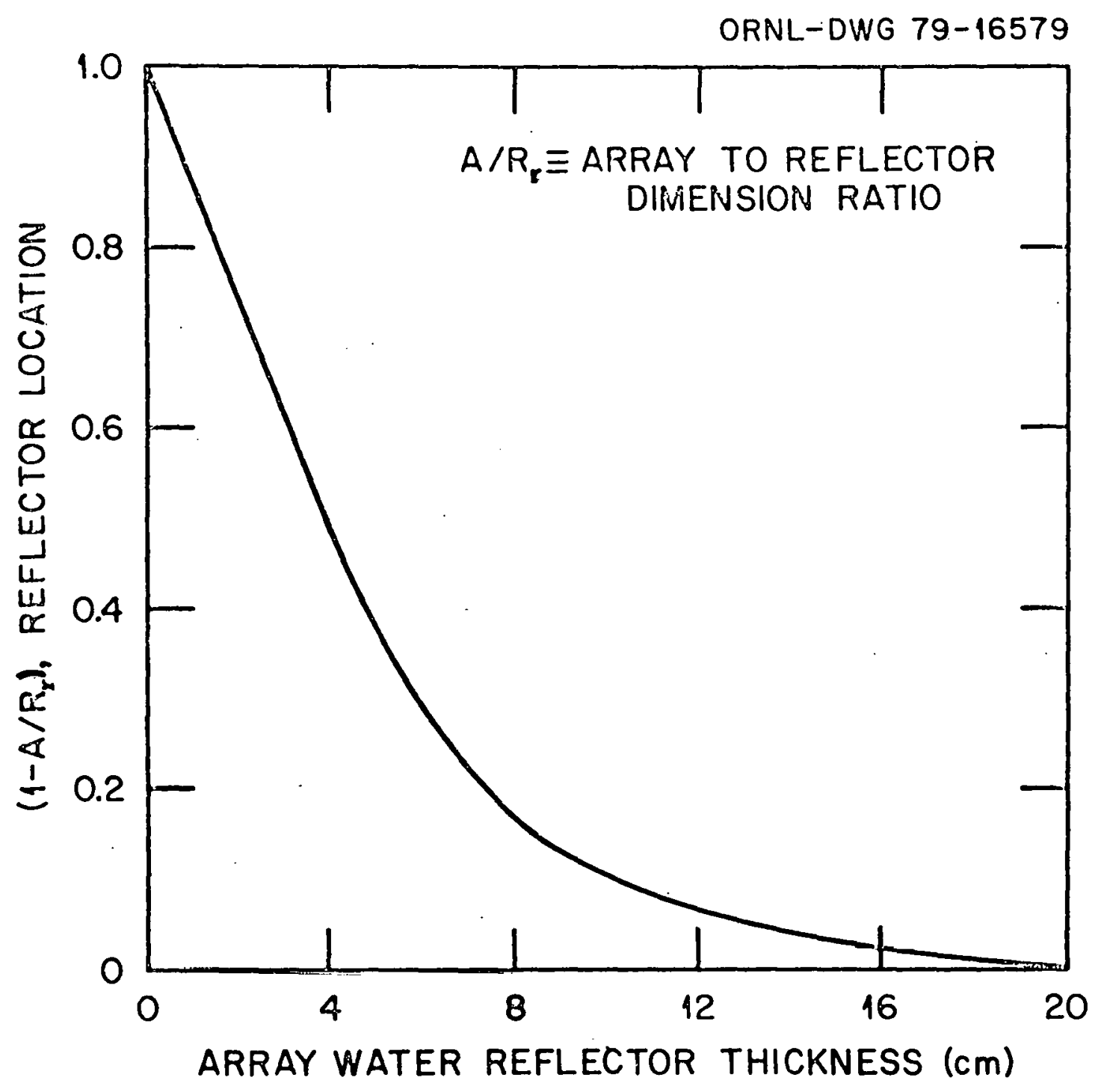

Fig. 22. Reactivity equivalence between the location of a thick rcfleotor from the array surfaces and the thickness of a closely fitting water reflector on arrays. 
ORNL-DWG 79-21083

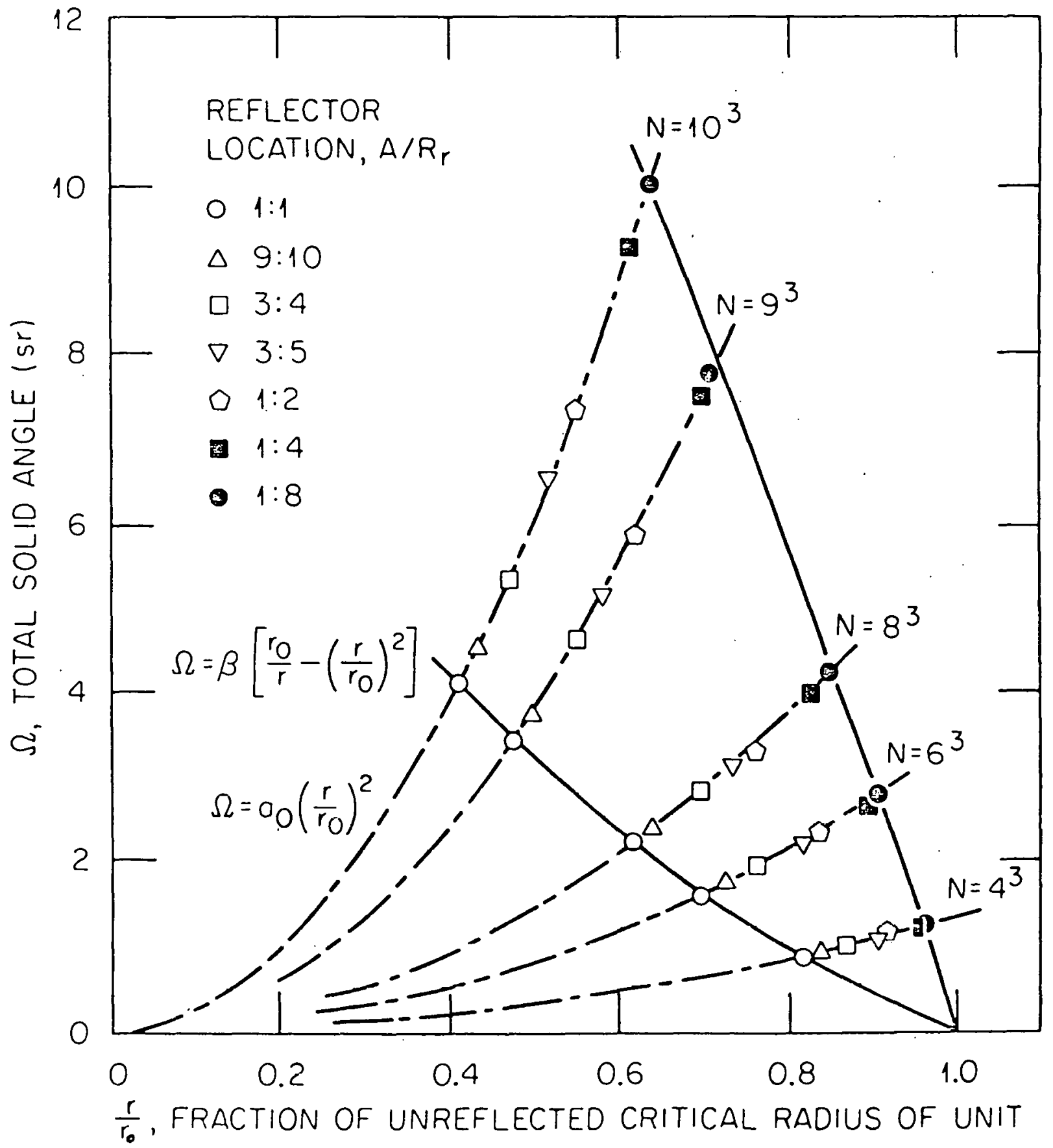

Fig. 23. Total solid angle required for concrete reflected critical arrays as the reflector recedes from the array surfaces. The reflector location is expressed in terms of the array dimension, A. Parabolic lines represent array geometries with constant cell dimension and number of units. 


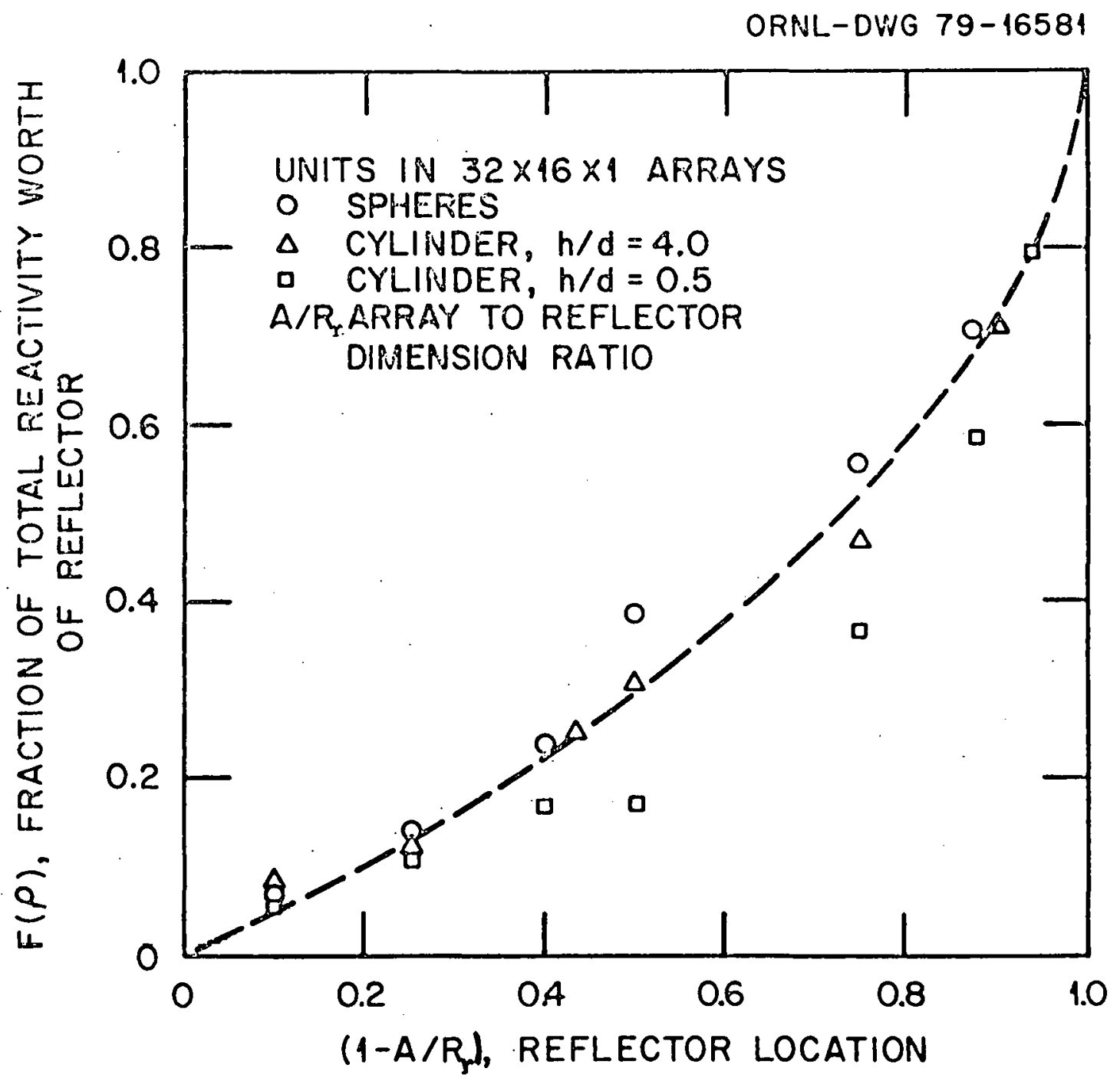

Fig. 24. Representation of array reactivity loss as a thick water refilector recedes from five surfaces of planar arrays. 
abscissa value of unity were the number of units in the $x$ and $y$ directions of the array to be increased.

Two particular conclusions can be drawn from this information on planar arrays. The first concerns criticality safety limits established by reference to infinite slab geometries. There cannot be a relaxation of a safety limit because of reflector location; further, unless there has been an evaluation for the effects of fissile material outside the planar arrangement, i.e., above or below the plane, there is a need for an administrative control to prevent the occurrence of such an event. Second1y, if it is desired to relax a safety 1 imit for finite planar arrangements because of reflector location, the magnitude of the effect on the array $k$-eff should be established by a validated calculational method.

The condition of a closely fitting reflector to an array has been used to compare the conditions necessary for criticality when the reflector location is some distance from the array boundary and, hence, from contained fissile materials. It may al so be used to display the relative effect of a reflector located in the space between the fissile material surface and the outer surface boundary of the array. As the reflector is moved toward the fissile material from the position of closely fitting the array, the array will experience a positive array reactivity contribution. A consequence of Eq. 16 is that the array reactivity increase cannot be greater than that experienced by a peripheral unit of the array.* A particular case maximizing the array reactivity response to reflector motion toward the fissile material is the case of a planar

* See appendix of Ref. 17 . 
"array in which each unit is subjected to the reactivity increase. An example of this is reported in Fig. 25 where the k-eff of a $32 \times 16 \times 1$ planar array of cylindrical units with an h/d of 0.5 having a $U(93.2)$ metal mass of $22.5 \mathrm{~kg}$ is given as a function of the reflector location. Each unit is centered in a $32.908 \mathrm{~cm}$ cubic ce11 and the array is evaluated for two reflector conditions as the bottom reflector is relocated to contact the base of the units. In one configuration, the array has only the bottom reflector and in the second, the array is reflected on six sides. Shown for comparison are similar and intermediate reflector conditions for a single cell. These data clearly show that the $\Delta$-eff (or change in reactivity) of the single unit is greater than that experienced by the array.

Relative to the total reactivity worth of a reflector closely fitting an array, the positive reactivity addition to the array associated with the motion of one face of the reflector to the point of contact with the units in a cuboidal array will be overestimated by the evaluation of the reactivity effect of the two reflector locations on a single unit of the array.

We may conclude from this study of reflector influence on array criticality that, when the reactivity worth of a closely fitting thick reflector to the array is known, the reactivity worth of

- a thinner reflector of the same material may be estimated from Fig. 16 .

- a thin reflector can be associatcd with a thick reflector of the same material at reduced density.

- reflootor ourfaooc locatod a distanne from the array can be estimated from Fig. 20 .

- reflectors located a distance from the array can be associated with a water reflector thickness closely fitting the array. 


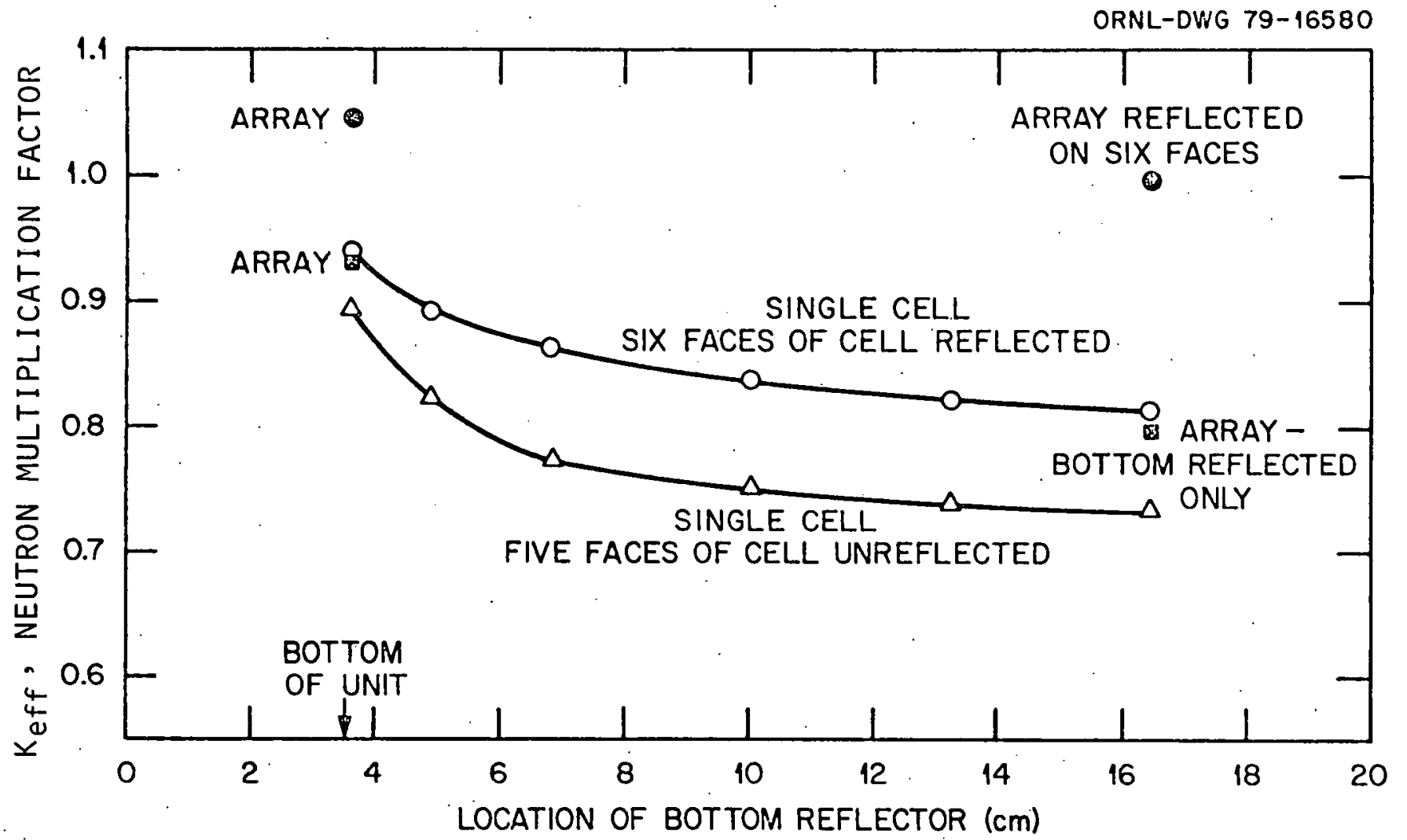

Fig. 25. Calculated neutron multiplication factors of a single cell having a centered $22.5 \mathrm{~kg}$ U(93.2) metal cylinder with a height-to-diameter ratio of 0.5 as a function of the cell reflector. Data for a $32 \times 16 \times 1$ array are shown for comparison. 
- a reflector located a distance greater than eight times the dimension of a cubic array is less than 0.01 .

The reactivity increase to an array caused by the motion of a reflector from the array boundary toward and into contact with the units of the array is less than the reactivity increase experienced by a peripheral unit.

OTHER FISSILE MATERIALS AND ARRAYS OF MIXED UNITS

Extension of the results thus far presented to fissile materials other than $U(93.2)$ meta1 is easily accomp1ished through the mass equivalence relation. The basic information required is

- the criticality of the fissile material as air-spaced units (in the geometry of interest) arranged into water reflected cubic arrays to establish the characterisitc slope $c_{2}$, and

- the unreflected critical mass, $m_{0}$.

There are data ${ }^{14}$ for a few tens of different fissile materials determined for spherical units in water reflected arrays. These data may be used with Eqs. 2 and 3 to define classes of fissile materials which will result in criticality for predetermined conditions.

Given the mass of units of a particular fissile material, Eq. 2 defines the value of $\sigma(\mathrm{m}) / \mathrm{m}$, i.e., corresponding to an arbitrary array geometry, and Eq. 7 may be solved for the number of units, N, required for criticality as a function of the cubic cell dimension, $d_{n}$. The mass of another fissile material (given that $c_{2}$ and $m_{0}$ have been established) necessary for criticality under the same array conditions $(\sigma(m) / m=$ constant $)$ is specified by Eq. 5, which may be said to determine c1asses or categories of mass of different fissile materials resulting in criticality under the specified conditions. Using $U(93.2)$ 
metal to define $N$ for selected values of $d_{n}$, a tabulation of equivalent masses is easily produced and may be presented as in Table 13. As an example of a typical entry for Table 13 used to define $N$, consider the mass category 5 for the $U(93.2)$ metal, which is $9.38 \mathrm{kgU}$. By Eq. 6

$$
\begin{aligned}
\sigma(9.38) / 9.38 & =1.762 \times: 10^{-3}[(52.1 / 9.38)-1] \\
& =8.02 \times 10^{-3} \mathrm{~cm}^{-2}
\end{aligned}
$$

so that by Eq. 3,

$$
n(1-0.55 / \sqrt{\mathrm{N}})^{2}=8.02 \times 10^{-3} \times \mathrm{d}^{2}
$$

If a $d_{n}=38.1 \mathrm{~cm}(15$ inches $)$ is chosen, then

$$
n(1-0.55 / \sqrt{\mathrm{N}})^{2}=11.649
$$

and

$$
\mathrm{N}=1,713
$$

This is not a perfect cube, but the array $k$-eff does not differ significantly from one that is, as was indicated in the discussion on array shape. The array may be visualized as a $12^{3}$ array minus 15 units from the top tier and will have a calculated k-eff within a standard deviation of that for the $12^{3}$ reflected array. Other materials in the category 5 may occupy a ce11 in the near cubic array of 1,713 units and result in an array which, for practical purposes, may be regarded as critical.

The concept of criticality by mass category leads naturally to a method for controlling criticality. Evidently; as long as a volume is associated with a unit whether in an array or in transport, the point at which criticality is achieved is determined by $N$, the number of accumulated cells. We can eliminate the need to know the $N$ associated 
Table 13. Categories of equivalent masses in water reflected cubic arrays

\begin{tabular}{|c|c|c|c|c|c|c|c|c|}
\hline \multirow{2}{*}{$\begin{array}{c}\text { Fissile } \\
\text { material } \\
\text { B:U or B:Pu }\end{array}$} & \multirow{2}{*}{$\begin{array}{c}\mathrm{D}(100) \\
0\end{array}$} & \multicolumn{2}{|c|}{$\mathrm{O}(100) \mathrm{O}_{2}$} & \multirow{2}{*}{$\begin{array}{c}0(93.2) \\
0\end{array}$} & \multicolumn{4}{|c|}{$\mathrm{U}(93,2) 0_{2}$} \\
\hline & & 0.4 & 3 & & 0.4 & 3 & 10 & 20 \\
\hline $\begin{array}{c}\text { Mass } \\
\text { category } \\
\end{array}$ & \multicolumn{8}{|c|}{ Mass of fissile material ${ }^{a}(\mathrm{~kg})$} \\
\hline 1 & 5.04 & 4.63 & 3.01 & 5.63 & 5.00 & 3.15 & 1.60 & 0.91 \\
\hline 2 & 5.88 & 5.46 & 3.55 & 6.57 & 5.89 & 3.71 & 1.88 & 1.07 \\
\hline 3 & 6.72 & 6.30 & 4.10 & 7.50 & 6.80 & 4.29 & 2.17 & 1.24 \\
\hline 4 & 7.56 & 7.16 & 4.67 & 8.44 & 7.73 & 4.88 & 2.47 & 1.41 \\
\hline 5 & 8.39 & 8.03 & 5.24 & 9.38 & 8.68 & 5.49 & 2.78 & 1.58 \\
\hline 6 & 9.23 & 8.92 & 5.83 & 10.32 & 9.65 & 6.11 & 3.09 & 1.76 \\
\hline 7 & 10.06 & 9.83 & 6.43 & 11.26 & 10.63 & 6.74 & 3.41 & 1.94 \\
\hline 8 & 10.90 & 10.76 & 7.04 & 12.19 & 11.64 & 7.39 & 3.74 & 2.12 \\
\hline 9 & 11.73 & 11.71 & 7.67 & 13.13 & 12.67 & 8.05 & 4.07 & 2.31 \\
\hline 10 & 12.56 & 12.68 & 8.31 & 14.07 & 13.72 & 8.73 & 4.41 & 2.51 \\
\hline 11 & 13.39 & 13.67 & 8.97 & 15.01 & 14.80 & 9.43 & 4.76 & 2.71 \\
\hline 12 & 14.22 & 14.68 & 9.65 & 15.95 & 15.89 & 10.14 & 5.12 & 2.91 \\
\hline 13 & 15.05 & 15.71 & 10.34 & 16.88 & 17.02 & 10.87 & 5.49 & 3.12 \\
\hline 14 & 15.88 & 16.76 & 11.04 & 17.82 & 18.16 & 11.62 & 5.87 & 3.33 \\
\hline 15 & 16.71 & 17.84 & 11.77 & 18.76 & 19.34 & 12.39 & .6 .26 & 3.55 \\
\hline 16 & 17.54 & 18.94 & 12.51 & 19.70 & 20.54 & 13.18 & 6.65 & 3.77 \\
\hline 17 & 18.37 & 20.07 & 13.27 & 20.64 & 21.77 & 13.99 & 7.06 & .4 .00 \\
\hline 18 & 19.19 & 21.22 & 14.05 & 21.57 & 23.02 & 14.83 & 7.48 & 4.23 \\
\hline 19 & 20.02 & 22.40 & 14.85 & 22.51 & 24.31 & 15.68 & 7.90 & 4.47 \\
\hline 20 & 20.84 & 23.61 & 15.67 & 23.45 & 25.63 & 16.56 & 8.34 & 4.72 \\
\hline 21 & 21.67 & 24.85 & 16.51 & 24.39 & 26.98 & 17.46 & 8.80 & 4.97 \\
\hline 22 & 22.49 & 26.11 & 17.37 & 25.33 & 28.37 & 18.39 & 9.26 & 5.23 \\
\hline 23 & 23.31 & 27.41 & 18.26 & 26.26 & 29.79 & 19.35 & 9.74 & 5.50 \\
\hline 24 & 24.13 & 28.74 & 19.17 & 27.20 & 31.24 & 20.33 & 10.23 & 5.77 \\
\hline 25 & 24.96 & 30.10 & 20.11 & 28.14 & 32.73 & 31.34 & 10.73 & 6.06 \\
\hline 26 & 25.78 & 31.49 & 21.08 & 29.08 & 34.27 & 22.39 & 11.25 & 6.35 \\
\hline 27 & 26.60 & 32.92 & 22.07 & 30.02 & 35.84 & 23,46 & 11,79 & 6.64 \\
\hline 28 & 27.41 & 35.39 & 23.09 & 30.95 & 37.45 & 24.57 & 12.34 & 6.95 \\
\hline 29 & 28.23 & 35.90 & 24.14 & 31.89 & 39.11 & 25.71 & 12.91 & 7.27 \\
\hline 30 & 29.05 & 37.45 & 25.22 & 32.83 & 40.81 & 26.89 & 13.50 & 7.59 \\
\hline 31 & 29.87 & 39.04 & 26.34 & 33.77 & 42.56 & 28.11 & 14.10 & 7.93 \\
\hline 32 & 30.68 & 40.67 & 27.49 & 34.71 & 44.36 & 29.37 & 14.72 & 8.27 \\
\hline 33 & 31.50 & 42.35 & 28.68 & 35.64 & 46.22 & 30.67 & 15.37 & 8.63 \\
\hline 34 & 32.31 & 44.07 & 29.90 & 36.58 & 48.12 & 32.02 & 16.03 & 8.99 \\
\hline 35 & 33.13 & 45.84 & 31.17 & 37.52 & 50.08 & 33.41 & 16.72 & 9.37 \\
\hline 36 & 33,94 & $47: 67$ & $32 ., 17$ & $38: 46$ & s2. & 34,85 & $17: 13$ & 9.76 \\
\hline 37 & 34.75 & 49.55 & 33.82 & 39.40 & 54.19 & 36.34 & 18.17 & 10.17 \\
\hline 38 & 35.56 & 51.48 & 35.22 & 40.33 & 56.33 & 37.89 & 18.93 & 10.59 \\
\hline 39 & 36.38 & 53.48 & 36.66 & 41.27 & 58.55 & 39.50 & 19.72 & 11.02 \\
\hline 40 & 37.19 & 55.53 & 38.16 & 42.21 & 60.83 & 41.17 & 20.54 & 11.46 \\
\hline
\end{tabular}


Table 13. (Continued)

\begin{tabular}{|c|c|c|c|c|c|c|c|c|}
\hline \multirow{2}{*}{$\begin{array}{c}\text { Fissile } \\
\text { material } \\
\mathrm{H}: \mathrm{U} \text { or } \mathrm{H}: \mathrm{Pu}\end{array}$} & \multirow{2}{*}{$\begin{array}{c}\mathrm{U}(80) \\
0\end{array}$} & \multicolumn{4}{|c|}{$\mathrm{U}(80) \mathrm{O}_{2}$} & \multirow{2}{*}{$\begin{array}{c}\sigma(70) \\
0 .\end{array}$} & \multicolumn{2}{|c|}{$\mathrm{J}(70) \mathrm{O}_{2}$} \\
\hline & & 0.4 & 3 & 10 & 20 & & 0.4 & 3 \\
\hline $\begin{array}{c}\text { Mass } \\
\text { category }\end{array}$ & & & Mass & fissi & mater & $1(\mathrm{~kg})$ & & \\
\hline $\begin{array}{l}1 \\
2 \\
3 \\
4 \\
5\end{array}$ & $\begin{array}{r}5.97 \\
7.00 \\
8.03 \\
9.07 \\
10.12\end{array}$ & $\begin{array}{l}5.67 \\
6.68 \\
7.72 \\
8.78 \\
9.86\end{array}$ & $\begin{array}{l}3.46 \\
4.08 \\
4.72 \\
5.38 \\
6.04\end{array}$ & $\begin{array}{l}1.67 \\
1.97 \\
2.28 \\
2.59 \\
2.91\end{array}$ & $\begin{array}{l}0.95 \\
1.12 \\
1.29 \\
1.47 \\
1.65\end{array}$ & $\begin{array}{r}6.75 \\
7.92 \\
9.11 \\
10.31 \\
11.53\end{array}$ & $\begin{array}{r}6.31 \\
7.45 \\
8.62 \\
9.81 \\
11.02\end{array}$ & $\begin{array}{l}3.76 \\
4.44 \\
5.13 \\
5.84 \\
6.57\end{array}$ \\
\hline $\begin{array}{r}6 \\
7 \\
8 \\
9 \\
10\end{array}$ & $\begin{array}{l}11.18 \\
12.25 \\
13.33 \\
14.42 \\
15.52\end{array}$ & $\begin{array}{l}10.97 \\
12.11 \\
13.27 \\
14.46 \\
15.67\end{array}$ & $\begin{array}{l}6.73 \\
7.43 \\
8.15 \\
8.89 \\
9.65\end{array}$ & $\begin{array}{l}3.24 \\
3.58 \\
3.93 \\
4.28 \\
4.65\end{array}$ & $\begin{array}{l}1.84 \\
2.03 \\
2.22 \\
2.42 \\
2.63\end{array}$ & $\begin{array}{l}12.76 \\
14.01 \\
15.27 \\
16.55 \\
17.85\end{array}$ & $\begin{array}{l}12.27 \\
13.55 \\
14.86 \\
16.20 \\
17.58\end{array}$ & $\begin{array}{r}7.32 \\
8.08 \\
8.87 \\
9.68 \\
10.51\end{array}$ \\
\hline $\begin{array}{l}11 \\
12 \\
13 \\
14 \\
15\end{array}$ & $\begin{array}{l}16.62 \\
17.74 \\
18.87 \\
20.01 \\
21.15\end{array}$ & $\begin{array}{l}16.92 \\
18.19 \\
19.50 \\
20.83 \\
22.21\end{array}$ & $\begin{array}{l}10.42 \\
11.22 \\
12.04 \\
12.88 \\
13.74\end{array}$ & $\begin{array}{l}5.02 \\
5.40 \\
5.79 \\
6.20 \\
6.61\end{array}$ & $\begin{array}{l}2.83 \\
3.05 \\
3.27 \\
3.49 \\
3.72\end{array}$ & $\begin{array}{l}19.16 \\
20.49 \\
21.84 \\
23.20 \\
24.58\end{array}$ & $\begin{array}{l}18.99 \\
20.44 \\
21.93 \\
23.45 \\
25.02\end{array}$ & $\begin{array}{l}11.36 \\
12.23 \\
13.12 \\
14.05 \\
14.99\end{array}$ \\
\hline $\begin{array}{l}16 \\
17 \\
18 \\
19 \\
20\end{array}$ & $\begin{array}{l}22.31 \\
23.48 \\
24.66 \\
25.85 \\
27.05\end{array}$ & $\begin{array}{l}23.61 \\
25.06 \\
26.54 \\
28.06 \\
29.62\end{array}$ & $\begin{array}{l}14.63 \\
15.54 \\
16.47 \\
17.44 \\
18.43\end{array}$ & $\begin{array}{l}7.04 \\
7.47 \\
7.92 \\
8.38 \\
8.86\end{array}$ & $\begin{array}{l}3.96 \\
4.20 \\
4.45 \\
4.70 \\
4.96\end{array}$ & $\begin{array}{l}25.98 \\
27.40 \\
28.84 \\
30.30 \\
31.78\end{array}$ & $\begin{array}{l}26.63 \\
28.29 \\
29.99 \\
31.74 \\
33.54\end{array}$ & $\begin{array}{l}15.97 \\
16.97 \\
18.00 \\
19.07 \\
20.16\end{array}$ \\
\hline $\begin{array}{l}21 \\
22 \\
23 \\
24 \\
25\end{array}$ & $\begin{array}{l}28.26 \\
29.48 \\
30.72 \\
31.96 \\
33.22\end{array}$ & $\begin{array}{l}31.22 \\
32.87 \\
34.56 \\
36.30 \\
38.09\end{array}$ & $\begin{array}{l}19.45 \\
20.51 \\
21.59 \\
22.71 \\
23.86\end{array}$ & $\begin{array}{r}9.35 \\
9.85 \\
10.37 \\
10.90 \\
11.46\end{array}$ & $\begin{array}{l}5.23 \\
5.51 \\
5.79 \\
6.08 \\
6.38\end{array}$ & $\begin{array}{l}33.27 \\
34.79 \\
36.33 \\
37.89 \\
39.48\end{array}$ & $\begin{array}{l}35.39 \\
37.30 \\
39.26 \\
41.29 \\
43.38\end{array}$ & $\begin{array}{l}21.29 \\
22.46 \\
23.66 \\
24.90 \\
26.18\end{array}$ \\
\hline $\begin{array}{l}26 \\
27 \\
28 \\
29 \\
30\end{array}$ & $\begin{array}{l}34.49 \\
35.77 \\
37.06 \\
38.37 \\
39.69\end{array}$ & $\begin{array}{l}39.93 \\
41.83 \\
43.79 \\
45.80 \\
47.88\end{array}$ & $\begin{array}{l}25.06 \\
26.29 \\
27.56 \\
28.87 \\
30.23\end{array}$ & $\begin{array}{l}12.02 \\
12.61 \\
13.22 \\
13.84 \\
14.49\end{array}$ & $\begin{array}{l}6.69 \\
7.01 \\
7.34 \\
7.67 \\
8.02\end{array}$ & $\begin{array}{l}41.08 \\
42.71 \\
44.36 \\
46.04 \\
47.74\end{array}$ & $\begin{array}{l}45.53 \\
47.76 \\
50.06 \\
52.43 \\
54.88\end{array}$ & $\begin{array}{l}27.50 \\
28.87 \\
30.29 \\
31.76 \\
33.27\end{array}$ \\
\hline $\begin{array}{l}31 \\
32 \\
33 \\
34 \\
35\end{array}$ & $\begin{array}{l}41.02 \\
42.37 \\
43.72 \\
45.09 \\
46.48\end{array}$ & $\begin{array}{l}50.02 \\
52.23 \\
54.51 \\
56.87 \\
59.30\end{array}$ & $\begin{array}{l}31.64 \\
33.09 \\
34.60 \\
36.17 \\
37.79\end{array}$ & $\begin{array}{l}15.16 \\
15.85 \\
16.57 \\
17.31 \\
18.08\end{array}$ & $\begin{array}{l}8.38 \\
8.75 \\
9.13 \\
9.53 \\
9.94\end{array}$ & $\begin{array}{l}49.47 \\
51.22 \\
52.99 \\
54.80 \\
56.63\end{array}$ & $\begin{array}{l}57.42 \\
60.05 \\
62.77 \\
65.59 \\
68.51\end{array}$ & $\begin{array}{l}34.85 \\
36.48 \\
38.17 \\
39.93 \\
41.76\end{array}$ \\
\hline $\begin{array}{l}36 \\
37 \\
38 \\
39 \\
40\end{array}$ & $\begin{array}{l}47.88 \\
49.29 \\
50.71 \\
52.15 \\
53.61\end{array}$ & $\begin{array}{l}61.82 \\
64.43 \\
67.12 \\
69.92 \\
72.82\end{array}$ & $\begin{array}{l}39.48 \\
41.23 \\
43.05 \\
44.94 \\
46.92\end{array}$ & $\begin{array}{l}18.88 \\
19.71 \\
20.57 \\
21.47 \\
22.40\end{array}$ & $\begin{array}{l}10.36 \\
10.80 \\
11.25 \\
11.72 \\
12.21\end{array}$ & $\begin{array}{l}58.49 \\
60.38 \\
62.30 \\
64.25 \\
66.22\end{array}$ & $\begin{array}{l}71.54 \\
74.69 \\
77.96 \\
81.37 \\
84.91\end{array}$ & $\begin{array}{l}43.66 \\
45.64 \\
47.70 \\
49.85 \\
52.09\end{array}$ \\
\hline
\end{tabular}


Table 13. (Continued)

\begin{tabular}{|c|c|c|c|c|c|c|c|c|}
\hline \multirow{2}{*}{$\begin{array}{c}\text { Fissile } \\
\text { material } \\
\mathrm{H}: \mathrm{O} \text { or } \mathrm{H}: \mathrm{Pu}\end{array}$} & \multicolumn{2}{|c|}{$\mathrm{U}(70) \mathrm{O}_{2}$} & \multirow{2}{*}{$\begin{array}{c}\sigma(50) \\
0\end{array}$} & \multicolumn{4}{|c|}{$\mathrm{U}(50) \mathrm{O}_{2}$} & \multirow{2}{*}{$\begin{array}{c}0(40) \\
0\end{array}$} \\
\hline & 10 & 20 & & 0.4 & 3 & 10 & 20 & \\
\hline $\begin{array}{c}\text { Mass } \\
\text { category }\end{array}$ & \multicolumn{8}{|c|}{ Hass of fissile materisl $(\mathrm{kg})$} \\
\hline 1 & 1.77 & 1.00 & 9.31 & 8.08 & 4.43 & 1.90 & 1.09 & 11.70 \\
\hline 2 & 2.09 & 1.18 & 10.96 & 9.55 & 5.23 & 2.25 & 1.28 & 13.80 \\
\hline 3 & 2.42 & 1.36 & 12.64 & 11.06 & 6.06 & 2.61 & 1.48 & 15.94 \\
\hline 4 & 2.75 & 1.55 & 14.36 & 12.61 & 6.90 & 2.98 & $1.69^{\circ}$ & 18.13 \\
\hline 5 & 3.10 & 1.74 & 16.11 & 14.20 & 7.78 & 3.36 & 1.90 & 20.37 \\
\hline 6 & 3.45 & 1.93 & 17.89 & 15.84 & 8.67 & 3.75 & 2.11 & 22.66 \\
\hline 7 & 3.80 & 2.13 & 19.71 & 17.52 & 9.59 & 4.15 & 2.33 & 25.00 \\
\hline 8 & 4.17 & 2.33 & 21.57 & 19.25 & 10.54 & 4.56 & 2.55 & 27.39 \\
\hline 9 & 4.55 & 2.54 & 23.46 & 21.03 & 11.51 & 4.99 & 2.78 & 29.84 \\
\hline 10 & 4.93 & 2.76 & 25.39 & 22.86 & 12.51 & 5.43 & 3.01 & 32.34 \\
\hline 11 & 5.33 & 2.97 & 27.36 & 24.75 & 13.54 & 5.88 & 3.25 & 34.91 \\
\hline 12 & 5.73 & 3.20 & 29.37 & 26.69 & 14.60 & 6.35 & 3.50 & 37.53 \\
\hline 13 & 6.15 & 3.43 & 31.42 & 28.69 & 15.70 & 6.84 & 3.75 & 40.22 \\
\hline 14 & 6.58 & 3.66 & 33.52 & 30.76 & 16.83 & 7.34 & 4.01 & 42.98 \\
\hline 15 & 7.01 & 3.90 & 35.66 & 32.89 & 17.99 & 7.85 & 4.27 & 45.80 \\
\hline 16 & 7.46 & 4.15 & 37.85 & 35.08 & 19.19 & 8.39 & 4.54 & 48.70 \\
\hline 17 & 7.93 & 4.40 & 40.08 & 37.35 & 20.43 & 8.94 & 4.82 & 51.67 \\
\hline 18 & 8.40 & 4.66 & 42.37 & 39.70 & 21.71 & 9.52 & 5.10 & 54.72 \\
\hline 19 & 8.89 & 4.92 & 44.70 & 42.12 & 23.03 & 10.11 & 5.40 & 57.84 \\
\hline 20 & 9.39 & 5.20 & 47.09 & 44.63 & 24.40 & 10.73 & 5.70 & 61.05 \\
\hline 21 & 9.91 & 5.48 & 49.53 & 47.22 & 25.81 & 11.37 & 6.00 & 64.35 \\
\hline 22 & 10.44 & 5.76 & 52.03 & 49.90 & 27.28 & 12.03 & 6.32 & 67.74 \\
\hline 23 & 10.99 & 6.06 & 54.59 & 52.69 & 28.80 & 12.73 & 6.65 & 71.21 \\
\hline 24 & 11.55 & 6.36 & 57.21 & 55.57 & 30.37 & 13.44 & 6.98 & 74.79 \\
\hline 25 & 12.13 & 6.68 & 59.88 & 58.56 & 32.00 & 14.19 & 7.33 & 78.47 \\
\hline $\begin{array}{l}26 \\
27\end{array}$ & $\begin{array}{l}12.73 \\
13.35\end{array}$ & $\begin{array}{l}7.00 \\
7.33\end{array}$ & $\begin{array}{l}62.63 \\
65.44\end{array}$ & $\begin{array}{l}61.67 \\
64.89\end{array}$ & $\begin{array}{l}33.69 \\
35.45\end{array}$ & $\begin{array}{l}14.97 \\
15.79\end{array}$ & $\begin{array}{l}7.68 \\
8.05\end{array}$ & $\begin{array}{l}82.25 \\
86.15\end{array}$ \\
\hline 28 & 13.99 & 7.67 & 68.32 & 68.25 & 37.28 & 16.64 & $8: 42$ & 90.16 \\
\hline 29 & 14.65 & 8.02 & 71.28 & 71.74 & 39.18 & 17.52 & 8.81 & 94.29 \\
\hline 30 & 15.33 & 8.38 & 74.31 & 75.38 & 41.16 & 18.45 & 9.21 & 98.55 \\
\hline 31 & 16.03 & 8.75 & 77.41 & 79.16 & 43.22 & 19.42 & 9.63 & 102.94 \\
\hline 32 & 16.76 & 9.13 & 80.60 & 83.11 & 45.37 & 20.44 & 10.05 & 107.47 \\
\hline 33 & 17.51 & 9.53 & 83.87 & 87.24 & 47.61 & 21.50 & 10.49 & 112.14 \\
\hline 34 & 18.29 & 9.94 & 87.23 & 91.55 & 49.96 & 22.62 & 10.95 & 116.97 \\
\hline 35 & 19.10 & 10.36 & 90.69 & 96.06 & 52.41 & 23.80 & 11.42 & 121.96 \\
\hline 36 & 19.94 & 10.80 & 94.23 & 100.78 & 54.97 & 25.04 & 11.90 & 127.11 \\
\hline 37 & 20.81 & 11.25 & 97.88 & 105.73 & 57.66 & 26.35 & 12.40 & 132.44 \\
\hline 38 & 21.71 & $11.71^{\circ}$ & 101.63 & 110.99 & 60.48 & 27.73 & 12.93 & $13 \% .96$ \\
\hline 39 & 22.65 & 12.20 & 105.48 & 116.38 & 63.44 & 29.19 & 13.47 & 143.67 \\
\hline 40 & 23.62 & 12.69 & 109.45 & 122.13 & 66.56 & 30.74 & 14.02 & 149.59 \\
\hline
\end{tabular}


Tab1e 13. (Continued)

\begin{tabular}{|c|c|c|c|c|c|c|c|}
\hline \multirow{2}{*}{$\begin{array}{l}\text { Fissile } \\
\text { material }\end{array}$} & \multirow{3}{*}{$\begin{array}{c}\mathrm{u}(30) \\
0\end{array}$} & \multirow{2}{*}{\multicolumn{4}{|c|}{$\mathrm{U}(30) \mathrm{O}_{2}$}} & \multirow{3}{*}{$\begin{array}{c}\mathrm{U}(10) \\
0\end{array}$} & \multirow{3}{*}{$\begin{array}{r}\text { Metal } \\
\delta(93.2) \\
+10 \quad \% t g \text {. }\end{array}$} \\
\hline & & & & & & & \\
\hline $\mathbf{H}: \mathrm{U}$ or $\mathrm{H}: \mathrm{Pu}$ & & 0.4 & 3 & 10 & 20 & & \\
\hline $\begin{array}{c}\text { Mass } \\
\text { category }\end{array}$ & \multicolumn{6}{|c|}{ llass of fissile material ( $\mathrm{kg})$} & \\
\hline 1 & 14.77 & 12.29 & 5.97 & 2.26 & 1.22 & 47.35 & 6.01 \\
\hline 2 & 17.46 & 14.55 & 7.05 & 2.67 & 1.44 & 56.25 & 7.05 \\
\hline 3 & 20.22 & 16.88 & 8.17 & 3.09 & 1.67 & 65.47 & 8.10 \\
\hline 4 & 23.05 & 19.28 & 9.31 & 3.52 & 1.90 & 75.05 & 9.15 \\
\hline 5 & 25.96 & 21.75 & 10.48 & 3.97 & 2.13 & 85.00 & 10.22 \\
\hline 6. & 28.95 & 24.30 & 11.69 & 4.42 & 2.37 & 95.34 & 11.30 \\
\hline 7 & 32.03 & 26.93 & 12.93 & 4.89 & 2.62 & 106.10 & 12.38 \\
\hline 8 & 35.19 & 29.65 & 14.20 & 5.37 & 2.87 & 117.29 & 13.48 \\
\hline 9 & 38.44 & 32.46 & 15.51 & 5.86 & 3.13 & 128.96 & 14.59 \\
\hline 10 & 41.79 & 35.36 & 16.86 & 6.36 & 3.40 & 141.12 & 15.71 \\
\hline 11 & 45.24 & 38.36 & 18.25 & 6.88 & 3.67 & 153.81 & 16.85 \\
\hline 12 & 48.79 & 41.47 & 19.67 & 7.42 & 3.95 & 167.07 & 17.29 \\
\hline 13 & 52.45 & 44.68 & 21.14 & 7.97 & 4.23 & 180.93 & 19.14 \\
\hline 14 & 56.22 & 48.01 & 22.66 & 8.53 & 4.53 & 195.45 & 20.31 \\
\hline 15 & 60.11 & 51.47 & 24.22 & 9.12 & 4.83 & 210.65 & 21.49 \\
\hline 16 & 64.13 & 55.05 & 25.83 & 9.72 & 5.14 & 226.60 & 22.68 \\
\hline 17 & 68.28 & 58.77 & 27.50 & 10.34 & 5.45 & 243.35 & 23.89 \\
\hline 18 & 72.56 & 62.63 & 29.22 & 10.98 & 5.78 & 260.97 & 25.10 \\
\hline 19 & 76.99 & 66.64 & 30.99 & 11.64 & 6.11 & 279.51 & 26.33 \\
\hline 20 & 81.57 & 70.82 & 32.82 & 12.32 & 6.46 & 299.07 & 27.57 \\
\hline 21 & 86.31 & 75.17 & 34.72 & 13.02 & 6.81 & 319.71 & 28.83 \\
\hline 22 & 91.22 & 79.70 & 36.68 & 13.75 & 7.18 & 341.54 & 30.10 \\
\hline 23 & 96.30 & 84.42 & 38.72 & 14.50 & 7.55 & 364.66 & 31.38 \\
\hline 24 & 101.58 & 89.36 & 40.82 & 15.27 & 7.94 & 389.19 & 32.68 \\
\hline 25 & 107.04 & 94.51 & 43.01 & 16.08 & 8.34 & 41.5 .26 & 33.99 \\
\hline 26 & 112.72 & 99.90 & 45.27 & 16.91 & 8.75 & 443.03 & 35.31 \\
\hline 27 & 118.62 & 105.55 & 47.62 & 17.78 & 9.17 & 472.65 & 36.65 \\
\hline 28 & 124.75 & 111.46 & 50.07 & 18.67 & 9.61 & 504.33 & 38.00 \\
\hline 29 & 131.13 & 117.67 & 52.61 & 19.60 & 10.06 & 538.29 & 39.37 \\
\hline 30 & 137.78 & 124.19 & 55.25 & 20.57 & 10.52 & 574.78 & 40.76 \\
\hline 31 & 144.70 & 131.05 & 58.00 & 21.57 & 11.00 & 614.09 & 42.16 \\
\hline 32 & 151.92 & 138.27 & 60.87 & 22.61 & 11.50 & 656.58 & 43.57 \\
\hline 33 & 159.46 & 145.89 & 63.86 & 23.70 & 12.01 & 702.63 & 45.00 \\
\hline 34 & 167.34 & 153.93 & 66.98 & 24.83 & 12.54 & 752.71 & 46.45 \\
\hline 35 & 175.59 & 162.44 & 70.24 & 26.01 & 13.09 & 807.39 & 47.92 \\
\hline 36 & 184.22 & 171.46 & 73.66 & 27.24 & 13.67 & 867.31 & 49.40 \\
\hline 37 & 193.27 & 181.03 & 77.23 & 28.52 & 14.26 & 933.28 & 50.90 \\
\hline 38 & 202.76 & 191.21 & 80.98 & 29.87 & 14.87 & 1006.26 & 52.41 \\
\hline 39 & 212.74 & 202.05 & 84.91 & 31.27 & 15.51 & 1087.43 & 53.95 \\
\hline 40 & 223.23 & 213.62 & 89.04 & 32.75 & 16.17 & 1178.25 & 55.50 \\
\hline
\end{tabular}


Table 13. (Continued)

\begin{tabular}{|c|c|c|c|c|c|c|c|c|}
\hline \multirow{2}{*}{$\begin{array}{c}\text { Fissile } \\
\text { material } \\
\text { H:D or H:Pu }\end{array}$} & \multirow{2}{*}{$\begin{array}{c}\mathrm{Pa}(100)^{\mathrm{b}} \\
0\end{array}$} & \multicolumn{4}{|c|}{$\mathrm{Pn}(100) \mathrm{O}_{2}$} & \multirow{2}{*}{$\begin{array}{c}\mathrm{Pu}(94.5) \\
0\end{array}$} & \multicolumn{2}{|c|}{$\mathrm{Pn}(94.5) \mathrm{O}_{2}$} \\
\hline & & $0 \overline{0.4}$ & 3 & 10 & 20 & & 0.4 & 3 \\
\hline \multicolumn{9}{|l|}{ Mass } \\
\hline 1 & 2.29 & 2.55 & 2.04 & 1.26 & 0.81 & 2.29 & 2.71 & 2.30 \\
\hline 2 & 2.61 & 2.99 & 2.39 & 1.48 & 0.95 & 2.61 & 3.16 & 2.70 \\
\hline 3 & 2.92 & 3.42 & 2.75 & 1.71 & 1.09 & 2.93 & 3.62 & 3.11 . \\
\hline 4 & 3.22 & 3.86 & 3.12 & 1.94 & 1.24 & 3.23 & 4.08 & 3.52 \\
\hline 5 & 3.50 & 4.30 & 3.49 & 2.17 & 1.40 & 3.52 & 4.55 & 3.94 \\
\hline 6 & 3.77 & 4.74 & 3.87 & 2.41 & 1.55 & 3.79 & 5.01 & 4.37 \\
\hline 7 & 4.03 & 5.18 & 4.25 & 2.65 & 1.71 & 4.06 & 5.48 & 4.80 \\
\hline 8 & 4.28 & 5.63 & 4.64 & 2.90 & 1.87 & 4.32 & 5.95 & 5.24 \\
\hline 9 & 4.52 & 6.07 & 5.03 & 3.15 & 2.03 & 4.57 & 6.42 & 5.69 \\
\hline 10 & 4.75 & 6.52 & 5.43 & 3.40 & 2.20 & 4.81 & 6.89 & 6.14 \\
\hline 11 & 4.97 & 6.97 & 5.83 & 3.67 & 2.37 & 5.04 & 7.37 & 6.60 \\
\hline 12 & 5.19 & 7.42 & 6.24 & 3.93 & 2.55 & 5.26 & 7.85 & 7.06 \\
\hline 13 & 5.40 & 7.88 & 6.66 & 4.20 & 2.73 & 5.47 & 8.33 & 7.54 \\
\hline 14 & 5.60 & 8.34 & 7.08 & 4.48 & 2.91 & 5.68 & 8.81 & 8.02 \\
\hline 15 & 5.79 & 8.80 & 7.51 & 4.76 & 3.09 & 5.88 & 9.29 & 8.50 \\
\hline 16 & 5.97 & 9.26 & 7.95 & 5.05 & 3.29 & 6.08 & 9.78 & 9.00 \\
\hline 17 & 6.15 & 9.72 & 8.39 & 5.34 & 3.48 & 6.27 & 10.26 & 9.50 \\
\hline 18 & 6.33 & 10.19 & 8.84 & 5.64 & 3.68 & 6.45 & 10.75 & 10.02 \\
\hline 19 & 6.49 & 10.66 & 9.30 & 5.94 & 3.88 & 6.63 & 11.25 & 10.54 \\
\hline 20 & 6.66 & 11.13 & 9.77 & 6.26 & 4.09 & 6.80 & 11.74 & 11.07 \\
\hline 21 & 6.82 & 11.60 & 10.24 & 6.57 & 4.31 & 6.97 & 12.24 & 11.60 \\
\hline 22 & 6.97 & 12.07 & 10.72 & 6.90 & 4.52 & 7.13 & 12.73 & 12,15 \\
\hline 23 & 7.12 & 12.55 & 11.20 & 7.23 & 4.75 & 7.28 & 13.23 & 12.71 \\
\hline 24 & 7.26 & 13.03 & 11.70 & 7.57 & 4.98 & 7.44 & 13.74 & 13.27 \\
\hline 25 & 7.40 & 13.51 & 12.20 & 7.91 & 5.21 & 7.59 & 14.24 & 13.85 \\
\hline 26 & 7.53 & 14.00 & 12.72 & 8.26 & 5.45 & 7.73 & 14.75 & 14.43 \\
\hline 27 & 7.67 & 14.48 & 13.24 & 8.62 & 5.70 & 7.87 & 15.26 & 15.03 \\
\hline 28 & 7.79 & 14.97 & 13.77 & 8.99 & 5.95 & 8.01 & 15.77 & 15.63 \\
\hline 29 & 7.92 & 15.46 & 14.30 & 9.37 & 6.21 & 8.14 & 16.28 & 16.25 \\
\hline 30 & 8.04 & 15.96 & 14.85 & 9.75 & 6.48 & 8.27 & 16.80 & 16.87 \\
\hline 31 & 8.16 & 16.45 & .15 .41 & 10.15 & 6.75 & 8.40 & 17.32 & 17.51 \\
\hline 32 & 8.27 & 16.95 & 15.98 & 10.55 & 7.03 & 8.52 & 17.84 & 18.16 \\
\hline 33 & 8.38 & 17.45 & 16.55 & 10.97 & 7.32 & 8.64 & 18.36 & 18.82 \\
\hline 34 & 8.49 & 17.96 & 17.14 & 11.39 & 7.61 & 8.75 & 18.89 & 19.50 \\
\hline 35 & 8.60 & 18.46 & 17.74 & 11.82 & 7.92 & 8.87 & 19.41 & 20.18 \\
\hline 36 & 8.70 & 18.97 & 18.35 & 12.27 & 8.23 & 8.98 & 19.94 & 20.88 \\
\hline 37 & 8.80 & 19.48 & 18.97 & 12.72 & 8.55 & 9.09 & 20.48 & 21.60 \\
\hline 38 & 8.90 & 20,00 & 19.60 & 13.19 & 8.88 & 9.19 & 21.01 & 22.32 \\
\hline 39 & 8.99 & 20.51 & 20.24 & 13.66 & 9.23 & 9.30 & 21.55 & 23.06 \\
\hline 40 & 9.09 & 21.03 & 20.90 & 14.15 & 9.58 & 9.40 & 22.09 & 23.82 \\
\hline
\end{tabular}


Table 13. (Continued)

\begin{tabular}{|c|c|c|c|c|c|c|c|c|}
\hline $\begin{array}{l}\text { Fissile } \\
\text { material }\end{array}$ & $\mathrm{Pu}(94.5) 0$ & \multirow{2}{*}{$\begin{array}{c}\mathrm{Pu}(80) \\
0\end{array}$} & \multicolumn{3}{|c|}{$\mathrm{Pu}(80) \mathrm{O}_{2}$} & \multirow{2}{*}{$\begin{array}{c}2300 \\
0\end{array}$} & \multicolumn{2}{|c|}{$233 \mathrm{JO}_{2}$} \\
\hline $\mathrm{H}: \mathrm{U}$ or $\mathrm{H}: \mathrm{Pu}$ & 10 & & $\overline{0.4}$ & 3 & 10 & & $\overline{0.4}$ & 3 \\
\hline $\begin{array}{c}\text { Mass } \\
\text { category }\end{array}$ & & & Mass of & fissile & materis & $(\mathrm{kg})$ & & \\
\hline 1 & 1.53 & 2.65 & 3.06 & 2.78 & 2.13 & 2.50 & 2.62 & 1.92 \\
\hline 2 & 1.80 & 3.02 & 3.57 & 3.28 & 2.52 & 2.89 & 3.08 & 2.26 \\
\hline 3 & 2.08 & 3.38 & 4.10 & 3.77 & 2.91 & 3.28 & 3.54 & 2.61 \\
\hline 4 & 2.36 & 3.73 & 4.62 & 4.28 & 3.32 & 3.65 & 4.01 & 2.96 \\
\hline 5 & 2.66 & 4.06 & 5.14 & 4.79 & 3.73 & 4.02 & 4.48 & 3.32 \\
\hline 6 & $\begin{array}{l}2.95 \\
3.26\end{array}$ & $\begin{array}{l}4.37 \\
4.68\end{array}$ & $\begin{array}{l}5.67 \\
6.20\end{array}$ & $\begin{array}{l}5.32 \\
5.85\end{array}$ & $\begin{array}{r}4.15 \\
4.59\end{array}$ & $\begin{array}{l}4.38 \\
4.74\end{array}$ & $\begin{array}{l}4.96 \\
5.44\end{array}$ & $\begin{array}{l}3.69 \\
4.06\end{array}$ \\
\hline $\begin{array}{l}7 \\
8\end{array}$ & $\begin{array}{l}3.26 \\
3.57\end{array}$ & $\begin{array}{l}4.68 \\
4.97\end{array}$ & $\begin{array}{l}6.20 \\
6.74\end{array}$ & $\begin{array}{l}5.85 \\
6.39\end{array}$ & $\begin{array}{l}4.59 \\
5.04\end{array}$ & $\begin{array}{l}4.74 \\
5.09\end{array}$ & $\begin{array}{l}5.44 \\
5: 93\end{array}$ & $\begin{array}{l}4.00 \\
4.44\end{array}$ \\
\hline 9 & 3.88 & 5.25 & 7.27 & 6.94 & 5.49 & 5.43 & 6.43 & 4.83 \\
\hline 10 & 4.21 & 5.52 & 7.81 & 7.50 & 5.97 & 5.77 & 6.93 & 5.22 \\
\hline 11 & 4.54 & 5.78 & 8.35 & 8.07 & 6.45 & 6.10 & 7.44 & 5.62 \\
\hline 12 & 4.88 & 6.04 & 8.90 & 8.64 & 6.94 & 6.42 & 7.95 & 6.03 \\
\hline 13 & 5.23 & 6.28 & 9.44 & 9.23 & 7.46 & 6.74 & 8.48 & 6.45 \\
\hline 14 & 5.58 & 6.51 & 9.99 & 9.83 & 7.98 & 7.06 & 9.01 & 6.88 \\
\hline 15 & 5.95 & 6.74 & 10.55 & 10.44 & 8.52 & 7.37 & 9.54 & 7.31 \\
\hline 16 & 6.32 & 6.96 & 11.10 & 11.06 & 9.07 & 7.67 & 10.08 & 7.75 \\
\hline 17 & 6.70 & 7.17 & 11.66 & 11.69 & 9.64 & 7.97 & 10.63 & 8.21 \\
\hline 18 & 7.09 & 7.38 & 12.22 & 12.34 & 10.23 & 8.26 & 11.19 & 8.67 \\
\hline 19 & 7.49 & 7.58 & 12.78 & 12.99 & 10.84 & 8.55 & 11.75 & 9.14 \\
\hline 20 & 7.91 & 7.77 & 13.35 & 13.66 & 11.46 & 8.84 & 12.33 & 9.63 \\
\hline 21 & 8.33 & 7.96 & 13.92 & 14.34 & 12.11 & 9.12 & 12.91 & 10.12 \\
\hline 22 & 8.76 & 8.14 & 14.49 & 15.03 & 12.77 & 9.39 & 13.49 & 10.62 \\
\hline 23 & 9.21 & 8.31 & 15.06 & 15.74 & 13.46 & 9.66 & 14.09 & 11.14 \\
\hline 24 & 9.66 & 8.48 & 15.64 & 16.46 & 14.16 & 9.93 & 14.69 & 11.66 \\
\hline 25 & 10.13 & 8.65 & 16.22 & 17.19 & $14: 90$ & 10.19 & 15.31 & 12.20 \\
\hline 26 & 10.61 & 8.81 & 16.81 & 17.94 & 15.65 & 10.45 & 15.93 & 12.75 \\
\hline 27 & 11.11 & 8.97 & 17.39 & 18.71 & 16.43 & 10.70 & 16.56 & 13.31 \\
\hline 28 & 11.62 & 9.12 & 17.98 & 19.48 & 17.24 & 10.96 & 17.20 & 13.89 \\
\hline 29 & 12.14 & 9.27 & 18.58 & 20.28 & 18.08 & 11.20 & 17.84 & 14.48 \\
\hline 30 & 12.68 & 9.41 & 19.17 & 21.09 & 18.95 & 11.45 & 18.50 & 15.08 \\
\hline 31 & 13.24 & 9.55 & 19.77 & 21.92 & 19.85 & 11.69 & 19.17 & 15.70 \\
\hline 32 & 13.81 & 9.69 & 20.37 & 22.76 & 20.78 & 11.92 & 19.84 & 16.33 \\
\hline 33 & 14.40 & 9.82 & 20.98 & 23.63 & 21.75 & 12.15 & 20.53 & 16.98 \\
\hline 34 & 15.05 & 9.95 & 21.59 & 24.51 & 22.76 & 12.38 & 21.23 & 17.65 \\
\hline 35 & 15.64 & 10.08 & 22.20 & 25.41 & 23.80 & 12.61 & 21.93 & 18.33 \\
\hline 36 & 16.28 & 10.20 & 22.82 & 26.33 & 24.89 & 12.83 & 22.65 & 19.03 \\
\hline 37 & 16.95 & 10.32 & 23.43 & 27.27 & 26.03 & 13.05 & 23.38 & 19.74 \\
\hline 38 & 17.64 & 10.44 & 24.06 & 28.23 & 27.21 & 13.27 & 24.12 & 20.48 \\
\hline 39 & 18.35 & 10.55 & 24.68 & 29.22 & 28.44 & 13.48 & 24.87 & 21.24 \\
\hline 40 & 19.09 & 10.66 & 25.31 & 30.22 & 29.73 & 13.69 & 25.63 & 22.01 \\
\hline
\end{tabular}


Table 13. (Continued)

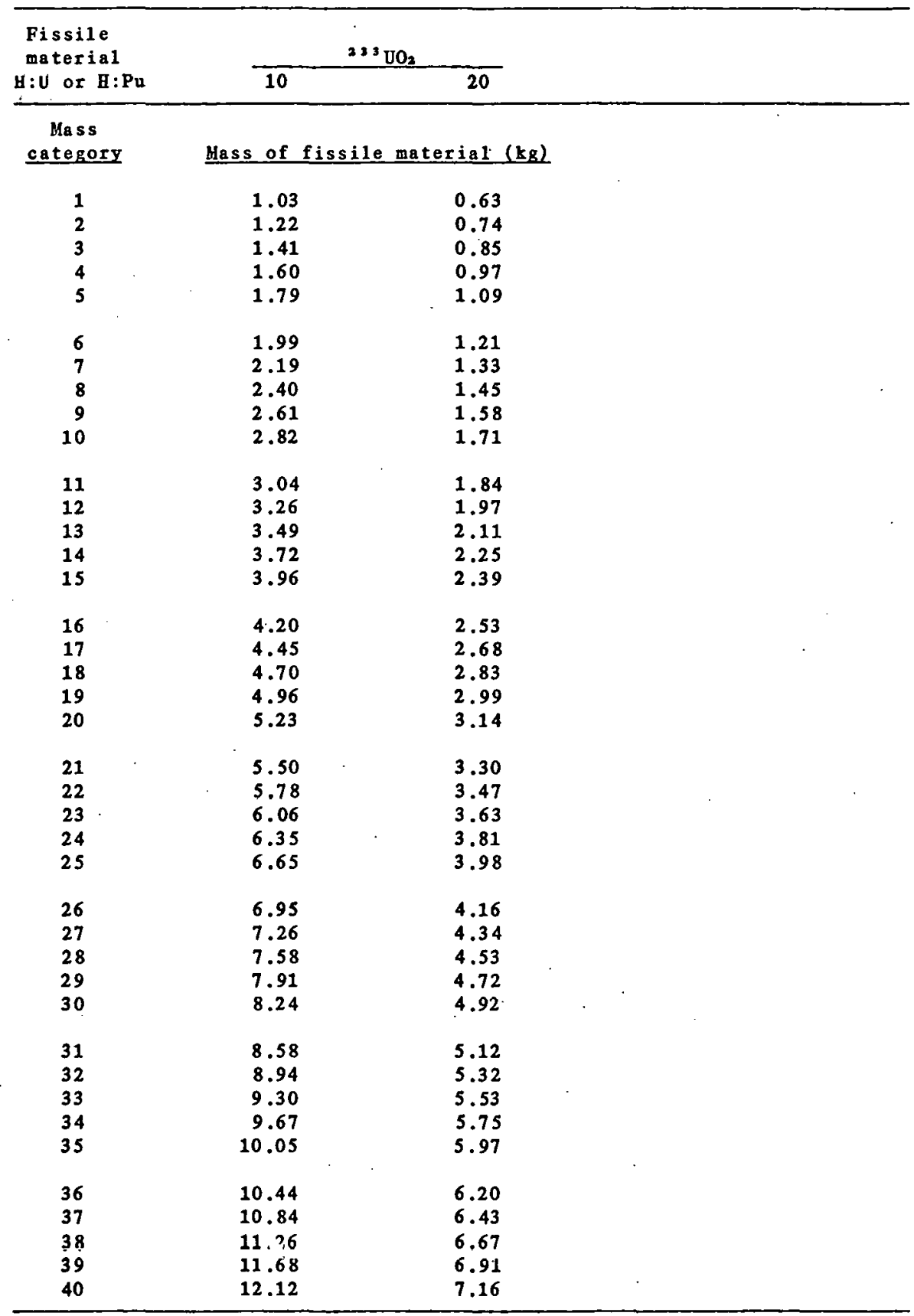

${ }^{a}$ Total aranium or total platonium.

${ }^{b}$ Kad Pu(x) as x wt \% 239 Pu. 
with a particular mass category and cell volume by introducing an index to label a cell which will depend only on its content. This is accomplished by a simple normalization. Since for each mass category in Table 13 there is a unique $N$ for a chosen $d_{n}$, we may associate with these a Criticality Index (CI) defined by the following relation,

$$
C I\left(d_{n}\right)=\frac{100}{N}
$$

In an arbitrary assemblage of cells containing units from the mass categories of Table 13, criticality will occur when the array is cubic or near cubic, reflected by water, and the CI of the individual cells sum to 100. A tabulation of CI values determined for selected ce11 volumes (or $d_{n}$ ) suitable for the mass categories of Table 13 is given in Table 14. The use of Table 13 is dependent on neutrons being returned to the array no more effectively than the water reflector condition on which the data in the table were established. It should be remarked that it is possible to generate a table of mass categories suitable to the reflector condition evaluated for a particular environment.

Tables 13 and 14 are applicable to arrays having noncubic ce11s with the volumes (i.e., $d_{n}^{3}=V$ ) corresponding to the tabulated values. The previous discussion of the influence of noncubic cells on the array k-eff would indicate that some configurations having an aggregate CI of 100 would result in cuboidal arrays which would be slightly subcritical. It is unlikely any would result in supercriticality, provided the caution concerning maintaining a minimum unit surface separation is observed. The tables may also be augmented to inclide units of nonspherical shapes. For example, criticality data for cylindrical units 
Tablo 14. Value of criticality indicator assigaed to a coll tn exitical water refleoted cable arrays as a function of mass category of fissile materials

\begin{tabular}{|c|c|c|c|c|c|c|c|c|c|c|c|}
\hline \multirow{2}{*}{$\begin{array}{c}\text { Mass } \\
\text { Gategory }\end{array}$} & \multicolumn{11}{|c|}{ Ce11 volume in litors } \\
\hline & 55.31 & 67.12 & 80.51 & 95.57 & 112.40 & 131.10 & 151.76 & 174.49 & 199.38 & 226.53 & 256.05 \\
\hline 1 & $1.0265 \mathrm{E}-02$ & $7.0100 \mathrm{E}-03$ & $4.8947 \mathrm{E}-03$ & $3.4862 \mathrm{E}-03$ & $2.5277 \mathrm{E}-03$ & $1.8625 \mathrm{E}-03$ & $1.3925 \mathrm{E}-03$ & $1.0550 \mathrm{E}-03$ & $8.0913 E-04$ & $6.2749 \mathrm{E}-04$ & $4.9164 \mathrm{E}-04$ \\
\hline 2 & $\because .7159 \mathrm{E}-02$ & $1.1738 \mathrm{E}-02$ & $8.2066 \mathrm{E}-03$ & $3.8513 \mathrm{E}-03$ & $4.2462 \mathrm{E}-03$ & $3.1309 \mathrm{E}-03$ & $2.3421 \mathrm{E}-03$ & $1.7754 \mathrm{E}-03$ & $1.3621 \mathrm{E}-03$ & $1.0567 \mathrm{E}-03$ & $8.2815 \mathrm{SE}-04$ \\
\hline 3 & $2.6964 \mathrm{E}-02$ & $1.8480 \mathrm{E}-02$ & $1.2940 \mathrm{E}-02$ & $9.2369 \mathrm{E}-03$ & $6.7094 \mathrm{E}-03$ & $4.9509 \mathrm{E}-03$ & $3.7061 \mathrm{E}-03$ & $2.8108 \mathrm{E}-03$ & $2.1574 \mathrm{E}-03$ & $1.6743 \mathrm{E}-03$ & $1.3126 \mathrm{E}-03$ \\
\hline 4 & $\$ .0421 E-02$ & $2.7760 \mathrm{E}-02$ & $1.9410 \mathrm{E}-02$ & $1.3916 \mathrm{E}-02$ & $1.0119 \mathrm{E}-02$ & $7.4735 \mathrm{E}-03$ & $5.5984 \mathrm{E}-03$ & $4.2484 \mathrm{E}-03$ & $3.2626 \mathrm{E}-03$ & $2.5330 \mathrm{E}-03$ & $1.9865 \mathrm{E}-03$ \\
\hline 5 & S.83 83E-02 & $4.0187 \mathrm{E}-02$ & $2.82 .36 \mathrm{E}-02$ & $2.0212 \mathrm{E}-02$ & $1.4714 \mathrm{E}-02$ & $1.0877 \mathrm{E}-02$ & $8.1546 \mathrm{E}-03$ & $6.1924 \mathrm{E}-03$ & $4.7580 \mathrm{E}-03$ & $3.6957 \mathrm{E}-03$ & $2.8995 \mathrm{E}-03$ \\
\hline 6 & $3.1833 E-02$ & $5.6467 \mathrm{E}-02$ & $3.9753 \mathrm{E}-02$ & $2.8501 \mathrm{E}-02$ & $2.0775 \mathrm{E}-02$ & $1.5374 \mathrm{E}-02$ & $1.1536 \mathrm{E}-02$ & $8.7662 \mathrm{E}-03$ & $6.7397 \mathrm{E}-03$ & $5.2377 \mathrm{E}-03$ & $4.1111 \mathrm{E}-03$ \\
\hline 7 & $1.1190 \mathrm{E}-01$ & $7.7418 \mathrm{E}-02$ & $3.4619 \mathrm{E}-02$ & $3.9226 \mathrm{E}-02$ & $2.8633 \mathrm{E}-02$ & $2.1213 \mathrm{E}-02$ & $1.5932 \mathrm{E}-02$ & $1.2117 \mathrm{E}-02$ & $9.3219 \mathrm{E}-03$ & $7.2485 \mathrm{E}-03$ & $3.6921 \mathrm{E}-03$ \\
\hline 8 & L.4986E-01 & $1.0398 \mathrm{E}-01$ & $7.3528 \mathrm{E}-02$ & $5.2905 \mathrm{E}-02$ & $3.8676 \mathrm{E}-02$ & $2.8690 \mathrm{E}-02$ & $2.1570 \mathrm{E}-02$ & $1.6419 \mathrm{~g}-02$ & $1.2641 \mathrm{E}-02$ & $9.8352 \mathrm{E}-03$ & $7.7274 \mathrm{E}-03$ \\
\hline 9 & $1.9718 \mathrm{E}-01$ & $1.3724 \mathrm{E}-01$ & $9.72 \mathrm{BgE}-02$ & $7.0142 \mathrm{~g}-02$ & $5.1362 \mathrm{E}-02$ & $3.8153 \mathrm{E}-02$ & $2.8717 \mathrm{E}-02$ & $2.1879 \mathrm{E}-02$ & $1.6858 \mathrm{E}-02$ & $1.3125 \mathrm{E}-02$ & $1.0318 \mathrm{E}-02$ \\
\hline 10 & $2.5554 \mathrm{E}-01$ & $1.7845 \mathrm{E}-01$ & $1.2684 \mathrm{E}-01$ & $9.1643 \mathrm{E}-02$ & $6.7226 \mathrm{E}-02$ & $5.0010 \mathrm{E}-02$ & $3.7687 \mathrm{E}-02$ & $2.8743 \mathrm{E}-02$ & $2.2166 \mathrm{E}-02$ & $1.7271 \mathrm{E}-02$ & $1.3586 \mathrm{E}-02$ \\
\hline 11 & $3.2682 E-01$ & $2.2902 \mathrm{E}-01$ & $1.6325 \mathrm{E}-01$ & $1.1823 \mathrm{E}-01$ & $8.6895 E-02$ & $6.4745 \mathrm{E}-02$ & $4.8856 \mathrm{E}-02$ & $3.7303 \mathrm{E}-02$ & $2.8794 \mathrm{E}-02$ & $2.2453 \mathrm{E}-02$ & $1.7674 \mathrm{E}-02$ \\
\hline 12 & $4.1317 \mathrm{E}-01$ & $2.9061 \mathrm{E}-01$ & $2.0778 \mathrm{E}-01$ & $1.5086 \mathrm{E}-01$ & $1.1110 \mathrm{E}-01$ & $8.2925 \mathrm{E}-02$ & $6.2665 \mathrm{E}-02$ & $4.7904 \mathrm{E}-02$ & $3.7015 \mathrm{E}-02$ & $2.8889 \varepsilon-02$ & $2.2757 \mathrm{E}-02$ \\
\hline 13 & $5.1701 \mathrm{E}-01$ & $3.6509 \mathrm{E}-01$ & $2.6188 \mathrm{E}-01$ & $1.9064 \mathrm{E}-01$ & $1.4072 \mathrm{E}-01$ & $1.0522 \mathrm{E}-01$ & $7.9636 \mathrm{E}-02$ & $6.0957 \mathrm{E}-02$ & $4.7153 \mathrm{E}-02$ & $3.6835 \mathrm{E}-02$ & $2.9041 \mathrm{E}-02$ \\
\hline 14 & $6.4107 \mathrm{E}-01$ & $4.5459 \mathrm{E}-01$ & 3.2720E-01 & $2.3887 \mathrm{E}-01$ & $1.7674 \mathrm{E}-01$ & $1.3242 \mathrm{E}-01$ & $1.0039 \mathrm{E}-01$ & $7.6949 \mathrm{E}-02$ & $5.9595 \mathrm{E}-02$ & $4.6603 \mathrm{E}-02$ & $3.6773 \mathrm{E}-02$ \\
\hline 15 & $7.8843 \mathrm{E}-01$ & $5.6155 \mathrm{E}-01$ & $4.0567 \mathrm{E}-01$ & $2.9706 \mathrm{E}-01$ & $2.2034 \mathrm{E}-01$ & $1.6544 \mathrm{E}-01$ & $1.2565 \mathrm{E}-01$ & $9.6460 \mathrm{E}-02$ & $7.4803 \mathrm{E}-02$ & $5.8560 \mathrm{E}-02$ & $4.6253 \mathrm{E}-02$ \\
\hline 16 & $9.6258 \mathrm{E}-01$ & $6.8876 \mathrm{E}-01$ & $4.9949 \mathrm{E}-01$ & $3.6694 E-01$ & $2.7292 \mathrm{E}-01$ & $2.0539 \mathrm{E}-01$ & $1.3629 \mathrm{E}-01$ & $1.2018 \mathrm{E}-01$ & $9.3327 \mathrm{E}-02$ & $7.3149 \mathrm{E}-02$ & $5.7835 \mathrm{E}-02$ \\
\hline 17 & $1.1674 E+00$ & $8.3939 \mathrm{E}-01$ & $6.1122 \mathrm{E}-01$ & $4.5057 \mathrm{E}-01$ & $3.3609 \mathrm{E}-01$ & $2.5354 \mathrm{E}-01$ & $1.9333 \mathrm{E}-01$ & $1.4893 \mathrm{E}-01$ & $1.1583 \mathrm{E}-01$ & $9.0902 \mathrm{E}-02$ & $7.1952 \mathrm{E}-02$ \\
\hline 18 & $1.4073 \Xi+00$ & $1.0171 \mathrm{E}+00$ & $7.4377 \mathrm{E}-01$ & $5.5028 \mathrm{E}-01$ & $4.1173 \mathrm{E}-01$ & $3.1142 \mathrm{E}-01$ & $2.3800 \mathrm{E}-01$ & $1.8368 \mathrm{E}-01$ & $1.4309 \mathrm{E}-01$ & $1.1246 \mathrm{E}-02$ & $8.9121 \mathrm{E}-02$ \\
\hline 19 & $1.6873 \Xi+00$ & $1.2259 \mathrm{E}+00$ & $9.0 C 548-01$ & $6.6883 \mathrm{E}-01$ & $5.0208 \mathrm{E}-01$ & $3.8082 \mathrm{E}-01$ & $2.9173 \mathrm{E}-01$ & $2.2561 \mathrm{~B}-01$ & $1.7606 \mathrm{E}-01$ & $1.3858 \mathrm{E}-01$ & $1.0997 \mathrm{~B}-01$ \\
\hline 20 & & $1.4705 \mathrm{E}+00$ & $1.0854 \mathrm{E}+00$ & $8.0940 \mathrm{E}-01$ & $6.0972 \mathrm{E}-01$ & $4.6384 E-01$ & $3.5624 \mathrm{E}-01$ & $2.7611 \mathrm{E}-01$ & $2.1588 \mathrm{E}-01$ & $1.7020 \mathrm{E}-01$ & $1.3525 \mathrm{E}-01$ \\
\hline 21 & & & $1.3628 \mathrm{E}+00$ & $9.7570 \mathrm{E}-01$ & $7.3771 \mathrm{~B}-01$ & $3.6300 \mathrm{E}-01$ & $4.3358 \mathrm{~B}-01$ & $3.3685 \mathrm{E}-01$ & $2.6391 \mathrm{E}-01$ & $2.0844 \mathrm{E}-01$ & $1.6589 \mathrm{E}-01$ \\
\hline 22 & & & $1.3579 E+00$ & $1.1720 \mathrm{E}+00$ & 8.B963E-01 & $6.8124 \mathrm{E}-01$ & $5.2618 \mathrm{E}-01$ & $4.0983 \mathrm{E}-01$ & $3.2179 \mathrm{E}-01$ & $2.5464 \mathrm{E}-01$ & $2.0301 \mathrm{E}-01$ \\
\hline 23 & & & & $1.4034 \mathrm{E}+00$ & $1.0697 \mathrm{E}+00$ & $8.2208 \mathrm{E}-01$ & $6.3695 \mathrm{E}-01$ & $4.9746 \mathrm{E}-01$ & $3.9153 \mathrm{E}-01$ & $3.1047 \mathrm{E}-01$ & $2.4796 \mathrm{E}-01$ \\
\hline 24 & & & & & $1.2828 \mathrm{E}+00$ & $9.8966 \mathrm{E}-01$ & $7.6936 \mathrm{E}-01$ & $6.0263 \mathrm{E}-01$ & $4.7552 \mathrm{E}-01$ & $3.7791 \mathrm{E}-01$ & $3.0243 \mathrm{E}-01$ \\
\hline 25 & & & & & $1.5349 \mathrm{E}+00$ & $1.1889 \mathrm{E}+00$ & $9.2759 \mathrm{E}-01$ & $7.2885 \mathrm{E}-01$ & $5.7670 \mathrm{E}-01$ & $4.5944 \mathrm{E}-01$ & $3.6845 \mathrm{E}-01$ \\
\hline 26 & & & & & & $1.4258 \mathrm{E}+00$ & $1.1166 \mathrm{E}+00$ & $8.8033 \mathrm{E}-01$ & $6.9863 \mathrm{E}-01$ & $5.5803 \mathrm{E}-01$ & $4.4855 \mathrm{E}-01$ \\
\hline 27 & & & & & & & $1.3425 E+00$ & $1.0622 \mathrm{E}+00$ & $8.4566 \mathrm{E}-01$ & $6.7738 \mathrm{E}-01$ & $5.4584 \mathrm{E}-01$ \\
\hline 28 & & & . & & & & $1.6124 \mathrm{E}+00$ & $1.2807 \mathrm{E}+00$ & $1.0231 E+00$ & $8.2203 \mathrm{E}-01$ & $6.6421 \mathrm{E}-01$ \\
\hline 29 & & & & & & & & $1.5435 \mathrm{E}+00$ & $1.2376 E+00$ & $9.9761 \mathrm{E}-01$ & $8.0846 \mathrm{E}-01$ \\
\hline 30 & & & & & & & & & $1.4971 \mathrm{E}+00$ & $1.2111 \mathrm{E}+00$ & $9.8462 \mathrm{E}-01$ \\
\hline 31 & & & & & & & & & & $1.4713 E+00$ & $1.2003 \mathrm{E}+00$ \\
\hline 32 & & & & & & & & & & & $1.4650 \mathrm{E}+00$ \\
\hline 33 & & & & & & & & & & & \\
\hline 34 & & & & & & & & & & & \\
\hline 35 & & & & & & & & & & & \\
\hline & & & & & & . & & & & & \\
\hline 37 & & & & & & & & & o & & \\
\hline 38 & & & & & & & & & & & \\
\hline 30 & & & & & & & & & & & \\
\hline
\end{tabular}


Table 14. (Continued)

\begin{tabular}{|c|c|c|c|c|c|c|c|c|c|c|c|}
\hline \multirow{2}{*}{$\begin{array}{l}\text { Mass } \\
\text { Category }\end{array}$} & \multicolumn{11}{|c|}{ Co11 volume tn 1iters } \\
\hline & 288.02 & 322.55 & 359.73 & 399.66 & 442.45 & 488.19 & 536.97 & 588.90 & 644.08 & 702.60 & 764.55 \\
\hline 1 & $3.8887 E-04$ & $3.1028 E-04$ & $2.4961 \mathrm{E}-04$ & $2.0232 \mathrm{E}-04$ & $1.6516 \mathrm{E}-04$ & $1.3571 \mathrm{E}-04$ & $1.1221 \mathrm{E}-04$ & $9.3325 \mathrm{E}-05$ & $7.8042 \mathrm{E}-05$ & $6.5599 \mathrm{E}-05$ & $5.5410 \mathrm{E}-05$ \\
\hline 2 & $6.5518 \mathrm{E}-04$ & $5.2289 \mathrm{E}-04$ & $4.2071 \mathrm{E}^{-04}$ & $3.4107 \mathrm{E}-04$ & $2.7845 \mathrm{E}-04$ & $2.2884 \mathrm{E}-04$ & $1.8924 \mathrm{E}-04$ & $1.5740 \mathrm{E}-04$ & $1.3163 \mathrm{E}-04$ & $1.1065 \mathrm{E}-04$ & $9.3470 \mathrm{E}-05$ \\
\hline 3 & $1.0387 \mathrm{E}-03$ & $8.2920 \mathrm{E}-04$ & $6.6729 \mathrm{E}-04$ & $5.4106 \mathrm{E}-04$ & $4.4180 \mathrm{E}-04$ & $3.6313 \mathrm{n}-04$ & $3.0032 \mathrm{E}-04$ & $2.4982 \mathrm{E}-04$ & $2.0894 \mathrm{E}-04$ & $1.7566 \mathrm{E}-04$ & $1.4839 \mathrm{E}-04$ \\
\hline 4 & $1.5725 \mathrm{E}-03$ & $1.2556 \mathrm{E}-03$ & $1.0107 \mathrm{E}-03$ & $8.1965 \mathrm{E}-04$ & $6.6940 \mathrm{E}-04$ & $5.5029 \mathrm{E}-04$ & $4.5516 \mathrm{E}-04$ & $3.7866 \mathrm{E}-04$ & $3.1674 \mathrm{E}-04$ & $2.6630 \mathrm{E}-04$ & $2.2499 \mathrm{E}-04$ \\
\hline 5 & $2.2960 \mathrm{E}-03$ & $1.8339 \mathrm{E}-03$ & $1.4765 \mathrm{E}-03$ & $1.1977 \mathrm{E}-03$ & $9.7832 \mathrm{E}-04$ & $8.0437 \mathrm{E}-04$ & $6.6542 \mathrm{E}-04$ & $5.53658-04$ & $4.6316 \mathrm{E}-04$ & $3.8945 \mathrm{E}-04$ & $3.2906 \mathrm{E}-04$ \\
\hline 6 & $3.2566 \mathrm{E}-03$ & $2.6019 \mathrm{E}-03$ & $2.0955 \mathrm{E}-03$ & $1.7002 \mathrm{E}-03$ & $1.3891 \mathrm{E}-03$ & $1.1423 \mathrm{E}-03$ & $9.4513 \mathrm{E}-04$ & $7.8649 \mathrm{E}-04$ & $6.5803 \mathrm{E}-04$ & $5.5337 \mathrm{E}-04$ & $4.6761 \mathrm{E}-04$ \\
\hline 7 & $4.5109 \mathrm{E}-03$ & $3.6053 \mathrm{E}-03$ & $2.9045 \mathrm{E}-03$ & $2.3572 \mathrm{E}-03$ & $1.9263 \mathrm{E}-03$ & $1.5844 \mathrm{E}-03$ & $1.3112 \mathrm{E}-03$ & $1.0913 \mathrm{E}-03$ & $9.1314 \mathrm{E}-04$ & $7.6801 \mathrm{E}-04$ & $6.4905 \mathrm{E}-04$ \\
\hline 8 & $6.1266 \mathrm{E}-03$ & $4.8986 \mathrm{E}-03$ & $3.9476 \mathrm{E}-03$ & $3.2047 \mathrm{E}-03$ & $2.6196 \mathrm{E}-03$ & $2.1551 \mathrm{E}-03$ & $1.7838 \mathrm{E}-03$ & $1.4849 \mathrm{E}-03$ & $1.2427 \mathrm{E}^{-03}$ & $1.0453 \mathrm{E}-03$ & $8.8354 \mathrm{E}-04$ \\
\hline 9 & $8.1848 \mathrm{E}-03$ & $6.5470 \mathrm{E}-03$ & $5.2780 \mathrm{E}-03$ & $4.2861 \mathrm{E}-03$ & $3.5045 \mathrm{E}-03$ & $2.8838 \mathrm{E}-03$ & $2.3875 \mathrm{E}-03$ & $1.9878 \mathrm{E}-03$ & $1.6639 \mathrm{E}-03$ & $1.3998 \mathrm{E}-03$ & $1.1833 \mathrm{E}-03$ \\
\hline 10 & $1.0782 \mathrm{E}-02$ & $8.6289 \mathrm{E}-03$ & $6.9591 \mathrm{E}-03$ & $5.6532 \mathrm{E}-03$ & $4.6237 \mathrm{E}-03$ & $3.8059 \mathrm{E}-03$ & $3.1516 \mathrm{E}-03$ & $2.6245 \mathrm{E}-03$ & $2.1973 \mathrm{E}-03$ & $1.8489 \mathrm{E}-03$ & $1.5631 \mathrm{E}-03$ \\
\hline 11 & $1.4036 \mathrm{E}-02$ & $1.1238 \mathrm{E}-02$ & $9.0673 \mathrm{E}-03$ & 7.368 & $6.0288 \mathrm{E}-03$ & $4.9639 \mathrm{~B}-03$ & $4.1115 \mathrm{E}-03$ & $3.4247 \mathrm{E}-03$ & 2.8678 & $2.4135 \mathrm{E}-03$ & $2.0408 \mathrm{E}-03$ \\
\hline 12 & $1.8083 E-02$ & $1.4487 \mathrm{E}-02$ & $1.1694 \mathrm{E}-02$ & $9.5075 \mathrm{E}-03$ & $7.7815 \mathrm{E}-03$ & $6.4091 \mathrm{E}-03$ & $5.3101 \mathrm{E}-03$ & 4.424 & 3.705 & 3.119 & 2.63 \\
\hline 13 & $2.3093 \mathrm{E}-02$ & $1.8511 \mathrm{E}-02$ & $1.4950 \mathrm{E}-02$ & $1.2160 \mathrm{E}-02$ & $9.9568 \mathrm{E}-03$ & $8.2036 \mathrm{E}-03$ & $6.7990 \mathrm{E}-03$ & $5.6662 \mathrm{E}-03$ & $4.7470 \mathrm{E}-03$ & $3.9967 \mathrm{E}-03$ & $3.3808 \mathrm{E}-03$ \\
\hline 14 & $2.9264 \mathrm{E}-02$ & $2.3473 \mathrm{E}-02$ & $1.8969 \mathrm{E}-02$ & $1.5436 \mathrm{E}-02$ & $1.2645 \mathrm{E}-02$ & $1.0422 \mathrm{E}-02$ & $8.6407 \mathrm{E}^{-03}$ & $7.2032 \mathrm{E}-03$ & $6.0363 \mathrm{E}-03$ & $5.0834 \mathrm{E}-03$ & 4.3010E-03 \\
\hline 15 & $3.6837 \mathrm{E}-02$ & $2.9569 \mathrm{E}-02$ & $2.3910 \mathrm{E}-02$ & $1.9468 \mathrm{E}-02$ & $1.5955 \mathrm{E}-02$ & $1.3156 \mathrm{E}-02$ & $1.0911 \mathrm{E}-02$ & $9.0989 \mathrm{E}-03$ & $7.6271 \mathrm{E}-03$ & $6.4248 \mathrm{E}-03$ & $5.4372 E-03$ \\
\hline 16 & $4.6104 \mathrm{E}-02$ & $3.7036 \mathrm{E}-02$ & $2.9968 \mathrm{E}-02$ & $2.4415 \mathrm{E}-02$ & $2.0019 \mathrm{E}-02$ & $1.6515 \mathrm{E}-02$ & $1.3703 \mathrm{E}-02$ & $1.1431 \mathrm{E}-02$ & $9.5849 \mathrm{E}-03$ & $8.0763 \mathrm{E}-03$ & $6.8366 \mathrm{E}-03$ \\
\hline 17 & $5.7412 \mathrm{E}-02$ & $4.6159 \mathrm{E}-02$ & $3.7378 \mathrm{E}-02$ & $3.0471 \mathrm{E}-02$ & $2.4999 \mathrm{E}-02$ & $2.0634 \mathrm{E}-02$ & $1.7127 \mathrm{E}-02$ & $1.4294 \mathrm{E}-02$ & $1.1990 \mathrm{E}-02$ & $1.0106 \mathrm{E}-02$ & $8.5567 \mathrm{E}-03$ \\
\hline 18 & $7.1187 \mathrm{E}-02$ & $5.7286 \mathrm{E}-02$ & $4.6425 \mathrm{E}-02$ & $3.7873 \mathrm{E}-02$ & $3.1091 \mathrm{E}-02$ & $2.5676 \mathrm{E}-02$ & $2.1323 \mathrm{E}-02$ & $1.7803 \mathrm{E}-02$ & $1.4939 \mathrm{E}-02$ & $1.2596 \mathrm{E}-02$ & $1.0668 \mathrm{E}-02$ \\
\hline 19 & $8.7940 \mathrm{E}-02$ & $7.0838 \mathrm{E}-02$ & $3.7457 \mathrm{E}-02$ & $4.6909 E-02$ & $3.8536 \mathrm{E}-02$ & $3.1842 \mathrm{E}-02$ & $2.6458 \mathrm{E}-02$ & $2.2100 \mathrm{E}-02$ & $1.8553 \mathrm{E}-02$ & $1.5649 \mathrm{E}-02$ & $1.3259 \mathrm{E}-02$ \\
\hline 20 & $1.0829 \mathrm{E}-01$ & $8.732 .8 \mathrm{E}-02$ & $7.0900 \mathrm{E}-02$ & $5.7932 \mathrm{E}-02$ & $4.7626 \mathrm{E}-02$ & $3.9379 \mathrm{E}-02$ & $3.2740 \mathrm{~B}-02$ & $2.7361 E^{-02}$ & $2.2980 \mathrm{E}-02$ & $1.9391 \mathrm{E}-02$ & $1.6435 \mathrm{E}-02$ \\
\hline 21 & $1.3300 \mathrm{E}-01$ & $1.0738 \mathrm{E}-01$ & $8.7271 \mathrm{E}-02$ & $7.1375 \mathrm{E}-02$ & $5.8724 E-02$ & $4.8590 \mathrm{E}-02$ & $4.0423 \mathrm{E}-02$ & $3.3802 \mathrm{E}-02$ & $2.8403 \mathrm{E}-02$ & 2.39 & 02 \\
\hline 22 & $1.6300 \mathrm{E}-01$ & $1.3177 \mathrm{E}-01$ & $1.0721 \mathrm{E}-01$ & $8.7769 \mathrm{E}-02$ & $7.2276 \mathrm{E}-02$ & $5.9851 \mathrm{E}-02$ & $4.9825 \mathrm{E}-02$ & $4.1690 \mathrm{E}-02$ & $3.5051 \mathrm{E}-02$ & $2.9604 \mathrm{E}-02$ & $2.5114 \mathrm{E}-02$ \\
\hline 23 & $1.9941 \mathrm{E}-01$ & $1.6143 \mathrm{E}-01$ & $1.3150 \mathrm{E}-01$ & $1.0778 \mathrm{E}-01$ & $8.8836 \mathrm{E}-02$ & $7.3627 \mathrm{E}-02$ & $6.1341 \mathrm{E}-02$ & $5.1359 \mathrm{E}-02$ & $4.3207 \mathrm{E}-02$ & $3.6513 \mathrm{E}-02$ & $3.0990 \mathrm{E}-02$ \\
\hline 24 & $2.4363 \mathrm{E}-01$ & $1: 9752 \mathrm{E}-01$ & $1.6113 \mathrm{E}-01$ & $1.3221 \mathrm{E}-01$ & $1.0909 \mathrm{E}-01$ & $9.0499 \mathrm{E}-02$ & $7.5460 \mathrm{E}-02$ & $6.3229 \mathrm{E}-02$ & $5.3228 \mathrm{BE}-02$ & $4.5009 \mathrm{E}-02$ & $3.8221 \mathrm{E}-02$ \\
\hline 25 & $2.9737 \mathrm{E}-01$ & $2.4150 \mathrm{E}-01$ & $1.9729 \mathrm{E}-01$ & $1.6209 \mathrm{E}-01$ & $1.3390 \mathrm{E}-01$ & $1.1120 \mathrm{E}-01$ & $9.2803 \mathrm{E}-02$ & $7.7825 \mathrm{E}-02$ & $6.5563 \mathrm{E}-02$ & $5.5476 \mathrm{E}-02$ & $4.7138 \mathrm{E}-02$ \\
\hline 26 & $3.6276 \mathrm{E}-01$ & $2: 95$ & 2.41 & 1 & 1 & 1 & 1 & 9. & 8.0 & 6.8 & 5.81 \\
\hline 27 & $4.4243 \mathrm{E}-01$ & $3.6066 \mathrm{E}-01$ & 2.95 & $2.4361 \mathrm{E}-01$ & 2.01 & 1.6 & 1.404 & 1.1804 & -02 & -02 & $7.1828 \mathrm{E}-02$ \\
\hline 28 & $5.3968 \mathrm{E}-01$ & $4.4088 \mathrm{E}-01$ & 3.620 & 2.988 & 2.47 & 2.06 & 1.730 & $1.4558 \mathrm{E}-01$ & $1.2298 \mathrm{E}-01$ & $1.0431 \mathrm{E}-01$ & $8.8830 \mathrm{E}-02$ \\
\hline 29 & $6.5861 \mathrm{E}-01$ & $5.3931 \mathrm{E}-01$ & $4.4385 \mathrm{E}-01$ & $3.6708 \mathrm{E}-01$ & $3.0503 E-01$ & $2.5465 \mathrm{E}-01$ & $2.1354 \mathrm{E}-01$ & $1.7984 \mathrm{E}-01$ & $1.5208 \mathrm{E}-01$ & $1.2913 \mathrm{E}-01$ & $1.1007 \mathrm{E}-01$ \\
\hline 30 & $8.0443 E-01$ & $6.6041 \mathrm{E}-01$ & $5.4477 \mathrm{E}-01$ & $4.5148 \mathrm{E}-01$ & $3.7587 \mathrm{E}-01$ & $3.1431 \mathrm{E}-01$ & $2.6397 \mathrm{E}-01$ & $2.2261 \mathrm{E}-01$ & $1.8849 \mathrm{E}-01$ & $1.6023 \mathrm{E}-01$ & $1.3671 \mathrm{E}-01$ \\
\hline 31 & $9.8369 \mathrm{E}-01$ & $8.0986 \mathrm{E}-01$ & $6.6974 \mathrm{E}-01$ & 5.563 & 4.64 & 3.888 & 3.2710 & 2.762 & 2.3425 & $1.9937 \mathrm{E}-01$ & $1.7030 \mathrm{E}-01$ \\
\hline 29 & 1.20 & $9.9492 \mathrm{E}-01$ & $8.2509 \mathrm{E}-01$ & 6.870 & 5.74 & 4.823 & 4.0652 & 3.439 & 2.920 & 2.489 & $2.1291 \mathrm{E}-01$ \\
\hline 33 & $1.4783 E+00$ & $1.2250 \mathrm{E}+00$ & $1.0190 E+00$ & $8.5094 \mathrm{E}-01$ & $7.1333 \mathrm{E}-01$ & $6.0024 \mathrm{E}-01$ & $5.0696 \mathrm{E}-01$ & $4.2973 \mathrm{E}-01$ & $3.6557 \mathrm{E}-01$ & $3.1206 \mathrm{E}-01$ & $2.6729 \mathrm{E}-01$ \\
\hline 34 & & $1.5122 \mathrm{E}+00$ & $1.2622 \mathrm{E}+00$ & $1.0573 \mathrm{E}+0 \mathrm{D}$ & $8.8880 \mathrm{E}-01$ & $7.4981 \mathrm{E}-01$ & $6.3477 \mathrm{E}-01$ & $5.3922 \mathrm{E}-01$ & $4.5960 \mathrm{E}-01$ & $3.9304 \mathrm{E}-01$ & $3.3719 \mathrm{E}-01$ \\
\hline 35 & & & $1.5688 \mathrm{E}+00$ & $1.3186 \mathrm{E}+0 \mathrm{D}$ & $1.1119 \mathrm{E}+00$ & $9.4075 \mathrm{E}-01$ & $7.9850 \mathrm{E}-01$ & $6.7994 \mathrm{E}-01$ & $5.8082 \mathrm{E}-01$ & $4.9770 \mathrm{E}-01$ & $4.2778 \mathrm{E}-01$ \\
\hline 36 & & & & $1.6516 \mathrm{E}+00$ & $1.3976 \mathrm{E}+00$ & $1.1862 \mathrm{E}+00$ & $1.0098 \mathrm{E}+00$ & $8.6223 \mathrm{E}-01$ & $7.3837 \mathrm{E}-01$ & $6.341 \mathrm{sE}-01$ & $5.4621 \mathrm{E}-01$ \\
\hline 37 & & & & & & 1.5 & & & & 8.1377 & $7.0261 \mathrm{E}-01$ \\
\hline 38 & & & & & & & $1.6463 \mathrm{E}+00$ & $1.4149 \mathrm{E}+00$ & $1.2190 \mathrm{E}+00$ & $1.0528 \mathrm{E}+00$ & $9.1147 \mathrm{E}-01$ \\
\hline 39 & & & & & & & & & $1.5862 \mathrm{E}+00$ & $1.3747 \mathrm{E}+00$ & $1.1939 \mathrm{E}+00$ \\
\hline 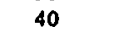 & & & & & & & & & & & $1.5815 \mathrm{E}+00$ \\
\hline
\end{tabular}


which permit the establishment of the constants $c_{2}$ and $m_{0}$ of Eq. 2 for water reflected cubic arrays may be included in Table 13 by applying the mass equivalence relation, Eq. 5. Succinctly stated, Tables 13 and 14 are broadly applicable and define arrays of irregular or mixed units having a potential for criticality. Expression of criticality of arrays of mixed units in terms of the solid angle method is complex compared to the simple criticality indicator concept developed from the surface density method. Difficulties with expression in terms of solid angle are more easily comprehended by examination of several mixed unit critical arrays in terms of $\Omega$. Consider the two uniform arrays of Tab1e 15 , one with cylindrical units of aqueous solution as $\mathrm{U}(93.2) \mathrm{O}_{2}\left(\mathrm{NO}_{3}\right)_{2}$ and the other of $U(93.2)$ metal cylinders. Each 27-unit array calculates as a critical water reflected array. The total solid angle, $\Omega_{s}$, is distinct for each array. Two arrays of mixed units are described in the table and each of these calculate as critical. The units, therefore, satisfy the definition of mass equivalence. Again, the solid angles are distinct and are bracketed in value by those of the uniform arrays. The individual arrays define the quantities necessary to apply the CI critoria to establish oriticality based on the mass equivalence of the units. In terms of the parameter $\Omega$, however, there is not a unique value for criticality and it will be different for various combinations of the units.

A second example of mixed unit critical arrays is given in Table 16 and illustrates arrays with different units and different cell volumes. The upper pnrtions of the table describes the uniform arrays and the lower portion presents mixed arrays in which one quadrant of a uniform array has been rep1aced by a quandrant of another array. While the CI system would 
Table 15. Description of units in 27-unit critical, water reflected. arrays and their arrangement in mixed unit arrays. Cells are cubic with a dimension of $30.48 \mathrm{~cm}$.

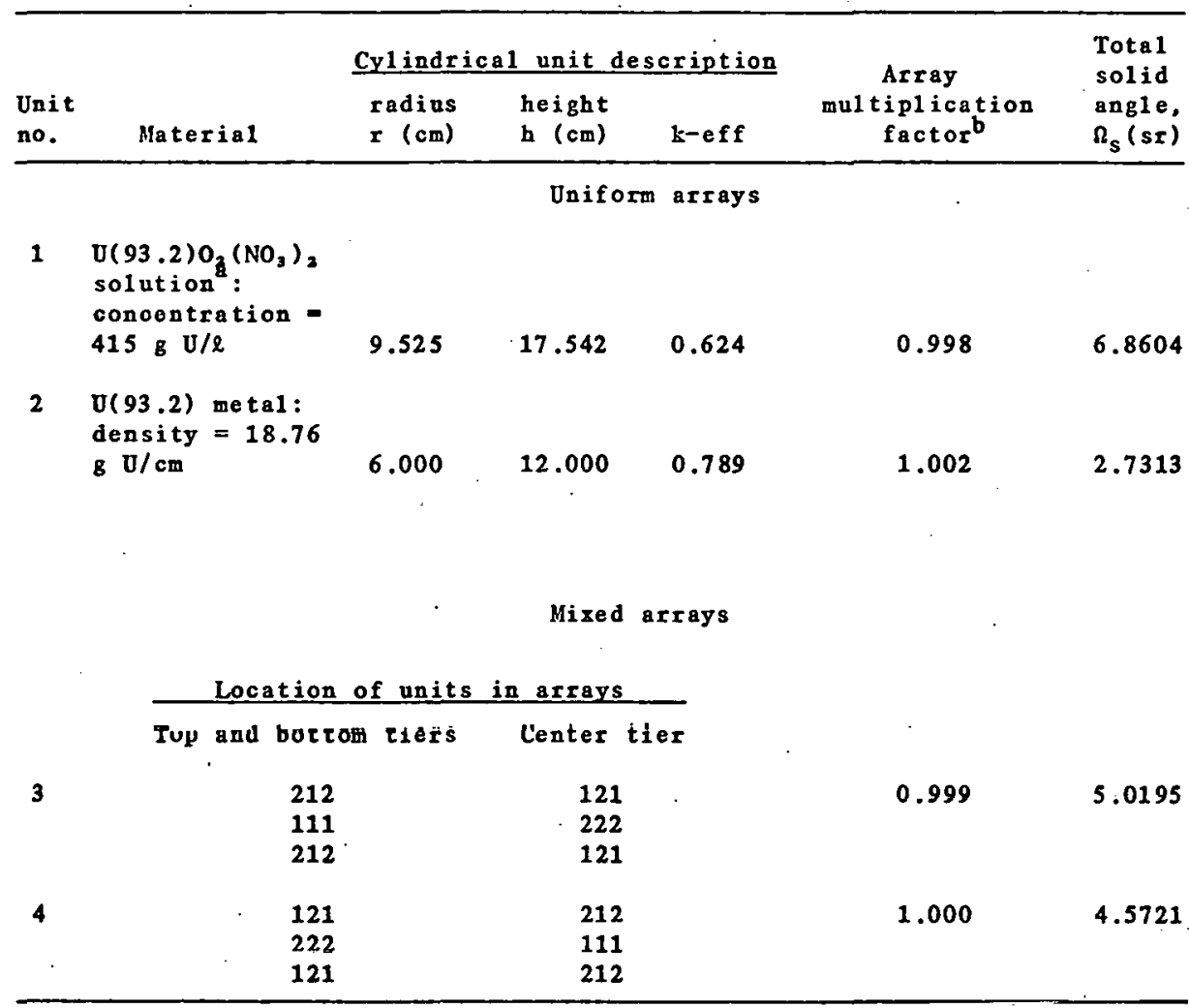

asolution is contained in $0.64-\mathrm{cm}-$ thick Plexiglas, $p=1.18 \mathrm{~g} / \mathrm{cm}^{3}$.

bstandard deviation for $30 \times 10$, neutrons is \pm 0.005 . 
Tab1e 16. Monte Car1o calcnlated reflected critioal arrays of $0(93.2)$ metal at a density of $18.76 \mathrm{~g} / \mathrm{cm}^{2}$ and of mired nnit arrays with different cell volumes and unit masses

\begin{tabular}{|c|c|c|c|c|c|c|c|}
\hline \multirow[b]{2}{*}{$\begin{array}{l}\text { Array } \\
\text { no. }\end{array}$} & \multirow[b]{2}{*}{$\begin{array}{c}\text { Number of } \\
\text { units in } \\
\text { array } \\
\left(n_{x}=n_{y}=n_{z}\right)\end{array}$} & \multicolumn{3}{|c|}{$\begin{array}{c}\text { Unit description } \\
h=d\end{array}$} & \multirow[b]{2}{*}{$\begin{array}{c}\text { Cubic } \\
\text { helf-cell } \\
\text { dimension, } \\
{ }_{n}(\mathrm{~cm})\end{array}$} & \multirow[b]{2}{*}{$\begin{array}{l}\text { Array } \\
\text { multipli- } \\
\text { cation } \\
\text { factor }\end{array}$} & \multirow[b]{2}{*}{$\begin{array}{r}\text { Total } \\
\text { solid } \\
\text { angle } \\
\Omega_{\text {s }}(\mathrm{sr}) \\
\end{array}$} \\
\hline & & $\begin{array}{l}\text { Cylinder } \\
\text { radius, } \\
\text { r (cm) }\end{array}$ & $\begin{array}{c}\text { Mass } \\
(\mathbf{k g ~ U})\end{array}$ & $\begin{array}{c}\text { Unit } \\
\text { multipli- } \\
\text { cation } \\
\text { factor }\end{array}$ & & & \\
\hline \multicolumn{8}{|c|}{ Uniform cubic arrays } \\
\hline 1 & 64 & 4.785 & 12.9 & 0.641 & 12.7 & 1.002 & 3.5393 \\
\hline 2 & 512 & 3.906 & 7.0 & 0.532 & 12.7 & 0.993 & 5.8149 \\
\hline 3 & 64 & 5.236 & 16.9 & 0.697 & 15.24 & 1.007 & 2.9243 \\
\hline 4 & 512 & 4.314 & 9.5 & 0.583 & 15.24 & 1.008 & 4.9151 \\
\hline 5 & 8 & 7.099 & 42.2 & 0.921 & 25.4 & 1.006 & .0 .4295 \\
\hline 6 & 64 & 6.238 & $=28.6^{\circ}$ & 0.818 & 25.4 & 0.996 & 1.4667 \\
\hline 7 & 8 & 7.254 & 45.0 & 0.939 & 30.48 & 1.004 & 0.3066 \\
\hline 8 & 64 & 6.730 & 35.9 & 0.877 & 30.48 & 0.998 & 1.1800 \\
\hline
\end{tabular}

Hixed-ce11 cubic array

\begin{tabular}{rcccc}
7 octants & & & $\begin{array}{c}\text { Array } \\
\text { of array no. }\end{array}$ \\
& 5 & $\begin{array}{c}1 \text { octant } \\
\text { of array no. }\end{array}$ & $\begin{array}{c}\text { mactor } \\
\text { faction }\end{array}$ \\
9 & 7 & 1 & 1.007 & 1.5098 \\
10 & 6 & 3 & 0.996 & 1.1727 \\
11 & 8 & 2 & 1.000 & 2.6111 \\
12 & 8 & 4 & 0.991 & 2.0917 \\
\hline
\end{tabular}

${ }^{a}$ Standard deviation is 1 ess than \pm 0.006 for $30 \times 10^{2}$ nentron histories including noutrons tracked in tho water refloctor. 
apply to the various possible arrays, the solid angle as a parameter, however, lacks any unique property to properly predict when criticality will occur for a mixed array. The solid angles given in the table were computed with the SNAKE code and the contributions were summed at the center of the unit nearest the center of the array.

It is suggested, by experience with criticality of arrays expressed in terms of the limiting surface density method and its translation to analytic expressions in terms of the solid angle, that given the $\Omega$ for the criticality of uniform arrays, one should be able to correctly calculate the $\Omega$ for criticality in an established geometry of mixed units and cell volumes. The question to be addressed is whether or not it is possible to represent the data of: Tables 13 and 14 in terms of the solid ang1e parameter. Explicit in the data of the tables are the mass of the unit and the cell dimension, while implicit in the CI value is the number of units in the array. The array geometry is cubic or nearly cubic. Let $\mu(\mu=1,2,3, \ldots)$ index the different fissile materials of Tab1e 13, then for each $\mu$ and cell dimension there is defined an $\Omega_{\mu}$ for the uniform arrays, by Eq. 4 , as

$$
\Omega_{\mu}=\sum_{i} F_{i}(N)\left(\frac{A_{\mu}}{d_{i^{2}}^{2}}\right)=F_{\mu}(N)\left(\frac{A}{d^{2}}\right)_{\mu}
$$

where the i-sumation is over the cell coordinates of the array. We interpret the quantity $\mathrm{A} / \mathrm{d}^{2}$ as the steradians per cell and each unit is weighted by its location in the array, i.e., by $F_{i}(N)$, and the summation is over the occupied cells of the array to produce $\Omega_{\mu}$. For an array of mixed units, the solid angle to associate with criticality is 


$$
\Omega_{\tau}=\sum_{\mu} \Omega_{\mu}=\sum_{\mu} \sum_{i} F_{i}(N)\left(\frac{A_{\mu}}{d_{i}^{2}}\right)
$$

There is no way, a priori, to know what the $\Omega_{\tau}$ will be; however, it is not necessary to know. The condition comparable to $C I=100$, i.e., control1ing criticality, is expressible as

$$
\sum_{\mu} \frac{1}{\Omega_{\mu}} \sum_{i} F_{i}(N)\left(\frac{A_{\mu}}{d_{i}^{2}}\right)=1
$$

Now

$$
\frac{1}{F_{\mu}}=\frac{1}{\Omega_{\mu}}\left(\frac{A_{\mu}}{d_{i}^{2}}\right)
$$

and if we denote the partial sum, $F_{\mu}=\sum_{i} F_{i}(N)$, i.e., the contribution to $F_{\mu}$ from the cell, $d_{i}$, occupied by the fissile materials presenting an area $A$, the relation simplifies to

$$
\sum_{\mu} \frac{F_{\mu}^{\prime}}{F_{\mu}}=1
$$

Application of this formalism to the mixed arrays of Table 15 is made in Table 17; and it is evident that control of criticality, as with the CI system, is functional. A similar interpretation of the mixed arrays of Table 16, however, results in failure since $F_{\mu} / F_{\mu}$ does not sum to unity and the $\Omega_{\tau}$ is not correctly inferred from the individual $\Omega_{\mu}$ 's. The reason is the arbitrary choice of the point about which to sum the contributions to $\Omega_{\tau}$, i.e., the center of the unit nearest the center of the array. The mixed cell sizes causes a shifting of the reference points for all the $\Omega_{\mu}^{\prime}$ 's involved except that $\mu$-material at which the solid angle summation 
Table 17. Solid angle calculation of mixed unit arrays of Table 15

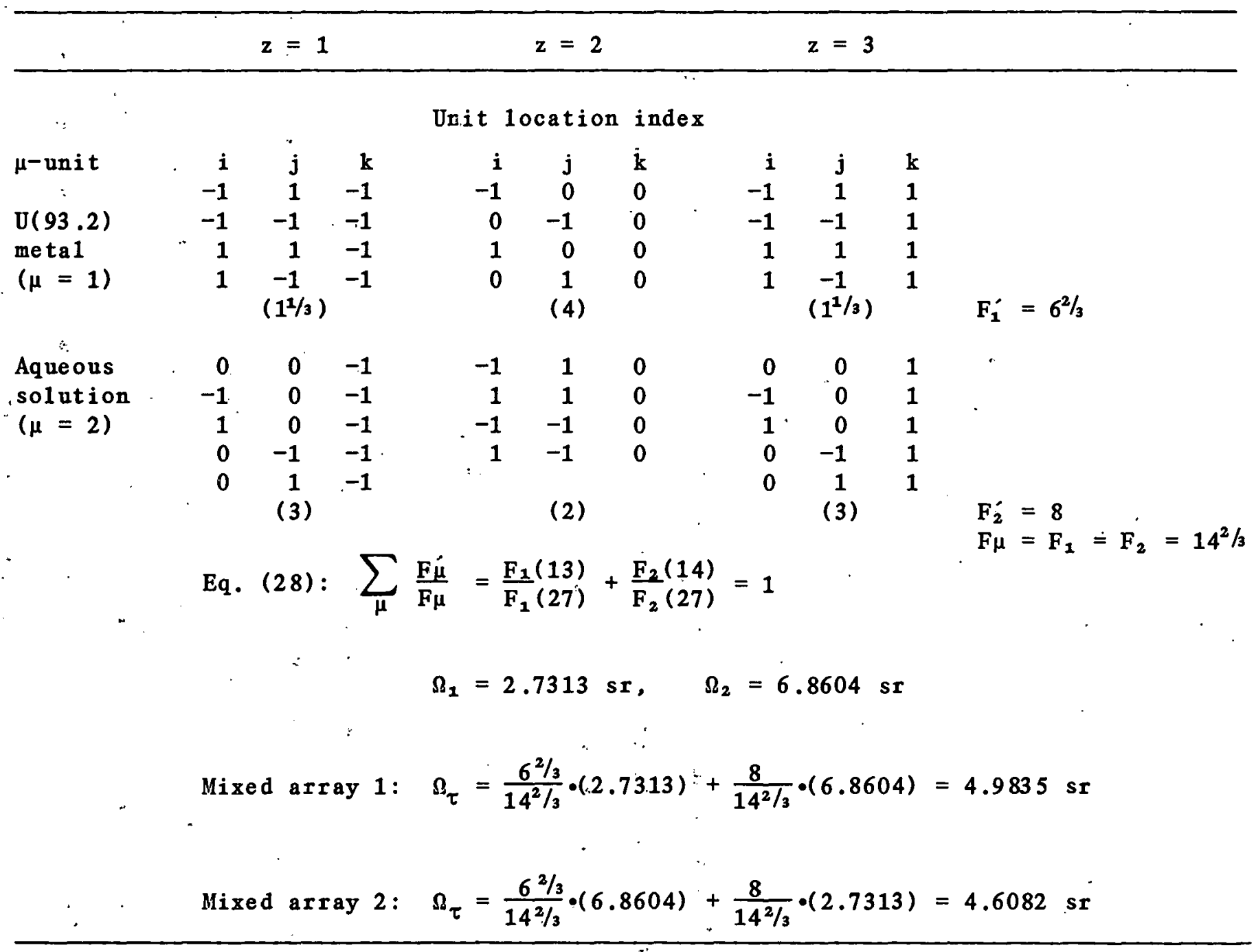


takes place. Fortunately, this problem is easily resolved by choosing the geometric center of the array as the position to sum the solid angle contributions. No significance is attached to whether or not the center of a unit coincides with the center of the array. The $\Omega$ associated with a critical array is also unique with this convention. The use of such an invariant point would reduce some of the dispersion already observed in the data presented in earlier sections. The value of the location function will be changed for some values of $N$ (the even $n$ ) and the total solid angle will be increased slightly from that of the initial definition.

Using the center of an array as the point at which to sum $\Omega$ allows the criticality of arrays with mixed units of fissile material to be specified either by the limiting surface density method or by the solid angle method. Information required and basic to both methods is the criticality of uniform arrays of the fissile materials under specific reflector conditions. Presented in Table 18 are the $\Omega_{\mu}$ (SNAKE) values of the eight uniform arrays of Tab1e 16 as well as the $\Omega_{\tau}$ for the four mixed arrays. The value of $\mathrm{F}_{\mu}^{-} / F_{\mu}$ for the seven-octant portion of the mixed arrays is $7 / 8$ and for the one-octant portion, it is $1 / 8$. The fractions of the $\Omega_{\mu}$ values for the uniform arrays reproduce the calculated $\Omega_{\tau}$ values of the mixed arrays given in the table when the $\Omega_{\mu}$ is measured at the center of the array. They clearly do not when the $\Omega_{\mu}$ is measured at the center of the unit nearest the center of the array. The adoption of summing $\Omega$ contributions at the center of an array distinguishes unit patterns in an array determined by the number of units along the edges of the array. For example, $\Omega_{s}$ for an odd number of units along the three edges of a cuboidal array will, in general, be less than the $\Omega_{s}$ for an 
Table 18. Comparison of calculated solid angles subtended at the center of arrays with those subtended at the center of the unit nearest the center of the array. The arrays are those of Table 16.

\begin{tabular}{clcc}
\hline & & \multicolumn{2}{c}{ Solid angle $(s r)$} \\
\cline { 3 - 4 } $\begin{array}{c}\text { Array } \\
\text { no. }\end{array}$ & $\begin{array}{l}\text { Number of } \\
\text { thits in }\end{array}$ & $\Omega_{\mu}$ & $\Omega_{s}$ \\
& the array & Array center nearest & array center \\
\hline
\end{tabular}

Uniform arrays

\begin{tabular}{|c|c|c|c|c|c|c|c|}
\hline 1 & & 64 & & & 4.4206 & & 3.5393 \\
\hline 2 & & 512 & & & 6.3834 & & 5.8149 \\
\hline 3 & & 64 & & & 3.6823 & & 2.9243 \\
\hline 4 & & 512 & & & 5.4100 & & 4.9151 \\
\hline 5 & & 8 & & & 1.0418 & & 0.4295 \\
\hline & & 64 & & & 1.8899 & & 1.4667 \\
\hline 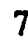 & & 8 & & & 0.7590 & & 0.3066 \\
\hline & & 64 & & & 1.5291 & & 1.1800 \\
\hline & & & ed & cell cubic & c arra & & \\
\hline & 7 & $\begin{array}{l}\text { Octants of } \\
\text { array no. }\end{array}$ & + & $\begin{array}{l}1 \text { Octant } \\
\text { array }\end{array}$ & $\begin{array}{l}t \text { of } \\
\text { no. }\end{array}$ & $\Omega_{\tau}(\mu)$ & $\Omega_{\tau}(s)$ \\
\hline & & 5 & & 1 & & 1.4649 & 1.5098 \\
\hline & . & 7 & & 3 & & 1.1244 & 1.1727 \\
\hline & & 6 & & 2 & & 2.4516 & 2.6111 \\
\hline & & 8 & & 4 & & 1.9486 & 2.0917 \\
\hline
\end{tabular}


even number of units. This minor refinement results in an improved correlation of the data previously presented in Fig. 8 to illustrate unit shape effects. These data are repeated in Fig. 26 showing an improved agrement between the sphere data using an odd and even location function in Eq. 12, and the results from the SNAKE code for the cylindrical unit which show a diminished dependence on cell dimension. The 1 ines for the sphere data have a constant $\beta$ satisfying Eq. 15 of $3.107 \pm 0.030$ for $n$ even and $2.918 \pm 0.087$ for $n$ odd.

The 1 imiting surface density method expresses array criticality of fissile materials for which the characteristic constants $c_{2}$ and $m$ have been established. The constants may be used to define masses equivalent to the mass categories of the Criticality Indicator system given in Tab1e 13. The CI values of Table 14 implicitly specify the number of units necessary for criticality. A lower bound to the number of different critical systems represented by a single entry in Table 14 is $49^{\mathrm{N}}$ since there are $N$ cells and the 49 distinguishable forms of fissile materials in Table 13 from which to choose the content of each cell in the array. This, of course, may be augmented by combining different ce11 sizes.

Mixed arrays describable in the $\sigma(m)$ method have a one-to-one correspondence with the $\Omega$ method provided the solid angle is measured at the center of the uniform regular arrays of the fissile materials.

\section{LOW ${ }^{235} \mathrm{U}$ ENRICHED URANIUM}

Thus far, we have concerned ourselves with critical systems having a mean energy of fission (mef) greater than about $0.1 \mathrm{eV}$. The effect on the representation of criticality in the limiting surface density method 


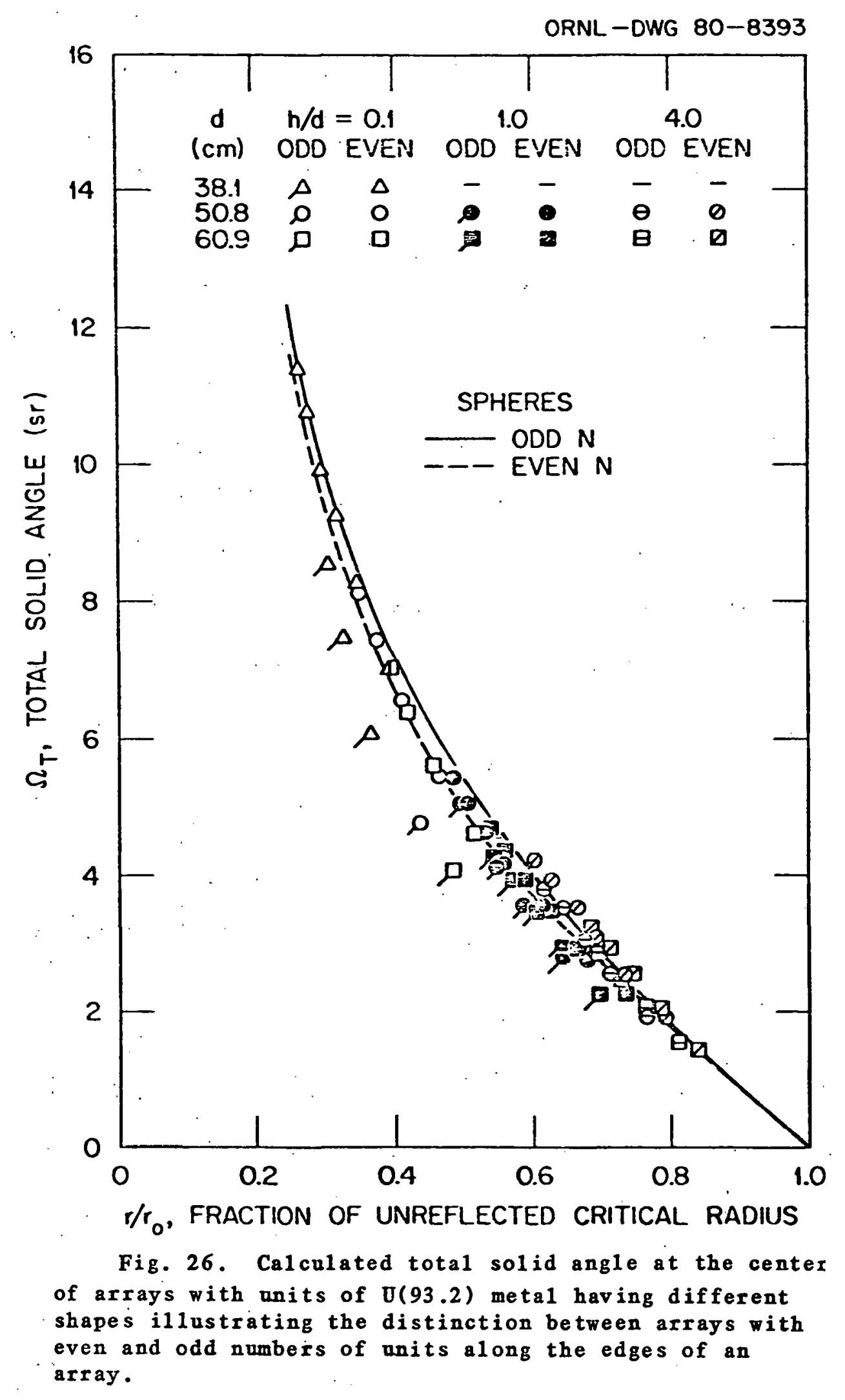


of systems with a lower mef is principally in the constant c of Eq. 1 , which approaches zero as the fraction of thermal fissions occurring at critical increases. The data and analyses of $10{ }^{235} \mathrm{U}$ enriched uranium is 1 imited, but the information to follow exhibits this tendency in the constant $c$ and does illustrate two points that need to be addressed when generating calculated criticality data. The first of these concerns the relation of the data to the realities of experimental criticality with the fissile materials and to the establishment of the magnitude of factors affecting criticality. The second point concerns the significance of the accuracy with which criticality is defined and its effect on the analytic descriptions of the potential for criticality.

The energy of neutrons linking the fission events producing the chains of fission necessary for criticality in uranium containing 5 wt ${ }^{235} \mathrm{U}$ or less, $U(\leq 5)$, is predominately below $0.1 \mathrm{eV}$. Criticality of a single unit of $U(5)$ is not possible without the presence of an internal neutron energy moderating material, independent of the quantity and density of the $U(5)$ and of the presence or absence of a neutron reflector. Hydrogen bearing materials are common neutron energy moderators most likely to be encountered as in added chemieal bindcrs or in aquoous process streams or, simply, by absorbed moisture. The quantity of the moderating material present strongly affects the mass required for criticality, and hence, is a factor for consideration in the potential for criticality. It follows that control of neutron moderating materials mixed with $U(\leq 5)$ materials is an effective means for controlling urtiuality.

Information on the criticality of mixtures of $U(5)$ and water would be snitable bases upon which to judge the criticality'safety of such 
systems. We arbitrarily select from the uncountable number of possibie combinations of $U(5)$ and water the oxide form of uranium and that quantity of water which produces an H:U of 3 . The neutron spectrum for this mixture has been bracketed by experimental measurements of $U(\leq-5)$ systems with aqueous $f 1$ uoride solutions, 26 damp and moderated oxide, 27 and metal 28 and oxide rods 9-31 $^{-3}$ atticed in water. Monte Carlo calculations ${ }^{3-34}$ of these experiments with the Hansen-Roach cross sections evidence a bias having an apparent dependence on the mean energy of fissions (mef) occurring in the critical systems. The results of these calculations indicate that near thermal systems (mef below 0.1 eV) calculated as having a k-eff of 0.98 may be regarded as having a potential for criticality and that the $k$-eff increases as the mef increases. Calculations of $U(5)$ at an. H:U of 3 (mef above $0.1 \mathrm{eV}$ ) may be interpreted as being potentially critical for calculated k-eff's of about 1.01. The calculations of arrays reported in the following were conducted to define criticality as $k=1.00$, introducing some degree of nonlinearity into the correlations made.

The mass of spherical units required to result in a calculated k-eff $=1.00$ was determined for cubic arrays reflected by $30 \mathrm{~cm}$ of water and these are given in Table 19. Similar calculations for cubic arrays reflected by $41 \mathrm{~cm}$ of concrete are reported in Table 20. Examination of arrays with the same mass and different $N$ show that the ratio of cell dimensions varies almost directly as the square root of the ratio of number of units. This result can imply that the constant c of Eq. 1 has a small value, near zero. We assume c as zero, since we do not know the

*Such data represented in a density analog mode1 14 would exhibit a slope near the theoretical 1 imit of 2 . 
Table 19. Criticality of $U(5) \mathrm{O}_{2}$ at an $\mathrm{H}: \mathrm{U}=3$ in water reflected cubic arrays

\begin{tabular}{|c|c|c|c|c|c|c|c|}
\hline \multirow[b]{2}{*}{$n=n_{i}$} & \multirow[b]{2}{*}{$\begin{array}{l}\text { Radius } \\
\text { (cm) }\end{array}$} & \multirow[b]{2}{*}{$\begin{array}{r}\text { Mass } \\
\text { kgU }\end{array}$} & \multirow{2}{*}{$\begin{array}{c}\text { Ce11 } \\
\text { dimension } \\
d_{n}(c m)\end{array}$} & \multirow[b]{2}{*}{$\begin{array}{l}\text { Array } \\
\text { z-eff }\end{array}$} & \multirow[b]{2}{*}{$\begin{array}{l}\sigma(\mathrm{m}) \\
\mathrm{gm} / \mathrm{cm}^{2}\end{array}$} & \multicolumn{2}{|c|}{ Solid angle $(s x)$} \\
\hline & & & & & & $n_{s}$ & $\boldsymbol{D}_{\mathbf{c}}$ \\
\hline \multicolumn{8}{|c|}{ Spherical units } \\
\hline 4 & 10.91 & 25.00 & 23.768 & 1.002 & 177.018 & 13.862 & 16.967 \\
\hline 6 & & & 29.110 & 1.007 & 177.015 & 16.133 & 18.023 \\
\hline 8 & & & 33.614 & 1.007 & 177.008 & 17.225 & 18.572 \\
\hline 4 & 15.314 & 69.13 & 41.478 & 0.997 & 160.728 & 8.968 & 10.997 \\
\hline 6 & & & 51.760 & 0.996 & 154,728 & 10.054 & 11.232 \\
\hline 8 & & & 58.658 & 0.999 & 160.732 & 11.145 & 12.017 \\
\hline 10 & & & 65.582 & 0.999 & 160.730 & 11.560 & 12.235 \\
\hline $\begin{array}{l}4 \\
6\end{array}$ & 19.620 & 145.39 & 63.664 & 0.996 & 143.485 & 6.248 & 7.648 \\
\hline $\begin{array}{l}6 \\
8\end{array}$ & & & $\begin{array}{l}77.794 \\
91.792\end{array}$ & $\begin{array}{l}1.000 \\
1.007\end{array}$ & $\begin{array}{l}144.143 \\
138.043\end{array}$ & $\begin{array}{l}7.306 \\
7.441\end{array}$ & $\begin{array}{l}8.161 \\
8.055\end{array}$ \\
\hline 4 & 21.276 & 185,40 & .74 .634 & 1.002 & 133.129 & 5.346 & 6.544 \\
\hline 6 & & & 92.710 & 0.999 & 129.415 & 6.049 & 6.757 \\
\hline 8 & & & 109.648 & 0.998 & 123.360 & 6.156 & 6.638 \\
\hline 4 & 22.600 & 222.20 & 85.484 & 1.002 & 121.628 & 4.598 & 5.628 \\
\hline 6 & & & 104.396 & 1.006 & 122.328 & 5.383 & 6.013 \\
\hline 8 & & & 120.992 & 1.003 & 121.429 & 5.714 & 6.161 \\
\hline 4 & 23.139 & 238.50 & 94.060 & 0.999 & 107.833 & 3.947 & 4.873 \\
\hline 4 & 24.394 & 279.40 & 111.070 & 1.000 & 90.612 & 3.173 & 3.884 \\
\hline 4 & 25.185 & 307.50 & 120.296 & 1.004 & 84.997 & 2.884 & 3.529 \\
\hline 4 & 27.492 & 400.00 & 173.580 & 1.004 & 53.103 & 1.650 & 2.020 \\
\hline 6 & & & 220.080 & 1.004 & 49.550 & 1.792 & 2.002 \\
\hline 8 & & & 257.520 & 1.003 & 48.253 & 1.863 & 2.009 \\
\hline 4 & 28.593 & 450.03 & 292.766 & 0.999 & 21.001 & 0.628 & 0.768 \\
\hline 6 & & & 344.564 & 1.002 & 22.742 & 0.730 & 0.816 \\
\hline 8 & & & 414.034 & 1.003 & 21.001 & 0.780 & 0.841 \\
\hline 2 & 23.850 & 261.17 & 73.430 & 0.998 & 96.871 & 1.602 & 3.535 \\
\hline 2 & 26.031 & 339.57 & 96.236 & 0.999 & $7,3.332$ & 1.111 & 2.452 \\
\hline 2 & 26.769 & 369.28 & 120.184 & 0.997 & 51.133 & 0.753 & 1.662 \\
\hline 2 & 27.977 & 421.57 & 181.110 & 1.000 & 25.705 & 0.362 & 0.800 \\
\hline 2 & 28.749 & 457.44 & 299.940 & 0.999 & 10.170 & 0.140 & 0.308 \\
\hline \multicolumn{8}{|c|}{ Cylindrical units, $h / d=1.0$} \\
\hline 4 & $\begin{array}{l}13.273 \\
17.015\end{array}$ & $\begin{array}{r}67.53 \\
143.7 !\end{array}$ & $\begin{array}{l}41.478 \\
63.644\end{array}$ & $\begin{array}{l}0.998 \\
0.997\end{array}$ & $\begin{array}{l}157.103 \\
141.878\end{array}$ & $\begin{array}{r}10.731 \\
7.396\end{array}$ & $\begin{array}{l}16.159 \\
11.223\end{array}$ \\
\hline & 18.354 & 178.55 & 74.634 & 0.998 & 128.215 & 6.166 & 9.313 \\
\hline & 19.488 & 213.73 & 85.484 & 0.997 & 116.991 & 5.262 & 7.902 \\
\hline & 20.273 & 240.61 & 94.060 & 1.004 & 108.784 & 4.681 & 6.991 \\
\hline & 21.775 & 298.15 & 111.070 & 1.002 & 96.672 & 3.844 & 5.682 \\
\hline & 24.086 & 403.51 & 173.580 & 0.998 & 53.569 & 1.884 & 2.678 \\
\hline & 25.530 & $\Delta 81.02$. & 292.766 & 0,994 & 22.449 & 0.730 & 0.999 \\
\hline
\end{tabular}


Table 20. Criticality of $\mathrm{U}(5) \mathrm{O}_{2}$ at an $\mathrm{H}: \mathrm{U}=3$ in concrete reflected cubic arrays

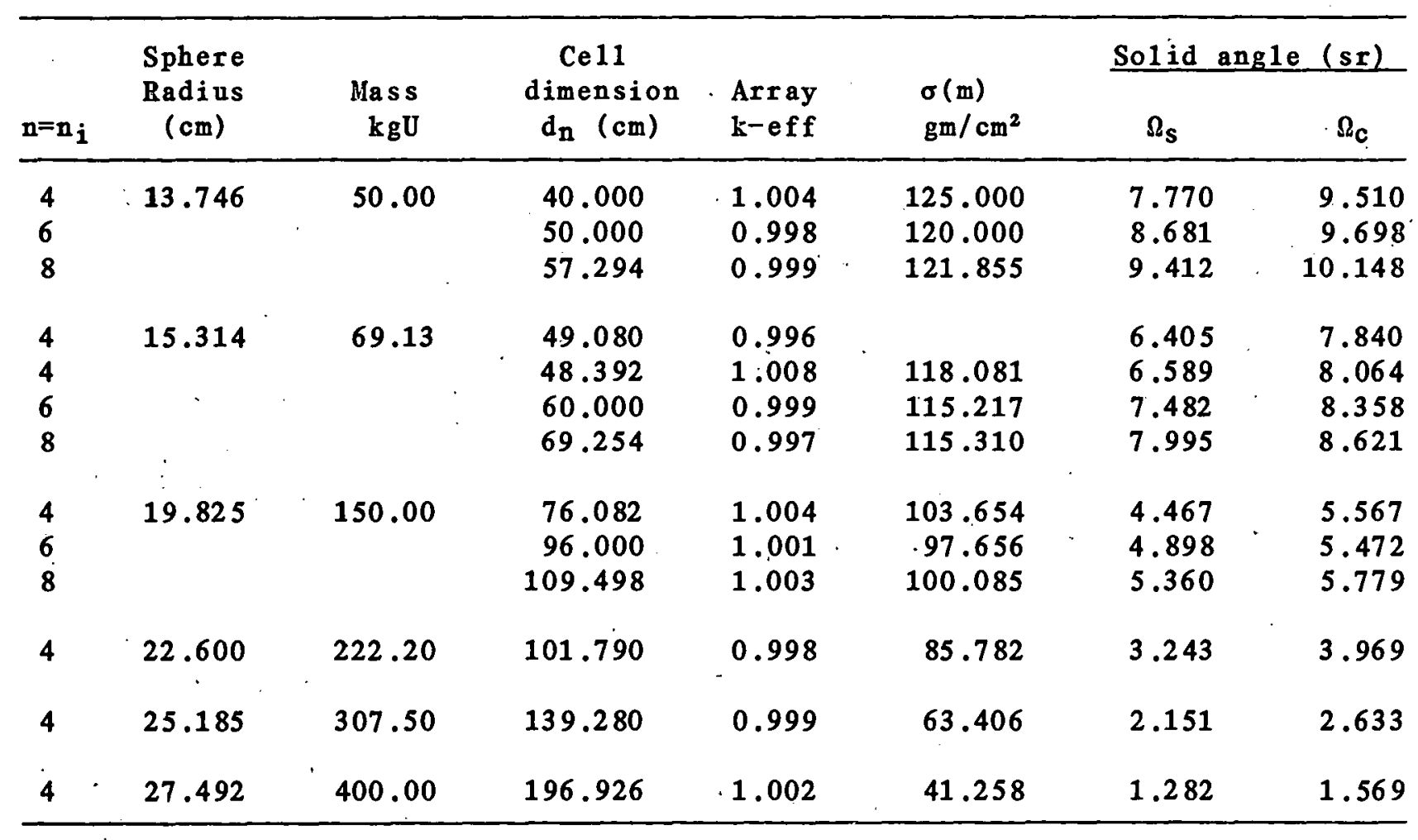


precise calculated k-eff to associate with criticality. The resulting $\sigma(\mathrm{m})$ from Eq. 1 is also given in Tables 19 and 20. These data are presented graphically in Fig. 27, where the nonlinear appearance of the data is due to the combined effect of the imprecise definition of criticality and the assumption of $c=0$.

A least squares fit of the data defines a value for the constant $c_{2}$ of Eq. 2, recognizing that systems will be defined within a few percent of a calculated k-eff of 1.00 . A $c_{2}=3.76 \times 10^{-4} \mathrm{~cm}^{-2}$ was obtained for the water reflected data, and $c_{2}=2.69 \times 10^{-4} \mathrm{~cm}^{-2}$ for the concrete reflected data. These values of $c_{2}$ and an $m_{0}$ of $494 \mathrm{~kg}(5) \quad\left(r_{0}=29.5\right.$ cm) adequately represent the data with spherical units. The data with the cylinders would require a slightly larger value of $m_{0}$ and a necessarily smaller value of $c_{2}$. The results presented in Fig. 27 indicate that concrete replacing water as a reflector on arrays of $U(5) \mathrm{O}_{2}$ at an $H: U=3$ is less effective than on arrays of $U(93)$ metal.

Calculated data for infinite planar arrays of $\mathrm{U}(5) \mathrm{O}_{2}$ arrays are given in Tables 21 and 22 . These data are represented in Fig. 28, and they yield values for $c_{2}$ of $1.27 \times 10^{-4} \mathrm{~cm}^{-2}$ and $8.91 \times 10^{-5} \mathrm{~cm}^{-2}$ for the water and concrete reflected arrays, respectively. More typical representation of data for planar arrays is by normalization to the surface density of the infinite slab configuration of the fissile material. The thickness of an infinite $s 1 a b$ when reflected by water is approximately $13.8 \mathrm{~cm}$, and when concrete is the reflector, approximate $1 \mathrm{y} 9.5 \mathrm{~cm}$. The normalization is presented in Fig. 29.

The solid ang1e ropresentation nf the data of Tables 19 and 20 is given in Fig. 30 where the $\Omega_{c}$ is the total steradians at the center of the arrays. The broken lines appearing in the figure are from Eq. 15 


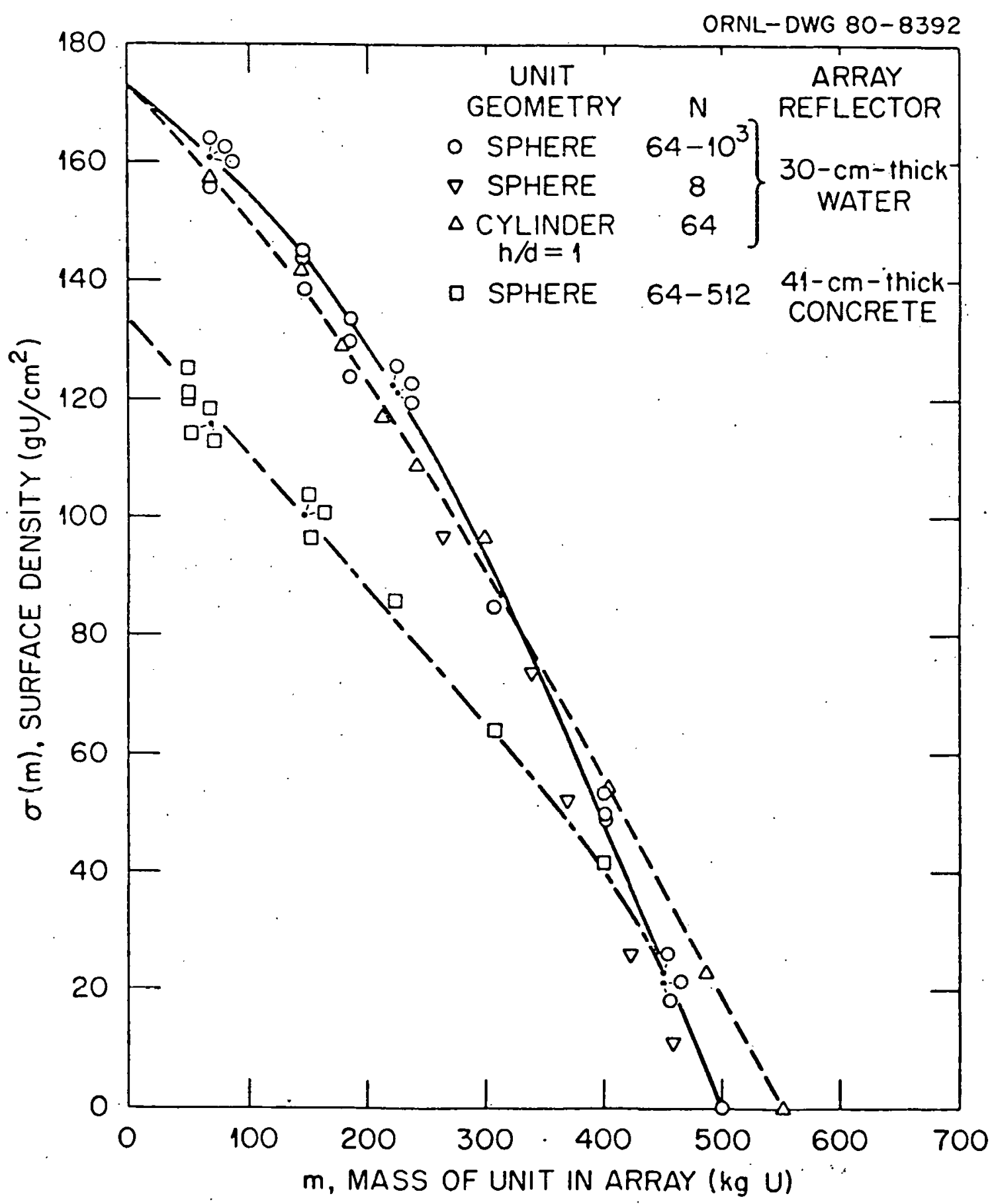

Fig. 27. Limiting surface density representation of spherical units of $U(5) \mathrm{O}_{2}$ at an $H: U=3$. The arrays are cubic and are reflected by concrete and water. 
Table 21. Criticality of $U(5) \mathrm{O}_{2}$ at an $\mathrm{H}: \mathrm{U}=3$ in water reflected infinite planar arrays

\begin{tabular}{|c|c|c|c|c|c|c|}
\hline $\begin{array}{c}\mathbf{n}_{\mathbf{x}}=\mathbf{n}_{\mathbf{y}}=\infty \\
\mathbf{n}_{\mathbf{z}}\end{array}$ & $\begin{array}{l}\text { Unit } \\
\text { radius } \\
(\mathrm{cm})\end{array}$ & $\begin{array}{l}\text { Mass } \\
\mathrm{kg} \mathrm{U}\end{array}$ & $\begin{array}{c}\operatorname{Ce} 11 \\
\text { dimension } \\
(\mathrm{cm})\end{array}$ & $\begin{array}{l}\text { Array } \\
k-e f f\end{array}$ & $\begin{array}{l}\sigma(\mathrm{m}) \\
\mathrm{g} / \mathrm{cm}^{2}\end{array}$ & $\begin{array}{c}\Omega_{c}(s r) \\
n_{x}=n_{y}=10^{4}\end{array}$ \\
\hline \multirow[t]{6}{*}{6} & 11.028 & 25.82 & 50.800 & 0.998 & 60.032 & 21.114 \\
\hline & 14.190 & 55.00 & 77.758 & 1.003 & 54.585 & 14.920 \\
\hline & 15.735 & 75.00 & 92.710 & 0.997 & 52.356 & 12.906 \\
\hline & 16.885 & 92.68 & 104.396 & 1.004 & 51.022 & 11.720 \\
\hline & 23.501 & 249.88 & 220.080 & 0.997 & 30.954 & 5.109 \\
\hline & 26.832 & 371.90 & 378.564 & 0.997 & 17.356 & 2.251 \\
\hline \multirow[t]{8}{*}{4} & 11.028 & 25.82 & 41.472 & 0.993 & 60.049 & 23.008 \\
\hline & 14.385 & 57.31 & 63.664 & 1.002 & 56.555 & 16.612 \\
\hline & 15.735 & 75.00 & 74.634 & 1.004 & 53.859 & 14.463 \\
\hline & 17.042 & 95.29 & 85.484 & 1.003 & 52.158 & 12.932 \\
\hline & 19.215 & 136.58 & 111.070 & 1.005 & 44.285 & 9.738 \\
\hline & 19.705 & 147.30 & 120.296 & 0.998 & 40.715 & 8.731 \\
\hline & 23.128 & 238.17 & 173.580 & 1.001 & 31.619 & 5.777 \\
\hline & 26.542 & 359.97 & 292.766 & 1.000 & 16.799 & 2.674 \\
\hline \multirow[t]{5}{*}{2} & 11.028 & 25.82 & 29.320 & 0.998 & 60.070 & 25.831 \\
\hline & 14.385 & 57.31 & 45.020 & 1.003 & 56.548 & 18.640 \\
\hline & 17.042 & 95.29 & 60.440 & 1.001 & 52.169 & 14.517 \\
\hline & 19.215 & 136.58 & 78.540 & 1.003 & 44.283 & 10.929 \\
\hline & 23.167 & 239.38 & 122.740 & 1.002 & 31.779 & 6.505 \\
\hline \multirow[t]{4}{*}{1} & 14.893 & 63.59 & 31.840 & 1.001 & 62.729 & 24.057 \\
\hline & 17.330 & 100.20 & 42.740 & 0.995 & 54.852 & 18.078 \\
\hline & 23.128 & 238.17 & 86.800 & 0.995 & 31.611 & 7.806 \\
\hline & 26.542 & 359.97 & 146.400 & 1.001 & 16.795 & 3.614 \\
\hline
\end{tabular}


Tab1e 22. Criticality of $U(5) \mathrm{O}_{2}$ at an $\mathrm{H}: \mathrm{U}=3$ in concrete reflected infinite planar arrays

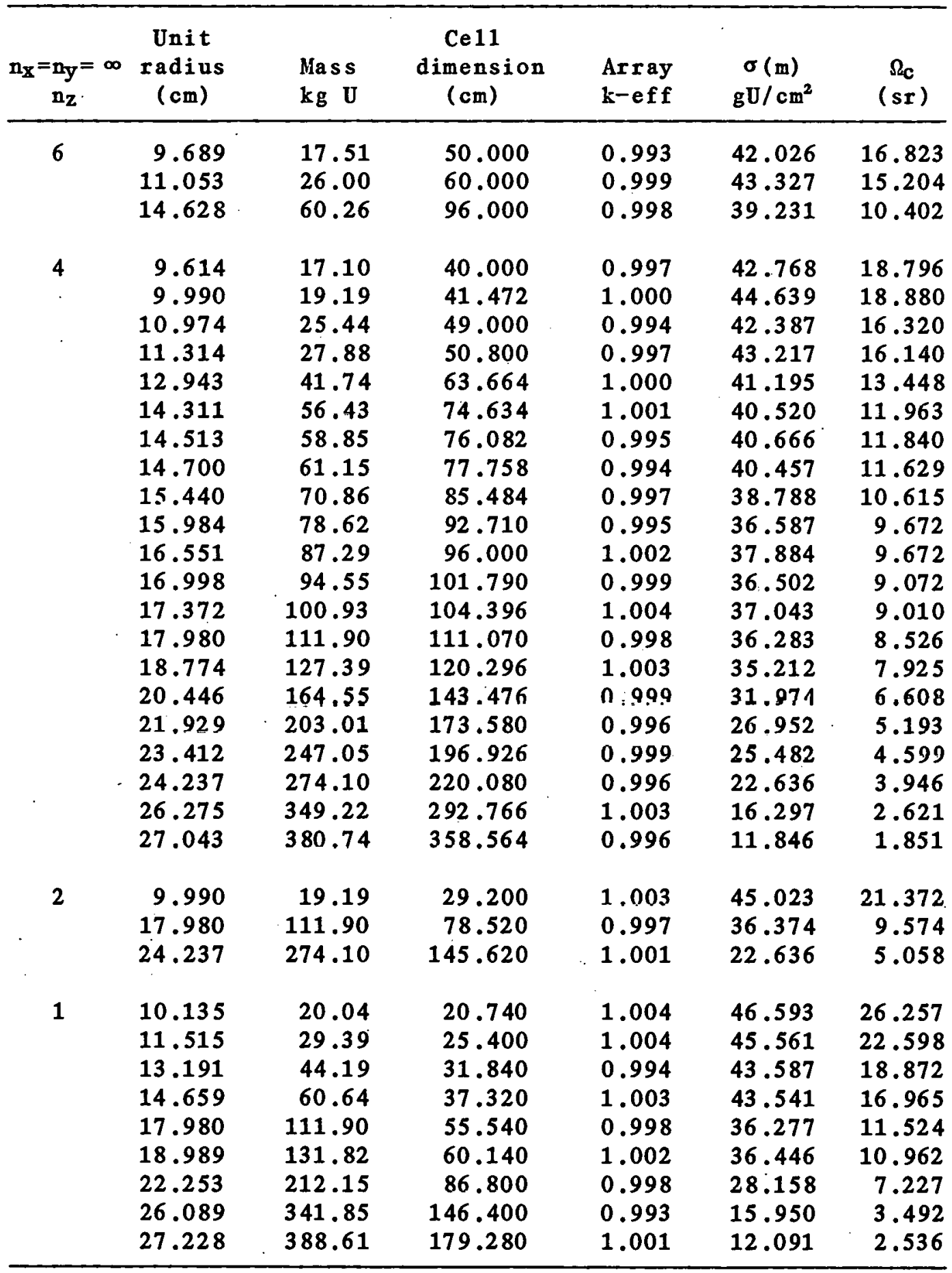




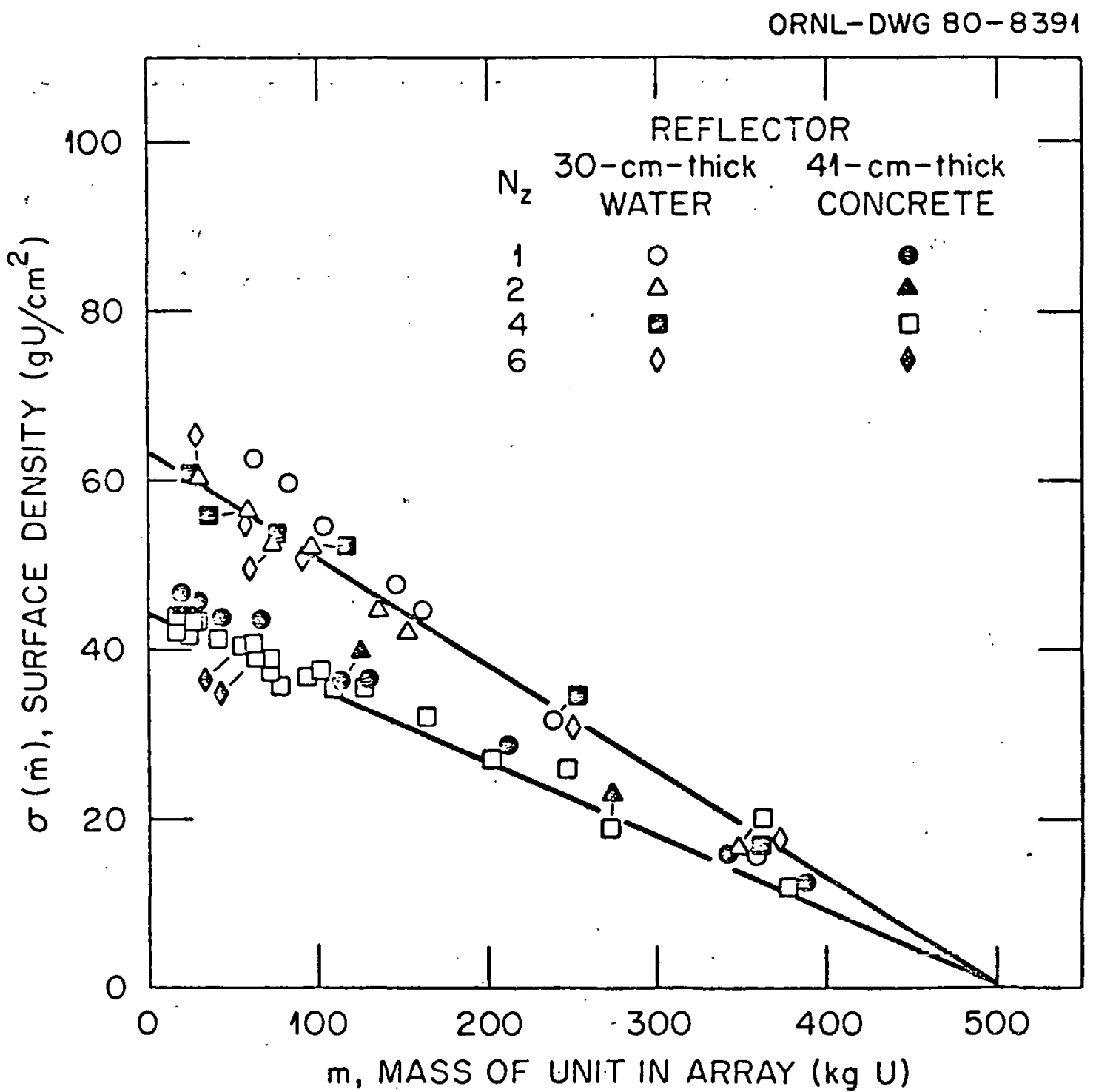

Fig. 28. Limiting surface density representation of infinite planar arrays of $U(5) O_{2}$ at an $H: U=3$ as spheres. The arrays are reflected by concrete and by water. 


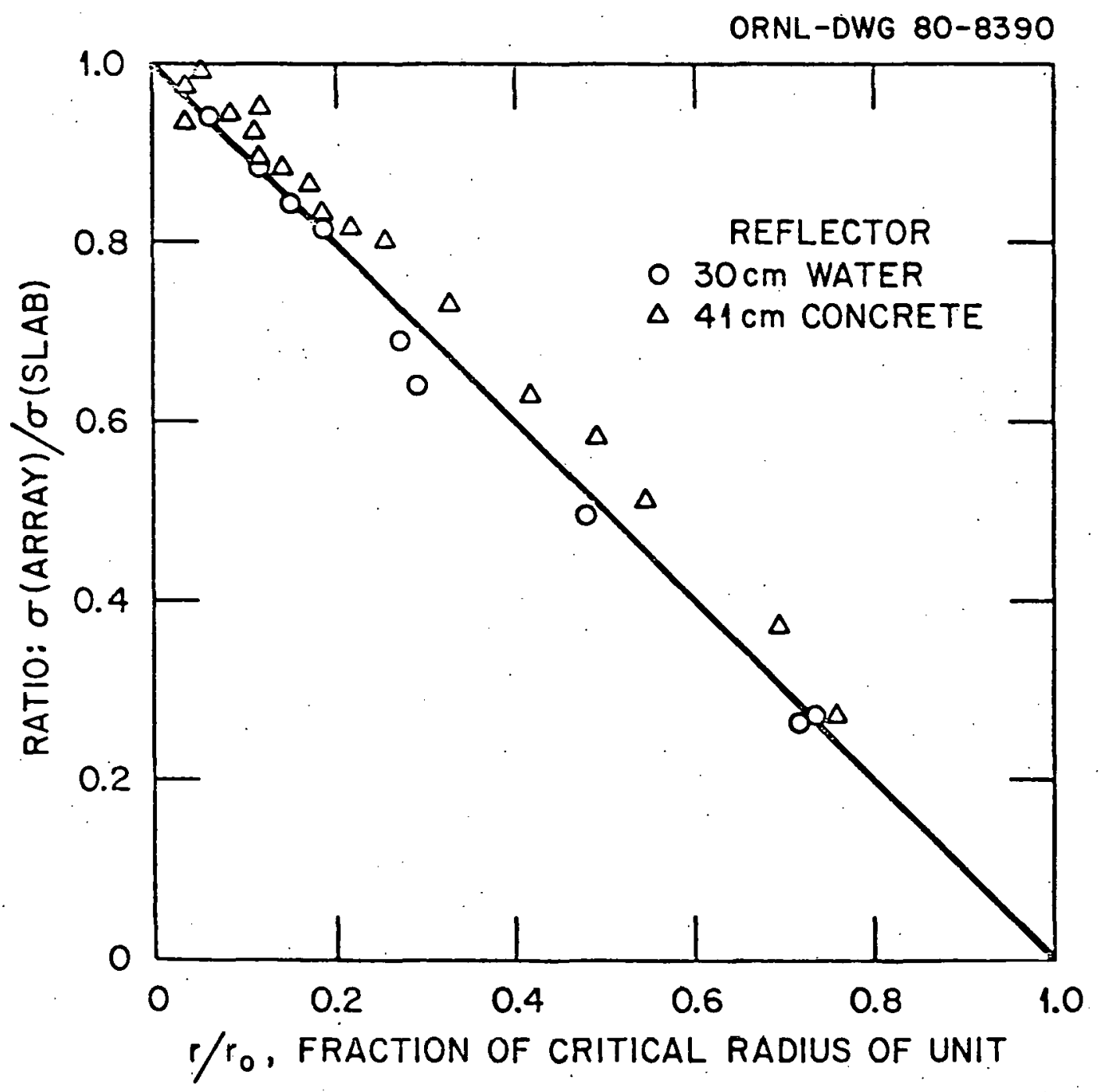

Fig. 29. Criticality of water and concrete reflected infinite arrays of spherical units of $\mathrm{U}(5) \mathrm{O}_{2}$ at an $\mathrm{H}: \mathrm{U}=3$ normalized to the critical slab surface density for the respective reflector condition. 


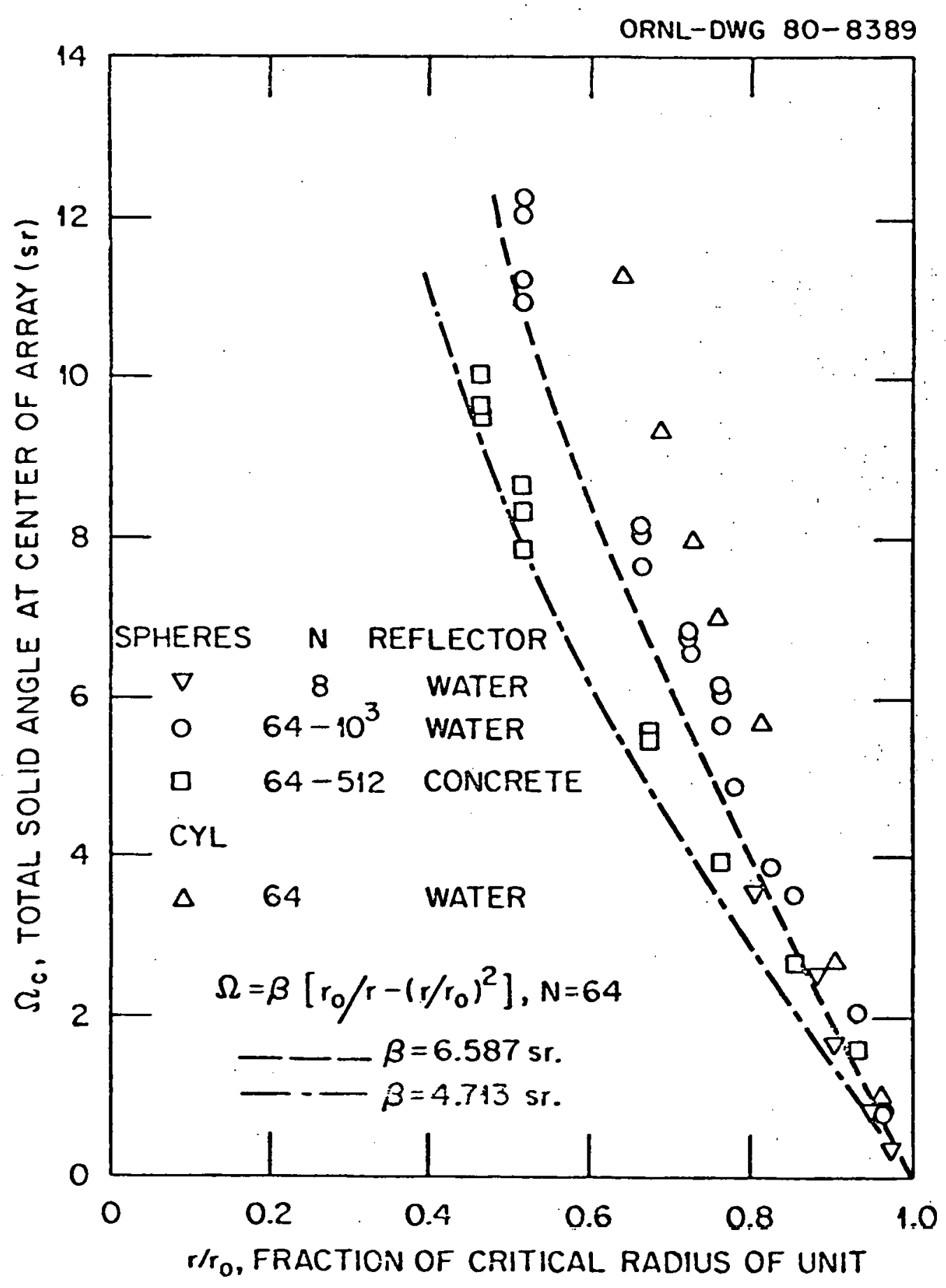

Fig. 30. Total solid angle representation of concrete and water reflected cubic arrays of $\mathrm{D}(5) \mathrm{O}_{2}$ at an $\mathrm{H}: \mathrm{U}=3$. The $\Omega$ contribution of the units is summed at the center of the array. 
for the $N=64$-unit arrays. The coefficient $\beta=(F(64) / 4)\left(A_{\circ} c_{2}\right)$ is $6.587 \mathrm{sr}$ for the water reflected arrays and $4.713 \mathrm{sr}$ for the concrete reflected arrays. The values of $\Omega$ computed by the SNAKE code at the center of the unit nearest the center of the arrays, appearing in the tables would evidence a much stronger dependence on the number of units in an array than does the $\Omega_{c}$ plotted in Fig. 30 .

The $\Omega_{c}$ given in Tables 21 and 22 for the infinite planar arrays of spheres was determined for $N 1$ arge, but finite; therefore, the $\Omega$ associated with estimated criticality would be larger but by no more than $1 \%$ of the value shown. Again, the $\Delta$-eff resulting from the slight increase in $\Omega$ would be less than the uncertainty of criticality for the array geometry. The values of $\Omega$ are larger than those shown in Fig. 30 for the reflected cubic arrays.

It is to be noted. that while Eq. 16 is valid for arrays in general, the reasonable approximation that the unit k-eff varies directly with the fraction of the critical radius is not valid for thermal systems. The response of the unit k-eff of $U(5) 0_{2}$ at an $H: U$ of 3 as a function of the fraction of the critical radius was calculated for spheres and for cylinders, where the h/d varied from 0.1 to $\infty$. These results are presented in Fig. 31 and the calculated critical radii appear in Table 23 . The k-eff for all the geometries are within the limits given for the data points. A change in an array k-eff of this fissile material will require a larger change in the dimension of the units than would the same k-eff change for ${ }^{23}{ }^{3} \mathrm{UO}_{2}$ at an $\mathrm{H}: \mathrm{U}$ of 3 , for example.

An indication of the behavior of $\sigma(m)$ for cylindrical units of $\mathrm{U}(5) \mathrm{O}_{2}$ in a planar and in a 1 inear array as a function of the $\mathrm{h} / \mathrm{d}$ ratio is given in Figs. 32 and 33 . The arrays are reflected by $41-c m-t h i c k$ concrete. The calculated 35 planar array data of Fig. 32 are for 


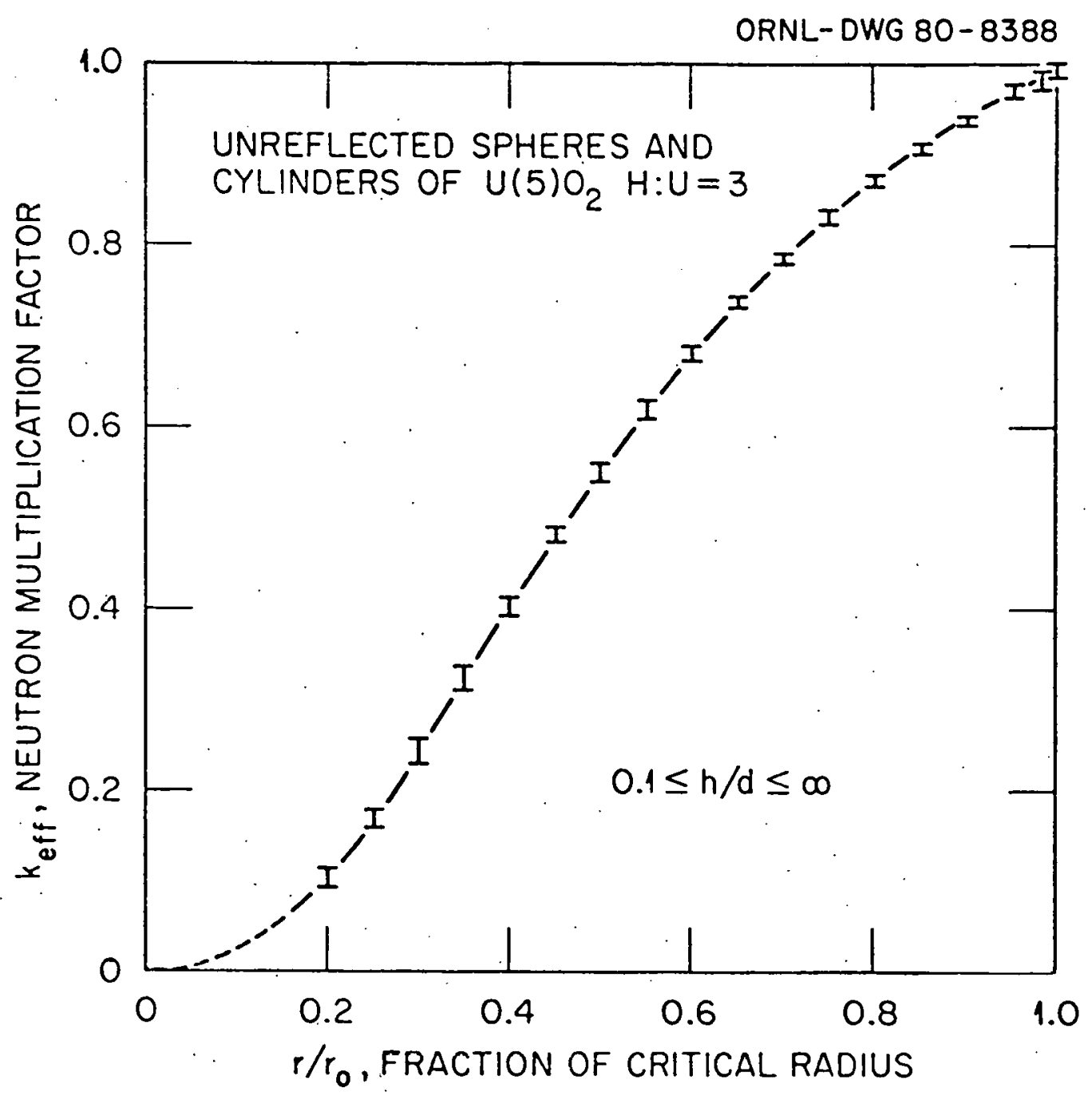

Fig. 31. Calculated k-eff of unreflected single units of $\mathrm{U}(5) \mathrm{O}_{2}$ at an $\mathrm{H}: \mathrm{U}=3$ as a function of the fraction of the critical radius of the unit geometry.

Tab1e 23. Calculated critical radius for a single unit of $U(5) 0_{2}$ at an $H: U=3$ for various cylinder geometries

\begin{tabular}{cccc}
\hline $\begin{array}{c}\text { Radius } \\
(\mathrm{cm})\end{array}$ & $\mathrm{h} / \mathrm{d}$ & $\begin{array}{c}\text { Radius } \\
(\mathrm{cm})\end{array}$ & $\mathrm{h} / \mathrm{d}$ \\
\hline 134.0 & 0.1 & 26.7 & 1.0 \\
71.5 & $\dot{2}$ & 29.2 & 2.0 \\
50.1 & 0.3 & 22.4 & 3.0 \\
36.1 & 0.5 & 22.2 & 4.0 \\
30.3 & 0.7 & 21.6 & 8.0 \\
28.5 & 0.8 & 21.0 & $\infty$ \\
27.4 & 0.9 & & \\
\hline
\end{tabular}




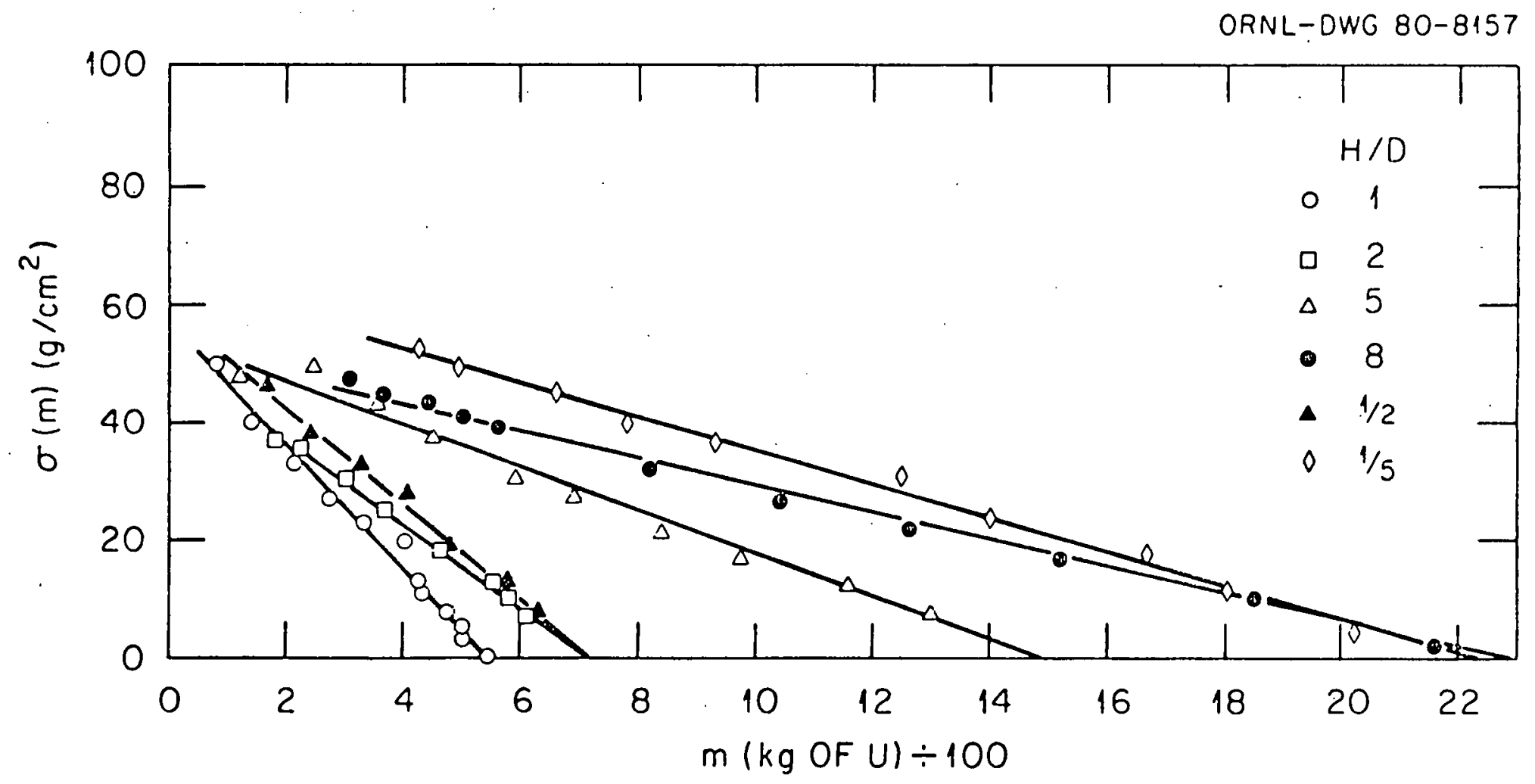

Fig. 32. Limiting surface density representation of concrete reflected planar arrays of 1024 units of $\mathrm{U}(5) \mathrm{O}_{2}$ at an $\mathrm{H}: \mathrm{U}=3$ arranged in a $32 \times 32$ unit pattern. The units are cylinders of various shapes. 


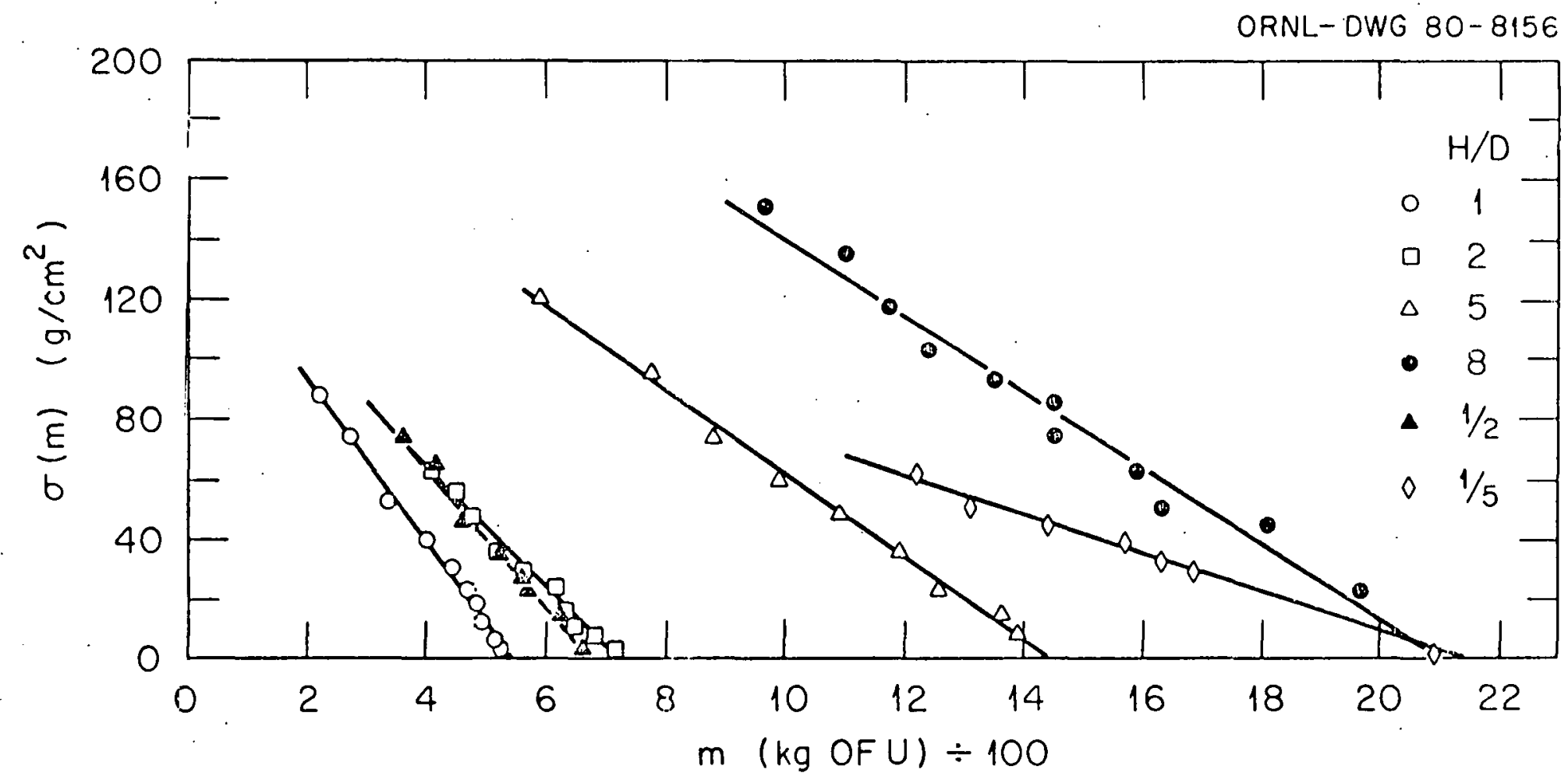

Fig. 33 . Limiting surface density representation of concrete reflected linear arrays of 128 units of $\mathrm{U}(5) \mathrm{O}_{2}$ at an $\mathrm{H}: \mathrm{U}=3$ for cylinders of various shapes. 
$32 \times 32 \times 1$ units, while the 1 inear arrays of Fig. 33 are for 128 units. A least square $f i t$ of the data for each h/d ratio yields the characteristic constants given in Table 24. The mass corresponding to the calculated single unit critical radius of Table 23 is repeated for comparison with the values of "mo" derived from the array calculations. These data of finite systems show that $\sigma(m)$ and $m$ values required for criticality are greater than those for infinite planar arrays of spherical units. Expression of the data in terms of $\Omega_{s}$ appears in Fig. 34. The data for units with h/d $<0.5$ are displaced below the less extreme cylindrical shapes as was observed in Fig. 8 with the U(93) metal cylinders. The use of $\Omega$ summed at the center of the arrays improves the representation, but it is evident that the criticality of units with slab-1ike geometries does require individual investigation.

The cursory examination of the criticality of systems in which an appreciable fraction of fission is thermal has shown the applicability of the limiting surface density and solid angle methods to yield reasonable results. The condition of a relaxed accuracy in k-eff of a few percent does not greatly affect the representations of criticality. The most influenced result appears in the reduced reactivity change in response to a change in the dimension of a unit, Fig. 31, compared to $k \sim r / r_{0}$ for the nonthermal systems. Implication of this observation is that factors derived from nonthermal systems and applied to critical thermal systems will result in subcriticality. For example, replacing a water reflector by a concrete reflector on an array of units composed of $\mathrm{U}(93)_{2}$ at an $\mathrm{H}: \mathrm{U}=0.4$ results in a positive reactivity addition to the array. Compensation of the positive reactivity by reducing the mass of the unit is easily made. However, applying that reactivity change to a 
Table 24. Characteristic constants for $U(5) \mathrm{O}_{2}$ at an $H: U=3$ for finite 1 inear and planar arrays

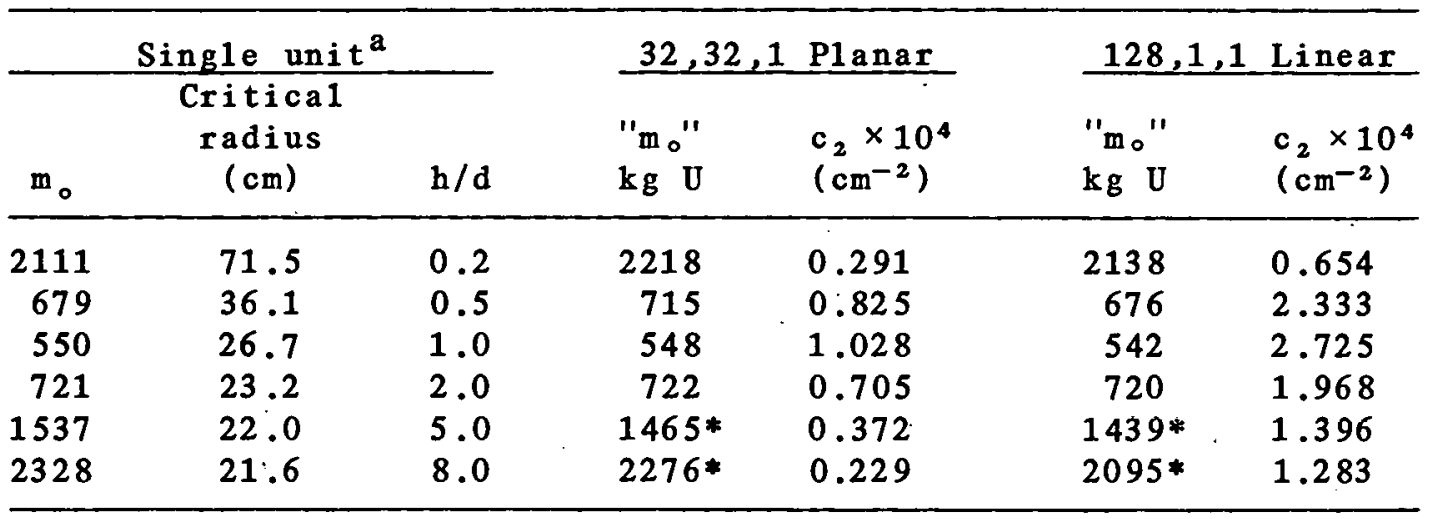

${ }^{a}$ From Tab1e 23 .

* Concrete in contact with units. 


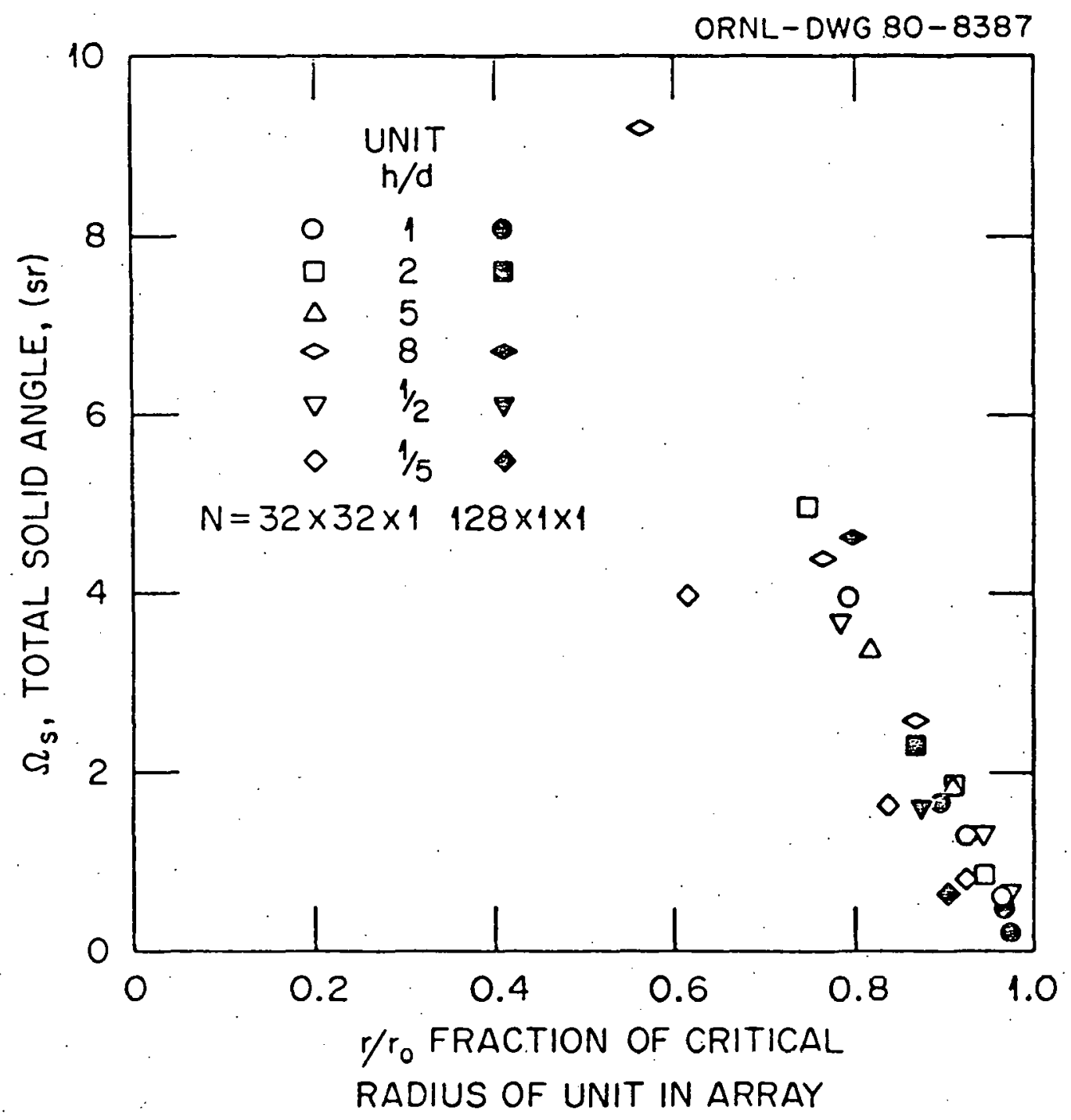

Fig. 34. Total solid angle representation of criticality for concrete reflected 128 unit 1 inear array and 1024 unit planar arrays of $U(5) \mathrm{O}_{2}$ at an $\mathrm{H}: \mathrm{U}=3$ as cylinders of various shapes. 
- critical array of equivalent $\mathrm{U}(5) \mathrm{O}_{2}$ units at an $\mathrm{H}: \mathrm{U}=3$ to compensate for the reflector change will result in subcriticality. Furthermore, supercriticality could result if one were to replace a concrete reflector by a water reflector on a subcritical array using the same factor to increase the reactivity.

\section{DISCUSSION AND CONCLUSIONS}

Models for Subcriticality

Surface density. The original concept of the surface density method, to specify subcritical configurations of fissile materials in a plane, is certainly valid when the ratio $\sigma(a r r a y) / \sigma(s 1 a b)$ is 1 ess than 0.4 and the units are no more than 0.3 of the unreflected critical mass ${ }^{2}$ for the unit shape being evaluated. There is no evidence to suggest this is not a general result for air-spaced units in reflected planar arrays. Arrangements of units of fissile materials in a plane with $n_{z} \geq 1$ meeting the above criteria are reliably subcritical. The single $\sigma_{z}$ value is sufficiently independent of the projected surface density values in the remaining two directions of the array. Individual situations of uniform arrays with units or regions of the array having different fissile materials should be evaluated by a validated calculational method. This and similar questions of application concerning planar arrays of large but finite numbers of units could be evaluated by establishing acceptable surface densities of mixed arrays from the CI system (Tables 13 and 14) associated with subcritical arrays. For example, suitable reductions in the masses of Iable 13 aud air rangemonto of the mixed units inten reflected planar arrays having $C I \leq 100$. The application of a derived $\sigma_{z}$ value to an operation assumes the reflector condition of the environment returns neutrons to the 
fissile materials no more effectively than the reflector condition of the infinite $s 1 a b$ or the conditions of Tab1es 13 and 14 .

Solid angle. The solid angle method used to specify subcritical arrangements of units based upon a particular linear relationship* cannot have general applicability independent of the form and type of $f$ issile material. Units which have a neutron multiplication factor proportional to the unit dimension, i.e., $k$-eff $\sim r / r_{o}$, clearly result in $\Omega$ not having a linear dependence on k-eff. This is evident in Eq. 15 and is displayed in Fig. 2. Furthermore, the relation can be more complex as is apparent from the $k$-eff dependence on $r / r_{0}$ shown in Fig. 31. The method is basically a "safe or nonsafe" technique applicable to systems having the characteristics of water-reflected arrays of fissile materials in aqueous solutions similar to the experimental bases. There is no measure of the conservatism of the associated subcriticality in the absence of defined criticality. Application of the linear relation to other forms or types of fissile materials should require demonstration of subcriticality.

\section{Models for Criticality}

Surface density - solid angle methods and criticality. Experimental and calculated criticality data are expressible in terms of the 1 imiting surface density and solid angle methods. The two methods can be placed into one-to-one correspondence. The ideal water-reflected cubic arrays of spherical units centered in cubic cells are suitable data to exhibit the properties of criticality dependent on the parameters used in the two methods. These properties are explicit in the semi-empirical relations

\footnotetext{
*The relation currently in use is $\Omega=9-10 \mathrm{k}$-eff, see Ref. 24 .
} 
and are subject to the limitations specified by the constraints on the expressions. For example, the constant c of Eq. 1 is subject to the condition of the neutron fission energy spectrum having a mean energy of fission greater than $0.1 \mathrm{eV}$ at critical. The constant tends toward zero as the fraction of thermal fissions occurring increases, as was evidenced by the data on $U(5) \mathrm{O}_{2}$ at an $\mathrm{H}: \mathrm{U}$ ratio of 3 . The significance and importance of the constant $c_{2}$ of Eq. 2 is evidenced by its ability to prescribe the sign and magnitude of changes in k-eff resulting from variations in array conditions. These include shape of the unit, cell and array, the reflector material thickness, density and location, and the form and type of fissile material.

The constant $c_{2}$ characterizes the array criticality as a function of the fissile material mass of the units when each of the conditions is varied and the others are maintained constant. The quantities $c_{2}$ and $m_{0}$ are defined by criticality data and, as exemplified by the unit shape studies, may require several sets (e.g., Tab1e 4) to model criticality over the entire mass range from 0 to the single unit critical mass, $m_{0}$. Given $c_{2}$, the corresponding $\sigma(m)$ for criticality is determined from Ey. 2 by the mass of tho unit, while Eq. 1 exhihits the dependence of criticality on the number of units and their spacing in an array. These relations have their counterparts in the solid angle method as expressed in Eqs. 14 and 15. When the array geometry and reflector conditions are maintained, a situation described by Eq. 4 in the $\sigma(m)$ method and by Eq. 17 in the $\Omega$ method, the neutron multiplication factor of the array under this oonotraint ie dixestly prnportional to the nequtron multiplication factor of the units in the array (Eq. 16). The criticality of different fissile materials in the same array geometry provides a working definition 
of equivalent masses. Units of different fissile materials satisfying. this definition of equivalence do not have the same neutron multiplication factor, a result implicit in Eq. 5. The differences in k-eff may not be large and equality would be an unusual happening.

The information contained in this study show that the criticality of fissile materials in arrays can be adequately monitored by the semiempirical relations derived. The relations provide reasonable estimates of changes in array neutron multiplication factors resulting from changes in array conditions described by the following.

Number of units. Criticality of different $N$-unit arrays are characterized by a single set of constants, $c_{2}$ and $m_{0}$, in the 1 imiting surface density method, $\sigma(m)$, for $N \geq 64$. The reliability of specifying criticality for smaller N-unit arrays, 27 or 1 ess, is probably not better than a $\Delta k$-eff of 0.02 because the unit self-multiplication does not remain constant at the sma1l cell sizes required. The constants $c_{2}$ and $m_{0}$ in the expression of criticality by Eqs. 1 and 2 in the $\sigma(m)$ method does not depend upon the number of units in the array. The constant $\beta$ of Eq. 15 , however, does have an $\mathrm{N}$ dependence as displayed in Fig. 3. The solid angle associated with the criticality of units, with a particular mass, will have a slowly varying dependence on the number of units in the arrays. Smaller values of $\Omega$ will be attained by arrays with small N.

Unit shape. Changes in unit shape for a given mass of units result in a change in the unit k-eff and this is mirrored as a change in the array reactivity of the same sign and approximately the same magnitude as the unit. Each unit shape is characterized by a set of constants $c_{2}$ and $m_{0}$ in the $\sigma(m)$ method and by $\beta$ and $a_{\circ}$ in the $\Omega$ method. In both methods, 
the unit shape is constant as the mass is varied. Estimates of changes in array k-eff caused by changing mass of units require data for k-eff of the unit as the mass is varied under the constraint of constant shape, (Eq. 16). Extreme shapes of units, typified by cylinders with h/d ratios outside the range $0.3 \leq h / d \leq 3$, may require several sets of constants to represent criticality over the entire mass range from $0.1 \mathrm{~m}_{0}$ to $\mathrm{m}_{0}$.

Array shape. Arbitrary arrangements of units into an array are related to cubic array data by the shape factor, $R$, relation, Eq. 6. The quantity $R$ is the ratio of the surface-to-volume ratio of the array to that of a cell in the array and is thus independent of the cell size and shape. The shape factor is used to give the characteristic slope $c_{2}^{-}$associated with arrays having the same relative dimensions (Eq. 8). Equations 7 and 8 specify the criticality of arrays under the 1 imitation that $R$ not exceed a maximum value of 5.34. This constraint is necessary to avoid single unit criticality. The change in array reactivity due to change in array shape from cubic can range from slight to a value of about 0.45 . The 1atter corresponds to a change in the mass of the units by a factor of approximately 3 . In addition, the magnitude of the $\Delta k$-eff change is dependent on the number of units in the cubic array and on the mass of the units. The $\Delta$-eff controlled by array shape increases with increasing the number of the units and decreases with increasing the mass of the units.

The extreme geometries of unlimited numbers of units in 1 inear or planar arrays is expressible by both the $\sigma(m)$ and $\Omega$ methods.

Cell shape. Data for criticality of reflected arrays having units centered in cubic cells has broad applicability in both methods provided the cell shape is not so extreme as to violate some roasonable surface 
separation of units in the array. There is a slight negative reactivity to the array neutron multiplication factor for deviations from the cubic ce11 volume. Criticality of arrays with constant ce11 shape, other parameters such as reflector condition, array shape, or unit shape also constant, result in characteristic constants for each cell shape.

Reflectors. The study, conducted with water and concrete as reflectors surrounding arrays, has shown that it is possible to express criticality of arrays as a function of the type of reflector material, its thickness, its density, and its location with respect to the array surfaces. The total worth of a reflector, defined as the $\Delta k$-eff or reactivity associated with the presence or absence of the reflector on the array, provides a method to compare reflector conditions and define their equivalence. The total reflector worth is interpreted as that reactivity change to units in an array necessary to accommodate a closely fitting reflector surrounding an unreflected array of the units. Opper 1 imits to the effect of reflector changes to an array $k$-eff can be made by examining similar effects to a unit in a single cell of the array. The sensitivity of the array k-eff to reflector location is less for planar arrays than it is for cuboidal arrays.

Arrays of mixed units. The equivalence relation, Eq. 4 or 5, easily associates critical arrays having units of different fissile materials. Because of the larger amount of information on water reflected critical arrays of different fissile materials, it is prudent to determine the characteristic constants $c_{2}$ and $m_{0}$ for a new form of fissile material in water reflected cubic arrays. This minor bit of information allows application to the new material of analyses already performed and magnitudes of 
-array k-eff's to be associated with array perturbations already evaluated for a known fissile material through the equivalence relation. Criticality of arrays with different fissile materials, different cell volumes, and different numbers of units in critical arrays is concisely expressed by the Criticality Indicator system. Expression of criticality for arrays of mixed units by the solid angle method is more complex than the $\sigma(m)$ method and does require that the solid angle be summed at the center of the individual uniform arrays rather than at the center of the unit nearest the center of the array. The equivalence relation, Eq. 4 or 5 , and the k-eff of a unit as a function of the fraction of its critical dimension, i.e., $r / r_{0}$, are important to the interpretation of array criticality in both methods. The equivalence relation and unit k-eff are central relations in evaluating array perturbations.

We can conclude from this study that each form of fissile material in an environment has a unique representation of criticality in either the surface density or the solid angle method. 


\section{REFERENCES}

1. H. C. Paxton, "Correlations of Experimental and Theoretical Critica1ity Data," Proceedings of Kar1sruhe Symposium, 173-205, OECD, ENLA (1961).

2. H. C. Paxton, Criticality Control in Operations with Fissile Material, LA366(RW) (1972).

3. R. L. Stevenson and R. H. Odegaarden, "Studies of Surface Density Spacing Criteria Using KENO Calculations," ANS Trans. 12, No. 2890 (1969).

4. T. Gutman, "A Surface-Density Evaluation of Critical Array Data," Nuc1. App1., 2, 121 (1968).

5. S. J. Altschuler and C. L. Schuske, "Models for the Safe Storage of Fissile Meta1," Nuc1. Tech. 13, 131 (1972).

6. S. J. Altschuler and C. L. Schuske, "A Study of Criticality Parameters Affecting the Handling and Storage of Fissile Metal," Nuc1. Tech., 18, 55 (1973).

7. C. L. Schuske and S. J. Altschuler, "Models for the Safe Storage of Dry and Wet Oxides," Nuc1. Tech., 19, 84 (1973).

8. H. F. Henry, C. E. Newlon, and J. R. Knight, "Self Consistent Criteria for Evaluation of Neutron Interaction," UCC-ND Oak Ridge Gaseous Diffusion Plant, K-1317 (1956).

9. H. F. Henry, Ed., "Studies in Nuclear Safety," UCC-ND Oak Ridge Gaseous Diffusion Plant, K-1380 (1958).

10. H. F. Henry, C. E. Newlon, and J. R. Knight, "Extensions of Neutron Interaction Criteria," UCC-ND Oak Ridge Gaseous Diffusion Plant, $\mathrm{K}-1478$ (1961).

11. J. S. Tang, "Investigation of the Solid Angle Method Applied to Reflected Cubic Arrays," Oak Ridge Nationa1 Laboratory, ORNL/CSD/ TM-13 (1976).

12. D. R. Oden, et a1., "Critique of the Solid Ang1e Method," NUREg/ CR-0005 (1978).

13. American National Standard, "Validation of Ca1culational Methods for Nuclear Criticality Safety," ANS 8.11, Am. Nuc. Soc., 244 East Ogden Avenue, Hinsdale, I11 inois (1975)

14. L. M. Petrie and N. F. Cross, "KENO IV--An Improved Monte Carlo Criticality Program," Oak Ridge National Laboratory, ORNL-4398 (1975).

15. Gordon E. Hansen and William H. Roach, "Six and Sixteen Group Cross Sections for Fast and Intermediate Critical Assemblies," Los Alamos Scientific Laboratory, LAMS-2543 (1961). 
16. J. T. Thomas, Nucl, Sci, Eng, 62, 424 (1977).

17. J. T. Thomas, "The Effect of Reflector Location on Array Criticality," Oak Ridge National Laboratory, ORNL/CSD/TM-102 (1980).

18. J. K. Thompson, et a1., "SNAKE: A Solid Angle Calculational System," NUREG/CR-0004 (1978).

19. J. S. Tang and J. T. Thonas, Trans, Am, Nuc1, Soc, , 32, 332 (1979).

20. G, E. Whitesides and J, T. Thomas, Trans, Am, Nuc1, Soc, 12,889 (1969).

21. J. T. Thomas, "Uranium Metal Criticality," Monte Carlo Ca1culations and Nuclear Criticality Safety, UCC-ND Y-12 P1ant (1970).

22. J. T, Thomas, "Generic Array Criticality," UCC-ND Y-12 P1ant (1973).

23. J. T. Thomas, Nucl, Sci, Eng,, 52, 350 (1973).

24. J. T. Thomas, Ed., "Nuclear Safety Guide, TID-7016 Revision 2," NUREG/CR-0095 (1978).

25. J. T. Thomas, "Comparative Method for the Evaluation of Array Reflector Materials," Oak Ridge National Laboratory, ORNL/CSD-42 (1979).

26. E. B. Johnson, "The Nuclear Criticality of Intersecting Cylinders of Aqueous Uranyl Fluoride Solutions," Oak Ridge Y-12 Plant (1974).

27. G. Tuok and I. Oh, "Benchmark Critical Experiments on Low-Enriched Uranium 0xide Systems with H:U = 0.77," Rockwell International Energy Systems Group, Rocky F1ats P1ant, RFP-2895 (1979).

28. E. B. Johnson, Trans. Am, Nuc1, Soc, 10, 190 (1967).

29. S. R. Bierman, et al., "Critical Separation Between Subcritical Clusters of 2.35 wt $\%{ }^{235} \mathrm{U}$ Enriched $\mathrm{UO}_{2}$ Rods in Water with Fixed Noutron Poisons," PNL-2438 (1977).

30. S. R. Bierman, et a1., "Critical Separation Between Subcritical C1usters of $4.29 \mathrm{wt} \%{ }^{23} \mathrm{U}$ Enriched $\mathrm{UO}_{2}$ Rods in Water with Fixed Neutron Poisons," NUREG/CR-0073 (1978).

31. S. R. Bierman, et a1., "Crit1cality Exporiments with Subcritica1 Clusters of 2.35 wt $\%$ and 4.29 wt \%346 U Enriched $\mathrm{DO}_{2}$ Rods in Water with Uranium or Lead Reflecting Wa11s," PNL-2827 (1979).

32. G. R. Handley and C. M. Hopper, "Va1idation of the 'KENO' Code for Nuclear Criticality Safety Calculations of Moderated, Low-Enriched Uranium Systems," Oak Ridge Y-12 P1ant, Y-1948 (1974).

33. R. M. Westfal1 and J. R. Knight, Trans. Am. Nucl. Soc,, 33, 368 (1979). 
34. Private communications with criticality studies group (CAD) ORNL 1979:

35. P. J. Maudiin and J. T. Thomas, "Surface Density Representation of Critical Configurations of $\mathrm{U}(5) \mathrm{O}_{2}$ Planar and Linear Arrays," Oak Ridge National Laboratory, ORNL/CSD/TM-115 (1980). 
NUREG/CR-1615

ORNL/NUREG/CSD/TM-15

Distribution Category RC

INTERNAL DISTRIBUTION

1. J. W. Arendt

2. G. H. Burger

3. H. M. Butler, Jr.

4. A. D. Callihan

5. H. P. Carter/A. A. Brooks/ CSD X-10 Library

6- 7. H. R. Dyer

8. C. M. Hopper

9. F. B. Johnson

10. N. F. Landers

11. R. W. Levin

12. D. W. Magnuson

13. J. H. Marab1e

14. P. J. Maudlin

15. J. D. McLendon
16. F. R. Mynatt

17. C. E. Newlon

18. J. P. Renier

19. J. S. Tang

20. R. G. Taylor

21-34. J. T. Thomas

35. G. E. Whitesides

36-37. Centra1 Research Library

38. Y-12 Document Reference Section

39-40. Laboratory Records

41. Laboratory Records - RC

42. Radiation Shielding

Information Center

43. ORNL Patent Section

\section{EXTERNAL DISTRIBUTION}

44. J. N. Rogers, Division 8324, Sandia Laboratories, Livermore, California 94550

45- 46. D. E. Solberg, Office of Nuclear Regulatory Research, U. S. Nuclear Regulatory Commission, Washington, DC 20555

47. Chief, Mathematics and Geoscience Branch, Department of Energy, Washington, nC. 20545

48. Office of Assistant Manager for Energy Research and Development, Department of Energy, Oak Ridge Operations Office, Oak Ridge, Tennessee 37830

49-50. Technical Information Center, Department of Energy, Oak Ridge Operations, Oak Ridge, Tennessee 37830

51-315. Distribution Category RC ( 10 copies to NTIS) 